\title{
Making a Claim on the State: The Experiential Accounts of Repetitive Strain Injury Sufferers in Different Policy Regimes
}

\author{
by
}

Friskjen M. van Veldhoven, B.A. (Hons.), M.A.

A thesis submitted to the Faculty of Graduate Studies

in partial fulfillment of the requirements of the degree of

Doctor of Philosophy

Carleton University

Ottawa, Ontario

March 17, 2005

(C) Copyright 2005, Friskjen M. van Veldhoven 
Library and

Archives Canada

Published Heritage

Branch

395 Wellington Street Ottawa ONK1A ON4

Canada
Bibliothèque et

Archives Canada

Direction du

Patrimoine de l'édition

395, rue Wellington

Ottawa ON K1A ON4

Canada
NOTICE:

The author has granted a nonexclusive license allowing Library and Archives Canada to reproduce, publish, archive, preserve, conserve, communicate to the public by telecommunication or on the Internet, loan, distribute and sell theses worldwide, for commercial or noncommercial purposes, in microform, paper, electronic and/or any other formats.

The author retains copyright ownership and moral rights in this thesis. Neither the thesis nor substantial extracts from it may be printed or otherwise reproduced without the author's permission.
AVIS:

L'auteur a accordé une licence non exclusive permettant à la Bibliothèque et Archives Canada de reproduire, publier, archiver, sauvegarder, conserver, transmettre au public par télécommunication ou par l'Internet, prêter, distribuer et vendre des thèses partout dans le monde, à des fins commerciales ou autres, sur support microforme, papier, électronique et/ou autres formats.

L'auteur conserve la propriété du droit d'auteur et des droits moraux qui protège cette thèse. $\mathrm{Ni}$ la thèse ni des extraits substantiels de celle-ci ne doivent être imprimés ou autrement reproduits sans son autorisation.
In compliance with the Canadian

Privacy Act some supporting forms may have been removed from this thesis.

While these forms may be included in the document page count, their removal does not represent any loss of content from the thesis.

\section{Canadä}

Conformément à la loi canadienne sur la protection de la vie privée, quelques formulaires secondaires ont été enlevés de cette thèse.

Bien que ces formulaires aient inclus dans la pagination, il n'y aura aucun contenu manquant. 


\begin{abstract}
This thesis is a comparative analysis of workers who suffer with a repetitive strain injury and their experiential accounts of being faced with the process of claiming workers' compensation in the Netherlands and Ontario.

Comparative policy regime theorists tend to examine policies between jurisdictions at the structural or policy level. It is at this level that they assess social citizenship rights within social policy regimes. I argue, however, that it is misleading to observe the structural level alone. It is also revealing to examine the experiences of those who have the option of making claims on the state. The process of their claims-making activities qualifies the realization of social citizenship.

Two social policy regimes are compared. Each approaches the issue of worker injury policies in a very different manner. The policies in place at the structural level differ in significant ways between these two jurisdictions. In the Netherlands the system seems relatively more generous. An injured worker, prior to accessing the workers' compensation system, is afforded a paid fifty-two week waiting period. This is not the case in Ontario. Given this it would then be reasonable to expect that the process of claiming workers' injury benefits would differ at the individual or experiential level across these two jurisdictions. A more detailed look at the experiential accounts of injured workers in both policy regimes, however, finds that workers who suffer from a repetitive strain injury and who opt to make a claim have similar experiences in both jurisdictions. This is accounted for by the practice that both policy regimes use medical gatekeepers to govern the access of injured workers to the process of making a claim.

Based on this finding, I contend that researchers interested in comparative analysis of welfare states should not focus solely on the manifest policy differences at the structural level but should also investigate the processes by which individuals access policies and their experiences in terms of the procedural practices with these policies, so that a deeper understanding of barriers to the realization of social citizenship rights can be achieved.
\end{abstract}




\section{Acknowledgements}

This project would not have been possible without the generosity of the injured workers who participated in the study. Their trust, candidness and cooperation are deeply appreciated.

I would especially like to thank my committee for their help and direction, while at the same time challenging me during the research process and writing of the dissertation. To my supervisor, Dr. Wallace Clement I would like to express my sincerest gratitude for his guidance, understanding and encouragement during some very difficult times. As well, I thank Dr. Janet Siltanen for her insights, valuable comments, sensitivity and generous support and Dr. Gail Fawcett for her assistance, suggestions and contributions.

A special word of thanks to Paul, my life partner, who stood by me throughout the entire process without fail and my two beautiful daughters, Nicole and Rachel, who believed in me. As well, I thank my parents, siblings and other family members who patiently gave me their support in many different ways.

I dedicate this dissertation to my father Dr. Michael van Veldhoven who will always be very special to me! 


\section{Table of Contents}

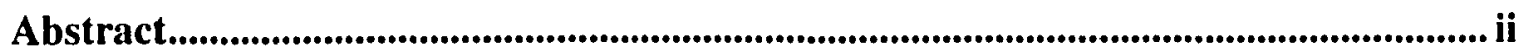

Acknowledgements ....................................................................................................................... iii

Table of Contents ............................................................................................................................ iv

List of Appendices.................................................................................................................................... vi

Chapter 1 - Repetitive Strain Injury Sufferers and Social Policy Regimes................... 1

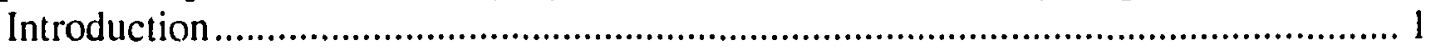

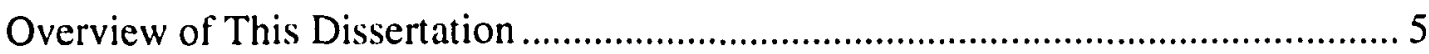

Repetitive Strain Injury - The Name Game.......................................................... 12

The Research Process ........................................................................................ 18

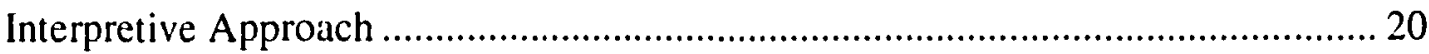

Physicians: A Tension Between the Local and the Extra-Local ................................ 22

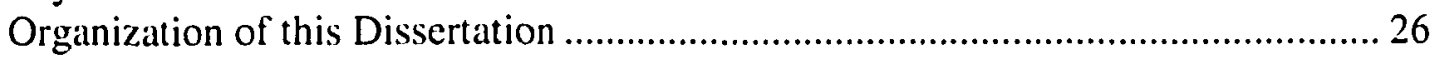

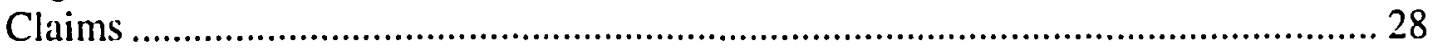

Chapter 2 - Locating This Dissertation............................................................................ 32

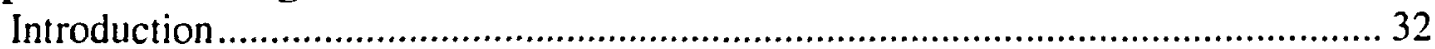

Ruling Relations: The Local and Extra-local.......................................................... 34

Social Problems Work and Claims Making Activities .......................................... 36

Social Policy Regimes ......................................................................................... 39

Commodification/Familialization .................................................................. 44

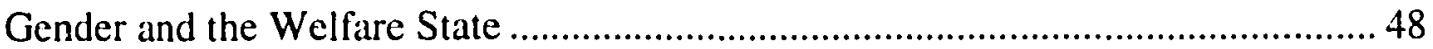

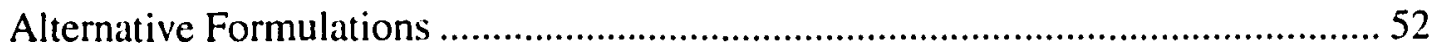

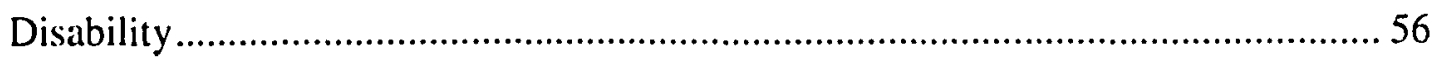

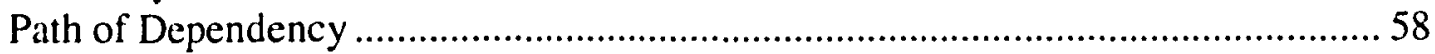

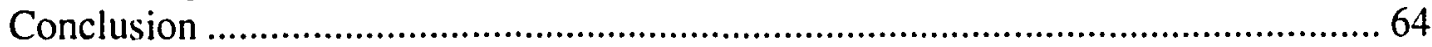

Chapter 3 - Methodological Considerations and Collection of the Data .....................6 67

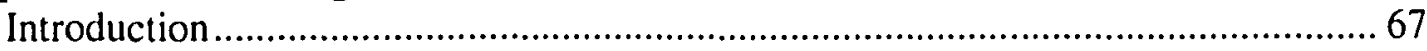

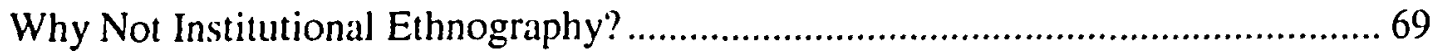

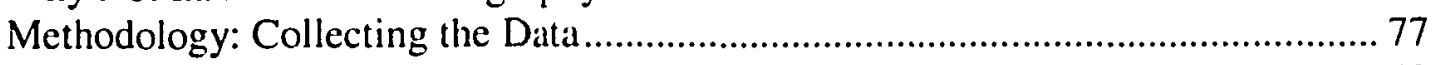

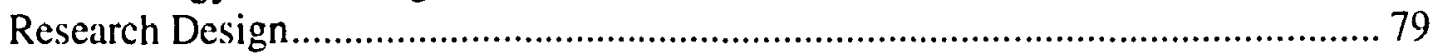

Seeking Dutch Interviews and a Brief Account of the Findings................................ 87

The Case of Ontario ........................................................................................... 94

Rationale for Choosing the Netherlands and Ontario .............................................. 98

Common Experiences: Nuancing the Debate on Social Policy Regimes .................. 99

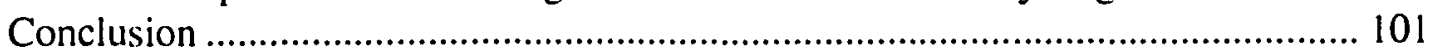

Chapter 4 - The Process of Work-Injury Policies....................................................... 104

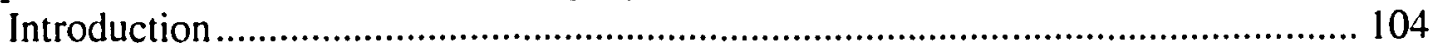

RSI, An Insidious Work Injury and Workers' Compensation ................................ 106

Disability Policies in the Netherlands and Ontario ................................................. 109

The Dutch Disability System ............................................................................... 114

The Ontario Disability System................................................................................ 121

The Ziektewet and Workers' Compensation: Experiential Accounts...................... 128

Report the Injury - employers must be notified .................................................... 128

The Ziektewet - Rest Before Entering Deeper into the World of Ruling Relations 134 
Initiating the Compensation Process - Time to Engage the Medical Gatekeepers 142 Struggle for Benefits - My Body Aches and I Need to Pay the Rent.................... 149

Alternative forms of income maintenance support - for those who can afford it .. 155

Conclusion

Chapter 5 - Gender Relations and Paid/Unpaid Work ................................................ 160

Introduction ................................................................................................ 160

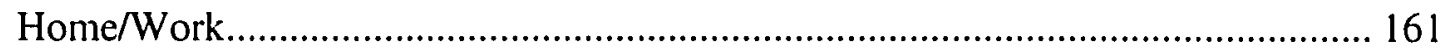

Men as RSI Sufferers and Health Behaviour .............................................. 166

Women, RSI and Occupational Health and Safety .............................................. 173

The Family: Home Life and Where is the Support? ............................................. 182

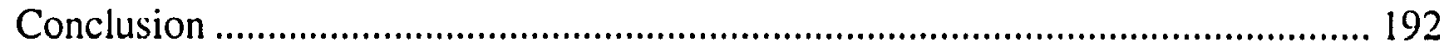

Chapter 6 - Compliance and Resistance ................................................................................ 195

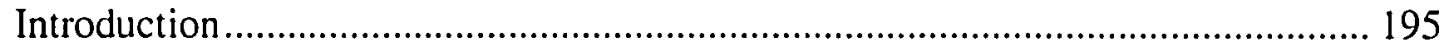

The Medical Profession and the RSI Sufferer ………....................................... 196

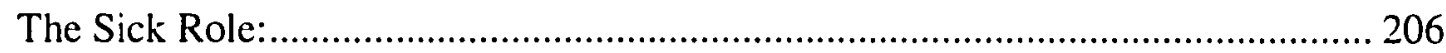

RSI, Claims-Making Activities and Adopting the Sick Role ……........................ 209

A Note on Trade Unions: Are They Facilitating the Process?................................ 227

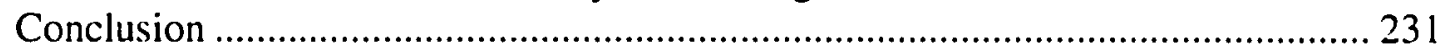

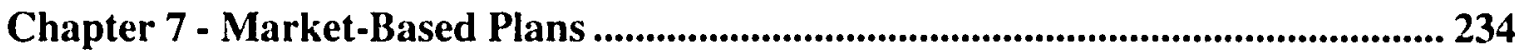

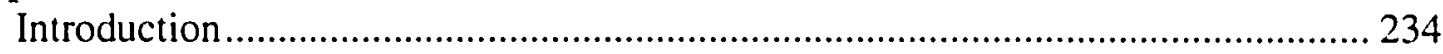

Employer Provided Support Programs .............................................................. 236

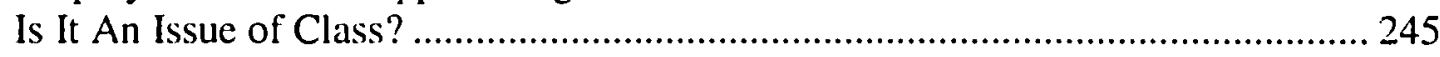

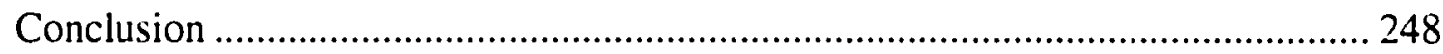

Chapter 8 - Social Policy Regimes and RSI................................................................ 251

Introduction:................................................................................................. 25 I

Laying Claim on The Sick Role and Domestic Chores: Where Is The State In All of

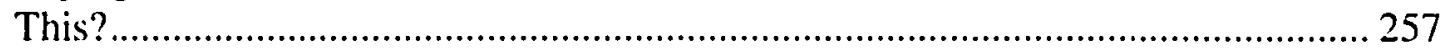

Resistance and Compliance - Striving for The Sick Role and The State ............... 265

Making a Claim on The State: Experiential Accounts of RSI Sufferers in Two

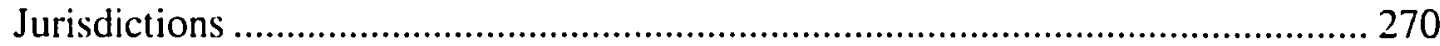

Why Bother: RSI Sufferers and Market-Based Income Maintenance Programs.... 281

Concluding Remarks: The Devil is in the Details ................................................ 286

Appendix 1 - Ethical Considerations....................................................................... 295

Appendix 2 - Consent Agreement................................................................................... 29697

Appendix 3 - Interview Schedule.................................................................................... 298

Bibliography ....................................................................................................................... 301 


\section{List of Appendices}

Appendix 1: Ethical Considerations.......................................295

Appendix 2: Consent Agreement...........................................297

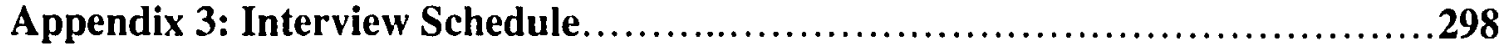




\section{Chapter 1 \\ $\underline{\text { Repetitive Strain Injury Sufferers and Social Policy Regimes }}$}

\section{Introduction}

In this dissertation I examine the way social policies differ at the state or structural level within a comparative social policy regime analysis. I explore the dynamics when a social policy is investigated at the experiential level of the individual who suffers with a repetitive strain related injury and hence faces a possible interruption in paid work. Within this context, this dissertation is a comparative examination that considers different policy regimes and the manner in which each regime addresses a similar social concern from the point of view of the individual. When an individual opts to make a workers' compensation claim in either Ontario or the Netherlands, the differences witnessed at the policy level do not appear to materialise at the individual level. In fact, by examining the experiential accounts of repetitive strain injury (RSI) sufferers' claims-making processes in the Netherlands and Ontario it became clear that their everyday lived experiences in terms of accessing workers' compensation benefits are not so different. Yet, each jurisdiction has approached the administration of work injury benefits very differently. My claim is that despite the different approaches to work-injury policies, and the different principles of workers' compensation programs within each of the regimes, the experiences of RSI sufferers that are socially located in the procedural practices of making a claim on the state are similar in both policy regimes. This is attributable to the fact that both social policy regimes employ the use of medical practitioners to perform gatekeeping functions and guard entry into the respective compensation systems. 
Policy combinations adopted by states dealing with social concerns tend to differ from one nation to the next. Indeed, we do not have standardized policy initiatives across jurisdictions. While standardized policy approaches may not exist between nations, different states frequently take similar policy approaches to address social concerns within particular areas. Within this context, social policy theorists (for instance Arts and Gelissen, 2001; Esping-Andersen, 1990, 1999; Janoski, 1998; and Siaroff, 1994, among others) posit that social policy regimes can be grouped into broadly defined social policy clusters. The distinction between social policy regimes is based on the provision of social rights and the manner in which states address the tensions between state/market/family and the social provision of service, within each of the policy regime's jurisdictions.

These analysts' models take a 'top down' or a 'macro' approach to performing comparative social policy regime analysis, an approach commonly used in political economy. Unfortunately, such an analysis is too abstract for and excludes the experiences of individuals who are affected by social policy regime's policies. Instead, I advocate adding some depth and richness to the discussion by peeling away some of the layers within which policies are nested. What is necessary is a more inclusive approach to comparative policy regime analysis in order to acquire a more holistic sense of the differences between social policy regimes. In this dissertation I examine the everyday lived experiences of individuals who feel the intersecting effects of social policy regimes at the local level, and by doing so I challenge the mainstream top-down approach to analyzing manifest differences between social policy regimes. That is, I plan to show what is to be gained by a more process oriented and experiential form of analytic inquiry. 
Indeed, despite differences in policies that address injured worker social provision at the state level, ultimately the experiences of workers with RSI are not so different between these two jurisdictions.

Two different social policy regimes (the Netherlands and Ontario) are examined to investigate the way they each approach the issue of compensating for work related injuries at the experiential level of injured workers. Workers' compensation policies are considered in this dissertation because in many jurisdictions such as Ontario, and in other industrialized countries, the work-relatedness of an injury is a key factor for compensation eligibility (Aarts et al, 1996; Cox, 1993). Yet, in the Netherlands this is not the case. In the Netherlands, the issue is not whether the injury is work-related but rather whether the injured worker was employed at the time of injury. Since most workers' compensation schemes are publicly administered policies and as such fall under the purview of the state, it is possible to investigate and compare how different jurisdictions address the issue of compensating injured workers. How policy affects individuals at the experiential level is also examined. Additionally, my dissertation considers alternate forms of disability insurances; some of them privately run such as company insurances that play an important role in the overall mix of social policy regimes.

In this dissertation, I focus on workers who are faced with the dilemma of maintaining an income while suffering with a work-related repetitive strain injury. Repetitive Strain Injury (RSI) is a disabling condition that is caused by frequent, constant and consistent repetitive motions on a daily basis. RSI is the lens through which I demonstrate the ambiguity in conducting comparative policy analysis at the structural 
level, or by using a top-down approach to comparing social policy regimes. To achieve this, I interviewed individuals with RSI in two separate jurisdictions. I examine the Netherlands because this social policy regime has taken a qualitatively different approach to worker injury policies, and at the structural level appears to be very injured worker friendly. Ontario, on the other hand, appears at the structural level to be taking a far more restrictive approach and does not appear to be injured worker friendly. In my dissertation I aim to demonstrate that the conventional top down approach traditionally taken by social policy theorists to performing comparative social policy regime analysis, cannot account for the layered or nuanced differences of welfare states. Instead of analyzing the policies at the structural level, I take a process oriented and experiential form of analytic inquiry to comparing social policies across jurisdictions. In the dissertation I take account of RSI sufferer's experiences with their injury in the context of claiming workers' compensation so that I can capture how social policies, and by extension social policy regimes, affect injured workers at the individual level. This in turn nuances the debate on comparative social policy analysis.

The Netherlands and Ontario were chosen because each jurisdiction has taken a very different approach to addressing the social security of the injured worker. It follows then that since each jurisdiction has very different policy approaches to this issue that the experiences of those who go through the process of making a workers' compensation claim should reflect this difference. However, I submit that despite the very different approaches to work-injury or workers' compensation policies in these jurisdictions, RSI sufferers' experiences of making a claim in Ontario and the Netherlands are remarkably similar, both in how they came to have their condition heard, as well as in their 
subsequent struggle for legitimation, support and validation of their condition. This finding challenges the idea of comparing policies strictly at the structural level. It also emphasizes the need for a more inclusive process oriented form of analytic inquiry thereby exposing the significant role of individuals' claims-making activities as they relate to the realization of social citizenship.

\section{Overview of This Dissertation}

In this dissertation I examine the experiences of RSI sufferers in terms of their dealings with the respective workers' compensation systems in two different social policy regimes - the Netherlands and Ontario. Both regimes have jurisdiction over setting the relevant policies relating to worker injury, which can be seen as part of two broader concepts, namely occupational health and safety, and disability. Since differences exist among social policy regimes, it follows that approaches to disability issues and occupational health and safety would likely differ between states and/or jurisdictions, based on their ideological and cultural beliefs and historical backgrounds (Newman et al., 1996; Bates, 1996). The cluster of social programs, which together constitute the welfare state or 'state social provision' (see O'Connor et al., 1999) centre around the concept of social citizenship, which involves the granting of social rights (Esping-Andersen, 1990). State activities in providing for the rights of its citizens are also "interlocked with the market's and the family's role in social provision" (Esping-Andersen, 1990: 21).

Occupational health and safety and disability issues can be observed to intersect with the three main institutions of social policy regime theory: the state, market and family. These issues fall under the purview of the welfare state with respect to health and 
safety, workers' compensation and disability legislation and policy. As well, disabling work-related injuries may be dealt with differently among jurisdictions, depending on the relations between the state, market and family within the particular social policy regimes. For instance, disabling work-related injuries effectively remove workers from the labour market and, depending upon the regime, may require accommodation or payment by employers. Furthermore, the consequences of such injuries intersect with the family as well by affecting relationships, functions and roles of family members.

In comparative social policy regime analysis states are broadly defined into three different policy regime types: liberal, corporatist and the social-democratic ( $\mathrm{O}^{\prime} \mathrm{Connor}$, 1993 among others). Ontario, with its adherence to needs-based social welfare provisions for families (see for instance Jenson, 2003) among other policy initiatives that tend to encourage the privatization of public/social services, is considered to be liberal, while the Netherlands appears to be difficult to categorize and is often labelled both corporatist and social democratic, but definitely not liberal (Esping-Andersen, 1999; O'Connor et al., 1999). A major aspect of a liberal social policy regime is its reliance on the market to supply social programs. These programs often have strict eligibility rules and/or are means-tested and provide only modest universal transfers or social insurance plans with minimal social rights. Indeed, with an emphasis on the market and the family, the intervention of the state is subordinated. Corporatist social policy regimes, on the other hand, focus on the preservation of status differentials rather than on the granting of social rights. Such policy regimes are often strongly influenced by the Church, committed to preserving the 'traditional' family. Social-democratic regimes extend social rights and universalism to the middle classes and promote equality of the highest standards. It is 
within this context that welfare states are part of regimes: the interactive relations that exist between the state, market and family within a jurisdiction (Esping-Andersen 1990; 1999).

Comparative social policy theorists employ a 'top down' or 'macro' approach to performing a comparative policy regime analysis. An analysis that rationally organizes regimes into 'boxes', one in which the individual's every-day lived experiences are invisible. In other words, an analysis that looks at society and its social activities from the perspective of the 'ruling apparatus'- the extra local (Smith, 1987: 2-6). However, such an approach to conducting comparative social policy regime analysis is rather flat and lacks richness and depth in terms of how policies play out at the local or individual level. As O'Connor et al. (1999) have demonstrated, there is variation within regimes as well as across regimes. Thus, to get a more complete picture of a social policy regime it is important to consider more than just the type of official policies that make up a social policy regime. We must also consider how these policies are practiced and accordingly how they are experienced in terms of the claims making processes at the individual level, so that a full appreciation of the layered quality of policy regimes can be achieved.

Early comparative social policy analysts had not considered the gendered nature of welfare states and as such gender relations were not well developed in earlier work. However, policies tend to be inherently gendered, that is gender relations influence social policies and conversely these policies influence gender relations (cf. O'Connor et al., 1999). Therefore, it is important that gender relations are integrated into social policy regime analysis (cf. O'Connor et al., 1999 among others). A similar claim can be made about disability relations. Disability issues, like gender issues or occupational health and 
safety concerns, are very much aspects of a social policy regime. However, Oliver (1996) observes that hardly any research is done on disability and disabled people in comparative social policy regime analysis.

While, earlier work in comparative social policy regime analysis is criticized for its exclusion of gender (see for instance: Orloff, 1993; O'Connor, 1993 among others), it is also noted that earlier work utilized a narrow definition of welfare state clusters, referred to as 'welfare state regimes' or typologies. However, O'Connor et al. (1999) point out that the narrowly defined concept 'welfare regime' does not allow for policy contradictions within social policy regimes. They attempt to rectify this shortcoming by moving beyond the narrow conception of 'welfare regime' and by putting forward the notion of 'social policy regime'- a more inclusive and flexible concept, which refers to institutionalized patterns across a number of areas of policy. Regime, within this framework, moves beyond the narrow conception of welfare state and refers to "the full range of domestic policy interventions as well as broader patterns of provisioning and regulation" (O’Connor et al., 1999: 12). Though I favour O'Connor et al.'s (1999) broader connotation of policy regime, rather than the narrower conception of welfare regime, they too render an analysis that does not include the views of individuals' every day lived experiences, which leaves their analysis incomplete.

When a top down approach is taken to doing a policy regime analysis, researchers frequently rely on the stated goals and aims of the policy as written in legislation to do the investigation. However, such an approach cannot tell how a particular policy affects people in their every-day life at the 'local' level. Nor can such a policy regime analysis reveal whether there is a gap between the formal intent of policy and the actual lived 
experience of policy - that is, a break between the 'local' and the 'extra local'. A way to find out whether this is the case is by talking to people who are affected by a particular policy. It is for this reason that I consider various social provisions (at the policy level) that are available to RSI sufferers, focusing on the perspective of the injured workers and their experiences with the process of making a claim. In other words, I move beyond a macro approach to policy analysis to one that peels away the layers to examine individuals' practices, claims and experiences in order to get a more holistic sense of the various dimensions of particular social policy regimes. The process of making a workers' compensation claim from the perspective of the injured worker is examined and compared between the two jurisdictions. As well, gender related issues are explored in terms of their state, market and family dynamics within the context of the relevant disability concerns such as life style changes and support issues.

One way of examining health and safety and disability issues within comparative policy regime analysis is by considering a specific workplace injury and how issues surrounding such an injury play themselves out at the experiential level of the injured or disabled worker. Injuries caused by consistent and constant repetitive motion fall under the rubric of Repetitive Strain Injury (RSI). As such, RSI is a health and safety as well as a disability issue. Research contends that RSI is a leading source of workplace injury/disability in North America (cf. Korrick et al, 1994; Ashbury et al., no date; Kome, 1998). Yet despite this contention, no official statistics are kept under the category of RSI in Ontario, rendering the injury 'officially' invisible in this jurisdiction (van Veldhoven, 1996). In contrast, at the time of the research, RSI was officially recognized by state authorities in the Netherlands as a legitimate injury and a valid workplace claim 
(Ministerie van Sociale Zaken en Werkgelegenheid, 1999; 2001). Indeed, state-wide regulations safeguarding employees against the development of the injury have been introduced in the Netherlands. Accordingly, statistics are gathered under this nomenclature. The ministry reports that 48 per cent of all WAO (the Dutch workers compensation system) approved claims in 2001 were specifically for Repetitive Strain Injuries (RSI). Thus, unlike in Ontario, RSI has been made a visible and frequently invoked occupational health and safety issue in the Netherlands.

The recognition of a workplace injury as legitimate and visible is necessary and crucial in obtaining entitlement to compensation in both policy regimes. Access to compensation is important for those with RSI, caused by doing repetitive tasks, because it is a potentially permanently disabling condition. If medical experts do not recognize RSI as a legitimate injury, or as a work related injury, it could have dire consequences for those who suffer with the condition. Indeed, when gatekeepers of the system, in both jurisdictions, do not accept the condition as legitimate, RSI sufferers are not eligible for workers' compensation and, hence, need to find an alternative method of maintaining their income. Often times this entails a continuation of working in the workplace that injured them in the first place. Doing this means that these workers run the risk of further injuring themselves to the point of permanent disability.

This situation need not develop, however, since it is argued that RSI can be prevented if proper health and safety measures in terms of proper office ergonomics ${ }^{1}$ are taken before or during very early onset of the condition (see for instance van Veldhoven,

\footnotetext{
${ }^{1}$ However, within this regard, Guelke (2003: 393) points out that the ideal ergonomic position is difficult to obtain and turns the body/workstation interface into an unsolvable Rubik's cube. Moreover, holistic approaches are seldom applied to office design.
} 
1996; Kome, 1998; Arksey, 1998, among others). Or RSI can be prevented if the injured worker is allowed to take leave from their paid work duties without economic penalty (see for instance van Veldhoven, 1996; Kome, 1998; Arksey, 1998, among others). Thus, by not allowing an exit strategy in terms of income maintenance to RSI sufferers, they will be faced with the prospect of permanent disability. Moreover, when permanently disabled, these injured workers will have to rely on alternative forms of social provision. Therefore, Workers' Compensation policies, in terms of Occupational Health and Safety, play a significant role in the recovery of injured workers. Yet, analyses of work-injury programs are largely overlooked in comparative policy regime analysis, despite the fact that they may be of consequence to the overall policy mix in a regime. To address this shortcoming I set out to compare workers' compensation policies covering support systems for workers who become injured and/or disabled.

The paradox is that even though the process differs between the two regimes, the experiences of the RSI sufferers in the study group(s) are the same when they reach the point of making the workers' compensation claim. As part of the process for making a claim both social policy regimes require that injured workers have their injuries validated by medical gatekeepers. It is within the clinical encounter where the differences between the two jurisdictions disappear. Moreover, experiences with the injury beyond the clinical encounter are also very similar in both jurisdictions. Within the context of paid/unpaid work, women in both jurisdictions still face the pressure of being responsible for caring work, regardless of their injury. While men in the study group across the two regimes tend to minimise their injury in the context of refusing to take sick leave from work. In both cases, the injured worker is at risk of further injuring themselves thereby 
increasing the chance of permanent disability. Thus, there is also a gendered aspect to my dissertation in terms of the social provision of care and income maintenance.

Furthermore, some injured workers in both jurisdictions find themselves in a situation where they have to appeal decisions that are made by their respective compensation boards. Often times, the appeal involves opposing views within the medical community regarding the medical characterization of their condition. This has repercussions in terms of adopting the sick role, which has consequences for the RSI sufferer in terms of receiving proper medical treatment for their condition. While the state and the family play an important role in the social provision of the injured worker, some injured workers fall outside the purview of the state social provision and some prefer to rely on private insurance schemes. In other words, both jurisdictions also support market-based social provision programs to fill this space. Lastly, employers, in both policy regimes, play an important role in terms of accessing workers' compensation schemes.

\section{Repetitive Strain Injury - The Name Game}

Repetitive Strain Injury (RSI) is a generic term that encompasses a number of different medical conditions found among both white- and blue-collar workers (Arksey, 1994: 453). The umbrella term includes conditions such as "musculoskeletal disorders of the tendons, muscles, nerves, and bones of the upper extremities resulting from strains precipitated by repeated movements" (Robinson, 1994: 183). In fact, "RSI is not a single entity but an assemblage of discrete disorders" (Hopkins, 1989: 248). Prolonged exposure to repetitive tasks increases the risk of inflammation of the joints; specific 
repetitive motion injuries include "carpal tunnel syndrome, tendinitis, tenosynovitis, and epicondylitis" (Robinson, 1994: 183)². Thus, a number of specific medical conditions are brought under one single phrase in order to account for the cause and nature of the disease or injury. While it may seem that there is agreement over the existence of such a condition, Arksey (1994: 449) notes that "RSI-type conditions are a contentious [issue] within medical circles in so far as there is little or no consensus on causation or pathology or even on whether they exist". The condition known as RSI is still in the process of being socially constructed as a legitimate health condition and/or occupational health problem. While some physicians may be willing to acknowledge the fact that a worker has an injury such as tendinitis, they are unwilling to classify this condition as RSI.

Disagreement and controversies among physicians as to the validity of RSI-type disorders is widespread, existing in the United Kingdom, Australia, the United States, the Netherlands and Canada (Arksey, 1994, 1998; Hopkins, 1989, 1990; Meekosha and Jakubowicz, 1991; van Veldhoven, 1996). Competing claims have been made by physicians as to whether the problem is physically, neurologically, or psychologically based (Arksey, 1994, 1998; Kome, 1998, among others). For instance, members of the

\footnotetext{
${ }^{2}$ Carpal Tunnel Syndrome - nerve damage in the area of the wrist known as carpal tunnel.
}

Tendinitis - inflammation of a tendon, also known as tendonitis or tenonitis. A tendon attaches a muscle to the bone, in contrast to a ligament, which attaches two bones together, without any muscle in between.

Tenosynovitis - Inflammation of the sheath of a tendon, causing swelling and pain when the tendon is moved. Synovitis is the inflammation or infection of the membranes that produce synovial fluid. These membranes and their synovial fluid surround tendons, joints, and other places where friction occurs. Also known as capsulitis or bursitis. Epicondylitis - inflammation of the epicondyle or tennis elbow - pain of the lateral epicondyle of the humurus, radiating to outer side of arm and forearm, aggravated by dorsiflexion and supination of the wrist, or turning your hand over and back. 
British Orthopaedic Association contend that RSI does not exist, whereas British rheumatologists maintain that the condition is legitimate and real (Arksey, 1994: 454). Arksey (1998: 231) argues that, in the case of physicians, the underlying political issue is one of control - who gets to define, and who gets to apply definitions of, disease and disability within the medical community. Moreover, she notes, "whether or not RSI is a disease or will become a disease is a political issue, and the outcome, not of biological factors, but social relations" (Arksey, 1998: 229).

The inconsistency of the terminology makes it very difficult to compile accurate data from existing official statistics, if one hopes to study RSI as a social phenomenon. This is attributable to the fact that official statistics of worker injury do not necessarily recognize RSI as a cause of injury, or injury type - in fact whether it actually exists at all. Hopkins (1990: 370), for example, notes that statistics in the United States show that keyboard operators - data entry workers - do not suffer from RSI, but that blue-collar assembly line workers do. In Australia, the reverse is true - keyboard operators suffer from RSI, blue-collar workers do not. In both countries, RSI is present in the official statistics but for different categories of workers. What we are observing in the differing categories of workers afflicted by the injury is the extent to which the category of disease is being differently defined in the two countries. This is mentioned not to invalidate the existence of the condition, but rather to point out that medical conditions with the exact same symptoms can have different labels attached to them (see for instance van Veldhoven, 1996). Nor is it my intention to trivialize the practices of the medical community, but rather to point to the fact that members of the medical profession in their differing functions face external policy constraints that might limit their autonomy (cf. 
Harrison and Dowswell, 2002).

Indeed, during the 1980s in Australia, RSI seemed to be widespread among public service workers; reference was made to a RSI 'epidemic'. It was claimed that RSI was a “purely Australian phenomenon ... [in fact] ... an 'Australian' disease”" (Hopkins, 1990: 365). However, the reaction by many in the medical community was to deny the 'reality' of any such injury. The problem was deemed to be imaginary, "a result of hysteria conversion" (Hopkins, 1990: 371). Resistance by a number of physicians in Australia to a category of injury called RSI manifested itself as denying the physical nature of the problem and attempting to blame the individual. Hopkins' (1990) research showed that differential responses of societal institutions play an important role in making a particular problem either visible or invisible.

While statistics collected by workers' compensation boards on RSI related injuries produced an awareness for RSI in Australia among keyboard operators, a similar collection of data by United States-based workers' compensation systems generated RSI for blue-collar workers but not for keyboard operators in the United States. That is, statistics on RSI among keyboard operators in the United States were not collected for a variety of reasons and hence the condition was made invisible for this group of workers in the United States (cf. Hopkins, 1990). Instead, injuries caused by repetitive motion were given a specific medical term, for instance bursitis or tendonitis, by attending workers' compensation physicians. The result of this was to obscure the RSI problem among those who work with keyboards. The tendency was not to deny the reality of the disease in the case of keyboard operators, "but to deny that it was work related" (Hopkins, 1990: 366-371). Yet at the same time, it was acknowledged by the National 
Institute of Occupational Safety and Health (NIOSH) in the United States (USA) that blue collar workers in the manufacturing sector, working on assembly lines, do suffer RSI injuries and that these were work-related (Hopkins, 1990: 360; Jensen et al., 1983). Thus, RSI as a problem is recognised in some job sectors, while it is not acknowledged in others.

Unfortunately the same can be said for Ontario. A preliminary analysis of Ontario's Workers' Compensation Board statistics for the years 1990 to 1994 did not yield any reported cases of RSI (Workers' Compensation Board, 1995) and subsequent information from the Workers' Safety and Insurance Board (WSIB) confirmed this observation (Workers' Safety and Insurance Board, Summer 1999; Fall 2002). Instead, work-related injuries are reported under specific medical terms (such as tendinitis, bursitis, and so forth), hence rendering RSI officially invisible in Ontario. In contrast, the Netherlands officially accepts the category of RSI as a legitimate and compensable injury (Ministerie van Sociale Zaken en Werkgelegenheid, 1999). Despite this fact, though, some Dutch physicians still refuse to accept the existence of RSI, making it difficult for patients to receive appropriate treatment and support (e-mail conversation on RSI-forum, 1999) $)^{3}$. Hopkins (1989: 251) notes that in Australia "cases of RSI are likely to be distributed amongst the following five classifications:

1. Polymyalgia

2. Peripheral enthesopathies and allied syndromes (including tendinitis, epicondylitis and Peritendinitis)

3. Disorders of the synovium, bursa and tendon (synovitis, bursitis and tenosynovitis)

4. Disorders of muscle, ligament and fascia

${ }^{3}$ RSI-forum is a Dutch listserve to which I subscribe (see chapter 3 for more information regarding methodology). 
5. Other soft tissue disorders"4.

Hopkins (1990: 367) further contends that "none of these more precise medical terms has the easy appeal of RSI ... [and] the absence of any consistently applied terminology ... hinders the widespread recognition of the problem of injuries caused by repetitive motion".

A number of different terms are used to describe essentially the same set of symptoms in different countries, further confusing the issue. For instance in the USA repetitive strain injury is called Cumulative Trauma Disorder or CTD, while in Australia, the terms repetition strain injury, repetitive strain syndrome or occupational overuse injury are preferred (Littlejohn, 1989, Hopkins, 1989). Diwaker and Stothard (1995) found that when asked about the meaning of the term RSI, doctors in the United Kingdom (UK) attached a host of completely different meanings to the term. In fact, the authors argued that the meanings attached to the term "RSI" by doctors were so variable that this term in itself should be considered meaningless.

Given the problems inherent in relying upon official statistics for data, this dissertation derives its empirical data from interviewing RSI sufferers in two different regimes or jurisdictions. Their views, perspectives and experiences of their injury were obtained in an effort to understand the way in which individual people live with illnesses

\footnotetext{
${ }^{4}$ Polymyalgia - Poorly understood muscle pain, generally shoulder and pelvic girdle. Peritendinitis - Inflammation of the sheath of fibrous connective tissue investing a fibre bundle of a tendon. Sounds like fascia. Peri $=$ around; tendon $=$ a fibrous connective tissue attaching muscles to bone and other parts. It is similar in description to tendosynovitis or tenosynovitis, which is an inflammation of the sheath of a tendon. Bursitis - Inflammation of a bursa, especially those located between bony prominences and muscle or tendon, such as in the shoulder, knee, etc.

Fascia - A fibrous membrane covering, supporting and separating muscles. It also unites the skin with underlying tissues.
} 
in social contexts and to consider the implication for treatments and services they receive. This dissertation investigates the circumstances encountered by injured workers when they engage in the medical encounter, in the context of getting validation from official medical gatekeepers who affect whether workers will get access to benefits. As well, experiences in terms of the circumstances surrounding the injured workers' households and issues related to obtaining any necessary support are considered.

\section{The Research Process}

This is a qualitative research dissertation. The data were gathered by interviewing RSI sufferers in the Netherlands and in Ontario. The research began by following an online Dutch RSI listserve. This allowed me to gain an insight regarding what issues were considered important to those who were suffering with RSI in the Netherlands. Through the listserve I was able to make initial contact with some Dutch RSI sufferers who consented to a potential interview.

Once in the Netherlands, I asked for referrals from participants to gain access to RSI sufferers beyond the RSI forum, which is a nonprobability sampling method referred to as a snowball sampling technique and frequently used in qualitative research. I stopped interviewing once I reached the saturation point, which is the point at which emerging experiences had been fully explored and no new insights were being generated (Bryman, 2004). It so happened that all those who volunteered for an interview in the Netherlands had a computer related RSI, all of them were Caucasian, and there were five men and eight women, thirteen RSI sufferers in total. The Dutch study group for this dissertation determined the target for the study group in Ontario. 
I used a purposive sampling technique in Ontario. However, the gathering of my Ontario data proved to be a bit more challenging than the data gathering in the Netherlands. Whereas it took about two months to interview thirteen RSI sufferers in the Netherlands, it took over a year to interview that many RSI sufferers in Ontario. Even though I tried to maintain an equal comparison across the jurisdictions by attempting to keep both research or study groups as comparable as possible, I was not able to match the exact number of male participants in Ontario compared to number in the Netherlands.

My criteria for inclusion in my Ontario study group was to interview anyone who had a computer related RSI, the same criteria as used in the Netherlands. I did not consider gender and/or race as a criterion for selection of participants. The Ontario study group consisted of three men and ten women and all but one were Caucasian.

A total of twenty-six participants self diagnosed their RSI condition and compose the study group for this dissertation. In some cases, members of the medical profession had provided a participant with a diagnosis of RSI. In the Netherlands most interviews were conducted in the homes of the RSI sufferers, while some were conducted in the workplace. In Ontario, some interviews were conducted in the home, some in the workplace and some by telephone. All interviews were taped and transcribed by myself. In the case of the Netherlands, the interviews were conducted in the Dutch language and I translated any Dutch interview that was used as evidence in this dissertation.

In both jurisdictions there was a mix of experiences in terms of the medical encounter. Both jurisdictions have physicians either disregarding the condition or accepting and supporting it. It is within the context of the medical encounter that my results suggest that there are no discernable differences observed in terms of the 
procedural experiences of the RSI sufferers. Thus, for those who opt to make a workers' compensation claim and need to go through the gatekeeping validation process, the experiences are remarkably similar, despite the fact that each jurisdiction has taken a very different approach to addressing the dilemma of the injured worker who needs to maintain an income while unable to work. In other words, there may be manifest policy differences at the structural level, but at the experiential level there seems to be very little difference in terms of workers compensation validation practices. The key to this mystery is the use of medical practitioners who govern the validation or legitimization process of an injury or illness.

\section{Interpretive Approach}

When injured workers visit the doctor's office, they enter the domain of ruling relations (Smith, 1987). Smith draws attention to institutional practices that perpetuate a traditional sociology from the perspective of ruling relations. This perspective excludes the point of view of individuals' activities in the everyday world, a perspective that originates from bureaucratic and professional processes that are tied into dominant forms of social organization and objectify social processes. She points out that such a view hides the every day lived experiences of individuals who are the knowers of their every day lived world. Indeed, the presence of the active subject is obviated in favour of an abstracted mode of knowledge instituted to "perform a work of ruling ... [and] ... are not expressions of the actualities of a naturally existing world..." (Smith, 1987: 152-153). Smith's sociological method prompted me to look for an interpretive approach that would allow me to demonstrate the invisible social practices of active subjects who are the 
knowers of their every day lived experiences whose activities are not otherwise made visible in a conventional approach to researching social policies across different policy regimes or welfare states. That is, I am attempting to make the invisible visible, so that I can gain an insight into whether state compensation policies, as a practice of formal organization, 'work' for injured workers. Within this vein, I utilize some of Smith's concepts to consider and analyse the data collected for this dissertation.

Furthermore an additional interpretive technique that I found useful is utilizing the concept of claims-making activities, more commonly found in social constructionism or the sociology of social problems. This concept allows me to go beyond a top down or political economy approach, and allows me to peel away some of the layers within which experiences are embedded from the point of view of the RSI sufferer. In particular, 'claims making activities' or social problems work (Spector and Kitsuse, 1987; Holstein and Miller, 1993; Best, 2001; among others) allows me to view the actions, or inactions, that some injured workers opt to take with regard to their experiences of their injury in terms of claiming workers' compensation. Indeed, Holstein and Miller (1993) posit that a focus on claims making activities is one way to link aspects of everyday reality to larger public structures. In other words, it is a way in which we can link everyday lived experiences to a broader social organization. That being said, to make claims to workers' compensation injured workers must enter the world of medical professionals, which is the world of the ruling relations. Within this regard clinical encounters are the sites of intersecting political struggles on several levels. On the one hand, we have injured workers who have an invisible injury and who enter the world of pain and medicine. On the other hand we have physicians, who duly fulfill their different functions and 
accordingly play their different roles within the medical community. As professionals they are seen as part of the ruling apparatus or the ruling relations, yet they too are subject to abstracted discourses and forms of organization which create a consciousness outside the local and particular (Smith, 1999). Indeed, the realm of extra-local is situated outside the boundaries of one's everyday lived experience; it is the social organization that extends from somewhere else into people's lives and back out again (Campbell and Gregor, 2002). It is the invisible hand that directs people's actions.

\section{Physicians: A Tension Between the Local and the Extra-Local}

The medical community is hardly a homogeneous group of professionals. As such, there is a hierarchy within the medical community, which itself is grounded in objectifying practices and formal bureaucratic processes, separating the medical elite from the rank and file general practitioners (Harrison and Dowswell, 2002). In other words, the medical profession has its own ruling relations within it. As well they are subject to the ruling apparatus that directs them from outside of it. I am referring to, for example, state imposed regulations that direct physicians in their profession, such as "standards of professional responsibility and the establishment of codes of professional ethics" (Bayer, 1988). Not all physicians perform the same function within the medical community - some are insurance doctors, some are company doctors, some are surgeons in various different specialties, some are general practitioners or family physicians, some are members of management while others are part of research teams and so forth. However, most do hold consultations with patients and as such are major actors in clinical encounters. Notwithstanding the tensions between doctor - patient relations, 
there are also tensions between physicians depending on the capacity of their function within the medical community. Within this regard physicians, and not just patients who enter the domain of ruling relations, are also subject to the dynamics of the local and extra-local as put forth by Smith $(1987 ; 1999)$. They too are subject to falling within a system of ruling relations that circumscribe their ability to practice medicine independent of their position. Indeed, Bayer's (1988: 9) research in the history of social responses to occupational disease and injury within the realm of health and safety regulation, reveals that those physicians who do not run their own independent practices and/or who work for the private sector are not very likely to publicly defend the health interests of workers when such action will bring them into conflict with their employers.

Harrison and Dowswell (2002) note that the agenda of the medical elite, physicians who act in a managerial capacity within the medical community, is largely driven by state policies - the extra-local. Within this context, the rank and file or general practitioners are expected to maintain records of their clinical decisions that point to a contingent rather than an independent character of their professional autonomy. That is, even when physicians practice medicine in their own clinics, their professional autonomy is limited to the formal processes and practices set by external policies mediated by text(s). As well, Bayer (1988: 7) notes that some “... physicians assume partisan stances definitively marked by the social interests with which they [are] allied." In other words, not all physicians remain objective during clinical encounters when meeting with workers who have injuries. Some are motivated by external forces - the extra local - which encourage views that are not necessarily in the best interest of the patient. Indeed, Campbell and Gregor (2002: 20) note that members of the medical profession who fill 
out standardized forms for the gathering of information as part of their work routine are drawn into the dominant practices of the institution(s) as their agents. Arksey and Sloper (1999) note that physicians should keep in mind that individual patients who are injured have unique experiences, and they should consider the every day lived experiences and knowledge of patients as valid when considering a diagnosis. Indeed, they note that a dismissive attitude by physicians and their denying the validity of patients' experiences and perceptions of their injury or disease during clinical encounters can have serious implications for obtaining an accurate diagnosis, which could, in turn, make access to appropriate health care and treatment problematic. Thus, the authors argue that it is necessary that physicians take patients' experiences into account, so that their chance of recovery can be improved.

Medical doctors often perform gate-keeping functions. In the context of this dissertation they are the gatekeepers to workers' compensation benefits. Their diagnosis of the condition allows injured workers into the compensation system. Without it injured workers are not eligible to collect workers' compensation benefits. Medical experts are the unconscious arbiters between the local and the extra-local in that the medical profession tends to perpetuate and emphasize ideologic messages that reinforce current social patterns, such as acceptable gender role behaviour (Waitzkin and Britt, 1989a). In other words, when messages of acceptable social behaviour are transmitted to and are accepted by patients who come to the clinical setting for legitimation regarding a medical condition, one can read the extra-local in the local. For instance, when a doctor helps an injured worker or RSI sufferer who has trouble doing housework because of pain in her arms and shoulders, by giving her medication, the doctor may subtly reinforce the idea 
that housework is desirable and that she should continue to do it. Similarly, when a doctor counsels someone who suffers from RSI type symptoms, the physician mediates workers' participation in economic production - the result may be that the worker becomes unemployed, receives disability benefits or changes jobs. Thus doctors, during clinical encounters, unconsciously exercise social control and tend to perpetuate socially accepted behaviour within the larger institutional context. These are some examples of reading the extra-local in the local.

Last but not least, a note on the idea of adopting Parson's concept of the sick role (see for instance Doyal, 1979; Frankel, 1988; Nettleton, 1995; Clarke, 2000; and Glenton, 2003 among others). It may contended that some physicians may be apprehensive to accredit the sick role to someone who has RSI type injuries for fear that the patient may turn into a chronic complainer. The original concept developed by Parsons assumed "the authority of professional technical knowledge and competence" (Glenton, 2003: 2244). Indeed, Glenton (2003) notes that the concept is based on an acute medical model of sickness, which is time constricted as well as responsive to treatment and is related to physical rather than mental health. However, a patient with a chronic condition faces an uncertain future in terms of finding a cure and medical experts often have no biomedical insight to offer - they have no answer for the patient. Within this vein, Glenton (2003: 2244) argues that patients with a chronic condition are not well suited for the sick role. A physician must acknowledge a patient's suffering before the sick role can be achieved. However, when faced with the constant complaining of chronic patients during clinical encounters, an attending physician may inadvertently discredit the legitimate patient by dismissing out of hand their complaints and thus not assigning the sick role to them. 


\section{Organization of this Dissertation}

Chapter Two: "Locating the Project", locates the discussion within the comparative social policy regime literature. The chapter begins with a brief introduction to Smith's concepts of the local/extra local, followed by an explanation of claims-making activities, which is used as an interpretive tool. Next I offer a general overview of policies that address income maintenance concerns in social policy regimes. I move the discussion from an outline of the theoretical research dealing with comparative social policy regime analysis to a discussion about the concept of disability. I discuss the specifics of the relative policies, such as the use of experience rating in both jurisdictions to finance their respective compensation schemes. Moreover, the idea of commodification/de-commodification is problematised, while issues relating to occupational health and safety - specifically issues pertaining to RSI - are also discussed. Gender concerns are incorporated in the theoretical considerations within this chapter.

Chapter Three: "Methodological Considerations and Collecting the Data", this chapter sets out the Methodology of my dissertation - how to read the story. The chapter also discusses the general methods used in collecting the data, as well as explaining any limitations or problems encountered in the data collection.

Chapter Four: "The Process of Work-Injury Policies", here I explore the process of claiming workers' compensation benefits in both jurisdictions. The chapter starts with a brief background on policies that address social provision for injured workers. Within this context, RSI is discussed in relation to workers' compensation and the chapter concludes with the experiential accounts of the participants in terms of their injury and 
opting to go forward with the process of making a compensation claim. The different and similar experiential accounts between the two jurisdictions are introduced within the discussion.

Chapter Five: "Gender Relations and Paid/Unpaid Work", in this chapter I explore the gendered relation between paid and unpaid work spheres in terms of state sponsored social provision programs. I point out that in the case of the paid work sphere the state is willing to recognize a work-related condition and offer subsequent and necessary support in terms of social provision, while by the same token such support is denied in the unpaid work sphere, regardless of the fact that work related injuries spill over into the domestic sphere. This then places the injured workers in a position where they will further injure themselves and possibly place them in a situation where they do permanent damage to their bodies.

Chapter Six: "Compliance and Resistance", the fact that physicians play a mediating role in the experiences of injured workers is examined in this chapter. I argue that despite the differences at the policy level, the experiences of injured workers in the study group are remarkably similar in both policy regimes when they make workers' compensation claims. Thus, I argue, to do comparative analyses of policy regimes, the experiential accounts of relevant actors should be taken into account to further nuance the debate on social policy regime analysis.

Chapter Seven: "Market-Based Plans", employers in Ontario tend to offer supplementary insurance plans. Experiential accounts of the participants in the Ontario study group indicate that they opt to make a claim on their long-term disability plans rather than make a claim on workers' compensation. This leads to problematizing social 
class as a mediating factor in opting to make a long/short-term disability claim over workers compensation benefits.

Chapter Eight: "Policy Regimes and RSI", is the concluding chapter which briefly touches on the differential experiences of gender within jurisdictions. Each jurisdiction is analysed in terms of comparing the experiences of RSI sufferers and their efforts to make compensation claims within their respective jurisdictions. I show how injured workers, who are denied their access to a social safety net and thus marginalized, form a resistance from the margins by using third parties to have their claims legitimated. I consider both successful and unsuccessful claims as well as 'no claims' in this chapter. The point is that some participants made efforts to have their voices heard; they made the effort to become visible, while others resisted the surveillance practices of the state. The chapter concludes that there is a break between the experience of policy and the intent of policy in both jurisdictions. I close with a discussion around some of the implications that have come to light through this research dissertation

\section{Claims}

This dissertation makes an original contribution to the debate on comparative social policy regime analysis in two ways. First, it takes into consideration the views of actors at the individual level as they participate in the process of realizing their citizenship rights. Within this context, it adds another dimension to a political economic perspective in that it analyses power differentials from the point of view of the localized individual (D. Smith, 1987) or injured worker rather than exclusively from the standpoint of the elite or ruling apparatus. Second, it inserts disability into comparative social policy 
regime analysis.

The conventional approach to doing a comparative policy regime analysis investigating policies at the structural level - obscures the nested character of particular policy regimes within which people's experiences with procedural practices are embedded. This dissertation shows that solely relying only on a 'top down' or 'macro' approach to comparative regime research is not sufficient. Such a perspective cannot assess how different workers' compensation systems affect injured workers at the individual level. It is essential to take into account the experiences of the individual RSI sufferers as they proceed through the process of making a claim when doing comparative social policy regime analysis. A more inclusive analysis is necessary to get at issues that are easily overlooked when data and policies are analysed from a macro perspective Two very different social policy regimes are considered in this dissertation, the Netherlands and Ontario. These two regimes were chosen because they address the issue of workers' compensation and injured workers very differently. In the case of Ontario, as in most industrialized jurisdictions regardless of their regime allocation, eligibility rules require the work-relatedness of the injury as the criteria for entitlement to workers' compensation benefits. In the Netherlands, however, it is not the work-relatedness of the injury that counts, but rather the consideration is whether you have an injury while also employed. The point being that injured workers must still be able to participate in their social responsibilities. Moreover, unlike in Ontario, the Netherlands has a one-year Ziektewet provision, which allows injured and/or ill workers to 'rest' for up to a year without losing income. Despite this, in both jurisdictions RSI sufferers who opt to make a claim on the state had similar experiences in their clinical encounters when dealing with 
members of the medical profession such as insurance and/or regulatory doctors who act as gatekeepers to benefits.

My dissertation also shows that RSI sufferers in the two jurisdictions faced similar prejudice or disbelief regarding their condition. This disbelief and prejudice is generally linked to that fact that the injured worker does not appear to have a disability to others. That is, the injury is invisible and is difficult to detect medically. As well, societal attitudes towards those with a disability tend to be universal across cultures and have an influencing factor on the experiences of those who have a disability, such as RSI (cf. Hansen, 2002). Furthermore, the gendered nature of the debate tends to cross policy regimes as well. Within this respect the experiential accounts of the participants in both jurisdictions expose many similarities. In sum, the experiences of the RSI sufferers in the study group tended to be similar in their consequences at many different levels.

This dissertation primarily investigates health and safety concerns such as 1) the ease of access to benefits from workers' compensation programs, and 2) the use of medical experts as gatekeepers to have injuries or work-place injuries legitimated. Within these contexts, the needs and necessities of RSI sufferers as disabled people are considered and measured against the intent of the relevant policies. One issue that came to light is how RSI sufferers in these two jurisdictions face similar barriers to accessing workers' compensation benefits, despite the fact that the policies in question come from ideologically divergent backgrounds. On the whole, in the context of procedural practices of workers' compensation and worker disability, the experiences of RSI sufferers across Ontario and the Netherlands were essentially the same, while approaches to compensation issues from a policy perspective were very different. Thus, I posit that a 
macro approach to social policy regime analysis is not capable of showing how considerable differences at the policy level may not be borne out at the individual or local level. This dissertation highlights the necessity to adopt a technique that is capable of peeling away some of the layers of the inter-institutional policy related dynamics within which experiential accounts of claims-making processes are embedded. To gain a better understanding of the differences between social policy regimes it is necessary to take the experiences of individuals and their interactions with the process and procedures of policies into account. From this it follows that in order to address the gap between the intent of policy and the actual lived experience of policy by citizens, it is necessary to include all possible actors when contemplating policy initiatives. Such an approach will add depth and richness to the discussion on welfare analysis. 


\section{Chapter 2 \\ Locating This Dissertation}

\section{Introduction}

The fiscal problems of the state over the past twenty-five plus years have had a profound impact on the number, type and quality of programs which are funded by the state. Important in this regard are the various social programs, which together constitute what is frequently referred to as the welfare state. Given the nature of capitalism's development and the impact policies in one nation can have upon another, a comparative approach to investigating such policies is helpful in revealing new directions or changes occurring in the welfare state. However, current comparative social policy regime analysis has tended to focus on a top down or macro approach by examining social policies at the structural policy level alone. Such analyses are given from the perspective of what Smith (1987: 3) refers to as the 'ruling apparatus'. The ruling apparatus or ruling relations is an expression that points to the intersection of the institutions organizing and regulating society.

A vitally important part of social policy analysis, but one that is absent in topdown analyses would include the views of those who are affected by policy outcomes and feel their impact at the individual level. Using concepts from Smith (1987) regarding institutions and the concept of 'claims-making activities' from social problem theorists, my dissertation brings the individual into the debate on comparative social policy regimes from their experiential perspective in terms of the processes of claims-making and procedural practices - a bottom up approach. On the one hand, my dissertation shows that despite the fact that policies are in place to help injured workers recover or maintain 
lost wages due to injury or disability, not all citizens who are qualified actually opt to access these programs. While on the other hand, other workers with an injury who do engage in the process of making a claim on the state can be either successful, or they are not given legitimacy by gatekeepers who govern access to such programs. Injured workers who are not given the required legitimacy to access worker-injury programs are then forced to turn to alternative income options. It is my view that regardless whether injured workers opt to make (or not to make) a claim on the state, they all engage in a form of claims-making activities or social problems work. That is, by opting not to make a claim on the state, they are still participating in a form of claims-making activities.

A central concept in comparative social policy regime analysis is that of decommodification (see for instance Esping-Andersen, 1990, 1999; O`Connor, 1998; Gal, 2004). It is meant to capture the extent to which an individual has to rely on the market, rather than the state, for the provision of care. That is, the less an individual needs to rely on the market (purchase care) for the provision of care the more de-commodified the individual is. It is consistently utilized in the literature on comparative social policy regimes for evaluation purposes. Within this context, de-commodification is usually conceptualised as 'one's ability to exit the labour market when necessary, while maintaining a socially acceptable standard of living' (see Gal, 2004) rather than 'one's ability to access services and care while maintaining a socially accepted standard of living independent of the market'. Moreover, de-commodification, as originally conceptualised in the literature fails to capture the extent to which some state-provided social programs, such as certain aspects of health care in Ontario, allow citizens to have 
universal access without ever needing to establish labour-market ties ${ }^{5}$. Within this vein, Gran (2003: 284) identifies the complex nature of health insurance provision and notes that such a provision is neither completely public nor completely private, but is often based in more than one sector. Gender relations within the context of comparative social policy regime analysis are considered in the latter part of this chapter, followed by a brief exploration of alternative formulations/possibilities for comparative policy regime research. The chapter ends with a critique of the current discussions in this area and points out what is to be gained from a more process oriented and experiential form of analytic inquiry into comparative social policy regimes analysis.

\section{Ruling Relations: The Local and Extra-local}

By investigating workers' compensation policies from the standpoint of everyday lived experiences - the primary goal of this dissertation - it is possible to uncover the extra-local mode of ruling that extends from elsewhere into people's lives and back out again (Smith, 1987; Campbell and Gregor, 2002). Extra-local ruling relations are external to local everyday lived experiences and are mediated through text (Smith, 1987). These ruling relations coordinate 'extra-locally' the everyday lived activities of working people 'locally'. In other words, social problems such as poverty, unemployment or health, have their origin in bureaucratic, legal and professional processes extra-locally. By the same token, the everyday lived activities of people influence the ruling apparatus

\footnotetext{
${ }^{5}$ Since I discuss the experiences of injured workers who have suffered a work-related injury, this dissertation considers individuals who have labour-market ties. Within this regard I consider the extent to which RSI sufferers in their respective jurisdictions are decommodified.
} 
extra-locally in return. By 'extra-local' I am referring to the set of practices and activities conducted by institutions that socially organize and coordinate the everyday lived lives of people at the local level. Through the gathering of standardized information in a textual format, such as income related or health related information, subjects become objectified and, hence, invisible as 'active' people with 'actual' lived experiences. Indeed, one's lived experience is subordinated by the extra-local ruling practices because primacy is given to textual based information about a person or persons. A similar dynamic can be observed in the encounter between patients and their interactions with physicians where their health information becomes text based and affected by the extra-local relations of ruling that no longer view them as 'actual' people with 'actual' lived experiences.

To unearth such information, Smith (1987) talks about the everyday world as problematic and develops a research method, institutional ethnography, which allows us to uncover this information. Though this is not an institutional ethnographic thesis, I am using Smith's technique and concepts to make visible the different forms of 'invisible' ruling practices behind policy decisions which are made at the extra-local level and which impact everyday people at the experiential or local level in terms of making a claim on the state. To this end, I am using Repetitive Strain Injury (RSI) as the lens through which I access the everyday lived experiences of people with disabilities and who opt to engage - or not - with the procedural practices of extra-local policies. In my dissertation I highlight the procedural practices of injured workers' claims-making activities in the realization of their social citizenship when they have the option of making a claim on the state. 


\section{Social Problems Work and Claims Making Activities}

Krahn and Lowe (2002: 110) note that in Canada "work-related stress, injuries, illnesses and fatalities constitute an extremely serious social problem". Early social problem theories contended that the core of social problems could be found in objective social conditions and thus targeting those conditions would then alleviate the problem (Foster and Tilse, 2003: 2204). Social problem theorists such as Spector and Kitsuse (1987: 73-81) note that social problems are not static situations or conditions but rather a fluid set of activities. As such they make the point that social problems are a set of claims-making activities by individuals (or groups) that lead to the definition of social problems. Within this context, they posit that social problems have changing boundaries and therefore do not lend themselves readily to empirical investigation, for they exist only in the steps that people take to make social problems visible or become a 'reality' (Spector and Kitsuse, 1987). That being said, the authors also maintain that it is important to understand that the context within which the claims are made matters, for any claim made out of context will be disregarded as irrelevant. However, what a claimsmaker might consider to be a valid claim might not be considered to be so by institutional authorities, such as physicians who might regard the claim as psychosocial thereby (a non-physical basis) effectively defusing the "claims-making activity, [and perhaps] relegating it to surveillance and control" (Spector and Kitsuse, 1987: 80).

Ibarra and Kitsuse (1993) posit that discursive practices must satisfy certain conditions before they can be accepted as claims-making activities, thereby implying that not all communication, or text, makes a claim. Leslie Miller (1993: 57) disagrees with Ibarra and Kitsuse (1993) and argues that all talk makes a claim. The intent of Ibarra and 
Kitsuse (1993) is to broaden the view on what constitutes social problems talk. However, by reconceptualizing what constitutes as claims-making activities, they hide from view those who make claims from a marginalized position, thereby favouring only those claims that reproduce dominant discourses. As Miller (1993) so aptly points out, it is only from the dominant perspective that there are 'those who make claims' and 'those who do not'. Indeed, since claims-making activities are equated with social interactions by Ibarra and Kitsuse (1993: 52), they are actually saying that there are 'those who engage in social encounters' and 'those who do not'. I could not disagree more. Regardless of one's station in life, we all engage in social encounters of one kind or another. Miller (1993: 57) utilizing a post structuralist point of view, notes that power has been displaced from elite groups and individuals to the dominant discourses of the day. Thus, she notes, power resides in social encounters between those who represent and reproduce dominant discourses and those whose accounts of the world have been marginalized by those who adhere to and perpetuate the dominant discourses of the day. While I agree with Miller's general point, such a view also has problems since it tends to attribute power to language itself, instead of the use of language, which is where power dwells.

The use of the concept 'claims making activity' must not be seen as an attempt to delegitimize the real life experiences of RSI sufferers, their material circumstances and chronic pain. But, by using a social constructionist concept that focuses on the empirically observable claims people construct to make their condition heard, rather than focusing on the condition of RSI, illuminates the processes and experiences of RSI sufferers. In other words, by focusing on the claims-making activities of actors we can 
see “... how participants in an activity define that activity" (Spector and Kitsuse, 1987:

79). Thus, typically the emphasis of social construction is on the social processes by which people engage in creating "putative conditions or condition-categories" (Ibarra and Kitsuse, 1993: 26) so that they can make sense of their world. In other words, the steps people opt to take - the claims-making activities - to participate in a social process.

Participation in social processes is key to being an active political agent. McKeen (2001: 37 - 53) notes that the bases of agents' claims are formed by broad societal and political conditions and discourses. Yet, political agency faces constraints in the activities of other actors or claims makers - even when they are potential allies. Walker et al (2002: 336) note that "...the probability of compliance [by an actor] is directly proportional to the amount of legitimacy and each legitimate object has an independent effect on the probability and extent of compliance". They argue that the legitimacy of objects is not mutually dependent. However, as Holstein and Miller (1993: 132 -144) point out, what is important in this regard is the fact that the process of claims-making activities is an interactional exercise where more than one party contributes to the social problems claims-making. Indeed, claims-making activities, they argue, lead to a focus on the myriad of everyday interactional matters that constitute social problems on a smaller scale. Moreover, anyone may demand membership to a social problems category. Thus, within this context, RSI sufferers may claim membership to the injured worker category by applying for workers compensation.

Holstein and Miller (1993: 132-133) further note that we should not focus on the large-scale public rhetoric, but rather take a more ethnomethodological approach to interpretive practices by which everyday lived realities are locally accomplished. They 
feel that this is necessary to link larger public interpretive structures to aspects of everyday reality. The authors refer to such an approach or practices as social problems work. The point being that this connects local experiences to larger (extra-local) social problem categories, so that experience can be combined with collective concerns, discourse structures, and gaze in a Foulcaudian sense (Holstein and Miller: 132). Within this regard we should keep in mind that everyday local activities are influenced by larger structural processes, and conversely larger structural or extra-local processes are influenced by everyday local activities in return.

For Spector and Kitsuse (1987) any claims-making activities are an attempt to transform private troubles into public issues. Following this line of thought, I view a worker's compensation claim to be the transformation of private troubles into a public issue. And as Holstein and Miller (1993) have pointed out, anyone can make a claim to membership of some social problems category. Therefore I feel that it is appropriate to use the concept of claims-making activities or social problems work, to describe the experiences of RSI sufferers when they attempt to get past medical gatekeepers to qualify for income replacement plans while they are unable to carry out their paid work.

\section{Social Policy Regimes}

An important concept in social policy regime analysis is that of social citizenship and its associated social rights (for instance Lister, 1997; O'Connor, 1993, among others). The notion of social citizenship rights refers to rights to economic welfare and security. This stems from Marshall's (1973) social rights definition, which states that one should have the right not to be poor, or not to have to live in fear of poverty. The concept 
of citizenship, though, assumes that all citizens equally benefit from achieved general citizenship rights and excludes those in marginalized positions. For instance, social citizenship rights are closely linked to the privileging of citizen-the-earner over citizenthe-carer, which can translate into second-class citizenship for many women.

There is a large body of literature that addresses gender related concerns within the welfare state/regime debate (cf. O'Connor, 1998; O'Connor et al., 1999; Lister, 1997; Lewis, 1992, among others). Within this vein, Janoski (1998: 6) argues that we need to go beyond the use of the working class' battle with capitalism as the motive force of explaining citizenship rights, since it cannot effectively account for gender, race and ethnicity issues. Instead, Janoski (1998) posits that regimes should be based on four citizenship rights (legal, political, social and participation rights) as opposed to just one (social rights); these rights are ensconced against an equilibrium of rights and obligations to be balanced at the micro and macro levels of society (Janoski: $217-224)$. Similarly, Oliver (1996) strongly argues that disabled persons have no claim to social citizenship rights because of impairment. However, unlike gender-related issues, disability concerns are largely overlooked within this body of research.

For this reason we need to find a way in which persons with a disability can be incorporated into a comparative policy regime analysis. Just as women are consumers of the welfare state (e.g. Mink, 1998), so too are persons with a disability (cf. Fawcett, 1996; Morris, 1996; Oliver, 1996 among others). Just as feminist scholars claim that women are denied access to the full rights of citizenship in the context of race and gender, so too do disability scholars claim that persons with a disability are not given this recognition. Moreover, just as feminists are making claims that women are invisible in 
the welfare state, so are disability activists making similar claims. Lastly, just as gender intersects with the market, the state and the family, so also does disability. The difference is that while there is a large and growing body of literature addressing feminists' concerns, few have drawn attention to issues important to persons with a disability within the welfare state debate, particularly from the perspective of injured workers.

Even though the granting of social citizenship rights are central to social policy regimes, we also need to look at "how state activities are interlocked with the market's and the family's role in social provision" (Esping-Andersen, 1990: 21). Using these principles one can configure three broad social policy regime-types: the liberal, corporatist, and the social democratic (see for instance O'Connor et al., 1999, O'Connor, 1993, Sainsbury, 1994, and Esping-Andersen, 1990). These regimes are distinguished by “international variations in social rights ... welfare state stratification ... [and] qualitatively different arrangements between state, market, and the family" (EspingAndersen, 1990: 26). Other concepts have been added to this general conceptualization in later work to expand upon the manner in which social policy regimes can be discussed, such as gender (O’Connor et al., 1999, O`Connor, 1993, and Sainsbury, 1994).

A major aspect of liberal social policy regimes is the state's reliance on the market to supply social programs. Within this regime category, the types of social programs available often have strict eligibility rules and/or are means-tested. The social programs available provide modest universal transfers or social insurance plans with minimal social rights and hence with minimal de-commodification effects. Corporatist social policy regimes, on the other hand, focus on the preservation of status differentials 
rather than on the granting of social rights. These social policy regimes are strongly influenced by the Church, are committed to preserving the 'traditional' family, and yet are moderately de-commodifying. Lastly, social-democratic social policy regimes extend the social rights principles of de-commodification and universalism to the new middle classes and by so doing promote equality of the highest standards.

Without diminishing the complex nature of the debate with regard to policy regimes which embed the interplay of the state/market/family, a debate of which I am quite aware, for the purpose of this dissertation I chose to focus on a particular income maintenance program for injured workers to examine social policy program differences. In particular my focus is on workers with RSI related disabilities, in the two jurisdictions of Ontario and the Netherlands. I chose to analyse and compare this type of program because of the program's potentially de-commodifying aspects.

Ontario and the Netherlands have taken a very different approach to the compensation of injured workers. In the Netherlands the injured or ill worker has the benefit of up to one year ${ }^{6}$ paid sick leave, before she or he is qualified to access the workers' compensation system. That is, injured workers in the Netherlands have up to one year to recover from injuries, thereby possibly circumventing the need to enter into the workers compensation program. As well, the Dutch workers' compensation system seems more accessible to injured workers. That is, in the Netherlands work-relatedness of the injury does not need to be established in order to qualify for benefits when a worker is injured and has a disability. All that is required, in the Netherlands, is to be employed by an employer/company/organization. While in Ontario the injury must be

\footnotetext{
${ }^{6}$ This one-year sick leave provision has been doubled to two years since the research on this project was completed.
} 
explicitly a work-related injury and there is no generous sick leave provision prior to entering the workers' compensation system.

However, despite these very different policy approaches to worker injury income maintenance, both jurisdictions employ procedural practices, in terms of workers' compensation programs, that result in similar experiential accounts by individuals. For instance the Dutch system, as in Ontario, uses 'gatekeepers' (usually members of the medical profession) to determine the degree of injury or disability of the injured worker and hence they govern eligibility for income maintenance. The governing of income maintenance programs by medical gatekeepers serves to limit the claims made on the state, which results in the de-legitimization of injured workers' experiences. Thus, despite the very different approaches to worker injury policies and the apparent ease of the Dutch system in relation to the Ontario system, 'gatekeepers' in both jurisdictions tend to make access to compensation challenging, or they may even prevent disabled persons from access to state funded benefits. As well, both jurisdictions use 'experience rating' as a way of financing their workers' compensation programs. Experience rating refers to the comparison of workplace-specific injury rates to industry-wide injury rates within a particular industry. If the specific workplace injury rates are higher than the industry-wide rates then the employer is taxed a higher levy to offset the higher cost of worker compensation claims originating out of that particular workplace. This has resulted in employers in the Netherlands attempting to discourage injured workers from claiming disability benefits, a practice not uncommon in Ontario (see Ison, 1988). 


\section{Commodification/Familialization}

Central to comparative social policy analysis is the concept of social citizenship rights - that is, rights to economic welfare and security. This concept of social rights originates from Marshall's (1973) formulation of citizenship rights, which he viewed as developing in three stages: 1) the achievement of civil rights, 2) political rights, and finally 3 ) social rights. To measure the level of social citizenship rights within policy regimes, the concept of de-commodification or the degree to which workers and their families are economically or financially independent from the market is utilized (see Esping-Andersen, 1990). This concept relies upon the idea that capitalism has transformed workers into discrete commodities because they need to sell their labour power in order to survive. However, "the commodity is easily destroyed by even minor social contingencies, such as illness, and by macro-events, such as the business cycle" (1990: 37). Illness in this context can also be considered as including injury or disability. However, a distinction can be made between illness and disease (cf. Asbring and Narvanen, 2003; Glenton, 2003; among others). Those suffering from hard to diagnose ailments such as RSI as well as chronic back pain, fibromyalgia ${ }^{7}$ or chronic fatigue syndrome, are given the status of having an illness rather than a disease. Where 'illness' is seen as based on the subjective experience of the patient and which cannot be objectively measured, as opposed to 'disease', which is a condition, that is objectively measurable and therefore accepted by physicians as legitimate. This distinction in turn negatively affects physicians' perceptions of patients with soft tissue injuries such as RSI.

\footnotetext{
${ }^{7}$ Elsewhere I have suggested that Fibromyalgia and RSI are one and the same condition (van Veldhoven, 1996). Indeed, Littlejohn (1989) claims that the two conditions are in fact one and the same.
} 
As mentioned, within the context of this dissertation, one aspect of a policy regime that can make it distinguishable from other policy regimes is the notion of the provision of care, such as health insurance. Within this vein, de-commodification measures whether injured individuals are eligible for the provision of health insurance as 'citizens' (universal access), as 'workers' (need to have labour market ties), or as individuals who fall outside any state mandated regulation and must rely solely on the market (purchased private insurance) for the provision of care within social policy jurisdictions.

Gran (2003), however, points out that the notion of insurance is not a simple private-public dichotomy, since there are many layers within which the provision of care is nested. His study attempts to capture the complexity in health insurance provision and conceptualizes four criteria to identify the different types. He posits that the provision of health insurance within jurisdictions is, to a varying degree, a combined endeavour by the social, individual, market or public (state) sectors. He uses four criteria to evaluate to what extent health insurance is provided for by these sectors: 1) the source of provision, 2) eligibility criteria, 3) the stimulus or impetus for provision and 4) the management of health insurance provision. While most comparative social policy theorists (for instance, O'Connor et al, 1999, among others) like to point to a triad relation between the state, market and the family in the provision of care, Gran (2003) makes this relation a bit more complex within the context of health insurance provision by making a distinction between the social, the state, the market and the individual to illuminate different patterns between different policy regimes. He shows that among the 40 OECD countries, he studied, there are no health insurance programs that are purely social, purely market 
based, purely individual or purely state provided. By doing so he pushes beyond the simple private-public dichotomy debate and underlines the complex nature of the decommodifying aspects of the provision for health insurance within jurisdictions.

Indeed, the concept of social rights and de-commodification are problematic in that they "assume a universal category of citizens, all of whom equally benefit from achieved citizenship rights" (O'Connor, 1998: 185, emphasis added). Furthermore, before de-commodification becomes an issue it is necessary to actually be commodified, or to have labour market ties (O'Connor, 1998: 188). This in turn depends, in part, on the type of labour market policies that are in place and if such policies support full employment. For instance, do labour market policies facilitate unencumbered access to the paid work world for everyone, or are policies developed in such a manner that they favour certain demographic groups over others? Are support services available that assist in active labour market policies in the face of rising numbers of dual-earner income units (O'Connor et al., 1999: 71), or is this an underdeveloped area? To answer these questions, it is necessary to explore the facilitation of labour force participation along two dimensions: 1) the social citizenship rights dimension in terms of the extent and quality of rights; and 2) the state, market, family dimension in terms of service provision and regulation (O'Connor et al., 1999). For example, in terms of parents and paid employment, are childcare facilities 'readily' available, how are they organized and are such facilities funded privately, or by the state? Providing access to appropriate childcare facilities encourages labour force participation for those who have childcare obligations. Such services, in terms of labour force participation, facilitate commodification and by extension de-commodification. This is important for women 
who are employed outside the home, especially if they are in a situation where they are the sole income earner in the family unit.

In the case of liberal social policy regimes, with their focus on market supplied services rather than state supplied services, support for childcare is multi-tiered along class lines (O'Connor et al., 1999). Those in poverty have limited, if any, access to such services, while those who are economically better off are in a position of choice where they can purchase adequate childcare (O'Connor et al., 1999). This is important, since most lone parents are female, and women tend to earn less than their male counterparts (Lewis and Ostner, 1991; Hobson, 1994; Doe and Kimpson, 1999 among others). Consequently, they often live in poverty, as do many elderly people and persons with a disability (Oliver, 1996; Fawcett, 1996). This serves to narrow the de-commodifying opportunities for the economically less fortunate who have caring responsibilities. This is in stark contrast to the social democratic regimes that fully support active labour market policies in terms of childcare (Gustafsson, 1994). However, in the Dutch case childcare services are underdeveloped, thereby limiting or undermining easy access to the labour market for those (predominantly women) with childcare obligations (Gustafsson, 1994). Therefore, one could argue that the de-commodification of women in the Netherlands in this regard lags behind other contemporary welfare states, regardless of its regime categorization.

In addition to considering the de-commodifying aspects of a welfare state EspingAndersen (1999) inserts the family as a crucial player. De-familialization, within this regard, refers to the degree to which policies reduce individuals' reliance on the family during times of (economic) need, thus the degree to which families absorb social risks 
vis-à-vis the state. The more an individual can depend on the welfare state for social support, the more 'de-familialized' that particular state is. By the same token, if an individual is wholly dependent on the family, the state is highly 'familialized'. That being said, Esping-Andersen holds that welfare states, from a policy point of view, still fall into policy regime clusters as originally conceived.

However, when attempting to get a sense of various social policy regimes in comparative social policy research I question the usefulness of analyzing policies solely at the structural level, which tends to create typologies that have a tendency to be static. What do such typologies explain? Unless we look at the processes of individuals' claims making activities and/or procedural practices that relate to the realization of social citizenship, we merely give labels to broad categories of social policies in the name of parsimony without fully understanding the mechanics of the relevant social policy regimes. This then may lead to the danger of rendering differences and/or similarities between welfare states invisible.

\section{Gender and the Welfare State}

Important in the analysis of social policy regimes is the examination of gender relations in state-society-market relations and how states interact with families as well as mediate between markets and families (O'Connor, 1999: 13). The significance of this has been demonstrated as women have entered the labour force. While women's labour force participation rates have increased since mid-century across all policy regimes, the division of unpaid work remains substantially the same in that women still do the bulk of domestic work in the home (Lewis, 1992; O'Connor, 1993; Luxton and Reiter, 1997). 
The hegemonic or commonly held view maintains that unpaid work done within the home, such as caring work, is solely women's work (Lister, 1997). Unfortunately, there appears to be a dearth of policy directives attempting to address this gender imbalance within the private sphere and consequently women continue to endure the arduous responsibilities and associated consequences (see Tierny et al., 1990) of the double day. In this regard it is important to keep in mind that domestic and paid work spheres interact to affect women's health and amplify the effect of workplace injury on women's identity (van Veldhoven, 1996).

Early comparative social policy regime analyses and the subsequent classification of these regimes, neglected to analyse how gender relations influence social policies and conversely how these policies influence gender relations (cf. O'Connor, 1993; Orloff, 1993, 1996; Mink, 1998; O’Connor et al., 1999, among others). Despite the different policy regimes (social democratic, liberal or corporatist), we must still take into account the fact that welfare states are, to varying degrees, gendered. Indeed, gender relations cannot be understood apart from the state, politics and policy. Thus, the state is a critical site for gender politics - there is no such thing as a 'gender free' social institution (O'Connor et al, 1999, see also Porter, 2003).

For example, income maintenance programs help to establish gendered identities as demonstrated by the gendered two-track or two-tiered welfare systems (Evans, 1997; Lippel, 1995, 2003). Sex segregation, it is argued, occurs in the welfare state in the case of access to social benefits, where men - as wage earners or worker citizens - tend to be the beneficiaries of work related social insurance schemes on the basis of individual entitlements. Women, however - predominantly as mothers - rely on social assistance on 
the basis of need (Sainsbury, 1993). Social insurance programs tend to offer higher entitlements, while social assistance programs are in most instances means-tested with barely subsistence level assistance. They are considered the inferior tier of income security, are very closely scrutinized, and have a considerable stigma attached to them (Mink, 1998; Evans, 1997). This illustrates that the process of de-commodification differs for men and women. Apart from the fact that women are caught in a two-tiered welfare system, they also face a bureaucracy, which determines whether they are entitled to benefits as individuals or on the basis of their ties to the family unit (Borchorst, 1994).

Women tend to be over-represented in the social assistance systems or inferior tier of income security and under-represented in social insurance plans (Sainsbury, 1994; Evans, 1997). This tendency is partly due to the bad jobs - good jobs syndrome. Jobs with a propensity for low unionization rates, poor pay and instability, thus no job security, are characterized as bad jobs. Jobs with high unionization rates, higher pay, standardized work forms and job security are characterized as good jobs (O'Connor et al., 1999). In addition to a higher representation in part-time work under the banner of flexibility (Krahn and Lowe, 1988, 2002) women, young people and visible minorities tend to be over-represented in bad jobs as well (O'Connor et al., 1999). Because of this a large number of women who perform paid work have limited or no access to the higher or superior tier of the de-commodifying aspects of the welfare state, despite the fact that they are part of the labour force. Concerns regarding childbearing and child rearing issues notwithstanding, as the working poor these women are in a precarious position. If they become injured or disabled they often have no other avenue but the lower tier social assistance with all of its conferred disgrace and poorer de-commodifying aspects. Within 
this context, we hear about the moral pariahs of society - the women and their children who are on welfare (Mink, 1998).

Canadian institutions of the welfare state are gendered, as Lippel $(1995,2003)$ demonstrates by observing that the workers compensation system in Quebec treats women and men differently. Women face a male bias within the compensation process when claiming reparation for workplace injuries. While men get recognition and compensation for work-related disabilities in Quebec, women are not given the same acknowledgement - especially in the case of work-stress related disabilities (Lippel, 1995) or musculoskeletal disorders related to repetitive work (Lippel, 2003). Indeed, some experts have argued that a mother's presence in the workplace is an indication of pathology, the message being that women do not belong in the workplace, particularly when there are children to be looked after at home (see for instance Reid et al, 1991). Unfortunately with such an attitude among professionals there tends to be little chance that poor or inappropriate working conditions will be held responsible for any disabilities which women might incur within the workplace (see for instance Reid et al, 1991).

In a similar vein, Cameron (1994), shows that in the context of workers compensation reform in Australia, working women's conditions were traded in order to ensure that men will receive benefits in the event they become injured at work. This trade-off seriously disadvantaged women in the paid workforce. Women's situation with regard to the evolution of workers' compensation law in Australia, reflects an intersection where capitalism exploits gender relations to the benefit of the state, the market and men (Cameron, 1994: 40). According to Lister (1997) this longstanding male bias flows from a preoccupation with the public sphere, which is implicitly male, and a dismissal of 
whatever happens in the domestic private sphere as irrelevant, which is implicitly considered female. Welfare states for the most part are constructed on the basis of a male template, hence the perpetuation of gender imbalances in policy regimes (Lister, 1997). Unfortunately, this underlying gendered template can be found, albeit in variable strength, across all social policy regimes.

\section{Alternative Formulations}

The lack of attention given to gender relations within any one regime type or welfare state is a significant weakness in Esping-Andersen's (1990) earlier analysis of policy regimes (based on social citizenship rights and the de-commodifying aspects of a particular welfare state) (cf. O’Connor, 1993; Orloff, 1993, 1996; O’Connor et al., 1999, among others). The contention is that such an analysis based on de-commodification and social citizenship rights is uni-dimensional. It only accords paid work any valuation, while unpaid work is not given any role or recognition within the formation of policy regimes. Thus, an analysis based on the de-commodifying aspects of a particular set of policies downplays the very complex nature of any one social policy regime and overlooks the many dimensions that play a role within policy formations. Moreover, it marginalizes the importance of gender relations within state formations and the fact that paid and unpaid work are interrelated rather than separate.

This criticism also applies to Esping-Andersen's (1999) recent work. EspingAndersen (1999) introduces the idea of familialization as a further way to differentiate policy regimes, though continuing to invoke the same three regime types. However, despite the fact that Esping-Andersen (1999) has accorded the family a role in his social 
policy regimes by measuring the degree to which a welfare state is 'de-familialized', the issue of gender relations remains outside the boundaries of his analysis. He continues to analyse social policy regimes through an 'able-bodied' (white) male lens, while women stay relegated to the folds of the family where they tacitly are expected to perform their 'caring' duties regardless of whether they are active participants in the paid labour-force.

In this regard, alternative social policy regime formulations have been suggested, in an attempt to incorporate or recognize the significance of gender relations when it comes to paid and unpaid work. Lewis (1992) suggests a continuum of breadwinner states where one moves from strong male breadwinner states to dual or weak male breadwinner states. Alternatively, Sainsbury (1994) attempts a somewhat similar approach, though her focus is more on breadwinner versus individual earner states. No priority is accorded to any specific gender and benefits are determined on an individual basis. Evidently when other indicators are used (such as the valuing of unpaid work and/or the sharing of it) to account for and measure the strength or weakness of women's social rights within welfare states, other and different groupings of welfare states than Esping-Andersen's regime clusters are produced. For instance, Siaroff (1994) identifies four alternative regime clusters based on female work desirability, the religious orientation of the society and family welfare orientation. However, the diversity of possibilities defies generalization and instead it becomes a claims-making exercise between experts as to which model is more legitimate and inclusive.

It is my contention that these approaches simply fall into the same conceptual difficulties as Esping-Andersen. Other than providing us with a 'rule-of-thumb', I question how helpful pigeon-holing welfare states into clusters really is. While it is 
certainly possible to measure welfare states along many different dimensions such as decommodification, familialization and gender, one must question whether it is desirable to do so. When we use one or a few dimensions to summarize differing welfare states we tend to overlook and oversimplify the complex nature of social policy regimes. Researchers can slice and dice welfare states along a number of different dimensions and thereby create different clusters and typologies, all of them legitimate according to the criterion used. But this can lead to failures, as witnessed by the inability of EspingAndersen's typology to incorporate the intricate intersections of such dimensions as race, ethnicity or disability, among others.

Olsen (1998) argues for a more inclusive analysis in comparative welfare state research. He advocates examining both social service and income security programs so that nations can be more accurately classified. Janoski (1998: 218-221) similarly argues for a more inclusive research project albeit from a different point of view. He advocates a regime analysis that places a stronger focus on societal rights and obligations in terms of citizenship theory and less of a focus on norms, which leads to a static view of society. With this in mind, I suggest that we must focus on an in-depth analysis of existing policies, using the conceptual dimensions mentioned above, such as the intersection of race, gender and disability relations with the state, market and the family, to get a clearer picture of how social policy regimes actually respond to their citizens and inhabitants and vice-versa. Historical and economic factors notwithstanding, it is the dynamic triad interaction between the state, the market and the family that influence the setting of policies that determine to a large extent the regime typology of a social policy regime. Yet comparative social policy analysts who try to summarize and categorize welfare 
states while incorporating a number of dimensions, miss this dynamism and hence, create a classification of individual states or regimes that have a tendency to be static.

The setting of policies is not uni-dimensional and in fact policies are frequently changed to reflect current conditions within regimes. Yet these changes are not always taken into account when a state is categorized. Indeed, within welfare states assigned to a particular cluster, we find many policies that are not characteristic of the regime type in which the country has been categorized. The case of Canada is a good example. Comparative social policy regime analysts classify the Canadian welfare state as a liberal welfare state. However if we examine its health policy Canada is very progressive and based on this policy it could be considered social democratic ${ }^{8}$. Similarly, the categorization of the Dutch welfare state is difficult, since in some cases the Netherlands instituted policies that would suggest that it is not necessarily a social democratic welfare state, in opposition to how some comparative social policy regime analysts classify this social policy regime. What this suggests is that by examining the individual policies in question, we can obtain a clearer picture of how each regime has approached a particular issue or set of issues and we can then observe how it fits within the larger context of the welfare state.

To be clear: typologies can be important summary devices, just like the mean (average) in a statistical distribution. But as with a statistical mean this single summary measure does not capture the full picture - a mean cannot communicate a distribution's

\footnotetext{
${ }^{8}$ Research paper by van Veldhoven for J. O'Connor in 1996. The purpose of the paper was to assess Esping-Andersen's regime typology and compared health care policy between the Netherlands and Canada. Similarly, Olsen (1998: 196) argues for 'multiple continua' and notes that Canadian health care policy demonstrates strands of both social democratic as well as liberal dimensions.
} 
breadth. What is needed is some manner of conveying more than simply summary information, as we do in statistical analyses where we rely upon many measures, including the standard deviation, to provide a full picture. That is, we need to investigate more than simple summary measures and typologies of welfare states as used by comparative social policy regime analysts. In addition to such analyses we must investigate and communicate the complex nature of social policy regimes by examining individual policy areas of welfare states. We need to examine and compare countries on a policy-by-policy situation, utilizing a number of different analytic dimensions. In my dissertation research I examine how RSI sufferers as persons with a disability are affected by the triad intersection of the state, market and family in terms of realizing social citizenship rights. My dissertation attempts to incorporate the complex nature of the claims-making processes that RSI sufferers must endure when they have the option of making a claim on state social provision, and as such disability relations are integrated into the comparative social policy regime debate from the individual's perspective.

\section{Disability}

The issue of disability and dependency is an important factor for social policy regimes. A person with an injury or disability within a set of social relations, either the household or the workplace, faces a number of challenges. This is true, not just for the person with a disability but also for those around her or him. When people first have an injury that leads to a disability they often can no longer perform their work. This can mean that the person with the injury will lose significance for those around them who depended on them at first, but who then gradually shift their relations of dependency onto 
others (de Swaan, 1990). This may prove to be troublesome for women who have incurred an injury and feel that their identity as wife and mother is compromised by their disability (see van Veldhoven, 1996). Another, perhaps challenging, circumstance for injured workers is that their relationship with their doctor can be echoed in "other relations in which the patient is embedded" (de Swaan, 1990: 28). That is, those around the worker with an injury or disability will make sure that doctor's orders are followed. Thus, the person with an injury or disability is incorporated into a set of ruling relations ${ }^{9}$ the medical regime - that will govern their modes of interaction and forms of experiences for the duration of their injury or disability (de Swaan, 1990).

For the many injured people who live alone they must depend on acquiring services from doctors, nurses and or homemakers, either through savings or state supported compensation programs. If a person with a disability who lives alone does not qualify for such benefits and has no savings, then they must rely on neighbours, friends or others to help with their material needs (see for instance Fawcett, 2000). EspingAndersen (1999: 114 -115) notes that North Americans have access to relatively lower priced consumer support services through the market, while Continental Europeans are faced with higher costs of such market-oriented support. This means that Europeans, and by extension the Dutch, are more likely to depend on close relatives for 'self-servicing'

\footnotetext{
${ }^{9}$ The concept of 'relations of ruling' is defined by Dorothy Smith (1987: 3) as “... a complex of organizational practices, including government, law, business and financial management, professional organization, and educational institutions as well as the discourses in texts that interpenetrate the multiple sites of power. A mode of ruling has become dominant that involves a continual transcription of the local and particular actualities of our lives into abstracted and generalized forms." Based on this definition, I see the medical regime as a relation of ruling.
} 
and less likely to rely on the market for aid. Such situations illustrate the intersection between the state/market/family found in the micro-foundations of society.

\section{Path of Dependency}

This brings me to a critical point. Analyses of social policy regimes, as conceived by various analysts, tend to be historically specific or institutionally path dependent and take a top down approach. As such they render social policy regimes essentially as static groups. That is, they do not anticipate significant changes to states and by extension to regimes (see for instance, Lewis, 1992; O’Connor, 1993; Esping-Andersen, 1999; Gal, 2004 among others). This is problematic. My concern with a top down approach to social policy regime analysis is that such an approach cannot account for the experiences of the claims-making processes by which individuals access policies in their attempt to realize social citizenship within their respective welfare states. Social policy regime analyses frequently emphasize unique historical circumstances specific to one point in time. As a result, we can expect that there will be neither movement nor change through time in the configuration of these regimes. Concepts such as path-dependency refer to rigidity and inflexibility, a taken for granted non-dynamic state. In other words, the concepts generally employed within comparative social policy regime analyses seem to imply that states are static and do not adequately allow for a dynamism in social policy regimes.

Social policy regimes are the sites where social institutions such as, the state, the labour market and the family intersect. Since social institutions are sites of dynamic power relations and by extension power struggles, it follows that social policy regimes 
cannot be and are not static. This then implies that there is room for movement and the possibility of permeability and/or regime reshaping exists. Indeed regime shifting has already occurred as illustrated by Esping-Andersen's (1999: 87) reference to the fact that Britain and Scandinavia would have been clustered together had comparisons between welfare states been made immediately after the second world war. Given that regimes are made up of 'dynamic' welfare states, I posit that social policy regimes are not static but are dynamic and vast areas of grey exist between and within regime types. Further to the point, if institutional traits and hence welfare states are unyielding to change, what then is the point of doing further research? Indeed, then why do we need to categorize welfare states into social policy regimes?

There is not always an easy fit between welfare states and social policy regime clusters. The Netherlands and Ontario are a case in point. It is argued that both jurisdictions demonstrate aspects of more than one policy regime classification (for instance, Knijn, 1994; Olsen 1998, among others). By the same token, significant differences can exist within social policy regimes as the analysis of liberal welfare states by O'Connor et al. (1999) demonstrates. In a similar vein, the viability of Scandinavian countries as one single regime typology is questioned given their differences in certain welfare state policies (Leira, 1989).

Furthermore, the use of the concept of de-commodification to measure whether state benefits are provided as citizen's rights or not, indicates a lack of understanding of the importance of incorporating gender relations into policy regime analysis. The problematic of de-commodification is further complicated by the fact that some persons with a disability receive benefits yet have never been commodified. Since they receive 
an income independent from the market it can be argued that they are de-commodified without actually ever having been commodified. As well, within this context, the provision of 'care services' often falls within the purview of the state sector, further decommodifying these individuals.

For that matter, commodification has not been applied to women on the same terms as men (O'Connor et al., 1999). While women may be employed and therefore commodified, their wages are usually too low for them to actually reap sufficient, if any, reward from the state (Mink, 1998; Pulkingham, 1998). Lippel (1995) demonstrates that state promoted workers' insurance plans can and have left women outside of their scope, thus failing to provide any compensatory protection and thereby denying them their access to de-commodification. Indeed, the use of de-commodification as a measuring tool has sparked a number of critiques from feminist analysts/critics concerned with incorporating a gender dimension into policy regime analysis. The main concern of feminist critics is that the archetypical model of the citizen in income security policy is neither gender neutral, nor gender sensitive (Evans, 1997).

In addition to being gendered, studies have shown that welfare state policies also have a racialized dimension. This is especially the case in the United States (USA) where African American women and Latinas are specifically targeted (Mink 1998). For instance, Mink shows that a disproportionate number of welfare (social assistance) recipients in the USA are non-white women, despite the fact that some Southern States eliminated a disproportionate number of black women and their children from their welfare rolls through racially targeted eligibility tests. In this regard, white women tend to be economically in better positions, while women of colour are further marginalized 
through racially specific welfare policies in the USA, (Mink, 1998; O'Connor et al, 1999).

Feminists have pointed to the weakness of using de-commodification in terms of using it to group social policy regimes. In particular they point out that decommodification does not differentiate between gender and assumes that all citizens are equally commodified, which is not necessarily the case (for instance O'Connor, 1993: 513). Thus de-commodification cannot adequately account for gender differences. Moreover, de-commodification only considers workers who are implicitly, not just male, but more importantly male and 'able bodied'. The concept of decommodification does not allow for a full understanding or accounting of the social rights of citizens with a disability because it cannot account for those with a 'disability' or who are 'cared for'! This is important, since a growing number of workers develop disabilities such as RSI in the workplace, most of who are women (for instance van Veldhoven, 1996). These injured workers with a disability quickly find themselves marginalized or delegitimized. Indeed, a significant number of those with a disability have large stakes in the welfare state, as recipients of disability benefits or subjects of occupational health and safety regulations in terms of workers compensation. It is therefore necessary to find a way to incorporate disability relations into the welfare state debate. Not from the point of view of those who care for them, but from the point of view of persons with a disability.

Nancy Hansen (2002) recently conducted a comparative study of women with a disability in both Canada and Scotland. Her research shows that the construction of disability is not culturally specific and indeed transcends borders. In both Canada and 
Scotland the experiences of these women were similar in terms of having to manage preconceived and biased notions about their disability on a daily basis. Indeed, ablebodied bureaucrats had certain expectations in terms of the physical, social and psychological needs of those with a disability. Such a universal lack of understanding about disability forces people with a disability to spend much of their time and energy on "trying to gain the right of passage; to cope with the negative attitudes, the poorly arranged surroundings, the constant fear of being 'on approval' in the non-disabled world" (Hansen, 2002: 181).

Feminist critics have argued for alternative formulations in an attempt to capture or account for the significant contributions made by women's unpaid labour. However, none have considered an alternative formulation that will allow for the incorporation of a welfare state analysis that includes the social rights of those with a disability or "cared for'. Unlike gender relations, disability relations are not addressed and therefore persons with a disability remain invisible from such an analysis. It is to begin to illuminate this issue that I examine the intersection of disability with the state, market and the family. In particular, I investigate the experiences of people with RSI in both the Netherlands and Ontario and their relations with the social institutions that provide income maintenance or compensation to people with work related disabilities.

De-commodification, as defined by Esping-Andersen needs to be addressed, if we want to integrate persons with a disability into social citizenship rights discourse. Persons with disabilities for the most part receive benefits through or from the state in one form or another (Fawcett, 1996; Oliver, 1996; Morris, 1996; among others). Therefore one could argue that this group is de-commodified - they have an income 
independent of the market. However, the low level of benefits provided forces most persons with a disability to live in poverty - the concept of de-commodification does not capture this tension. This is true for most welfare states regardless of type (Morris, 1996; Oliver, 1996; Fawcett, 1996; Bates, 1996; Doe and Kimpson, 1999; Hansen, 2002). In this regard, many persons with a disability are forced to live a lifestyle that is neither socially acceptable nor can it be considered as providing them with much economic benefit. We need therefore, to incorporate not just a gendered dimension into policy regime analysis but also a disability dimension, changing the landscape of the state to a site where gender and disability politics takes place. This would be a site where one's identities as citizen, as parent, as worker, as a person with a disability intersect - and would also include other important dimensions such as class and race.

Within social policy regime discourse, citizenship is constructed in terms of male independence based on their wage-earning capacity, and female dependence based on their perceived subsidiary position. But persons with disabilities are neither constructed as dependent nor as independent. In fact, Oliver (1996) strongly argues that persons with a disability are constructed as having no claim to social citizenship. Indeed, Oliver (1996) notes that persons with a disability are an oppressed or marginalized group who are denied access to full citizenship rights on account of impairment. It is within this vein that we need to find a way in which persons with a disability can be incorporated into comparative social policy regime analysis. Just as women are consumers of the welfare state (e.g. Mink, 1998) so are persons with a disability (Fawcett, 1996; Morris, 1996, Oliver, 1996). Just as feminist scholars claim that women are denied access to the full rights of citizenship in the context of race and gender, so do disability scholars lay 
claims that persons with a disability are not given this recognition. Moreover, just as feminists are making claims that women are invisible in the welfare state, so are disability critics making similar claims. The difference being that there is a large and growing body of literature addressing feminists' concerns, while few have drawn attention to issues important to persons with a disability within the welfare state debate.

\section{Conclusion}

I started this chapter by looking at the local and extra-local relations of ruling. I then explained how I understand claims-making activities, a concept commonly found in social constructionist theory, to be the connection between individuals' experiential accounts and larger social structures or extra-local policies. Within this context Holstein and Miller (1993) refer to claims-making activities as doing social problems work. Social problems work tends to be located within the tradition of social constructionism; however, my dissertation is not a relativist project. Instead the aim of my dissertation is to show that a comparative analysis of welfare states should not focus solely on the manifest policy differences at the structural level but should also investigate the processes by which individuals access policies and their experiences with the procedural practices of these policies. Thus the discussion on claims-making activities is therefore followed with a debate on social policy regimes.

Comparative policy regime analysts tend to examine manifest policy differences between jurisdictions at the structural level or state level. That is, they examine social policy regimes from the perspective of the extra-local or ruling relations. It is at this level that they assess individuals' social citizenship rights within social policy regimes. I 
argue however, that it is misleading to observe the structural level alone. It is also revealing to examine the experiences of those who have the option of making claims on the state. I locate the discussion within a comparative social policy regime debate, arguing for the necessity to include an analysis that incorporates the significant role of claims-making activities, and how procedural practices relate to the realization of social citizenship. I have also argued that social policy regimes are not static, but are very dynamic, encapsulating a myriad of everyday interactional processes. But the current social policy regime typologies cannot capture how this dynamism is played out at the level of the individuals who participate in particular policies. As a result there is a need to observe social policies at the level of individual experience and observe the processes of those encountering particular social policies, especially across differing social policy regimes.

A central concern is to broaden the scope of the discussion by incorporating disability related issues. I am aware that disability concerns are broad and far-reaching. However, for the purpose of this dissertation I limit myself to the investigation of injured workers who suffer RSI. That is, I am using RSI as the porthole through which I examine how worker injury programs, such as workers' compensation in two jurisdictions, the Netherlands and Ontario, treat workers with a disabling injury. I examine this issue from the perspective of the injured worker, through the eyes of the RSI sufferer. I focus this dissertation on RSI sufferers who should be able to make workers' compensation claims. In other words, RSI sufferers who are in a great deal of pain and who would benefit from a period of paid inactivity so that their condition might improve 
and mend. The next chapter will address methodological concerns that pertain to this dissertation. 


\section{Chapter 3 \\ Methodological Considerations and Collection of the Data}

\section{Introduction}

Comparative cross-jurisdictional policy research has traditionally taken a top down approach (see for example Esping-Andersen, 1990, 1999; O’Connor, Orloff and Shaver, 1999; O'Connor and Olsen, 1998 among others). Previous comparative social policy regime analyses have ranged from contrasting cross boundary expenditures on social programs in terms of a percentage of GDP, to a more holistic approach that included debates on balancing citizenship rights and obligations (see Janoski, 1998), or to a comparison of the substance and merits of particular social policies across particular states or jurisdictions (see for example Amenta et al., 2001; Esping-Andersen, 1990, 1999; Sainsbury, 1996; Olsen, 1998; and O'Connor, 1993, among others). However, regardless of the study's focus, in terms of analysing policies, comparative policy regime research traditionally has been examined at the level of the state, what Smith (1987) refers to as the ruling apparatus or the 'extra-local'. To the best of my knowledge, there are no comparative cross-jurisdictional policy analyses from the perspective of the individual - the micro-level or at the level of the "local'. Indeed, Janoski (1998: 5) observes that we should be moving away from a macro-level analysis and that we should be focusing on developing micro-level theories to account for how individual citizens balance rights and obligations in terms of their identities, and how this influences their behaviour and attitudes as citizens.

Debates on policy analyses tend to focus on the macro versus micro perspective. What gets lost in these types of approaches are the many shades of grey or dimensions 
that play an important role in the overall policy mix. That being said, I would like to add to the debate, by peeling away some of the layers of institutional dynamics that are embedded in the complex network of social policies from the perspective of the individual, using in this case Repetitive Strain Injury (RSI) sufferers. In general, my hope is to illuminate the various layers of social interactions that come into play when a worker becomes disabled and is in need of support - either financial, social or both. This support may come from various sources, such as state supported programs, market based programs, the injured worker may rely on family for support, or some combination of sources. In any case, the aim of this dissertation is to introduce a 'local' experiential perspective into cross-jurisdictional policy analysis. More specifically, I am interested to observe if policy differences witnessed at the state level bear out at the individual level.

For the purpose of this dissertation I focus mainly on injured workers and how they experience their injury within the context of gaining access to workers' compensation policies in two different jurisdictions. I collected experiential accounts of workers who developed RSI type injuries while they were in paid employment. All participants self diagnosed their condition and in some cases physicians agreed with their conclusions and reiterated the diagnosis of RSI. The focus of the analysis is on how these RSI sufferers experienced policy related social processes within the context of opting to claim workers' compensation benefits. Here the many layers of interinstitutional dynamics embedded in the complex network of social policies come into play. As will be shown, these workers are not faced with simple 'yes' or 'no', black or white situations. But rather, many different aspects of their particular life situations or everyday lived activities play a significant role in their decisions or claims making 
process. To gather the data necessary for this dissertation, I began by following an online Dutch RSI forum listserv. I then interviewed RSI sufferers personally about their experiences in both jurisdictions, the Netherlands and Ontario. I started my interviews in the Netherlands, this action helped set the parameters of those RSI sufferers whose experiences I should target when I began my interviews in Ontario.

Even though I use concepts developed by Dorothy Smith $(1987,1990)$ and I examine the experiential accounts of RSI sufferers, my research design or methodology is not an institutional ethnographic approach for this dissertation. That being said, I do find her concepts useful in accentuating the macro/micro divide between the RSI sufferers and the ruling relations. Moreover, the fact that I am not doing an institutional ethnography of workers' compensation policies should not preclude the use of Smith's concepts. As well I utilize a concept borrowed from the social constructionist perspective. I use the concept of claims making activities or social problems work (cf. Holstein and Miller, 1993) to identify the RSI sufferers' private troubles of pain and need for incomemaintenance as they attempt to move these into the public domain. The utilization of this concept helps illuminate some of the many layers that are situated between the structural and individual experiential level. As such my dissertation adds depth to the comparative social policy regime debate by focusing on the processes and experiences of RSI sufferers negotiating differing social policy regimes.

\section{Why Not Institutional Ethnography?}

Dorothy Smith (1987) formulated a research technique for capturing how everyday lived activities are tied into dominant, albeit invisible, forces that govern 
everyday lived activities of ordinary people. Her method grew out of doing a sociology for women and is grounded in the everyday lived world of people's experiences with it. Institutional Ethnography, which is a "theorized way of 'seeing' and 'knowing' that reorientates people in their everyday world" (Campbell and Gregor, 2002: 11), is not just limited to doing a sociology for women, but it is also an appropriate approach to doing research when investigating the experiences of any marginalized or oppressed group (Grahame, 1998). Indeed, institutional ethnography is a research technique that uses people's experiences to uncover the ruling relations that structure and govern them from across different sites of experiences in the overall institutional complex. The essence of this research method is to uncover "'how things work' [and sort out] "how they are actually put together"' (Smith, 1987: 147). Smith (1987: 148) notes that such a method “... begin[s] in an actual situation and explore[s] the actual relations that organize it". In other words, she aims to uncover the 'reality' of the everyday lived social relations of ordinary people by using experiential accounts as a point of entry into the investigation.

For Smith (1987: 152-155) social relations are not theoretical constructs, but rather the actual linking and coordinating of activities and work processes across multiple and divergent sites. We all tend to participate in such a socially organized character of everyday life (cf. Smith, 1987, 1990; Campbell and Gregor, 2002 among others). However, some forms of social organization in which we take part - either knowingly or unknowingly - are invisible to us. This, to Smith, is a problematic to be explored and it is within this context that she developed an alternative research methodology, one that sheds light on the hidden activities of the dominant forces which are generally embedded in their language and communicated to everyday ordinary people through different forms 
of text(s). To Smith these are the 'hidden' forces that direct and organize our daily-lived activities - the ruling relations. Smith argues that the language of institutional relations does not describe actual local experiences and can therefore only provide normative social analyses. Thus, Smith posits an alternative 'grounded' method of distilling generalizing concepts from the social organization of the local setting rather than from the practice of the ruling apparatus that organizes the local and variant character of the actual/lived experience into standard forms of organizational action.

Despite the fact that institutional ethnography draws on local experiences, and uses an actor's experience as data, it does not look at it as 'truth,' nor is it the object of inquiry in institutional ethnography (Campbell, 1998). Rather, institutional ethnography relies on experiential data as a point of support for sociological inquiry. It builds on the descriptions of local experiences and analyzes how people's lives come to be dominated and shaped by forces outside of them and their purposes. It does so from the standpoint of those who are being ruled, which is from the perspective of the local (Campbell and Gregor, 2002: 12 - 16). Institutional Ethnography uses the experience of exclusion as its point of departure. Within this vein, the standpoint of the local is not meant to be the end point of analysis, but rather the significance of the standpoint lies in its social location, how it provides a point of entry into the research (Grahame, 1998).

In institutional ethnography experience is the ground zero of the analysis. An institutional ethnographic analysis begins in experience and returns to it. However, my work does not necessarily return to experience, rather it uses the actor's experience as the entry point into analyzing policies as lived by actors. I entered my research with the perhaps naïve notion that RSI sufferers in the Netherlands had much less to worry about 
than those who suffered with the injury in Ontario. Indeed, I operated on the assumption that the Dutch welfare state would be much more generous, understanding and forgiving than the welfare state that was in place in Ontario at the time of this dissertation. Though my work may have similarities to an institutional ethnographic methodology, in actuality it is not. Rather than disclosing 'how things are', I am aiming to compare how RSI sufferers experience this debilitating, invisible and crippling disease when subjected to different approaches by social policy regimes to dealing with injured workers and their social circumstance. Injured workers enter into ruling relations out of necessity. Within this context, they are the objects who are subjected to the 'gaze' and who experience the injury from a different location than the physician, who is privileged. It is for this reason that I find it necessary to emphasize the injured workers' experience, to give them recognition, validity and legitimacy.

Thus, I use experience as data but not in the same manner as institutional ethnography uses experiential data. This should not preclude the use of Dorothy Smith's (1987) concepts. Not all of those who use Marxist concepts in their analyses employ a historical comparative method (see for instance Erik Olin Wright, 1985, among others); within a similar vein I incorporate Smith`s concepts into my analysis, but do not engage in an institutional ethnographic method.

Unlike an institutional ethnographic account where experiential data serves as a starting point into a research project, I begin my dissertation by researching secondary data sources first. I develop the idea to explore 'local' experiential accounts from there. In other words, I am not using experiential data as an 'entry' into my research dissertation and work back from that point but rather as the object of investigation - how do RSI 
sufferers in both jurisdictions experience social policy from their standpoint. I use the experiences of RSI sufferers to find out whether differences, witnessed in policies between jurisdictions at the macro or extra-local level, are borne out at the individual or local level. Indeed, my research question was informed by the literature and not by experiential data. Documented data sources provided me with a theoretical framework that was informed from the perspective of the ruling relations. Within this context, I found that the voices of those who were affected by policies that govern their everyday lives were notably absent. In order to investigate how policies drawn up by the ruling apparatus (or the extra local) played out at the experiential level (or the local level) I felt that I needed to get closer to the source of the local experience.

Familiar activities which we take for granted such as reading the morning newspaper, going to the bank, visiting the dentist, borrowing a cup of sugar from the neighbour, or consulting a physician are all different forms of social organization that warrant further examination in institutional ethnography. This is especially the case if these activities hold different 'meanings' or forms of 'knowing' for those who experience RSI injuries. Similarly, engaging with the state in the form of making workers' compensation claims or engaging with other forms of bureaucracies, also constitute different kinds of social organization worthy of investigation. Indeed, any time we submit information about ourselves or any time we request a service of some kind, such as injured workers who opt to make a workers' compensation claim, we participate in a socially organized activity. The premise of Smith's method is that the everyday world of one's lived experiences as a problematic flows out of social relations external to it and are present in its daily organization. Thus, by interviewing individuals about their 
everyday lived experiences in the local setting, we aim to discover the ruling relations stationed in an extra-local site. In other words, the purpose is to expose the extra local ruling relations which are outside the boundaries of one's everyday lived experience and which structure and govern people in the local setting in a consistent and concerted effort. Though my dissertation is not an institutional ethnography, I argue that Smith's ideas apply to my work in that RSI sufferers face the practices of the ruling relations when they are faced with the option to make a workers' compensation claim. In fact, RSI sufferers like any injured worker who opts to make a workers' compensation claim must get their injury validated by a medical expert and hence enter into the world of the ruling relations. The experiences of RSI sufferers do not originate out of their clinical encounters with their physicians, but rather out of the way in which the ruling relations organize the everyday lived worlds of these women and men (Smith, 1987; 1990; 1999). At issue are the constructed text based realities of privileged experts vis-à-vis the lived realities of individuals. Smith (1990: 212) contends that "the organizational processes that execute, control, regulate, inform, and order, in the various sites of governing, management, administration, discursive relations, professional organization, [and so forth], are loosely coordinated as a complex of ruling relations and apparatus". She continues by explaining that these ruling relations "objectify knowledge, organization, and decision processes, distinguishing what individuals do for themselves from what they do organizationally or discursively, thereby constituting properties of formal organization or of discourse that cannot be attributed to individuals". That is, the experiences of individuals, such as RSI sufferers looking to make a decision regarding workers' compensation, who are knowers 
of their every day world, are disengaged in favour of an unconnected mode of knowledge that is composed in terms of the relevances of a ruling apparatus.

The ruling apparatus or the relations of ruling, as noted, are located outside of the realm of the local. As such they are an external force to the local site where everyday people live their daily events in question. Campbell and Gregor (2002) reiterate Smith's position that in people's everyday lived experiences there are invisible forces that affect and organize their everyday lived lives outside of what they can know from an experiential level. That is, decisions made by institutional representatives (for instance bureaucrats and/or gatekeepers) external and disconnected to an actor (injured worker), have an affect on what happens to that actor. For example, physicians who validate injuries for workers' compensation boards such as the WSIB in Ontario or the WAO in the Netherlands, write up accounts of the injury using standardized forms. The information required from the injured worker is prearranged on the forms and may have no bearing or takes out of context, the experiences of that particular individual. Indeed it reorganizes the experiential accounts into ordered knowledge from the perspective of the ruling relations. It is at this juncture that the extra-local has an influencing effect on the local. The experiential accounts, through the use of text (standardized forms) are reordered to suit the purposes of the extra-local. In other words, injured workers' experiences are textually mediated when they enter the world of the ruling relations or extra-local.

In fact, the various institutions usually provide these standardized forms. For instance, in the case of WSIB in Ontario, physicians can download such forms from the official WSIB website. Once these forms are completed they become 'organizationally 
programmed accounts' of the injury. Campbell (1992) found that nursing case managers, in the course of filling out organizational forms, began to think about their work in the terms they were given by the institution. By extension, I would argue, the same can be said for other professions who must record and report standardized information such as physicians who act as gatekeepers for various programs. It follows then that these physicians will also begin to think about their work in the terms that they are given by the institution they represent - the WSIB in Ontario and the WAO in the Netherlands (or an insurance company etc.). Within this context, filling out forms is more than just an administrative task it draws any professional into the dominant practices of the institutions as their agents (Campbell, 1992; Campbell and Jackson, 1992), such as physicians who oversee the various workers' compensation boards. Thus, such accounts are written up from the perspective of the institution or ruling relations.

Therefore, we can say that standardized and normalized forms of organization of social relations are mediated through text (Smith, 1987, 1990). However, as noted above, such forms do not embrace the actual lived concerns of the individual. Instead they represent a disjuncture between the discourse of ruling relations and the actual lived experiences of individuals. Not all people are located in the same way towards the situation that is being researched. Differently located people's "coordinated actions generate local experiences that create for those in the setting ... different versions of reality - knowing something from a ruling versus an experiential perspective" (Campbell and Gregor, 2002: 48). I locate policy within this context, as mediator of social relations between the local (RSI sufferers) and extra-local (policy makers and their agents). 
Policies are created "by individuals in everyday local settings, who enter into and participate in objectified forms constituting organizational and discursive relations beyond themselves" (Campbell and Gregor, 2002: 211). The activities of individuals are objectified and categorized extra-locally within definitional boundaries that reflect institutional concerns, rather than considering the experiences of local every day/every night worlds. It follows then that the every day/every night activities of individuals, which are experienced locally, do not necessarily reflect the intended purpose of policy that is determined extra-locally. This then, constitutes a break between the local and extra-local. In other words, for the purposes of this dissertation, it constitutes a break between the experiences of RSI sufferers and the intent of policy. That is, the intent of policy is reflected in the extra-local institutional categorizations that are composed by ruling relations and has thereby revealed itself through text, but these need not match the experiences of the local, the RSI sufferers.

\section{Methodology: Collecting the Data}

This dissertation stems from my combined interest in comparative social policy regime analysis and occupational health and safety issues affecting workers along gender lines, with a particular focus on repetitive strain injury (RSI). More specifically, I set out to learn whether and/or how different states/jurisdictions address financial and/or social burdens that injured workers face when they are injured or become disabled while employed. In other words, this dissertation compares the manner in which the Netherlands and Ontario address the issue of support for injured workers and investigates 
whether support policies ${ }^{10}$ for injured workers achieve their intended goals within their respective jurisdictions. My previous research (van Veldhoven, 1996) focussed on women diagnosed with RSI within Ontario in white collar and blue-collar sectors. This previous research led me to undertake the present project.

The research for my dissertation was conducted at a time when greater fiscal restraint by the state was being advocated and advanced in the Netherlands, as well as in Ontario. Injured workers in both jurisdictions were faced with increasingly stringent restrictions on access to wage replacement income programs by the state. Gatekeepers governing access to such programs made sure that demands were kept to a minimum. However, in both jurisdictions, injured workers would engage in claims-making activities in the hope that their particular situation may be accepted as legitimate and beyond reproach. As the data in this dissertation show, the experiences of individuals were remarkably similar in either jurisdiction, despite the fact that each social policy regime had taken a very different policy approach to compensating injured workers.

\footnotetext{
${ }^{10}$ The primary focus of the dissertation is on health and safety or workers' compensation policies. However, the context of other support policies plays an important role as well. With 'support policies' I refer to the different sets of policies that address the various disability support programs. For instance, in the case of Ontario social security and support programs for persons with a disability are spread over different ministries (e.g. Ministry of Labour; Ministry of Social Services) and jurisdictions (federal and provincial). Within this regard, we have Workers' Compensation schemes (provincial), sick benefits under Employment Insurance (federal), Ontario Disability Support Programs (provincial) or CPP Disability Benefits (federal). The Netherlands addresses the various forms of disability support programs under one ministry at the national level (Ministerie van Sociale Zaken en Werkgelegenheid - Ministry of Social Services and Employment).
} 


\section{Research Design}

This dissertation asks whether there are experiential differences - perceived or otherwise - between the people who have repetitive strain injury (RSI) in Ontario and those who have RSI in the Netherlands. I framed this question within the context of a comparative social policy regime analysis. To get an understanding of people's experiences with their injury with respect to receiving support while injured, it was necessary to conduct in-depth interviews on location with RSI sufferers in the Netherlands and in Ontario.

Thus, the purpose of the research is to investigate the experiences of injured workers, (both men and women) who have RSI and are faced with the dilemma of maintaining an income or needing some form of support while in pain. In essence I used a Purposive Sampling Technique (Babbie, 2001) for this research dissertation. The majority of my interviews, both in the Netherlands and in Ontario, were initiated via the Internet. To facilitate the gathering of the data for the Netherlands I subscribed to a Dutch RSI forum (RSI-forum@yahoogroups.com), an electronic mailing list, and followed the discussion among its member participants for about a year. It is a cost effective way to assess events or processes over time (Berg, 1995). This list is in the Dutch language and is used by RSI sufferers in the Netherlands covering a host of issues related to RSI. It allowed me to get in touch with the Dutch RSI community and an analysis of the posted messages gave me the opportunity to identify issues important to RSI sufferers in the Netherlands.

There are some limitations if relying on this research technique alone. For instance, only messages that have been posted to the listserv can be examined. As well, 
this technique is ineffective for testing causal relationships. To overcome these limitations I also conducted face-to-face interviews. I used the listserv to obtain participants for the interviews. With the permission of the moderator of the listserv I posted a message introducing my dissertation and myself. I asked for volunteers to participate in the research for this dissertation and posted a message to that effect. Given the high financial costs of doing research abroad, I proceeded to do initial interviewing (screening) with Dutch participants over e-mail. These interviews were subsequently followed up with face-to-face interviews. Once I had made the initial contacts in the Netherlands I relied on Snowball Sampling to increase the number of my interviews in that jurisdiction.

For Ontario I used a Matched Case Selection Technique in an attempt to create a level playing field between the Dutch and Ontario participants. This was necessary given that I am conducting a cross cultural and cross jurisdictional comparison in terms of income maintenance and support policies. In order to be able to best match cases I thought it prudent to pursue the Dutch interviews first, these were then followed by interviews in Ontario. This strategy was taken because I felt that it would be less costly and more convenient to match Ontario participants to Dutch participants instead of the other way around.

In Ontario I used the Internet to contact potential informants. Though there are pockets of local community (regional or municipal) based RSI organizations, there is no cohesive provincial (or national) RSI collective in Ontario. Initial contact was usually made over email, followed up with phone calls and subsequently sending letters of introduction and information by mail to occupational health and safety activists in unions 
and other organizations, asking for their assistance in locating potential participants. I also put up information posters in local doctors' offices, I sent messages to RSI associations across the province, I participated in a mass mail-out to the disability community in Ontario with the help of the Canadian Council on Social Development (CCSD) and contacted the Health and Safety officer of a large local Ottawa based institution. Unlike the Dutch interviews, which took fewer than two months (Summer of 2000) to complete, the Ontario interviews took more than two years to finalize (September, 2000 - November, 2002).

RSI in the Netherlands, at the time of the interviews, was a topic of interest in the popular media. At that time it was also recognised as a legitimate medical concern by the Dutch state. Thus, the question of RSI was topical and timely for Dutch RSI sufferers. Moreover, in contrast to the Ontario participants, Dutch participants were perhaps a bit intrigued that a researcher out of Canada wanted to interview them about their experiences with the condition. The relatively small geographic area of the Netherlands facilitated speedy travel around the country and it was possible to conduct several interviews in a day. This combination of factors translated into a smooth and quick data gathering process in this jurisdiction.

The lengthy data collection in Ontario was in part attributable to the province's somewhat larger geographic area, which makes the issue of logistics a costly and time consuming exercise. In addition, there exists a culture of distrust in Ontario when it involves a work related injury, especially in terms of discussing a workers' compensation claim. This probably stems from a conflict approach to union-management relations within North America and the relatively weak position that labour has within this 
relationship (for instance Krahn and Lowe, 2002 among others). Workers tend to be more cautious when they discuss work-related concerns, especially when they are not covered by a collective agreement (cf. van Veldhoven, 1996). The fact that the RSI sufferers in the Netherlands who volunteered had a computer related RSI meant that in Ontario I could only interview participants with a specific task related RSI - namely an injury attributable to keyboarding or working with a mouse. This restricted my ability to interview all RSI sufferers, in the sense that many volunteers in Ontario with RSI who came forward could not be matched to the RSI sufferers in the Netherlands because their RSI was not computer related. Indeed, most of the volunteers who identified themselves, as having a RSI in Ontario did not have a computer related RSI. While this was tempting, I could not include these volunteers in my study group. Hence I found it a more time consuming exercise to obtain participants from Ontario.

In both jurisdictions I interviewed injured workers from diverse backgrounds. Some injured workers belonged to trade unions, some did not. I also interviewed RSI sufferers who were either part of management or executives in their respective companies. All participants/interviewees worked with computers and developed a form of RSI through the use of keyboards or working with a mouse. All cases were initially self-diagnosed, in some cases the condition was confirmed by a physician.

All interviews were taped and transcribed by myself. To facilitate the interview procedure I utilized a number of different strategies in identifying and selecting participants. Initial contacts with key-informants in the Netherlands were made over the Internet and in Ontario by telephone. These were then followed by personal interviews. Since my research involves the selection of data in two different nation states, it was 
decided that the comparability of cases could best be achieved through a matching process based on relevant and similar common characteristics of informants (Babbie, 1995). Some of the characteristics, on which a match was based, were 1) familiarity with the topic (experiences with RSI and the need to maintain an income); 2) currently involved in the field (suffers presently from RSI); 3) has the time and is willing to participate; and 4) tasks performed in the workplace (Neuman, 1994; Babbie 1995). A matched case selection technique tends to isolate the characteristics of interest - namely experiences with RSI - by controlling for the influence of the aforementioned and other characteristics.

My research does not focus on any particular industry and/or occupation. Rather, the focus of the research is on injured workers who suffer from RSI and their experiences within the intersection of state, market and family. That is, the steps they need to take to get a diagnosis, apply for benefits and possibly additional support. Where the participants developed RSI is secondary to this particular dissertation " and will be used as background information only. However, how the RSI sufferers developed their injury became a pivotal characteristic that helped determine the study group in Ontario. In terms of the age and sex of participants, I was interested in interviewing members of both sexes. As well, in my previous research (van Veldhoven, 1996), I found that the age of RSI sufferers varied widely from very young (early twenties) to more mature (fifties). For the purpose of this dissertation, I did not want to limit my search for participants to

\footnotetext{
"Within the context of RSI as a work-related issue, I have considered the labour process and the effectiveness of unionization within the workplace in previous research (cf. van Veldhoven, 1996).
} 
age and sex restrictions. In retrospect, I had a difficult time getting male participants and am grateful that I left the search for participants open in terms of sex and age.

The study groups in both jurisdictions consisted only of injured workers who developed RSI by using a computer such as working with a keyboard or using the mouse. The methods of data gathering I utilized are a combination of purposive sampling, selfselection sampling, matched case selection and snowball sampling. I used a semi structured interview schedule of points I wanted to cover. These points were in the form of questions, which were open-ended but controlled to lead discussion - when necessary. Generally speaking I needed to prompt the participant only once or twice with a question, they usually began to tell their stories following their own line of thought. Essentially my role in the process was to ensure that points on the interview schedule were covered during each of the interviews.

The unit of analysis were individuals who suffer from a computer related RSI and who needed to maintain an income while injured. The riumber of interviews depended on how many of the cases could be matched between the two jurisdictions. My research approach described above was the best way for obtaining the necessary data since state statistics and institutions do not necessarily gather data based on RSI injury as a single category - especially in the case of Ontario.

The research I was conducting was explained to all participants beforehand and they were informed that they could pull out at any lime during the interview process, they were asked to fill out a consent form for interviewing and the interviews were taped, when permitted, for my own ease of analysis (see Appendix 1). The interviews in the Netherlands were held in the Dutch language. I transcribed all interviews and translated 
the Dutch interviews into the English language. All identities of the participants are kept confidential and fictitious names (or numbers) are used when quoting participants.

This dissertation relies on a self-selection process, which unfortunately introduces a bias. This problem could not be avoided, given the nature of the topic and the research in question. For instance, in the case of the Netherlands, only those who have web access could initially be reached. In Ontario the problem is in the fact that only those who are activists and participate in disability community groups were initially considered in the study group for this dissertation. To overcome this problem I encouraged participants to contact friends and/or acquaintances of theirs with similar injuries and had them get in touch with me in both jurisdictions. In other words, in addition to convenience sampling and purposive sampling, I also employed a snowball sampling technique in an attempt to overcome the above noted problems with the study group ${ }^{12}$.

I began my interviews in the Netherlands, which meant that the composition of the Dutch study group determined the composition of the study group in Ontario.

\footnotetext{
${ }^{12}$ The qualitative nature of the research and the non-probabilistic, purposive sampling techniques employed in the dissertation, as well as the small number of informants who were interviewed, does not allow for the generalizability of the cases to the larger population. However, I am aware of the concept of 'saturation' within qualitative research. Within this context, Kirby and McKenna (1989), note that saturation occurs when additional interviews will not reveal additional information. Indeed, saturation in qualitative research is similar to the determination of adequate sample size in quantitative research. Saturation of the data allows for the confidence that the description of the phenomenon has been captured and is the equivalent to tests of confidence and random selection in quantitative research (cf. Jackson, 2003). Furthermore, I use the term study group rather than sample or sample size, since the term sample invokes the idea of a quantitative study where the issue of a biased sample in terms of the representativeness of the population would play a particularly important role. However, that is not my claim here. Moreover, it can be argued that the application of the different sampling techniques will allow me to advance a conclusion beyond those studied to people who face similar circumstances in the larger population. Therefore, I will attempt to draw some tentative conclusions regarding the experiences of RSI sufferers in the two regimes.
} 
However, by using the Internet as a way to first contact RSI sufferers in the Netherlands I inadvertently introduced limitations into the research design that need to be considered. It prevented me from performing a more encompassing examination of the experiential accounts of RSI sufferers in terms of their procedural practices in making a claim on the state, since only those with a computer related injury came forward. I had not anticipated this before I started the project and as such limited the findings to white-collar workers who work with computers in an office setting. Nevertheless, not all of those who participated in the study necessarily belong to the middle class. Unfortunately, the method I used to contact possible volunteers in the Netherlands did not include the accounts of blue-collar sector workers who work as gardeners or factory workers on an assembly line. I would like to investigate this further in a more comprehensive project that compares the experiential accounts between job sectors as well as between jurisdictions.

On the other hand, due to time constraints, and financial restrictions I was forced to utilize the method of gathering data set out in the dissertation. This had presented some limitations and should such a study be repeated these restrictions would need to be addressed. To overcome the limitations of the method used, it would be prudent to utilize an approach that includes segments from different labour market sectors. One way to accomplish this is to contact unions in the Netherlands; they may have access to a database that allows for a more inclusive segment of society - one that goes beyond the white-collar sector and takes the blue-collar sector into consideration. Such an approach would be far more time consuming and costly, however it would overcome the limitations that the present method has demonstrated. Next, I will first focus on a 
discussion of my experience with the gathering of interview data in the Netherlands, followed by a discussion of my experience of gathering the interview data in Ontario.

\section{Seeking Dutch Interviews and a Brief Account of the Findings}

I posted a message to the Dutch listserv and solicited for volunteers to participate in the research and received a number of replies from willing participants. I asked some preliminary questions over e-mail, which were then followed up with face-to-face interviews in the Netherlands. Before I left for the Netherlands I had eight Dutch volunteers who were willing to participate in the study. When I arrived in Holland, in July of 2000 , I made contact with the eight volunteers and set dates for interviews. Unfortunately not all of the original eight volunteers committed themselves any further for various reasons and five out of the original eight prospective participants from the RSI forum were interviewed. The remainder of the interviews I gathered through snowball sampling, participants in the study forwarded some names and family members forwarded other contacts. After approximately eight interviews I began to receive the same or similar replies to my questions. I felt that I had approached or was approaching the saturation point of responses and decided to wind-down the interviews in the Netherlands. It took approximately six weeks (mid July, 2000 to end of August, 2000) to complete these interviews. In the end the total number of people I interviewed in the Netherlands came to thirteen participants.

The participants in the study group located in the Netherlands lived and worked in different cities. These cities were concentrated between Amsterdam, Den Haag and Utrecht, which is essentially West Central Holland. There were five men and eight 
women ranging in age from the mid twenties to the late forties. All participants worked with computers in various capacities.

All interviewees identified themselves as 'having' or 'suffering' from RSI. In all instances the initial diagnosis was made by the participant - but only after they had read about RSI in the newspaper or heard about it in the popular media (at the time of the interviews Holland was engaged in a very active 'RSI awareness' campaign encouraged by the state). Despite the fact that the Dutch State was administering a RSI awareness campaign, physicians were hesitant in making the diagnosis of RSI - at best it was concluded by some family physicians that the patient exhibited RSI type complaints, though there were one or two exceptions, where 'RSI experts' had made specific RSI diagnoses. Family physicians were generally open and accepting of the claims made by their patients. However, insurance doctors, who are employed by the state, and who made decisions regarding the level of disability for validity of the claims made or compensation purposes, were dismissive of the participants' claims. Most of the insurance physicians were not willing or were unable to accept the participant's accounts of pain and inability to perform daily tasks, both at work and in the home.

As is usually the case with RSI, most neurological tests or blood tests do not show any physical problems, this was also the experience for this group of participants. However when operations were performed (two RSI sufferers in the Netherlands - one female and one male - were operated upon) the neurosurgeon performing the operation invariably needed to 'thin out' a thickening around some nerves - my previous research revealed a similar situation here in Ontario (vanVeldhoven, 1996). 
In the Netherlands, an employee's job is guaranteed for the first two years after an injury or becoming ill. However, the employer is required by law to find suitable work for the employee if the employee is unable to continue doing her or his original job during this period. If suitable work cannot be found within the company, the employer can ask the courts to release them from the employment contract - a judge has to rule on this. If an employee cannot come to work due to illness or injury, it is required under the Ziektewet to report the injury or illness to her or his employer. For the first year after a reported injury the employer is required under the Ziektewet to maintain the employee's salary, though the employee is considered to be 'in the Ziektewet'. During the second year the employee is still employed with the employer, but income is maintained through the WAO (workers' compensation) rather than the Ziektewet. At the time of the interview all of the participants 'were' or 'had been' in the Ziektewet, while five participants ( 3 males and 2 females) were actually in the WAO.

Claims were made by some of the participants (one of whom happened to be the chair of the RSI association in the Netherlands) that government employed physicians were under implied orders by authorities to make access to the WAO more difficult. Two of the participants had first hand experience. For example, in one case, an insurance doctor who sympathised with claims made by this participant ( 1 female) was moved to another office in another part of the Netherlands. The replacement physician looking after her case overturned any decisions made by the predecessor regarding the participant's approved WAO claim. This participant had to fight to keep her WAO benefits. While in another case a participant (a female) had to take 'het GAK' - the WSIB equivalent - to court on two separate occasions to overturn its decision that this 
participant's disability was only deemed 14 per cent. To be 14 per cent disabled means that you are healthy enough to do your job and thus do not qualify for WAO. She was forced to go on WW (welfare) while the case was being heard - it took two and half years. In her case, the insurance doctors at 'het GAK' would not accept the diagnosis of RSI from a leading expert in the field in the Netherlands. Both times the judge ruled in favour of the participant and overturned the rulings made by het GAK. According to the chair of the RSI association, even though RSI is more widely recognised and accepted as a legitimate condition in the Netherlands, half of all reported RSI sufferers still face such demoralizing encounters with state officials who try to delegitimize the condition. At the time of the interviews it was reported in the media that 20 per cent of the Dutch labour force suffered from RSI. These are the reported cases, that is, the RSI sufferers who came forward and reported their injury to their physician(s) - the known cases! There is no way of telling how many cases go unreported for whatever reasons.

However, there were also positive, co-operative and supportive experiences with officials from the WAO and some of the participants were able to secure full financial support as well as financial reimbursements for replacement tools/equipment to improve workstations or home environment. For the most part though, participants in this group expressed their deep concern of landing in the WAO. It was perceived that once branded with the 'WAO label', you were stigmatized for life as 'damaged goods' and job opportunities would be extremely limited. The perception was that an employer would not want to hire someone with a history of 'being' or 'having been' in the WAO. Those persons that I interviewed who were sick at home but not in the WAO (three females) expressed deep concern and eagerness to keep their jobs. 
Insurance doctors who control entry to the WAO are not the only hurdle RSI sufferers have to overcome in order to secure income maintenance and/or various medical or social supports. Employers play a significant role in this regard. Despite the fact that protective laws are in place to ensure that employees are treated fairly, many loopholes exist which allow for the circumvention of such legislation. Some employers tend to use these loopholes to defy the law and make life difficult for RSI sufferers employed by them, in the hope that the sufferers will leave. For example, for one male participant whom was fighting to keep his job it meant having to go to work, despite doctor's orders, and taking injections for the pain.

Employers are required to find alternative jobs within the company for injured workers. However, the experience of some of the participants has it that this rule was simple enough for the employer to bypass, and as such they lost their jobs (two females). Three participants (two females and one male) were employers themselves. As such, they had a full understanding of and supportive attitudes towards anyone with the injury in general and within their place of work specifically. They also expressed concern about the fact that lawsuits for damages by injured workers against employers who did not provide a safe workplace were on the rise in Holland. These participants believed that they were pro-active in the prevention of the injury in their workplaces, allowing their staff to take frequent breaks, purchasing ergonomically correct work stations and the like. However, they did not see the need to purchase software designed to prevent RSI. Moreover, despite the fact that these employers had adopted the cloak of understanding the nature of RSI and its work-relatedness, they were quick to point out that employees do a lot of 'internetting' within the home environment, somehow attempting to absolve 
themselves from taking any responsibility for their employees' injuries. Yet, when I interviewed employees with RSI, one of the first things they wanted to make clear was that they could not do any 'internetting' at home since their condition did not allow it - it was too painful.

None of the Dutch participants were able to secure state-financed help with household chores. Though some (three participants - two males and one female) did have cleaning help, this was paid for out of their own pockets. Only one participant (one female) attempted to obtain financial house care support, the rest did not, because waiting lists were too long (six months or longer), they did not think they would qualify for financial reasons, or it was perceived that their injury was not considered to be severe enough. Financially, four participants (four females) earned less than 22,689.01 Euros, four participants (three males and one female) earned about 22,689.01 Euros, and five participants (three females and two males) earned more than 22,689.01 Euros ${ }^{13}$. The sole participant (female) who did try to obtain financial support for house care was turned down. She was told that her injury was not considered dire - she lived alone and was unable to comb her hair, button her blouse, fasten her bra, brush her teeth, could not cook or peel, let alone do her other everyday household chores. Her partner had left her because he could not accept her injury. In the remainder of the cases, the participants relied on friends, family and partners to help them with their every day living chores and tasks. All of them agreed that strong social support was key to their ability to cope with their injury and perhaps recovery.

${ }^{13}$ In 2000 the value of FL. 50,000 Dutch guilders was approximately equal to $\$ 32,000$ Canadian dollars, and was the average income in the Netherlands at the time of the interviews. Currently (2005), Fl. 50,000.- is equal to 22,689.01 Euros, which is roughly $\$ 36,777.92$ Canadian. 
When I asked what it meant for them to have RSI, they all noted that it meant having to learn to live within the limitations of their bodies - to listen to their bodies! In one case, a participant (one male) expressed his profound irritation at not being able to fully participate in the household. Especially since his partner was pregnant and was facing a difficult pregnancy - he wanted to help but could not do so. Instead he had to rely on friends to help with renovating the home and preparing the baby's room. In another case, a male participant and his partner (female) moved into a house that needed fixing up. Since he was unable to do any of the 'major' tasks, his partner did the painting, sanding, replacing walls and the like, while he did the minor chores such as cooking and laundry, despite the fact that this was painful for him. A third male participant noted that he continued with doing household chores - such as vacuuming to keep the peace within the household, despite the fact that his doctor told him to give his arms complete rest.

Two of these participants had very young children - younger than 2 years old. They both expressed their deep sorrow that they were unable to grab them and play with them. One male participant made a comment about the affect that RSI had on his sex life and the strain this placed on his relationship. Two male participants also noted that their partners had difficulty understanding and accepting their injury and did not know how to deal with it. One female participant's relationship ended because of the injury, she also had difficulty with her parents who could not understand what she was experiencing. However, not all participants had negative experiences within their social circles. For example, in one case, a male participant - who was single - moved in with his parents who took care of him so that he could recover and mend. 
At their places of paid work participants' experiences were varied. Some received full support and understanding from co-workers and employers, while others faced opposition and suspicion at work. In some cases the participants' jobs were altered so that less computer work needed to be done, time was allowed to do stretches and exercises, or they were allowed to take frequent breaks. In other cases, workstations were redesigned to suit the injured person. However, others were not that lucky and were faced with resistance from their bosses and/or their co-workers. One participant noted that the legal rules were in place, and that RSI became known in Holland, but at a social level there was still a lot of discrimination and misunderstanding. Injured workers often were told that they looked just fine! These experiences, though, were not limited to the Dutch participants alone. In Ontario RSI sufferers encountered similar reactions

\section{The Case of Ontario}

Having decided what jurisdictions to investigate, it was necessary to obtain access to these jurisdictions and identify the study groups for this dissertation. Gaining access to work-related RSI sufferers in the Netherlands, as noted, was relatively straightforward and uncomplicated. In terms of profession, union membership, gender, industry, white or blue-collar sectors, I placed no restrictions or limitations on who should be considered for interviews. Indeed, the criteria for who should or should not be included were left open provided that the participant had a work related RSI injury. As mentioned, I was given permission to post messages to the RSI forum and asked for volunteers to come forward. Thus, I laid the groundwork for initial contacts and subsequently used a snowball sampling strategy to increase the number of participants once in the Netherlands. All 
Dutch participants who came forward, worked regularly with computers on a daily basis. Therefore, in terms of identifying the study group in Ontario it narrowed my focus from 'any' worker with RSI, to workers with RSI who performed their paid work tasks with a computer on a daily basis. In other words, for the purpose of my dissertation in terms of study group identification, the focus became the repetitive tasks these workers performed with their computers (keyboarding, mouse work) rather than the occupation these workers held in their respective jurisdictions. Thus, the characteristics or attributes of the injured workers I interviewed in the Netherlands laid the groundwork for identification of the RSI sufferers to be interviewed in Ontario.

Initially I used my previous contacts to introduce my present research to the RSI and injured workers' community. As well, in conjunction with a mail out of the Canadian Council on Social Development (CCSD), I sent a letter out to disability community groups introducing myself, the research for this dissertation, and how to reach me. However, gaining access to injured work-related RSI sufferers in Ontario proved to be a challenge. To begin with there is no central Ontario RSI forum to which messages could be posted asking for computer-related RSI sufferers to come forward. In other words, the RSI community is not as well organized as in the Netherlands. Ontario is much larger than the Netherlands. This meant that I was faced with geographic constraints. As well, it was my experience in my previous research that injured workers in Ontario who suffered with RSI type symptoms were leery about answering questions regarding their injury, especially when questions were asked about the possibility of collecting workers' compensation (van Veldhoven, 1996). I attribute this to the fact that the neo-liberal discourse has undermined the political will to collectively address 
occupational health and safety issues. Within this context, occupational health and safety has become a very individualized concern. Indeed, more emphasis is placed on life threatening situations within the workplace. However, it is my view that the prioritizing of life threatening workplace conditions over RSI related workplace concerns need not and should not be mutually exclusive.

In order to establish further contacts I contacted human resources personnel in larger organizations within the Ottawa area, several unions and non-union organizations province wide, including the Ottawa and District Injured Workers Group and the lead adviser on RSI for the Office of the Worker Adviser, which addresses the problems of non-union workers who have work-related injuries. Without the protection of trade unions, these workers are left to their own devices and the Office of the Worker Adviser attempts to address this gap in Ontario. These initial contacts put me in touch with RSI sufferers who met the criteria or allowed me to make presentations at meetings in the hope that some volunteers would come forward.

There is no shortage of RSI sufferers in Ontario and many volunteers did come forward to tell their story. Unlike in the Netherlands, though, reaching this study group in Ontario proved to be a time consuming and challenging exercise. Not all people who responded to my notices actually met the criteria stipulating a computer related RSI. Many of these people had RSI, but not computer-related RSI. For the purpose of this dissertation I had to limit myself to interviewing RSI sufferers in Ontario with similar characteristics or attributes in terms of how they developed RSI, as those I interviewed in the Netherlands. Therefore, given that I interviewed only computer related RSI sufferers in the Netherlands I restricted myself to do the same in Ontario. While all interviews in 
the Netherlands were face-to-face interviews, some interviews in Ontario were handled over the telephone (three females). In addition to taking notes, all interviews (face-toface and telephone) were taped so that I could refer back to the taped interviews when transcribing. In Ontario I was able to interview thirteen RSI sufferers (three males and ten females). Most interviews in Ontario were face-to-face interviews (three males and seven females). I transcribed all the interview tapes.

Apart from the three telephone interviews, five of the interviews were conducted in people's homes (four females and one male) and five were conducted at their places of work (three females and two males). Four (four females) of the participants made a claim for workers' compensation. Two of these were given a partial claim by the WSIB, while the other two were denied their claim. Both partial WSIB claimants are fighting to have their partial claims changed to a full claim. One of the rejected claimants is fighting the WSIB to have her claim accepted, while the other claimant who was rejected by the WSIB left it at that. The remainder of the Ontario study group felt that making a claim was not really necessary (five females and two males) or felt that it would be a useless exercise (one female and one male). Only one (female) of the Ontario participants made an EI sickness benefits claim, none made a CPP disability claim. For the most part the participants were concerned about maintaining their incomes. However, for most this meant not taking any time off work even when they were aware of the fact that the computer related tasks at work caused their injury. Moreover, some of the Ontario participants had access (two males and five females) to employer supported long-term disability benefits, and they still felt that they did not need to, or should not, take time off to recover from their injury. 
Like in the Netherlands and in my previous research, there were those who had volunteered initially, but who rescinded their participation when I tried to set a date for the interview. In most of these cases, they simply did not have the energy to go through with the interview or they had second thoughts about the process. When asked what it meant to these participants to have RSI their response was overwhelmingly that of pain, and having lost the ability to do things they were fond of doing (usually sports related activities). Support within the home varied from family to family, often times the issue of their condition was not raised at all, particularly in the case of men. None had considered an alternative solution (either monetary or otherwise) to the possibility that their condition may never clear up.

My dissertation also draws on some of the data collected via the Dutch RSI Forum. As well it will refer to my previous research conducted in 1996 for the MA thesis. Despite the lapse of time between the data collected for my previous research (1996) and my present research (2000/2002) and despite the different jurisdictions, there were no significant experiential differences between the different study groups over time and across policy regimes. Some workers of my previous research had also worked with computers.

\section{Rationale for Choosing the Netherlands and Ontario}

I chose to compare Ontario to the Netherlands for the following reasons: 1) the overall illness/injury system in the Netherlands is very different from that in Ontario, particularly it is the case that the Dutch workers' compensation system (WAO) is 
qualitatively very different from that in Ontario (WSIB) $\left.)^{14} ; 2\right)$ Repetitive Strain Injury is seemingly treated very differently in these two jurisdictions - RSI is an injury that is compensated under the Dutch compensation system but is essentially invisible in the Ontario compensation system; 3) following from these two points, it interested me to see what could be learnt by investigating the Dutch system and the experiences of workers with RSI given my work on the experiences of women workers with RSI in Ontario (van Veldhoven, 1996); 4) each of the two jurisdictions represents a very different social policy regime with the possibility that I might contribute to this academic area; 5) I have relatives and friends in the Netherlands whom were able to put me in contact with RSI sufferers, aiding the data collection process, and; 6) I am fluent in the Dutch language, which would facilitate the research process in the Netherlands.

\section{Common Experiences: Nuancing the Debate on Social Policy Regimes}

All of the people interviewed for this dissertation worked with the aid of computers. Their professions/occupations differed but they all used a PC as a tool in the type of work they did. In each case they firmly believed that the use of the PC or mouse was their cause of their injury.

\footnotetext{
${ }^{14}$ Whereas in Ontario the injury needs to be work related in order to qualify for compensation, in the Netherlands this is not the case. The qualification rests on whether the worker is employed at the time of the injury, regardless of where the injury occurs. Thus, if a Dutch employee injures her or himself while on holiday, to the point where they to need to convalesce outside of the workplace for a period of time, that worker would theoretically qualify for workers' compensation. In other words, the injury does not need to be specifically work related in order to qualify for financial support while unable to work.
} 
They all suffered debilitating pain and loss of strength in their arms, hands and legs to the point where they could not perform every day tasks any longer. Their pain emanated from the shoulders/neck area down to arms, wrists and in one case the whole body - including jaws.

All suffered from some depression and all frantically searched for and wanted answers as to the cause of their condition and how to treat it - unfortunately all encountered uncertainty and no consensus among members of the medical profession on whether their injury was 'real' or how best to address it. They were all looking for acknowledgement and legitimation. All had great personal difficulty with accepting the fact that they were injured and probably permanently disabled.

In essence family physicians were accommodating and granted patients' requests for therapy and/or visits to neurologists and/or other medical specialists. Not all of the participants trusted, or they were critical of, their physicians, and some refused to visit a physician.

Participants in both regimes encountered resistance in clinical encounters. Tests did not show anything. Uncertainty dominated their psyche and long waiting (anywhere from 6 months to 1.5 year) lists were part of their common experience. Insurance doctors (both private and state employed) were not accommodating and were less willing to accept patients' accounts of their problems. Without their co-operation the patient had two options, return to work or leave their job, in which case they would have to rely on welfare.

Some of the women expressed despair and found it difficult to relinquish their household chores. They all faced life style changes, some of the participants had 
difficulty accepting this. Participants in both regimes found their respective workers' compensation systems puzzling, causing stress and low confidence in the system. Within this context they were also very critical of the faceless adjudications they encountered. In both policy regimes the role that employers have in terms of accessing the respective workers compensation systems is significant. This is important since the workers compensation boards in both regimes cover the issue of rehabilitation and a number of therapies to encourage such rehabilitation, not to mention the idea of income maintenance while recovering from an injury. If employers, therefore, are not willing to help their employees access the system then these workers will not be able to access certain rehabilitation programs or particular therapies, or they will have to do so with their own money.

In both regimes some RSI sufferers resisted the decisions made by the various members of the ruling relations. They used various tactics to make their invisible condition visible. Participants in both policy regimes remarked how RSI had changed their lifestyles and previously taken for granted activities such as tying one's shoelaces or brushing teeth, had become arduous and painful tasks

Last but not least, participants' experiential accounts point out that while the state may acknowledge the injury within the paid work sphere, the state does not recognize or acknowledge the injury within the unpaid or domestic work sphere in both policy regimes.

\section{Conclusion}

As we have seen, debates on social policies and social policy regimes have tended 
to focus on the macro versus micro perspective. This leads to a problem since the abstract level of social policy regime analysis tends to be static. Using concepts from Smith (1987) and social problem theorists I maintain that to obtain a clearer understanding of social policy regimes we need to use the experiences of persons who interact with the processes of social policies. My focus in this dissertation is to concentrate on the experiences of injured workers with RSI and how they experience their injury within the context of gaining access to workers' compensation policies in two different jurisdictions.

To do this I collected experiential accounts of workers who developed RSI type injuries while they were in paid employment. All of the participants for whom I collected data in the Netherlands and Ontario were self-diagnosed regarding their RSI condition and in some cases physicians agreed with their conclusions and reiterated the diagnosis of RSI. The data and information was gathered from a number of sources, most importantly from interviews with a number of workers with RSI, and from a Dutch RSI forum listserv.

My dissertation is divided into four broad areas that delineate my discussion and which gave me direction on how to divide the remaining chapters. In the next chapter I begin by discussing the process of making a workers' compensation claim. A brief exploration of how the different regimes address the issue of worker injury policies is covered in the chapter.

In the chapter following the discussion of the claims process, I discuss the gendered nature of workers' compensation systems, which nuances the argument in terms of gender. Individuals see the world through a gendered lens, thus policies are inherently 
gendered, which adds a gendered dimension to the experiences of the RSI sufferers. Within this context, gender is an important aspect of the experiential accounts of the injured workers who participated in the research for this dissertation. Here, the discussion centres on the gendered nature of RSI and its associated problems in terms of occupational health and safety concerns and paid/unpaid work duties and how that differs or is similar across the jurisdictions.

The following chapter discusses how injured workers resist or comply with medical conclusions in the context of medical gatekeeping. Medical gatekeepers are an important aspect of the process of acquiring workers' compensation benefits in both jurisdictions. Thus, the participants' experiential accounts of the medical encounter are pivotal in terms of demonstrating the differences or similarities of the claims-making process across the different policy regimes. This leads to a discussion of the experiences of the participants in terms of offering resistance to or compliance with, decisions made by medical examiners and the ensuing struggle for the sick role. The issue of disability and its many associated concerns is implied throughout this dissertation as a universalizing force.

The last of the core chapters in this dissertation provides a brief discussion on market-based or private income maintenance schemes for those who fall through the cracks of state supported social provision programs and must therefore rely on alternative sources of social provision. A concluding chapter provides a summary and over-arching analysis of the discussions raised in the other chapters of my dissertation. 


\section{Chapter 4 \\ The Process of Work-Injury Policies}

\section{Introduction}

When a worker becomes injured while employed, either on the job or elsewhere, they are faced with the prospect of not being able to maintain an income. Two social policy regimes, the Netherlands and Ontario, take a different approach to addressing income maintenance programs for injured workers at the structural level. Upon the face of it, then, it is reasonable to expect that because each of the regimes address their worker injury concerns differently the experiences of those people in the process of making a claim using the two systems would be also be quite different. However, upon closer investigation of the Dutch and Ontario policies that address the issue of worker injury, I find that there are many similarities in the experiences of workers attempting to access the workers' compensation systems in both jurisdictions.

In the Netherlands, an injured worker reports to their employer and subsequently to their physician that they are unable to work and they are then allowed to take up to 52 weeks of paid sick leave, as long as their physician validates the injury - the injury need not be work-related. In doing so, they initiate the first step to securing wage replacement benefits from workers' compensation. This step is then followed by an automatic application to the workers' compensation program should their injury require a period of coverage beyond the 52 weeks. In Ontario, injured workers do not have the benefit of a 52-week paid waiting period before they are allowed to apply for workers' compensation. Furthermore, in addition to reporting the injury/illness to their employer, the injured worker in Ontario must also show that the injury is a work-related injury before they are 
eligible to secure income replacement benefits through workers' compensation programs.

Based on the policy differences between the Netherlands and Ontario, we would expect to find differences in the experiences of injured Dutch workers and Ontario workers in terms of the first step, which would be relatively straightforward in the Netherlands (the Ziektewet, a 52 week coverage) compared to Ontario. Moreover, since Repetitive Strain Injury (RSI) is recognized as a compensable injury in the Netherlands but not in Ontario, we would expect to see different experiences for injured workers applying for workers' compensation for this injury in the Netherlands compared to Ontario. However, our evidence suggests that, based on the experiential accounts of the participants in the two study groups, while there is a distinct difference in the first steps (workers in the Netherlands having relatively uncomplicaled access to 52 weeks of injury relief), there are many similarities in the experiences of workers applying to the workers' compensation programs in both jurisdictions.

This chapter begins by addressing the issue of Repetitive Strain Injury (RSI), and clarifies the disease category that encompasses RSI. In the next section of the chapter I briefly discuss the worker injury and disability policies within the two jurisdictions of Ontario and the Netherlands. This section delineates the differences between the two social policy regimes in terms of worker injury policies and how each regime addresses this issue. I discuss the process of claiming workers' compensation as set out by the relevant jurisdictions. That is, how the process is supposed to work according to the ministries responsible for administering workers' compensation boards in both social policy regimes. This is followed by an examination of the experiential accounts of a 
specific set of participants from both jurisdictions and compares how the process is experienced in the everyday lived lives of injured workers.

\section{RSI, An Insidious Work Injury and Workers' Compensation}

RSI is an insidious form of workplace injury, one that is not obvious to the naked eye. It is an umbrella term for a number of musculoskeletal disorders (MSDs) of the tendons, muscles, nerves, and bones of the upper extremities resulting from strains precipitated by repeated movements. These injuries caused by consistent repetitive motion fall under this rubric of Repetitive Strain Injury (RSI). Because of its debilitating properties, RSI is classified as an occupational health and safety issue (see van Veldhoven, 1996) as well as a disability issue. The concern within the medical community is the fact that its aetiology and physiology are not easily determined. RSI sufferers often find themselves within the crossfire between those medical experts who support their claim to the malady, and those who dismiss the condition out of hand, stating that RSI only exists in their head. This is true for both jurisdictions under investigation, albeit for different reasons. Unfortunately it translates into a situation where some injured workers, who suffer with a RSI type injury, need to continue with their paid work duties - the very work activities that caused the disabling condition. Injured workers, in both jurisdictions, must at least have a medically validated condition in order to qualify for workers' compensation benefits. This is relevant since workers compensation schemes in the Netherlands and Ontario rely heavily on medical validation before an injured or ill worker can go forward with claiming compensation. 
At the policy level, the Netherlands and Ontario address issues of social concerns very differently (Ministerie van Sociale Zaken en Werkgelegenheid, 2004; Ministry of Community and Social Services, 2003). Because differences exist in terms of social policy at the structural level between these jurisdictions, it follows that approaches to occupational health and safety and/or disability issues will also likely differ between them, based on their ideological and cultural beliefs and historical backgrounds. Similarly, it can be expected that approaches to compensation for a work related disability and/or injury, as a health and safety concern, are dealt with differently. One of the concerns with RSI is the fact that there is no consensus among medical experts as to what actually constitutes the condition (cf. Arksey, 1998, 1994; Kome, 1998; van Veldhoven, 1996).

Recent research contends that RSI is a leading source of workplace injury and/or disability in North America (cf. Korrick et al., 1994; Ashbury et al., no date; Kome, 1998). Yet despite this contention, no official statistics are kept under the category of RSI by the various relevant institutions in Ontario, rendering the injury 'officially' invisible in this jurisdiction (van Veldhoven, 1996). In contrast, at the time of doing the research for my dissertation RSI was recognized by state authorities in the Netherlands as a legitimate occupational health and safety disease entity with potential adverse social consequences (Ministerie van Sociale Zaken en Werkgelegenheid, 1999). Regulations safeguarding employees against the development of the injury in the workplace, as well as educational programs informing employers and front line physicians (usually family physicians) about RSI, had been introduced at the state level in the Netherlands. Thus, in the Netherlands RSI was being made a visible occupational health and safety issue. The 
recognition of a workplace injury as legitimate and visible is necessary and crucial in the case of entitlement to compensation. This is important because RSI is a potentially permanently disabling condition.

To qualify for workers' compensation in Ontario, the 'cause' of the injury is relevant. A disability needs to be specifically workplace related before the worker is entitled to benefits (Piva, 1975; Elgie, 1989; WSIB, 2004). In the Netherlands the 'consequence' of the injury is what matters and the injury does not have to be workrelated in order to qualify for compensation (cf. Cox, 1993; Aarts et al., 1996, Ministerie van Sociale Zaken en Werkgelegenheid, 1999, 2004). The effects on the practical aspects of everyday life following the injury, such as disruption to work and domestic routines are at issue, not the work-relatedness of the injury. If, for example, an employee in the Netherlands becomes injured (arbeidsongeschikt) while on holiday to the point where they cannot perform the everyday duties or tasks that their job requires of them, the employee would qualify for workers' compensation benefits. The only stipulation is that the injured person has to be employed at the time of injury. The definition of 'arbeidsongeschikt' (worker disabled) refers to a person who, because of their illness or injury, is unable to earn a similar wage as a healthy person with a similar education or training (Ministerie van Sociale Zaken en Werkgelegenheid, 2004). Thus, the Netherlands has adopted a broader view of entitlement based on the principle of 'social risk' rather than 'occupational risk,' while Ontario bases its compensation entitlements on the principle of 'occupational risk' more commonly found in workers' compensation insurance programs (Cox, 1993, among others).

Nonetheless, while each jurisdiction has taken a different approach to addressing 
occupational health and safety issues in terms of risk and entitlement, both employ the use of 'gatekeepers' to limit the demands made on the state ${ }^{15}$. In each jurisdiction medical experts are responsible for determining levels of disability and subsequent eligibility to benefits (cf. Cox, 1993; Schrijvers, 1991; van Veldhoven, 1996; Doe and Kimpson, 1999). They are also responsible for assessing any changes to the injured worker's condition so that entitlements to benefits can be (re)evaluated. This legitimation or validation process is true for both the Dutch and Ontario regimes (personal interviews in the Netherlands and Ontario summer of 2000 and summer of 2001; WSIB, 1999, 2004; Ministerie van Sociale Zaken en Werkgelegenheid, 1999, 2004). Thus, in either regime physicians are important actors in the implementation of occupational health and safety policies.

\section{Disability Policies in the Netherlands and Ontario}

Two social policy regimes, the Netherlands and Ontario, take a different approach to addressing income maintenance programs for injured workers at the structural level. It is then also reasonable to expect that each of the regimes address their worker injury concerns differently. Upon closer investigation of the Dutch and Ontario policies that

\footnotetext{
15 Indeed, Doe and Kimpson (1999: 4, emphasis added) note that in Canada's workers' compensation systems "[d]octors play a key gatekeeper role in access to benefits, because their accurate assessment and diagnosis of a condition are crucial to determining eligibility". This is especially problematic for women whose "cyclical and fluctuating illnesses also create difficulty for physicians who diagnose them, especially if the condition appears dormant or is judged to be psychological, as often happens with chronic fatigue, ... fibromyalgia [and RSI]" (Doe and Kimpson, 1999: 4, emphasis in original).
} 
address the issue of worker injury, I find that there is a significant difference between the two policy regimes in terms of how each addresses this issue.

The Workplace Safety and Insurance Board (WSIB) administers the Ontario Workplace Safety and Insurance Act and its vision statement is to "eliminate all workplace injuries and illnesses in Ontario" (www.wsib.on.ca, 2004). It is also the first point stated in section 1 of the Act. This vision statement is clearly posted on the Website of the WSIB. In order to accomplish this goal it is vital that all workplace injuries and illnesses are reported to and recorded by the WSIB. Without this, it is simply impossible to reach the goal stated by the WSIB. The problem is that not all work related injuries are reported to the WSIB. As such, the stated vision of the WSIB can never be achieved. Moreover, injured workers must report all work related injuries to their employer, no matter how small or minor under section 21 of the Act. Failing to do so will mean that claims will be denied by the WSIB. It is necessary for work-related injuries and illnesses to be reported within 6 months of the injury and - in the case of a chronic condition - within 6 months of finding out that the worker has developed a workrelated chronic condition such as repetitive strain injuries. As well, the WSIB has instituted more stringent eligibility rules for those suffering chronic stress or with a chronic pain condition such as soft tissue injuries or RSI. Even if a soft tissue injury is approved for compensation, the injured worker in Ontario can only receive benefits for a 3 to 6 month period. This is premised on the idea that workers with such an injury have reached their maximum medical recovery at 3 to 6 months, a point in their healing time "when it is not likely that there will be any further significant improvement in their medical condition" (WSIB Operational Policy Manual, Ontario, 2004). 
In stark contrast we have the Netherlands where there are two aspects to worker injury compensation. The first aspect is the Ziektewet, which allows RSI sufferers to recuperate without loss of income for up to 52 weeks. After this time injured workers must make a workers' compensation claim if they wish to receive income support (Ministerie van Sociale Zaken en Werkgelegenheid, the Netherlands, 1999, 2004). It might be expected, therefore, that fewer injured or ill workers would make workers' compensation claims in the Netherlands. However, this is not the case. Indeed, when the act regarding worker disability or injury (WAO) came into effect in 1967, it was estimated that no more than 200,000 individuals would make use of the state sponsored disability or workers' compensation (WAO) policy (Ministerie van Sociale Zaken en Werkgelegenheid, 2004). However, between 1967 and 2004 it turned out that five times that number actually made use of the WAO over this time period. A number of different actions by the state have been taken to reduce or stabilize the number of applications to use the compensation system over the years but to no avail. It has been documented that both employers and employees began using the WAO system after the 1973 oil crisis as an alternative to unemployment insurance (Ministerie van Sociale Zaken en Werkgelegenheid, 2004). Reasons why include the fact that it was a less expensive and less complicated alternative to unemployment policies for Dutch employers, while the employee benefited, since WAO paid higher benefits and for a longer period of time than unemployment benefits (Ministerie van Sociale Zaken en Werkgelegenheid, 2004). It was also much easier to get WAO benefits than unemployment benefits - especially for older unskilled workers (cf. Aarts et al, 1996). By 1976 there were more than half a million individuals, and by 1985764,000 individuals, who were taking advantage of the 
WAO system in the Netherlands. Currently the number of individuals entering the WAO system is still higher than the number of individuals who exit the system (Ministerie van Sociale Zaken en Werkgelegenheid, 2004).

In Ontario, medical 'gatekeepers' are primarily employed to determine whether a worker's injury is work-related, though not necessarily to deny that the injury actually exists $^{16}$. These 'gatekeepers' may be the family physician (van Veldhoven, 1996) or physicians employed by the Workers' Safety and Insurance Board - WSIB (Kome 1998; Doe and Kimpson, 1999). Family physicians do not determine eligibility to benefits, the WSIB makes such a decision. The family physician's role is to report the injury or disability to the WSIB if they are convinced that the injury is work related. Indeed, it is possible that a family physician will accept the work-relatedness of a person's condition only to find that a WSIB physician will disagree with that opinion. In such a situation the decision of the WSIB physician takes precedence over the decision made by the family doctor. When that happens, the injured worker does not qualify for compensation - even though they may have a disability and are unable to work.

In the Netherlands, the 'gatekeepers' are occupational health and safety physicians employed by the state (the Arbo Dienst) but who work as company doctors for the employer and insurance doctors who are employed by the WAO. They primarily determine whether the injury actually exists, whether the injury is legitimate, and whether the claim to having an injury is valid; the cause of the injury is not in question (see for instance Cox, 1993). Based on their diagnosis the level of disability is determined and accordingly the level of entitlement. Here the insurance physician's role is to objectify

\footnotetext{
${ }^{16}$ However, there have been cases where the WSIB physician denied the existence of a condition.
} 
and categorize the disability within the definitional boundaries that reflect institutional concerns, which are determined by the extra-local or policy makers. Indeed this is the case in both policy regimes.

Company physicians in both jurisdictions, though not the final arbiters regarding workers' compensation claims, also play a role. Their role is not to make a diagnosis regarding the work-relatedness of the injury but rather to determine if the injured worker is still capable of performing their job. However, in order to get validation from the insurance physician, it is necessary that the company doctor first validates the condition by prescribing complete rest and no work for those workers suffering from RSI. This 'gate-keeping' function allows for a delay into the workers' compensation system in both jurisdictions. The work-relatedness in the case of eligibility for WAO benefits is never in question. Moreover, family physicians, in either jurisdiction, do not play any role in determining eligibility for benefits. Their role is more to guide the patient toward recovery. Thus, in each regime we have medical 'gatekeepers' limiting claims on the state in spite of the fact that the Netherlands is considered to have a more tolerant view of entitlement to workers' compensation and also an understanding of the consequences of RSI and possibly a worker incurring a disability.

In both jurisdictions there are disability policies in place that are aimed at providing a range of social supports for those who have a disability, and who need to negotiate their daily routines in an able-bodied society. For this dissertation, I am particularly interested in policies that address income maintenance or wage replacement benefits for injured workers while they are unable to perform their paid duties. The stated aim of workers' compensation policies in both jurisdictions is to do just that. Even 
though Ontario and the Netherlands are classified as different social policy regimes, the income maintenance policies instituted in each of the jurisdictions have some similarities and also some differences in their approach to addressing the issue of injured workers and income maintenance.

The most striking similarity in the two jurisdictions is the use of medical gatekeepers to determine eligibility for benefits. It is at this juncture that the experiences of the participants in both jurisdictions are comparable. As well, in both jurisdictions workers' disability compensation entitlements are based on participation in the workforce and are mandatory contributory insurance systems. That is, entitlements are based on labour market ties. Similarities in the two jurisdictions' workers' compensation schemes may be due in part to the fact that both have benefited from policy borrowing (cf. Cox, 1993; Piva, 1975). Both systems use elements of Germany’s Bismarck social insurance schemes and Britain's Beveridge universal social security plans. Nonetheless, while there may be similarities we must not forget that there are differences too, most important being the differing eligibility rules between the two jurisdictions. In the Netherlands benefits are provided to any member of the labour force who incurs an injury, whereas in Ontario the disability has to occur as part of the labour process.

\section{The Dutch Disability System}

General social security in the Netherlands is a curious mix of Bismarckinfluenced social insurance programs and Beveridge-influenced universal entitlements (Aarts et al, 1996; Cox, 1993). The postwar welfare state in the Netherlands had a slow start in terms of its development compared to other welfare states such as Britain, West 
Germany or Sweden (Cox, 1993). However, since World War II it has grown rapidly from one of the lowest spending welfare states to one of the highest. The development of the Dutch welfare state was not so much a reaction to its society reaching a certain level of development or modernization, but rather a result of Dutch policy makers searching around and 'borrowing' policy ideas from other countries when social security issues became part of the political landscape (Cox, 1993). Income maintenance programs for the 'arbeidsongeschikten', the worker disabled, are legislated at the national level in the Netherlands, but administered by autonomous institutions, comprised of labour and business, at the local and regional level (Ministerie van Sociale Zaken en Werkgelegenheid, the Netherlands, 1999, 2004).

Over time, the Dutch developed a complex set of social security programs for persons with a disability, including those persons with a disability resulting from work injury, which are managed through the department of 'sociale verzekeringen' or 'social insurance'. The department of 'sociale verzekeringen' provides disability security via two programs: the 'Werknemers Verzekering' or Employee Insurance Program and the 'Volksverzekering' or National Insurance Program. The Werknemers Verzekering is based on labour-market ties and includes: short term sickness income coverage for workers; the 'Wet Uitbreiding Loondoorbetaling by Ziekte' (WULBZ) formerly known as the Ziektewet (ZW) ${ }^{17}$; long term disability, the Wet Arbeids Ongeschiktheid (WAO); and the Zieken Fonds Wet (ZFW) - a national health care plan. The Volksverzekering, on the other hand, is more universal in nature and covers Exceptional Medical Expenses such as long hospital stays (AWBZ), long term disability benefits for the self employed (WAZ),

${ }^{17}$ Though still popularly referred to as the Ziektewet in the media and by the research participants. 
which insures the self-employed against the financial consequence of long-term occupational disability and long term income security for young people with a disability (WAJONG).

The first major plan, the 'Wet op de Arbeidsongeschiktheids Verzekering' or WAO, which falls under the 'werknemers verzekering' or employee insurance, is designed to target those who have labour-market ties and become disabled during the course of their employment or career. To qualify for benefits the injury does not need to be work-related (Ministerie van Sociale Zaken en Werkgelegenheid, the Netherlands, 1999, 2004). The Act was legislated July 1, 1967. Prior to January 1998, employees alone paid WAO premiums. Since then, the employer also makes these contributions. The level of the premiums is determined by the type of industry and the number of accidents reported by the employer. In Ontario this practice is referred to as 'experience rating'. Dutch employers have used the WAO system to down size their labour force during economic downturns, which gave the appearance of low unemployment rates in the Netherlands. This happened especially after 1973 following the Middle East oil crisis and the Netherlands (like elsewhere in the Western world) experienced a sharp decrease in their economic activity and Dutch companies were faced with financial ruin (Ministerie van Sociale Zaken en Werkgelegenheid, the Netherlands, 2004). However, because of this practice the Dutch system showed a high work-related disability incidence (Aarts et al., 1996; Ministerie van Sociale Zaken en Werkgelegenheid, the Netherlands, 2004). To combat this trend the Dutch government implemented 'experience rating' in the hope of discouraging 'unsafe' workplace practices as well as discouraging employers from misusing the WAO system. Before injured or sick workers are able to make a 
WAO claim, they must have first satisfied the conditions of the Sickness Benefits Act

(Ziektewet). At the time of the research the Act stipulated that if an employee falls sick, the employer must continue to pay the employee's wages. This compulsory sick pay period is 52 weeks.

The second plan is the 'volksverzekering' or national insurance, which is a universal program, designed to target those with a disability but who do not have labourmarket ties. Both of these programs fall under the jurisdiction of the Ministerie van Sociale Zaken en Werkgelegenheid (Ministry of Social Well-Being and WorkOpportunity or Social Affairs and Employment) and are long term disability income maintenance or wage replacement programs (Ministerie van Sociale Zaken en Werkgelegenheid - SZW, the Netherlands, 1999, 2004).

The Dutch system works as follows: employees who fall ill or become disabled have the right to continuation of their wages/salary for up to 52 weeks after they incur the illness, injury or disability - that is they first fall under the purview of the Ziektewet ${ }^{18}$. Regardless of the cause of sickness or injury, the employer is required by law to pay at least 70 per cent of the last earned wage or the minimum pay which ever is higher. In other words, if 70 per cent of an employee's salary falls under the minimum wage, the

${ }^{18}$ At the time of the research this was the case. However a more right-winged government is in power presently. This administration is actively attempting to reduce the flow of new disability benefit claimants (Ministerie van Sociale Zaken and Werkgelegenheid, 2004). As of July 1, 2004 the government abolished the disability benefit scheme for the self-employed (WAZ). Moreover as stated by the ministry on the web in English, "Prevention of occupational disability starts with real incentives to prevent sickness absenteeism from January 1, 2004 employers must therefore continue to pay the wages of sick [or disabled] employees for two years - rather than one year" (Ministerie van Sociale Zaken and Werkgelegenheid, 2004). Thus as of the start of this year, there is a two year waiting period, during which the employer is held responsible for income maintenance of the injured employee before they can claim WAO benefits. 
employer has to pay up to the minimum wage by law. In some cases, it is possible that a collective agreement is in place which determines that the full salary should be paid, rather than 70 per cent of the salary. It was the case in the past that the state, in turn, would reimburse the employer. However, given the current fiscal restraint experienced by the Netherlands government, the employer is currently held solely responsible for the employee's salary. Indeed, employers are advised to purchase insurance for protection against such a situation.

This social citizenship 'right' to obtain 52 weeks of illness leave is a work-related benefit since labour-market ties are a necessary precondition under WULBZ. If after 52 weeks the disability persists, the worker then falls under the WAO, which is the longterm disability income replacement program. Thus, to qualify for long term disability there is a 52 week waiting period, during which the employer is responsible to maintain the wages. In addition to these two programs, at the time of the research, disabled workers (or any other) who earn 29,178.07 (in 2000) Euros annually or less have access to the Ziekenfonds Wet (ZFW), which is the health care program. Premiums are paid by the employee, are usually deducted at source and, are mandatory. An employee who earns more than 29,178.07 Euros annually is required by law to purchase private health insurance. This figure may have been adjusted since then.

If a person is self-employed, and an injury or disability occurs, it is possible to receive income support under the WAZ. In order to qualify for WAZ, it is necessary to be at least 25 per cent disabled and not older than 65 . Unlike the WAO, this particular social right is not transportable outside of the Netherlands. However, it seems that this policy (WAZ) is not well known among some of the Dutch participants who were self 
employed. For instance, when asked whether they knew of a policy through which selfemployed injured individuals could maintain an income while unable to work, I was told that there was no such protection for self-employed individuals offered by the state:

When [the doctor] at de Arbodienst determines that you are worker disabled, nothing happens ... In essence there is nothing much available for [those who are] self-employed. (Dutch interview \# 4, Summer, 2000)

The above-mentioned programs are wage replacement programs to cover loss of earnings due to sickness or disability. They are earnings-related supplements and fall under the Disability Security Act. The Public Disability Act - or National Insurance provides for a flat-rate benefit for income assistance to most permanently disabled citizens. These are individuals who have had a disability since birth or since their youth (Cox, 1993: 164-15). Those with a disability before the age of eighteen are covered by WAJONG and those who are self-employed are covered under WAZ. However, male students or single female students who become disabled between the ages of eighteen and thirty and do not have a work history but need financial support also qualify for WAJONG as long as they have been a student for at least six months prior to the injury or disability. Remarkably, married women who are students in this age category do not have access to this income support. Also, students over the age of thirty who become disabled (e.g. develop RSI) and have no labour-market ties similarly fall through the cracks and have to go on general social assistance or sociale voorzieningen, which is means tested and financed through general revenues (Ministerie van Sociale Zaken en Werkgelegenheid - SZW, the Netherlands, 1999). 
As noted, in the Netherlands it is not the cause of the injury or disease that matters, but rather the consequence of the impairment that is relevant (Aarts et al.1996: 23 , among others) and therefore policies are designed to reflect this concern. The Dutch have a program that allows those who become chronically ill or who have a disability (no matter how the injury is incurred) during the course of their career/work life, to collect benefits (ZW - sickness benefits; WAO - disability benefits) in lieu of lost earnings, so that income can be maintained (Aarts et al.1996; Cox, 1993, Ministerie van Sociale Zaken en Werkgelegenheid, 1999). Moreover, the Dutch have also instituted a policy that attempts to cover most persons with a disability but have not had the opportunity to develop a career or work relationships. The latter policy tends to be more universal in nature, while the former policy is hinged on having established labour-market ties. Both programs fall under the jurisdiction of the same ministry - the Ministeric van Sociale Zaken en Werkgelegenheid.

In the Netherlands an injury/disability needs to be legitimated by a series of physicians - medical gatekeepers. Initial diagnosis is established by the family physician, though a referral to and diagnosis by a specialist may be necessary before further steps can be taken towards the legitimation of the patient's condition. The family physician acts as the primary gatekeeper to the Dutch health care system.

All companies in the Netherlands are also required by law to register with a certified 'Arbodienst' (Ministerie van Sociale Zaken en Werkgelegenheid - SZW, the Netherlands, 1999). This is a state run institution that employs occupational health and safety specialists, including insurance physicians, ergonomists and the like. Their role is to give advice to companies in terms of occupational health and safety matters such as 
proper ergonomics within an office. As part of this service, insurance or occupational health and safety physicians employed by the Arbodienst, determine if an injured or disabled employee is capable of work. In other words, they determine whether the injured worker qualifies for continuation of pay while unable to attend their place of work under the provision of the Ziektewet. These physicians work in the interest of the company and as such are seen as company doctors even though employed by the state. Without the approval of the Arbodienst the injured or disabled worker will not be able to collect a salary from the employer, despite the diagnosis of a family physician. This is the reason why most family physicians engage a specialist, since they are seen as 'more of an authority' in certain health related conditions.

\section{The Ontario Disability System}

In Ontario there is a patchwork of programs and unlike the Dutch system, these programs fall under the jurisdictions of several separate ministries. Some programs are administrated at the federal level, while others fall under the jurisdiction of the province. In general, persons with a disability can follow a number of avenues to obtain income security while unable to do paid work. The former Ministry of Human Resources and Development (Ministry of Human Resources and Development Canada [HRDC], 1994) notes that in Canada the components of income maintenance for those with a disability are:

1) Canada Pension Plan benefits - a long term coverage for which the applicant must have a work history, but which is not limited to the cause of the disability;

2) Unemployment Sickness Benefits - a short term coverage with a two week waiting period and only fifteen weeks of coverage; 
3) Workers' Compensation; Benefits for Disabled War Veterans; Auto Accident Insurance, and Criminal Injuries Compensation - these are programs which provide benefits for disabilities caused by specific conditions or in specific circumstances;

4) Private Insurance or private pension plans - which are also not limited by the cause of the disability but are far from universal; and

5) Provincial Assistance Programs - these are means-tested programs of a last resort with a host of restrictions.

For the purpose of my research dissertation, I will focus on income maintenance or income replacement programs which are offered through the state. As such, the relevant programs under federal administration are: 1) Unemployment Sickness Benefits of the Employment Insurance Program (EI) and 2) the Canada Pension Disability Benefits of the Canada Pension Plan (CPP). Relevant programs under Ontario provincial jurisdiction are: 1) the Workers Safety and Insurance Board or WSIB (formerly known as the Workers' Compensation Board); 2) the Ontario Disability Support Program (ODSP); and 3) Social Assistance (SA) or workfare/welfare.

Canada does not have a federal policy that addresses and assures conformity and unity across the provinces in terms of Occupational Health and Safety standards, or in terms of income maintenance to citizens who are suffering a work-related injury, or for those persons with a disability. Instead, each province is responsible for its own Occupational and Health and Safety policies, this includes Workers' Compensation Systems. It does, however, provide for some national income security under EI and CPP. These programs have eligibility rules or are means tested, as would be expected in a liberal policy regime. That is, a strict eligibility test applies for both EI and CPP - most people who are considered as having a disability in Canada do not qualify for a CPP benefit (Ministry of Human Resources and Development Canada [HRDC], 1994). Under EI, citizens who are sick or have a disability have access to employment insurance 
sickness benefits. A work history or labour market ties are necessary in order to qualify for these benefits. Both the employer and employee fund this program through contributions from earnings. It is a short-term solution that pays only 55 per cent of wages for a maximum of 15 weeks with a two-week waiting period. However, if the employee does not qualify because she or he has not accumulated the minimum required hours worked in a calendar year for employment insurance benefits, then the person with a disability or injured worker is not eligible for sickness benefits either. If at the end of the fifteen weeks the disability has not cleared, the employee could be eligible for CPP disability benefits, which is for those deemed to have a long-term disability.

Like EI, both employee and employer finance the CPP through contributions from wages that are deducted at source. It is a national program and its primary role is to provide retirement benefits to those 'plan contributors' who are 65 and older and are no longer in the workforce. However, the CPP also offers income replacement to contributors who are suffering from a "severe and prolonged mental or physical disability" (Section 42(2)(a) of the CPP, as quoted by HRDC, 1994). The Act defines severe as "incapable regularly of pursuing any substantially gainful employment", and prolonged as "likely to be long continued and of indefinite duration or is likely to result in death" (HRDC, 1994). As such, benefits are payable while the disability persists until death or age 65 . Again, it is necessary to have a work-related history as a precondition of eligibility, as well as having made contributions to the plan over a number of years (four out of six years). Cause of injury or disability does not, however, need to be work-related for either EI or CPP. CPP disability is a wage replacement program and is paid to 
disabled citizens between the ages of eighteen and 65 until death or age 65 whichever comes first. At age 65 a person is switched to pension payments.

At the provincial level, if an injury or illness is specifically work-related, the injured or disabled employee has access to workers' compensation, which falls under the purview of the Workplace Safety and Insurance Board in Ontario (formerly known as the Workers' Compensation Board). In Ontario, Occupational Health and Safety Legislation falls under the jurisdiction of the Ministry of Labour and encompasses the Workers` Compensation System. The initial Workmen's Compensation Act was introduced in 1914 and went into effect in January 1915 (Piva, 1975: 41). Under the 1915 Act, injured workers gave up the right to sue their employers for damages in return for 'automatic' compensation, a guaranteed protection against income loss attributable to industrial injuries and disease, irrespective of fault (Elgie, 1989; Piva, 1975). This agreement is referred to as the 'historic compromise'. It means that injured workers cannot file a lawsuit against their employer, in the event they become injured.

Since then, the Act has undergone a number of changes with the most significant change occurring recently under Bill 99 that was introduced in November of 1996 and became law on January 1, 1998 (Workplace Safety and Insurance Board of Ontario, 2004). Bill 99 serves to rename the 'Workers' Compensation Act' to 'Workplace, Safety and Insurance Act'. Essentially the renaming of the Act has trivialized or marginalized workers by removing any reference to the 'worker' from the compensation system. With an emphasis on 'safety' and 'insurance' in the workplace, it gives the impression that workers are assured a safe - free from hazard - workplace. This language serves to 'hide' the fact that workers can and do suffer work-related injuries and diseases or syndromes, 
which translate into a loss of earnings for which they need to be compensated. Workers' compensation is now seen as an insurance against workers' injuries and illnesses rather than a compensation system and pays 80 per cent of wages. Benefits under WSIB cover both short and long term disabilities.

Like the recently implemented changes to the financing of the WAO in the Netherlands, the workers' compensation systems in Canada derive their primary revenue from assessments levied on employers (Ison, 1988: 723-742). Assessment rates depend on the number of reported injuries by the employer relative to their respective industry. This is called 'experience rating,' which hinges on a formula that reflects the claims cost experience of the employer. This form of financing the system is believed to provide employers with an incentive to provide for safe and healthy workplaces. However, research has shown that the opposite is the case (Ison, 1988). Experience rating in fact encourages employers to reduce the recorded claims by under-reporting accidents and injuries. Also, Ison (1988: 729) has shown that "... most occupational disabilities result from disease rather than trauma [and within this context], experience rating can be of no benefit".

Changes to workers' compensation programs in Ontario, over time, reflect a pattern where the onus is continually put on injured workers to show that their injury is work related before they can receive compensation. This in spite of the fact that the 'historic compromise' (to give up the right to sue an employer for damages in return for automatic compensation in the event of a workplace injury) supposedly assures workers that such action would be unnecessary (Piva, 1975). Part of the problem in this regard, are the 'gatekeepers' - usually physicians - who are unwilling to co-operate in workers' 
compensation claims (van Veldhoven, 1996) and employers who refuse, delay or incorrectly report an injury to the board out of concern that their rates may go up (Ison, 1988).

In the Netherlands a similar dilemma has surfaced, since the role of 'gatekeepers' is to ensure that employers or employees do not make false claims against the State. This means that some injured or disabled workers are left without an income if their injuries do not satisfy eligibility criteria. If considered ineligible, they then are left to turn to general social assistance or regular welfare benefits. This is true for both countries. In Ontario this would mean either provincial social assistance programs or CPP, if their work history were such that they qualify. Unfortunately, provincial social assistance programs pay lower benefits than the CPP or workers' compensation and leaves the claimant, especially women, in deep poverty (Doe and Kimpson, 1999; Fawcett, 1996). Provincial social assistance is also based on a strict means tested eligibility criteria and claimants are often required to use all of their liquid resources (savings) before they qualify for support. Such means-tested eligibility criteria are typical in liberal social policy regimes.

If an injury is not work related, or labour market ties have not been established, a disabled person has access to the Ontario Disability Support Program (ODSP) (Ministry of Community and Social Services, 2003). Formerly the administration of ODSP fell under the 'family benefits' program ${ }^{19}$, but is now administered under the general welfare program. A person with a disability has the option to work, but is not required to do so in order to receive benefits. It is possible to collect both CPP and WCB or ODSP.

${ }^{19}$ The family benefits program is a branch of the general welfare system. 
However, CPP benefits are deducted from both WCB and/or ODSP support payments. If the person with a disability already receives CPP disability benefits, then she or he automatically qualifies for ODSP. The ODSP provides for subsistence to those who are unable to do paid work and have medical certification that they are 'disabled'. The 'disabled' certification involves both the diagnosis and verification by health officials. Like in the Netherlands, it is not enough that the person's own physician does the diagnosis. An 'objective' or 'external' health professional has to provide an opinion that the disability meets the criteria for eligibility. However, if the recipient is eligible for CPP disability benefits than they are automatically eligible for this provincial income support on the grounds that the CPP has a narrower eligibility test than the ODSP. Those who were born with a disability or who became disabled before the age of 18 generally fall within this program, given that they were unable to establish a work history and thus are not eligible for CPP or Workers' Compensation.

Lastly, if neither of these programs is of any help, it is possible to apply for provincial assistance or welfare. A person with a disability can apply for general welfare benefits, which, at the time of this dissertation, was in the process of being transformed into workfare in Ontario. A work history is not necessary for this program, which is a plan of last resort for the injured or disabled whose disability is not the result of a workrelated incident, have no access to savings or private insurance, have not worked long enough to qualify for CPP, and where EI sickness benefits have run out. This option is generally not available to those with a spouse who earn a wage. Any person with a disability who uses this route faces a catch-22 situation. A disabled person may not qualify under the ODSP, but may qualify for welfare. However, in order to collect a 
welfare cheque in Ontario it is necessary to participate in a workfare program (in other words, to be employed) - despite the disability - or else no support. Of course, the fact that they were not able to work is why they needed to apply for welfare in the first place.

\section{The Ziektewet and Workers' Compensation: Experiential Accounts}

\section{Report the Injury - employers must be notified}

An important point that must not be overlooked is the role that employers play within the process of making a workers' compensation claim. In either jurisdiction, if the employer chooses not to cooperate with the injured worker when it comes to making a compensation claim then the worker is even further disadvantaged vis-à-vis the power relations that are inherent in capitalist systems. Experience rating is relevant within this context. Both jurisdictions use experience rating as a way of financing their workers' compensation systems (section 83, Ontario Workplace Safety and Insurance Act, 1997; Wet PEMBA, Ministerie van Social Zaken en Werkgelegenheid, 2004). So when injuries occur more frequently within a workplace, than the industrial average indicates, the employer is cited by state inspectors and as a result will have to pay a higher premium or levy to their respective state administered workers compensation organization (for instance het GAK in the Netherlands and WSIB in Ontario). This can affect workers:

It doesn't suit my employer that I am making a WSIB claim. They think that I am trying to pull a fast one. They are so angry at me. It is a private non-profit housing [corporation]. [My WSIB claim] ups their costs. The employer plays a large role!

(Ontario interview \# f13, Fall, 2002) 
Such a system tends to lead to the under reporting of workplace injuries (cf. Ison, 1988) and does not address the issue of preventing workplace injury satisfactorily. Employer cooperation, within this context, is vital to the successful application for workers' compensation benefits. As mentioned by an Ontario participant:

I went to WSIB. You know what, they [the employer and WSIB officials] don't care ... that is when you become the worst employee, you become garbage ... they treated me with disdain ... I was threatened, I was told that if I did not return back to work they would make sure that my WSIB claim would be denied. The employer is unbelievable ... WSIB as well ... both my boss and WSIB ... they would make me work during statutory holidays ... they would not believe that I was sick, [they insinuated] that I was faking [my injury]. They don't like it when you make WSIB claims.

(Ontario interview \# f1 1, Fall, 2001)

Lippel (2003: 256) points out that "employers often contest compensation claims for MSDs and ... [consequently] compensation boards in Canada are often likely to refuse such claims". Indeed, the possible lack of employers' cooperation in terms of addressing workplace injury, rehabilitation and possible access to their respective compensation systems occurs in both jurisdictions, as one of the participants in the Netherlands noted:

I was lucky ... if my employer had not cooperated ... [I believe that] it makes all the difference ... I know of a colleague of my husband who is employed by an American company [in the Netherlands], and they do not adhere to the rules ... [according to the law] they have to find modified work and they simply won't do it!

(Dutch interview \# f11, Summer, 2000)

In fact another employer simply terminated the employment contract with another respondent "because my employer was not 'able' to find 'modified' work" (Dutch interview \# $f 2$, summer 2000). These injured workers were left without much choice. 
They either succumbed to the pressure placed on them by their employers and their respective compensation boards, or they were facing the possibility of having to collect unemployment benefits or welfare, as explained by this respondent:

Het GAK and my employer did not accept [the diagnosis] and they declared that I could do administrative work for 40 hours per week!! I appealed their decision before the court and had to collect welfare in the meantime. (Dutch interview \# f7, Summer, 2000)

As well, when the illness or injury is reported to the employer, the condition or illness must also be verified by a family physician:

It depends on the employer how fast the Arbodienst controls whether you are really sick - it varies. At some organizations it is reported immediately [to the Arbodienst] and someone of the Arbodienst will call right away; the day that you report being sick [they check] to see what the matter is, to see if you have consulted a physician and when you expect to return to work. Where I work is not that strict, my first contact with the Arbodienst was two months after I reported being sick. In the mean time nobody asked officially what was wrong with me. Because the employer may not ask what the matter is with you [when you have reported being sick]

(Dutch interview \# $\mathrm{m} 1$, summer 2000)

Some of the Dutch participants expressed concern about reporting their injury to their employer, since they worried about becoming unemployed. For instance, one of the Dutch male RSI sufferers noted that the employer might dismiss any one person after two years of being sick; he explains:

During the first year you have time to heal. But ... if you do not recover within two years of getting sick, then they [the employer] may send you packing. (Dutch interview \# m8, summer 2000) 
Indeed, some workers felt very strongly about not going into the WAO and were thankful that they were working for an employer who was cooperative:

... I was lucky, because I have a doctor who believed that there was something wrong. If I had had a doctor who had not believed in me and if my employer had not cooperated ... then you are against a wall of disbelief and not understanding and you would not know which way to turn, that is when you end up in the WAO perhaps ... and [if you end up in the WAO] then you are written off for the rest of your life. I believe that the attending physician makes all the difference.

(Dutch interview \# f11, Summer, 2000).

Thus, the role of employers seems to have a double-edged sword. On the one hand their cooperation ensures that the injured worker is able to collect workers' compensation, particularly for injured workers in Ontario. On the other hand, their cooperation may also mean that the injured worker's needs are addressed outside of the compensation system (such as enough time to recuperate without reprisals, workplace adjustments in terms of proper ergonomics, modified work duties within the workplace and the like). It is important to bear in mind that workers compensation systems in both policy regimes address issues of therapy and rehabilitation. That is, an injured worker whose injuries are validated may get access to rehabilitation programs funded by the respective compensation systems (Ontario Workplace Safety and Insurance Act, 1997; Wet PEMBA, Ministerie van Social Zaken en Werkgelegenheid, 2004).

In the case of Ontario, all injuries that are work-related, no matter how minor, must be reported to the employer, who in turn must report the injury to the WSIB. Even when such an injury "... does not result in lost time from work, [it] must still be reported [to], and adjudicated by, the WSIB" (section $2 I$ of the Act, WSIB Operational 
Policy Manual, 2004). Furthermore, the policy indicates that Ontario employers who do not comply can face serious fines. However, the interview data show that, in the case of the Ontario participants, this was not necessarily their reality. For instance, one of the Ontario participants overheard her "boss phon[ing] compensation and ha[ving] a conversation with them about finding ways to fire [her]" (Ontario interview \# f13, Fall 2002), rather than finding accommodation within their workplace. An experience that is similar to some Dutch participants (for instance, Dutch Interview\# f2, Summer, 2000). In the Netherlands employers can be fined without the interference of the court system if the employer does not adhere to the provisions set out by the Arbo wet - the act responsible for social provision for injured or disabled workers (Ministerie van Sociale Zaken en Werkgelegenheid, 2004). In part the obligation to reduce workplace absence rests with the employer, under the Arbo-wet. Under this Act employers are responsible for prevention and absence policies in case of sickness and disability of their workers, and for the improvement of working conditions within their respective workplaces and/or companies. Labour-inspection agencies control the way corporations fulfil the rules of the Arbo-wet. By placing the financial responsibility onto the shoulders of employers, in terms of paying employees' wages under the Ziektewet and through the provision of experience rating, it is the dual aim of policy makers to reduce workplace absenteeism while at the same time reducing the cost to do so in the Netherlands (Oorschot and Boos, 1999: 6).

Thus, in both policy regimes employers play an important role in the social provision of injured workers, despite the differences in their policies addressing worker injuries. Without the cooperation of employers, injured workers not only have to try and 
address their injury but also face the additional burden of showing that their employer is not adhering to the respective policies in question. Often times, this extra burden is too arduous for those who are trying to overcome their condition. As well, pursuing action against their employer can result in their injury not getting legitimated and validated by the compensation programs, which of course means that the injured worker must rely on whatever weak social support structures are in place in their jurisdiction or rely on family, friends and or neighbours.

On a final note in the case of Ontario, employers are particularly important in the claims process. However, many employers will contest claims. Lippel (2003: 256) observes that employers in Canada often contest compensation claims for musculoskeletal disorders (MSDs) in particular and that compensation boards across Canada are often likely to refuse such claims. Indeed, she notes that the legitimacy of all MSDs is treated as questionable, regardless of diagnosis. Furthermore, she reports on "a colloquium held in Quebec, organized for employers by lawyers and physicians who had been part of a medico-legal team of Canada Post Corporation" (Lippel, 2003: 256), which was successful in contesting compensation claims for RSI type injuries. The aim of the gathering was to discuss strategies and inform employers on how to contest claims for MSDs or RSI type injuries such as tendonitis, bursitis and the like. Within this regard Lippel points out that "... the new approach to MSD claims following from the Canada Post decisions led to an important reduction in the acceptance levels of these cases ..." by compensation boards across Canada (Lippel, 2003: 262).

Nevertheless, to the best of my knowledge, Ontario does not keep records under the umbrella term RSI, nor does Ontario recognize RSI as a compensable disease entity 
or disease category. Instead, the Ontario compensation board, the WSIB, considers specific individual soft tissue injuries such as Carpal Tunnel Syndrome, Tendonitis or Bursitis $^{20}$ and collects data accordingly, obscuring the broader disease category of RSI. However, by doing this, the condition known as RSI is kept invisible in this jurisdiction (van Veldhoven, 1996). This, of course contradictory to and creates a tension with, the aim of the WSIB vision statement, which claimed that it's aim was the elimination all workplace injuries within Ontario, since not all soft tissue injuries are considered compensable under WSIB (Workers' Compensation Board, 2004). Moreover, in Ontario the injury has to be work-related before anyone is able to claim workers' compensation. This entails reporting the injury to your respective employer and a consultation with a physician. However, as mentioned, studies show a significant under-reporting of workplace injuries in Canada (cf. Shannon and Lowe, 2002). In a context where employers in Canada are briefed on how to contest MSD or RSI related claims (as Lippel (2003) suggests), and the workers' compensation system does not acknowledge RSI as a disease entity, let alone as a work-related injury, is it any wonder that some injured workers in Ontario may opt not to go through the worker injury process or claims making activity to gain benefits even is suffering from a debilitating condition.

\section{The Ziektewet - Rest Before Entering Deeper into the World of Ruling Relations}

Before an injured worker is able to make a workers' compensation claim, they must satisfy eligibility rules in each of their respective jurisdictions. Neither policy regime automatically accepts an injured workers' compensation claim. The process

\footnotetext{
${ }^{20}$ See chapter 1 for a more complete explanation of these injuries
} 
leading up to making a workers' compensation claim differs between the two jurisdictions. However, at the point of actually opting to make the workers' compensation claim the experiential differences between the jurisdictions disappear for the RSI sufferers in both study groups, despite the fact that each jurisdiction is classified differently in terms of social policy regimes. In this regard, Ontario with its tendency towards strict eligibility rules and means-tested programs is characterized as a Liberal policy regime, while the Netherlands is most frequently viewed as Social Democratic ${ }^{21}$. Based on these social policy regime differences, therefore, it would not have been unreasonable to anticipate that RSI sufferers in each jurisdiction would have different experiences in terms of the process of making a workers' compensation claim.

When they opt to engage in the claims making process with the state, injured workers, thus RSI sufferers, in both jurisdictions, have to submit to a medical examination, to establish the legitimacy or validity of their claim. It is within this context that the participants in the two study group(s) recount similar experiences in terms of the doctor-patient or clinical encounter. Thus, it is at this juncture in particular that the similar experiences of RSI sufferers are nested. However, there is one significant policy difference between the two jurisdictions that I anticipate to have a differential influence on the experiences of injured workers between Ontario and the Netherlands in terms of actually claiming workers compensation benefits.

As noted elsewhere, a person with labour market ties in the Netherlands who develops an ailment, falls ill, or gets injured, has the advantage of time to recuperate

${ }^{21}$ Though, the present government tends to lean towards deregulation of the market and the privatization of social programs, which is more characteristic of a liberal regime (cf. the website of Ministerie van Social Zaken en Werkgelegenheid, 2004) 
before they get to the point where they need to claim workers' compensation benefits.

This period of time allows injured or ill Dutch workers to take up to 52 weeks time off work without loss of pay while they are unable or too sick, to work. Dutch injured workers may stay at home without the fear of losing their income and/or their employment for up to a year upon injury or developing an illness - provided they have a doctor's note validating their condition (Ministerie van Sociale Zaken en Werkgelegenheid, $1999^{22}$ ). This advantage was demonstrated by one of the female participants in the Netherlands who had returned to work after taking some time to recuperate under the provision of the Ziektewet at home:

I developed pain in my wrists, I lost all strength in my grip ... but then it came back, you don't pay attention to it, you just continue [with your job tasks] ... until the moment that you drop plates out of your hands. ... I consulted my doctor ... and he thought that I had an inflammation in my shoulders, which extended to my arms, causing a blockage to my tendons in my hands. That is when I entered into the Ziektewet for two months... I seriously rested [my hands and arms] at home for two full months - that was three years ago.

(Dutch interview \# f11, Summer, 2000).

If after one year the illness or disability persists, the worker falls under the purview of the $\mathrm{WAO}^{2.3}$, which is the long-term disability income replacement program; the equivalent to the Ontario workers' compensation system or the WSIB. Thus, to qualify for state

\footnotetext{
${ }^{22}$ The present government has adjusted the waiting period in the Ziektewet to 104 weeks. 23. Throughout this dissertation I use the term Workers' Compensation interchangeably with the term WAO when I am describing the case of the Netherlands. Also, as noted elsewhere, as of January 2004, the waiting period before entering into the WAO is 2 years or 104 weeks. During this time the employer remains responsible for maintaining the wages of the injured or ill worker. By doing so the present government, has shifted the burden of income maintenance from the state onto the employer with the hope that, by doing so, the number of compensation claims will be reduced (Ministerie van Sociale Zaken en Werkgelegenheid, 2004).
} 
sponsored long term disability there is a 52 week waiting period in the Netherlands, during which time the employer is responsible to maintain the wages of the injured or ill worker (Ministerie van Sociale Zaken en Werkgelegenheid - SZW, the Netherlands, 1999, 2004). The policy states that a person, who is declared 80 per cent disabled by an insurance doctor of the WAO, will receive 70 per cent of their last earned salary. Moreover, once a year in May the injured worker will receive holiday pay, which is 8 per cent of annual earnings. Once an injured worker has been in the Ziektewet for eight months, they will automatically receive an application form for WAO benefits from het GAK (comparable to the compensation board in Ontario). This form has to be completed and returned before the end of the ninth month in the Ziektewet. If the application has not been received by het GAK in the time specified the board has the right to withhold WAO benefits. Within this regard workers in the Netherlands are well versed and very familiar with this system as explained by some of the RSI sufferers as follows:

During the first year of the Ziektewet (Illness Act) it is compulsory for the employer to pay your salary. It depends on your collective agreement whether you receive your full salary. In essence, your employer pays 70 per cent - but in almost all of the collective agreements among all trade unions for the sector, it has been determined that when you land in the Ziektewet, you get all your vacation days and your full ( 100 per cent) salary - this expense is absorbed by the employer. It used to be that the employer was responsible for [paying your salary] only 6 weeks, after that the state would continue to pay your salary. About four years ago the state transferred this cost solely to the employer - employers can get insurance for these sorts of things.

(Dutch interview \# ml, summer 2000)

Thus, in comparison to Ontario, the process of applying for WAO appears relatively uncomplicated and fairly straightforward in the Netherlands. Once you are in the 
Ziektewet for a period of time, transfer to the WAO is virtually an automatic process.

That is, after a period of time the injured worker in the Ziektewet receives an application form. Next a notification to report to WAO officials is received by mail and the subsequent gatekeeping and eligibility procedures are set in motion:

... [H]ow it actually works, I am not sure, but at a certain point you receive a notification from the authorities, after about 8 months in the Ziektewet. [You are then notified] that you are requested to submit to a WAO [medical] examination. You have to indicate yourself whether you do want to claim WAO [benefits],... Yes of course do you want to make a claim; otherwise you will not receive any benefits. ... It all happens automatically.

(Dutch interview \# ml, summer 2000)

And

You receive a letter ... you are asked whether you will be planning to claim WAO benefits ... you just submit to a WAO [medical] examination. (Dutch interview \# m6, summer 2000)

Or

... And after a couple of months - and that is really terrible - when you have been ill for a while, you suddenly receive a letter indicating that you have to claim WAO benefits. You receive all kinds of forms ... and it really frightens you. You think to yourself, how did I end up in the WAO? ... Thus you are ill and then you are sent all kinds of forms. (Dutch interview \# m8, summer 2000)

One might assume that allowing workers to access up to one year of illness coverage (the Ziektewet) would provide enough time for many to perhaps recover from injury before it becomes necessary for them to enter into the workers' compensation system and claim benefits. Indeed, the Netherlands then should be showing relatively low numbers of injured or ill workers collecting workers' compensation. 
However, this did not turn out to be the case. While there was such a generous policy (the Illness Act) on the books since the 1930's (Cox, 1996), the Netherlands, boasted the highest numbers of disabled workers claiming workers' compensation (Ministerie van Sociale Zaken en Werkgelegenheid, 2004). This gave the false impression that the Dutch workforce was in relatively poorer basic health or that the physical or mental demands of Dutch employment were significantly greater than the demands in other similar countries. Indeed, until the early 1990s the Netherlands had a disability prevalence rate triple the size of other comparable countries, a phenomenon referred to as the Dutch disease (cf. Aarts et al, 1996; Ministerie van Sociale Zaken en Werkgelegenheid, 2004). A remarkable situation, if one considers the recovery time that the Ziektewet allows Dutch injured workers, before they need to enter into the workers' compensation benefits system. However, upon closer examination, it appeared that Dutch companies, during times of economic down turn, were using workers' compensation benefit plans (the WAO), to lay-off their workers, which gave the impression of reduced unemployment rates. These circumstances inflated the workers' compensation rolls. A familiar situation among some of the men in the study group, one of whom explained:

... [T] hat bosses and the trade unions had an agreement. If the factories were not doing so well [economically] ... [so] that [they needed to reduce the workforce] ... Now if someone who is 40 or 45 [years old] ... however, they were actually a bit too old to find another job, [instead of the unemployment insurance] we will put them in the WAO [workers' compensation system]. Thus, those people were subsidised by the state - well, that became too expensive. Those laws became more and more strict ... it became increasingly more difficult to end up in the WAO.

(Dutch interview \# m8, summer 2000) 
The advantage of being placed in the WAO is that it paid relatively higher benefits and was longer in duration than other benefit programs at the time (Aarts et al, 1996;

Ministerie van Sociale Zaken en Werkgelegenheid, 2004). As well, it was a less onerous process to collect WAO compensation, since it was not required to look for work while collecting benefits.

Thus, unlike injured workers in Ontario, Dutch injured workers have the advantage of time in which their bodies have an opportunity to heal, before they need/are eligible to make a claim for workers' compensation benefits:

When I reported [to my employer] that I was ill under the Ziektewet (the Illness Act), it took a year [before I was eligible for WAO]. I started with reporting that I was partially (20 per cent) disabled, [but] after two months I reported that I was 100 per cent disabled. It stayed that way for a number of months, after that I changed it to 80 per cent. When I began to feel better I changed it to 50 per cent. After ten months in the Ziektewet, I was ordered to report to the CADANS ${ }^{24}$

(Dutch interview \# $\mathrm{m} 1$, summer 2000)

In the Netherlands, to take time off for illness, you need to report to your employer that you are unable to work. It is also possible to report a partial illness or partial disability, which allows one to work part time. That is, if you report that you are 50 per cent worker disabled, that means that you can work 50 per cent of the time:

I landed in the so called Article 44 ruling of the WAO ... That meant that even though I was considered to be 100 per cent worker disabled ... but still worked 50 per cent [of the time] and was thus eligible to hold on to 50 per cent of my

${ }^{24}$ CADANS is the authoritative/gatekeeping body, for the healthcare sector, that determines eligibility to WAO benefits; it is comparable to het GAK see chapter 2 
normal salary and for the remainder of the 50 per cent I received 50 per cent WAO benefits.

(Dutch interview \# $\mathrm{ml}$, summer 2000)

Keep in mind that WAO benefits pay 70 per cent of your last earned salary. Thus, to claim a partial disability has the advantage of securing a larger (and probably much needed) portion of the injured workers' income. Other participants in the Netherlands felt and dealt with their situation in a similar fashion, though the informant in this case was still under the purview of the Ziektewet:

I did not [want] to stop with work. However, I stayed home for 11 weeks. Then I began gradually to return to work. First I worked for half days, and then I started to work 75 per cent of the time and after half a year I am in full swing. I modified my workstation and I decide how many times I need to take a rest or pause. Some days I need to take [a pause] more frequently than on other days. Then, I just walk up and down [the hallway].

(Dutch interview \# m9, summer 2000)

In other words, Dutch injured workers can take advantage of the Ziektewet provision as well as the workers' compensation system on a part time basis, if they opt to do so. Thus, the Ziektewet provision gives Dutch injured workers an advantage over Ontario injured workers since it allows them some time before they need to subject themselves to the surveillance practices of the state to obtain workers' compensation. One could argue that most RSI sufferers in the Netherlands would have no need to enter into the workers' compensation system, given that a frequent prescribed treatment for RSI is time, that is, time for resting the injury and time for taking it easy for a while (Dutch interviews \# m6; \# m9; van Veldhoven, 1996; Kome, 1998). However, almost half of the Dutch RSI sufferers in this study group were actually collecting workers' compensation benefits, despite the fact that each of them had been in the Ziektewet for the duration of the 
eligibility period. The experience of actually entering into the WAO or the workers' compensation system was a mix of emotions such as surprise and fear. It was the distinct impression of the researcher, that it was an experience that these RSI sufferers would rather have missed.

\section{Initiating the Compensation Process - Time to Engage the Medical Gatekeepers}

Unlike injured workers in Ontario who are responsible for initiating the application process through their employer and also reporting the injury separately to the WSIB, in the Netherlands the injured worker does not initiate the application procedure for workers' compensation benefits. Instead, Dutch WAO officials initiate first contact with the injured worker, after the individual has been in the Ziektewet with an illness or an injury for a specified period of time, which is generally around 9 months (Ministerie van Sociale Zaken en Werkgelegenheid, 2004). It is then decided by the injured worker whether to go forward with the WAO application process, which entails submitting to a medical examination to determine the validity and/or legitimacy of the disability. The following participant describes a WAO medical examination, which consisted of answering standardized questions:

\footnotetext{
By answering a list of questions - an examination list [your level of disability] is determined [and] how much you can work. Then the insurance doctor asks a number of questions and they do a physical exam. These are standardized lists [of questions] (Dutch interview \# m8, summer 2000)
} 
In some cases the medical consultation was conducted over the phone as was explained by one of the forum participants (Dutch RSI forum communication, summer 2001) or the decision was based purely on written information:

... However without me seeing anyone or having spoken with anyone, I was immediately declared as 100 per cent work disabled again. Another insurance physician at CADANS determined this, that person simply made a 'paper' decision.

(Dutch interview \# m1, summer, 2000)

This is not dissimilar from the experience of some participants in Ontario where WSIB officials never met with the following participant. Yet, despite not meeting with her a decision was rendered that had serious financial consequences especially since this participant had a dependent and was responsible for her disabled mother. A serious financial impact on her life was made by officials without even meeting with her:

I never saw a Dr from the WSIB ... never saw me, never met me, never even spoke to me, based on solely paper work it was decided that my right side did not have a work related problem.

(Ontario interview \# f2, summer 2001)

This is an example of how decisions can be and are made based solely on text. The gathering of information in a standardized manner is an example of how "expert knowing' is organized, which Smith (1987) refers to as a form of control by the relations of ruling. Following this line of argument, Campbell and Gregor (2002: 20) note that filling in forms is more than a technical task that facilitates the practice of control. They posit that it draws the person collecting the data - in this case the WAO and/or WSIB insurance physician - into the dominant practices of the institution as their agent. A point that rang true when one of the Dutch forum participants, who was denied his WAO 
claim, noted that his WAO insurance physician stated that it was not him [the doctor] personally who did not validate RSI as a legitimate condition, but rather it was the institution's rules and regulations that did not take RSI seriously (Dutch forum participant, summer, 2001).

The gathering of information by medical experts, as described above, illustrates how the actions of physicians are coordinated with the actions of injured workers who make a workers' compensation claim. These coordinated actions take place around the filling out of the claims form - the gathering of standardized data, which is a textually mediated, coordinated and concerted action. Smith (1987: 3, emphasis in original) talks about exploring the relations of ruling and how "a continual transcription of the local and particular actualities of our lives into abstracted and generalized forms is an extralocal mode of ruling". As Campbell and Gregor (2002: 30) explain "... that social relations are actual practices and activities through which people's lives are socially organized" - thus ruling relations are social relations. From this it follows that the medical encounter such as that found in a WAO and/or WSIB examination is "merely a segment of a social relation that begins elsewhere and continues on after it does its part" (Campbell and Gregor, 2002: 31). Thus, workers compensation medical examinations are examples of the extralocal mode of ruling and are a form of social control. As such injured workers are the sites where extra-local ruling relations intersect with the everyday lived experiences of the local.

Furthermore, the practice of gathering standardized text-related information of an individual by an organization such as the WAO and/or WSIB obscures from view the real need of that patient or client. By gathering standardized personal data the WSIB/WAO 
as an institution makes it possible for the needs of organizational decision making to subordinate the interests of the RSI sufferer. When we witness such a practice we need to ask ourselves whose interests are 'really' being served/met and whose interests are actually being subjugated by a ruling practice.

It is argued that the needs of the welfare state supersede the needs of the individual since the welfare state stands for the accumulated needs of the many. Such a view is symbolic of the ideology that espouses self-reliance and individual responsibility. While many people would perceive the 'needs of the many' to actually mean 'cost saving measures,' such views resonate with many, even participants in this study: "I don't believe that ... you should be sucking off other taxpayers' money" (Ontario interview \# f12) - such comments are reflective of this perception. Evidence of a similar negative sentiment exists in the Netherlands in terms of collecting WAO benefits. One of the participants noted that her parents did not approve of her collecting WAO benefits. They stated that "they have to earn their money ... [this] collecting WAO benefits, - we don't believe in that!" (Dutch interview \#2, summer 2000, original emphasis by respondent).

One way to save money is by refusing injured workers access to workers' compensation. The needs of the individual are overlooked in order to conserve money for the many - an organizational goal. Indeed, concern regarding the reduction of workers' compensation costs was conveyed when one of the participants noted that:

[WAO officials] were told by the government to make sure that fewer injured workers end up in the WAO ... you can read it in the newspapers as well ... the number of people in the WAO has risen again ... yeah ... then they come up with different proposal again [on how to reduce the number of injured workers] people are being kicked out of the WAO system ... or access is denied to something that is a 
citizenship right.

(Dutch interview \# f7, summer 2000).

The aim of the state to conserve financial resources and the dogma of individualism and pushing for a smaller state is found through many current social policy regimes. Injured workers, however, are falling through the cracks and outside of the compensation system. This push to save reduce expenses does not simply mean accepting partial claims as a cost saving measure, it also entails the out right denial of a WSIB claim even when it is medically established that the worker is suffering a work-related injury:

The physician sent the forms to WSIB ... next thing I get was this [letter] ... [stating] your claim has been denied ... despite the fact that my doctor felt that it was work related. They said that I could appeal it, but I never saw any of their doctors. They never asked to see me.

(Ontario interview \# f6, Summer 2001)

The interview data showed that the experiences of the study group were similar in terms of accessing workers' compensation in either jurisdiction. Regardless of the jurisdiction and the fact that the policies differed between them, across both regimes there were those participants who had no trouble accessing workers' compensation and those who ran into difficulties when accessing workers' compensation. In particular, both the Dutch and the Ontario participants who suffered from RSI related symptoms found that their experiences were similar in their dealings with medical experts who were employed by the state to act as gatekeepers.

A point of interest, in the case of Ontario and in relation to this study group, unlike some of their female counter parts, none of the male Ontario participants were attempting to collect workers' compensation, nor were they considering doing so. This seems to be somewhat strange behaviour. One would think that an injured worker would 
make use of a system that is set up specifically for such circumstances. Especially since injured workers in Ontario do not have the benefit of an illness provision of 52 weeks as in the Netherlands. Therefore, theoretically speaking, an argument can be made that it should be more likely that someone suffering with RSI in Ontario would want to make a compensation claim in order to give their bodies time to heal. Yet this did not turn out to be the case for the Ontario men in this study group:

I did not report the injury at work, because it is a small employer and ... Huh ... chances are [that] they won't do anything about it. I won't be able to take time off work ... and ... I need the money ... (Chuckles with embarrassment). ... I don't think that anybody would take it serious enough to say they are going to pay me to have time ... time off ... all because of an injury.

(Ontario interview \# m8, summer 2001)

There may be a number of reasons why the Ontario men were disinclined to follow through with a workers' compensation claim. It may in part be because it is common knowledge that RSI as a disease category is not recognized as a valid and compensable injury in Ontario (see chapter 5 of this dissertation). However, it may also be attributable to a 'macho' culture some men adhere to regarding injury and pain. In some instances it is the men themselves whom do not take the injury seriously:

I would not [consider going on workers compensation or disability insurance] ... with this type of injury - I would not, I would try to find a way of being somewhat useful to the department and myself.

(Ontario Interview, \# m9, summer 2001) 
Lippel (2003: 253) points out that for some injured workers in Canada, timely access to certain forms of health care such as physiotherapy $y^{25}$ depends largely on acceptance of a workers' compensation claim. Within this context, when an injured worker is refused a claim, they are forced to continue with their job. This is problematic, particularly for RSI sufferers since it is the conditions of the job that are causing the injury to begin with. This leads to a situation where the injured workers are, in most instances, further injuring themselves when they remain at their paid workplace. Such unjust delays can have a detrimental effect on the injured workers' health in that a delay in treatment can lead to permanent damage and disability (see for instance van Veldhoven, 1996 among others). It is also possible that medical gatekeepers mistakenly misdiagnose the condition and refuse a claim that should have been accepted, in which case the injured worker is forced to return to the source of their injury - the paid job.

As noted, workers in the Netherlands who are injured or who suffer from an illness have the benefit of a relatively lengthy recuperation time of up to 52 weeks through the provisions of the Ziektewet. In other words, Dutch women and men who suffer with RSI have an advantage over their Ontario counterparts, in that they get a generous state supported recuperation time without having to worry about income or employment. Indeed, the Ziektewet provision allows them to meet their financial needs while recuperating away from the place that caused their injury in the first place. This is a significant added benefit, because eliminating their job duties/tasks from their daily routines means that they improve their chances of not further injuring themselves, thereby increasing their chances of recovery. Keep in mind that the Ziektewet provision

${ }^{25}$ Physiotherapy is an out of pocket expense in Canada 
is not workers compensation and that the similarities between experiential accounts are manifest in the medical or clinical encounter - when the injured worker is at the point of entering into the workers' compensation system.

\section{Struggle for Benefits - My Body Aches and I Need to Pay the Rent}

Data from a previous research project (van Veldhoven, 1996) revealed that women in Southern Ontario who suffered with RSI and who did not attribute their injury solely to their workplace were not likely to make a workers' compensation claim. Most of the Ontario participants in the present study group, who were not considering making a WSIB claim, did not actually make a claim. They felt that they did not need to make a WSIB claim, since they had access to alternative income maintenance plans. This finding suggests that RSI related injuries sustained in the work place will be underreported in official Workers' Compensation statistics and hence undermines the collection of valuable Occupational Health and Safety related data.

Exactly how large this under-reporting might be is not able to be determined. Nonetheless, such a situation leads to an under appreciation of this particular workrelated problem within the relations of ruling and accordingly, proper steps to address this specific workplace concern in terms of regulating proper ergonomics within the office work space should be the order of the day. This would entail recognizing the fact that computer and software manufacturers should be held accountable for designing ergonomically correct workstations and software packages. Employers should be considering enough variation during the workday to break up the time and allow a variety of tasks so that employees are not forced to perform the same repetitive motions 
throughout the day. In other words, within the context of this particular occupational health and safety concern, I am arguing for a re-organization of the workspace within which labour is performed on a daily basis.

Interestingly, when asked, all but a few of the participants felt that it was the role of the state to ensure that both employers and employees were educated about this work place danger. Most of the participants also felt that it was the responsibility of the employer to make sure that employees do not get burdened with this injury. However, when such an injury is under-reported, the true magnitude of the problem does not become evident, and hence the state will not recognize the need to spend money on educational programs for employers in terms of addressing the prevention of this particular issue. Nor will the state see the necessity to regulate the industry and force them to design ergonomically correct products that meet the needs of the individual user (the employee) so that RSI may be prevented.

Despite all of this, the same people who felt that it is the state's responsibility to educate employers and employees regarding the dangers of RSI were the same people who opted not to report their workplace injury to state officials in terms of workers compensation boards. Keep in mind that in the case of Ontario the introduction of workers' compensation means that the injured employee gives up the right to sue her or his employer in the event of a workplace injury. However, this does not preclude the injured worker in Ontario from suing the workers' compensation board, if they do not agree with their decision.

Those participants in the study group who opted to go forward with the claimsmaking process for workers' compensation benefits did so with a struggle: 
For three-quarters of a year they (WSIB officials) dragged their feet. It was only [through] my persistence that the WSIB payments came into play ... quite honestly it was my persistence. I got a new adjudicator ... and [finally] my payments. I think [that] her job (the adjudicator) was to get me off their system ... [The] WSIB doctor ... said that it was possible [that the injury was work-related] but not likely - [I] did not see him in person, [I] don't even know what his name was.

(Ontario interview \# f13, fall 2002)

Or

It was not easy to get those [WAO] benefits ........ I had to fight for it. I quarrelled with all of het GAK. [The fight was] about whether I had a [medical] problem or whether I did not have one. It scared me beyond belief - they simply did not want to acknowledge it.

(Dutch interview \# f2, summer 2000).

These were not isolated incidents. For some of the RSI sufferers in the study group(s) it required a great effort to get their condition recognized as a (work related or medical) compensable condition. Indeed, in the case of Ontario, and in the context of RSI, we came across the bizarre situation where the WSIB was willing to recognize RSI related injuries on one side of the body, but not the other in terms of the work-relatedness of the condition:

I was O.K. on the Wednesday, the Thursday morning I woke up with severe shooting pain coming down my left arm. I thought that I had slept funny or something. One of my union representatives contacted me and convinced me to report it to the WSIB, because it was work related. I submitted my claim to the WSIB - I had very quick results with them - that was no problem, my doctor sent in all of the information. The WSIB confirmed, they could see that yes ... 13 hours on the computer, I am a right-handed person, it was in my left arm/hand that went ... they could say ... O.K. it is work- related.

(Ontario interview \# $\mathrm{f}$, Summer 2001) 
Or

No trouble getting WSIB for my left hand - went back to work when my left hand healed. WSIB would not recognize the right hand [though]. [I was] operated on my left hand - got compensation for that side, now they want to see the workstation. My doctor said that both my hands were injured by the type of work I do. He did not agree with WSIB for not recognizing the right hand.

(Ontario interview \# fl, Winter 2001)

This situation was very frustrating to these participants since they were expected to continue to work despite the fact that it was recognized that they were 'officially' suffering from RSI on at least one side of their body. Indeed one participant developed RSI on both her left and her right side, but that did not seem to make a difference to WSIB officials:

They started to press the issue - O.K. you have one arm, so let's get you into something in the office. The difficulty when you work in a call-centre is ... that is all you can do ... I can't operate the computer one handed ... but they got me back - in April - doing a modified job. I started off with doing just phone interviews and follow up things for people. That lasted all of seven days.

(Ontario interview \# f2, Summer 2001)

Then this same respondent developed 'shooting pain' in her right arm:

... my right arm went completely numb from my elbows to my fingertips and excruciating pain in my right shoulder. I went back to the Dr., and immediately it was like 'you obviously can't function with two arms' ... when I tried to resubmit my claim to WSIB. They denied that in that period of time I could possibly have injured my other arm at work. They would still acknowledge that my left arm was work related - they had no problem with that. But they would not acknowledge in any way shape or form a problem with my right arm. Not just that it was not workrelated, but because they would not acknowledge that it was work -related, they said that I could go back to work, 
and work with one arm.

(Ontario interview \# f2, Summer 2001)

In the case of the Netherlands these struggles were a little less obvious, since the Dutch injured worker enjoys the benefit of the Ziektewet provision. Yet those participants who opted to move beyond the Ziektewet into the WAO found that they too were met with the same levels of scepticism as expressed by medical gatekeepers in Ontario. When these participants applied for WAO the medical gatekeepers assessing their cases expressed scepticism of the worker's exhibited signs of RSI and claims that they were not able to work. Indeed, some, like their Ontario counter parts, had to fight for their right to receive workers' compensation benefits as well. In other words, the appearance of relative ease in terms of applying for workers' compensation in the Netherlands, does not necessarily translate into an automatic granting of benefits as these members of the Dutch study group experienced. Indeed, they did not have an easy time of it at all, when they opted to claim WAO benefits as explained by two female participants in the Netherlands:

... [F]irst in the Ziektewet ... after a year [in the Ziektewet] it is determined whether you are able or not able to return to work ... then in the WAO you get 70 per cent of your last earned income. [Once in the WAO] you get benefits for five years ... every month I was called back - for 5 whole years - everytime I had to fill out the [same] forms. It had not been easy to get those [WAO] benefits ... I had to fight hard for it.

(Dutch interview \# f2, Summer 2000)

The next participant upon initially being denied workers' compensation decided to appeal the decision in court. The court ruled in her favour. She recounted the following memory 
... [During] the five years after that, [the medical gatekeepers at het GAK] examined me every year over and over again. Not too bad when you are still so young and you prefer to just return to work. ...every year it was the same big fight with het GAK over and over again to be given the right [to collect workers' compensation benefits].

A fight for which you actually do not have the energy, because on the one hand you try your best to recover from the condition because you would like to work, dance and do sports like everyone else, and on the other hand you try to accept that you are faced with [physical] limitations. (Dutch interview \# f7, Summer, 2000)

Interestingly, neither in Ontario nor in the Netherlands did men with similar experiences come forward, while I was conducting personal interviews. That is not to say that there were not any men with such experiences; they simply did not participate in the interview process of the study. However, some men on the Dutch forum have had similar accounts:

I have been rejected for WAO benefits, at least now I know what I am up against. Do I have to tell them [members of het GAK] that I rest in bed all day? I have a family to look after, there are corresponding responsibilities associated with this, age discrimination [is a factor]. Who will pay for the post-WAO period to [the time of my] pension [especially] if this is a work-related illness? (Dutch RSI Forum male participant, Fall, 2001)

In any case, it appears that there are similarities of experience across the differing regimes regarding accessing workers' compensation. In both Ontario and the Netherlands the workers face opposition and resistance to their claims from both physicians and the compensation boards in the respective jurisdictions. While the first year of illness coverage for workers in the Netherlands may have been relatively unrestricted, this quickly changed when they applied for WAO. It was at this juncture that the experiences of the workers in Ontario and those in the Netherlands become similar in terms of the process of obtaining workers compensation. However, those who 
opted not to report to the workers' compensation board in Ontario had access to an alternative source of income maintenance. Those workers who were self-employed in the Netherlands also have alternative coverage.

\section{Alternative forms of income maintenance support - for those who can afford it}

Out of the thirteen Dutch RSI sufferers, I interviewed, there were two women and one male who were owners of their own small businesses. These three individuals, though suffering with RSI, believed that they were not eligible for workers' compensation. The remaining ten Dutch participants were either recuperating at home under the provisions of the Ziektewet or their condition had improved to the point where they could return to work. The three small business owners did not have access to Ziektewet provisions and thus had to rely on private insurance should their condition worsen. In fact, these three RSI sufferers had remained at work while injured: “...I kept on working, I just walked around with a cast for a number of weeks" (Dutch interview \# f5, Summer, 2000) or:

It is a question of stress, the way I sit in front of the computer; the way in which I transfer all my energy to my keyboard ... approximately 5 hours per day computer work. As soon as I feel something I stop [my work]. I can do that because I have my own business. I am in a [good financial] position that I can allow myself to stop working if that were to be necessary. [Then] I'll just run some errands. For someone [who develops RSI and] who is not an employer and who lives alone this is a problem of catastrophic proportions.

(Dutch interview \# f12, Summer, 2000). 
In other words, in the case of these two self employed women, there seemed to be less of an incentive to take the time to recuperate properly thereby increasing the risk of further injury. However, having control over their own work schedule and labour time meant that they were not being monitored by an employer. Nevertheless, the Dutch male selfemployed RSI sufferer did stop working for a period of time to allow for the pain to subside and his body to heal:

I developed a business plan that allowed for the smooth operation and continuation of my organization [while I was unable to perform my duties] ... I would never work eighteen hours per day again ... RSI is a warning [signal] to listen to and better treat your body (Dutch interview \# m4, Summer 2000).

In the case of the Ontario RSI sufferers, one would expect that all of the workers would feel forced to either remain at work while injured or collect workers' compensation benefits, given that there is no special provision under the Health and Safety Act in Ontario to be granted a generous recuperation time without loss of income when ill or injured before entering into the workers' compensation system (as found in the Netherlands). In fact, of the thirteen Ontario RSI sufferers I interviewed, five women were either in the process of filing a workers' compensation claim or were actually collecting workers' compensation benefits. The remaining eight RSI sufferers opted to keep on working while injured. However, all but one of these eight injured workers had access to employer supported long-term disability benefits. As such, they felt that when it became necessary in their minds to stop working they would file for long term insurance disability benefits rather than claiming WSIB benefits: 
I have a long-term disability plan ... I will never need to go on WSIB. But if it ever got that bad, I would go back to the doctor and get physiotherapy on it.

(Ontario interview \# f5, Summer 2001)

This respondent continued to work for the time being "while I have ... a[n] [ice] pack on my neck ... I can tolerate what [pain] there is". Another RSI sufferer who, when asked about considering the prospect of not being eligible to collect WSIB, noted that:

... I do have long term disability at work ... I would not go on welfare ... I grew up on welfare and I am not proud of it. I don't believe that if you are able to [do] something that you should be sucking off other taxpayers' money. You can always work ... do phone work or whatever, you never are too sick to work.

(Ontario interview \# f10, Fall 2001)

On a final note, in the case of Ontario, injured workers also have the option to apply for EI sick benefits. Out of all participants in the Ontario study group, one participant had applied for this option. She was granted "fifteen weeks of sick benefits under EI - [but] I had to sign that I would pay [EI] back once I would get my WSIB benefits" (Ontario interview \# f13, Fall 2002).

\section{Conclusion}

This chapter considered injured workers who have developed a RSI type of injury or condition within the context of income maintenance programs and available welfare state provisions in two vastly different jurisdictions. Specifically, the processes of the claims-making activities in terms of worker injury policies or workers' compensation were discussed. Men and women workers with RSI in both Ontario and the Netherlands dealt with negative as well as positive experiences in both policy regimes. Moreover, 
their experiential accounts have demonstrated that there are both differences and similarities in the two policy regimes in terms of falling ill or becoming injured while employed and the process of making a claim on the state.

The difference lies in the fact that the Netherlands allows for a generous waiting period before disabled workers are eligible to claim compensation, during which time the employer is required by law to maintain the injured workers' wages. In Ontario the injured or disabled worker does not have access to such a provision. Such a difference in administering worker injury policies should also mean differential experiences in terms of accessing workers' compensation systems. However this did not turn out to be the case. The difference between the two jurisdictions in the initial period quickly turns to one of many similarities between the two jurisdictions at the point of entering into the workers' compensation system for both policy regimes. Predominantly this similarity is because both jurisdictions require a medical examination before benefits are granted to the injured worker.

Thus, it is within the medical gatekeeping function that the differences between the policy regimes disappear in terms of RSI sufferers. Those workers in the two study groups who opted to make a workers' compensation claim, report very similar experiences regarding their contact with medical and compensation board officials. In other words, despite the difference across these two social policy regimes at the level of the state, something accepted by various comparative regime theorists (see for instance, O’Connor, 1993, Sainsbury, 1993; Lewis, 1992; Esping-Andersen, 1990, 1999; and Ruggie, 1984; among others), when we focus on the actual experiences of injured workers making workers compensation claims, we observe a narrowing of the differences 
that we thought existed between the two policy regimes. The policies that seemed so different are not necessarily experienced as such at the individual level of those who follow the policy processes. This to me indicates the necessity to nuance the debate on comparative social policy regimes with more in depth discussions regarding how best to understand the different social policy regimes. The next chapter will do just that by considering the gendered aspect of social policy regimes. 


\section{Chapter 5 \\ Gender Relations and Paid/Unpaid Work}

\section{Introduction}

An analysis that includes the family is not the same as one that studies genderrelations. Though the state intersects with the family and the labour market, studying the family does not point out the gendered nature of welfare policies and how these affect women within the larger context of welfare production. As pointed out by $\mathrm{O}^{\prime}$ Connor et al. (1999: 232), it is important to consider gender relations in comparative welfare state analysis - it is simply not sufficient to relegate gender just to the family (cf. O’Connor et al., 1999, O’Connor, 1993, Sainsbury, 1994, and Esping-Andersen, 1990). Gender relations need to be examined when we look at the intersection of states, markets and family. Indeed, all social institutions are sites of gender relations or gender struggles; as such welfare states or social policy regimes are gendered (see also Porter, 2003). Hence, gender relations must be considered separate and in addition to the family within comparative social policy regime analysis.

Without overlooking the fact that social policy regimes involve the interaction between gender, states and markets, a focus on the family as an institution allows us to observe the intersection of gender and paid and unpaid work, and the home and the market. Particularly important is the issue of health and the intersection of these spheres, and how gender plays an important role in investigating health issues. In this chapter I focus on the gendered aspect of policy regimes within the context of worker injury and workers' compensation policies, and how this plays out at the intersection of paid/unpaid work. Policy makers tend to make their policies based on the notion that the family still 
relies on the notion of a family wage, thereby - inadvertently perhaps - perpetuating the division of labour within and between the public and private spheres (Doyal, 1995). The analysis in this chapter begins with an overview of the home and work. Following this is a discussion of the experience of men suffering from Repetitive Strain Injury (RSI) and the health and home. This is followed by an analysis of women's health, the family and the home. Lastly we observe the family and RSI sufferers.

\section{Home/Work}

The intersection between home and work needs to be integrated into an analysis of welfare states and regimes. The importance of this has been demonstrated as women have entered the labour force. While women's labour force participation rates have increased since mid twentieth century across all social policy regimes, the division of unpaid work remains substantially the same in that women still do the bulk of domestic work in the home (Lewis, 1992; O'Connor, 1993; Luxton \& Reiter, 1997, among others). Moreover, because most welfare states do not adequately consider the problem of combining paid and unpaid work, they undermine policies addressing gender equality in the work place (O'Connor 1993).

The state assumes a gender-neutral tone when addressing workplace related issues. This false gender neutrality, however, renders women effectively invisible. It underscores the unequal citizenship rights women face within welfare state systems. This flows from the notion that men, as 'worker-citizens', are bestowed a preferred rightsbased status - as deserving and independent, while women are primarily seen as wives and/or mothers and as subordinate to the 'worker-citizen' and considered dependent 
(Orloff, 1993; Lister, 1997; O’Connor et al, 1999). 'Worker-citizens' are implicitly male, but are talked about in gender-neutral language and perform paid work in the public sphere. These members of society are considered to be productive, while women, doing unpaid work within the home or private domestic sphere are not seen in the same light. The gender division of labour within the domestic or private sphere with its gendered implications receives little notice from many policy makers. Productivity has value, while unpaid work unfortunately, is not considered as productive and therefore has no value. In other words, unpaid work has no societal worth and is therefore seen as undeserving, while paid work is deemed worthy and as deserving in terms of measuring social citizenship rights in western societies.

De-commodification is an inadequate measure when we want to account for paid and unpaid work in terms of welfare policy analysis (O'Connor, 1993; Orloff, 1997; Lister, 1997; Lewis, 1992) because it is fixated on the impact of wage labour and neglects the crucial role of unpaid caring work in the welfare state (Bussemaker \& v. Kersbergen, 1994). This impairs a proper assessment of the value of unpaid work done in the private sphere, for it marginalizes and delegitimizes domestic caring work, while paid work is unequivocally considered legitimate. This also has implications for women who perform paid work outside the home.

Although the patriarchal image of society sets the work of the domestic sphere as the domain of women, not all women necessarily internalize this view in a similar fashion (Luxton, 1986). However, it is an ideology that still greatly affects the identity of many women (Luxton and Rosenberg, 1986; van Veldhoven, 1996). When women become injured they often perceive their injury to have compromised their identity and ability as a 
mother/wife since they cannot perform the tasks previously taken for granted. Yet these perceptions of inadequacy do not spill over into the paid workplace. Paid work is seen in relatively non-gendered terms in comparison to the domestic work tasks. Women who perform a double day of work feel compelled to perform the domestic work in spite of any injury. This notion that they must fulfill their household tasks is perpetuated by an ideology of patriarchy. Indeed, domestic work is an important part of women's identity even if they also perform paid labour tasks, as demonstrated by Gannagé (1986).

In this regard it is important to keep in mind that domestic and paid work spheres interact to affect women's health and amplify the effect of workplace injury on women's identity. Many studies have demonstrated the linkages between women's health and their paid employment (Walsh and Egdahl, 1980; Tierny et al, 1990; among others). Research, for example, has shown the adverse health effects on women's reproductive capacities stemming from occupational hazards (Walsh and Egdahl, 1980). As well, other studies have established the connection between an increased incidence of stress and associated physical ailments in women with paid employment (Stellman, 1977; Goldenberg and Waddell, 1990). For instance, Goldenberg and Waddell (1990: 541) assert that a heavy workload is a significant contributor to high levels of stress in women. Such research findings are important given that high stress levels are associated with such physical ailments as rose angina, a potentially fatal heart discase (Haynes et al., 1987).

Women's health is adversely affected by activities outside of the paid labour market as well. Evidence suggests that the risk of accidents may be approximately equal for homemakers and women in the labour force (Krute and Burdette, 1978). Rosenberg (1986: 37) contends "that a rigid sexual division of labour in the household contributes to 
significant health and safety hazards for women who work in the home". These hazards affect all women, those who are in the paid labour force and those who are not. As well, existing occupational health problems and injuries can be compounded by activities in the home. Tierny et al. (1990) demonstrate the perils of the double day of work (paid and unpaid) that confront employed women. They note that the combined workload of household labour tasks in addition to paid employment tasks leads to increased levels of insomnia and fatigue in women. Furthermore, this double day of work leads to raised stress levels due to the heavier workload and hence heightens the potential for developing associated physical ailments.

Other studies suggest that the occupational health and safety views and problems of women have been trivialized (Reid et al., 1991). That is, despite the occupational health and safety concerns voiced by women, many researchers have simply attributed any such health problems to 'mass hysteria', 'mass psychogenic illness' or, 'occupational neurosis', rather than to the working conditions. Ready-made psychological categories are used as explanations of physiological effects (Voiss, 1995). As a result, women's occupational health concerns are viewed as unimportant and their observations marginalized (Messing et al., 1995).

Indeed, the medical profession often discounts the views held by women. Within this regard, Sanford and Donovan (1984) recount a research project that investigated the manner in which doctors treated male and female patients who had reported the same physical symptoms. They discovered that the doctors in the study tended to take reports from men more seriously than those from women. The authors also found that doctors are taught that all medical problems which women experience "have their roots in mental 
illness (it's all in your head) or in a pathological inability to adjust to 'the feminine role"" (Sanford and Donovan, 1984: 248). Similarly Asbring and Narvanen (2003: 718) in their research of Chronic Fatigue Syndrome (CFS) and fibromyalgia sufferers note that "women's descriptions of symptoms are more often interpreted as psychosocially related than men's, and most of the patients with CFS and fibromyalgia are women". These traditional stereotypical labels are systematically used to devalue the subjective experiences of women, and by extension the experiences of women workers. This is most apparent in Lippel's (1995) findings which show that injured women workers are more likely to be denied workers compensation than men workers in Quebec. Lippel's research indicates that experts viewed women's problems as pathological rather than workplace related, hence they did not qualify for workers' compensation, a clear indication of a gendered welfare state.

What is important is the fact that many women stand a good chance of sustaining injury - either at work or on the job - but face considerable resistance when attempting to collect compensation or income replacement benefits (see for instance, Pulkingham, 1998; Lippel, 1995; Mink, 1998; van Veldhoven, 1996; Knijn, 1994). When we place this situation within a gendered and private/public context, we find that the marginalization of caregivers has left them powerless. In other words, "the political and ideological creation of a split between public and private spheres exempts from political consideration and remediation the 'private' processes that affect men's and women's capacities and relative power" ( $O^{\prime}$ Connor et al., 1999: 26). The next two sections separate out the experiential accounts of the men and women participants for this dissertation's research and compares these across the two policy regimes. By considering 
aspects of gendered experiential accounts in terms of these men and women's experiences with Repetitive Strain Injury (RSI) as a disease category, I aim to gender my analysis and add disability into the comparative debate of the two policy regimes under question.

\section{Men as RSI Sufferers and Health Behaviour}

Of the 26 injured people I interviewed across the two policy regimes, eight were men, three resided in Ontario and five lived in the Netherlands. Their ages ranged from 26 to 53 years. Each of them identified themselves as RSI sufferers, which they attributed to their computer work (using the key board or doing a lot of mouse work) at their places of employment. All, but one of the men, were married, while all but three of the men had dependents beside their partners. None of the men participating in the research for this dissertation, had any doubt that they had developed computer related RSI. However, only two of the eight men were actually diagnosed by a physician as having RSI, one in Ontario and one in the Netherlands. The remainder determined the diagnosis of their condition themselves. At first, one of the three Ontario men did not suspect that he might have RSI, nor did he have any knowledge of the condition; a doctor's visit did not clear this up for him. Indeed, he visited several physicians in an attempt to find an answer to his condition of:

Pain ... pain and not having the ability to do everything the way I would [like to].

(Ontario interview \# m3, summer 2001) 
An initial visit to a sports clinic did not result in a diagnosis. Not happy with the lack of results in terms of a diagnosis he decided to go for a second opinion elsewhere. After visiting several doctors on his pilgrimage of pain, the injured worker was told that the condition was RSI, though it still was not clear to him what that meant exactly:

Yeah ... 'I saw at least 4 doctors'.... The Doctor at the sports clinic could not come up with anything. I went to see another Doctor near where I live, just to get a second opinion. A friend of mine was visiting me and he saw me suffer. He took me to another Doctor. ... RSI was mentioned by some of the physicians, they did not explain to me what the term meant though.

(Ontario Interview \# m3, summer 2001)

As for the man diagnosed with RSI in the Netherlands, the RSI sufferer was initially diagnosed by his family physician. The injured worker subsequently suggested the diagnosis of RSI to his company physician when he was asked to explain his absence from work:

...My family physician in 1998 - he believed me [that I had pain] and he diagnosed RSI. Then I had to go to the company doctor - [he] believed that I suffered with pain I told him that my family physician had diagnosed RSI. He [the company doctor] said something like ... 'that is possible ... but ... Uh ... Yes you can call that RSI'. (Dutch Interview \# m8, summer 2000)

This last instance is particularly interesting, given that the Netherlands, at the time of the research, was engaged in educating physicians, employers and employees about RSI related injuries and how to avoid developing such an injury. One would assume that under such circumstances a company doctor would not need prompting to recognize the injury. 
At the time of doing the interviews for this dissertation, all men in the study group were earning in the middle-income range for their respective jurisdictions, none had any doubt that their injury was work-related. Two of the Ontario men did mention that they had suffered a previous sports injury and wondered whether their injury was exclusively a work-related injury or whether their previous injury was the cause and their computer work had merely exacerbated the original injury. Medical professionals (not doctors) that they visited would not establish the link between their work and their injury:

I am familiar with RSI - I possibly have it. Because when I have been away from work for an extended period of time the injury [pain] decreases. It [the pain] gets worse as the day progresses. Ten or twelve years ago I sustained a sports injury in my shoulder, my shoulder kept getting worse, that is when I went to a chiropractor and a massage therapist. They are saying that the original injury is the cause - not my work.

(Ontario Interview \# m8, summer, 2001)

And

Initially I damaged my wrist with playing sports - after writing one sentence my hand all cramps up. Probably three years after starting working here - initially it was not very painful. That is what I noticed first - the writing. [I] keep going back to the chiropractor. [The] Physiotherapist helped quite [a bit] - the electrical treatment worked - but then the pain returned - [I] tried acupuncture, that worked well - I have not had much pain since then - that was since the winter. Recently it started to come back a bit.

(Ontario Interview \# m9, summer 2001)

However, their sports injuries had occurred a decade earlier in both cases (Ontario Interviews \# $\mathrm{m} 8$ \& \# $\mathrm{m} 9$, summer 2001$)^{26}$. By laying the blame at the feet of a previous

${ }^{26}$ It is possible that in some cases a previous injury compounds the development of RSI. However, that does not explain why in other cases, these same symptoms or injuries 
injury, medical professionals are apt to deflect larger organizational concerns away from the workplace. Furthermore, it serves to attribute the injury to the individual and their responsibility to maintain good personal habits, characteristic of an individualized culture, without taking account of how the nature of their work could have contributed to affecting their injury. Nonetheless, all men in the study group identified themselves as having a work-related RSI in that the injury had developed by working with computer keyboards or a mouse in the workplace.

Only three of the eight men interviewed had actually claimed and were actually receiving workers' compensation benefits. All of these men were living in the Netherlands. Most of the men, five of the eight, did not feel that their injury warranted a workers' compensation claim, despite the fact that they were suffering a great deal of pain. An interesting piece of research on gender and health reveals that men in general tend to ignore pain, they prefer not to go to a doctor and if they have a chronic medical condition they will "work diligently to hide their disabilities" (Courtenay, 2000: 1389). In fact, Lupton (2003) notes that dominant assumptions about masculinity tend to represent men as the stronger sex and therefore less susceptible to ailments and illness than women. Within this respect she points out that "[h]egemonic masculinities have emphasized the importance of men displaying little concern about the state of health or appearance of their bodies and exerting the power of rational thought over the weakness of the body" (Lupton, 2003: 28).

Indeed, health related behaviour is influenced by many different factors, of which gender is the most important (Courtenay, 2000). Within this regard, the author argues

develop without the injured worker ever having had a previous injury. 
that men are less likely to be aware of medical conditions and tend to "make far fewer health care visits than women do" (Courtenay , 2000: 1386). Lupton (2003) underscores this notion by noting that the idea of men submitting to the care of a physician implies a weakened body, which undermines perceived dominant notions of maleness. The men interviewed for this dissertation research were making comments that exhibited such attitudes, as illustrated by the following:

I did not [go to a doctor] ... I am not sure [why I do not go to a doctor]. There is no reason why - it is just something you don't find the time [to do] - before you call a doctor - I mean - a lot of people ... say that it is stereotypical of men ... when there is something wrong - [men] just keep on going. (Ontario Interview \# m9, summer 2001, emphasis added)

Moreover, "men ... refuse to admit to or acknowledge their pain" (Courtenay, 2000) as exemplified by the following:

While at work the pain was not so bad. But after work in the train ... that is when the pain would really start especially at night - the pain would wake me. One time, when I was carrying my infant son up the stairs, I suddenly lost all of my strength in my arm, and I dropped [my son] just like that! But luckily I was able to catch him with my other arm; he did not fall down the stairs. I did not go to my physician.

(Dutch Interview \# m9, summer 2000)

Furthermore, men tend to refuse to take sick leave from work since this could be seen as not conforming to the dominant norms of masculinity (Courtenay: 1386 -1389). As was the case for this Ontario man:

[I have] primarily pain in the neck and shoulder area [and] tingling in the neck - pain in the fingers - [the pain] started 
two years ago. [I] did not go to a doctor .... I don't think that the incapacity that I have is severe enough to take time off [work] for.

(Ontario Interview \# m3, summer 2001)

This type of behaviour and/or attitude was evident among the men in both jurisdictions in the study group, for example:

I have a lot of pain in my arms. I reported [to my employer] that I was ill - at least partially ill. Oddly enough [the employee] determines whether [they] are partially ill or ill. I determined that I was $32 \%$ ill, but it was determined [by the WAO insurance doctor] that I was a $100 \%$ incapacitated. ... At first it scared me to be declared $100 \%$ unfit for work, I mean, ... it is true, I don't feel well - but to say that I am not $100 \%$ capable to work ... that is not right ...but I kept working haif time ... Yeah ... I just wanted to keep on working!

(Dutch Interview \# ml, summer 2000)

Indeed, this participant wanted to continue working so badly, despite his injury, he modified his workstation so that he could continue to work:

I tried to keep working ... I could not use my arms any longer to work with my computer ... Perhaps I could use voice recognition ... I switched from keyboard typing to voice recognition on my own accord. - .I manage my computer with my voice [so that I can continue to work]. (Dutch Interview \# ml, summer 2000)

In other words, as argued by Courtenay (2000) and noted by Lupton (2003), men in general do not like to admit that they are weak, nor do they like to admit to suffering with pain or ask for help. To admit to such is seen as signs of weakness and does not fit society's dominant view of the socially constructed idea of masculinity. This tendency was evident among all men in both jurisdictions. 
To make a workers' compensation claim, in either jurisdiction, it is necessary to consult insurance physicians who perform medical gatekeeping functions - within this context they are the watchdogs of worker injury programs. The doctor's visit serves to validate the injury. In the case of the Netherlands the function is to determine whether there is an injury, while in Ontario the function is primarily to establish the workrelatedness of the injury. If men with a chronic injury such as RSI prefer to hide such a condition, tend to ignore their pain, are wary of taking sick leave or tend to be disinclined to visit a physician, then this might be a partial explanation as to why some men with a chronic condition such as RSI do not make a workers' compensation claim. Indeed, as Courtenay (2000: 1386) points out, men are more likely "to engage in ... behaviours that increase the risk of disease, injury and death" and are more likely to suffer from chronic conditions than women, but are less likely to seek medical attention than women.

This is unfortunate, because without the reporting of such data, it is not possible to keep 'up to date' records of the extent to which inhabitants of any jurisdiction suffer from a chronic condition such as RSI. Indeed, without any data it is not possible to determine whether and to what extent the situation should be, or to what extent the situation needs to be addressed. Moreover, without such data the state cannot assess the largely unseen or invisible hazards within any workplace that depends on its workers having to perform multiple repetitive tasks on a daily basis.

As well, by keeping RSI as an occupational health hazard that is invisible, states can deflect any accountability and defer responsibility to the individual rather than institute policies at the state level. Policies that force organizations to institute protection so that such workers can be shielded from injuring themselves at their paid work within 
the workplace must be instituted or enforced. This could include information sessions for employees as noted by one of the Ontario men in the study group:

It is possible that such legislation is already there, but it is not appropriately enforced in office environments. I used to work in management of a large manufacturing plant in the 'real' world and I know the labour code to some extent. Supervisors can be held liable if they ask the workers to do something that is not considered safe ... To that end I don't see a difference between the manufacturing and office environments. Employers are responsible for their employees within the office environment. It is their responsibility to educate the employees about the dangers of computer work. I don't know whether ergonomic regulations are enforceable ... why did $I$ have to go ask for a new table and chair, why is it not automatically provided ... why are there so many people around the workplace with these sorts of injuries ... no information sessions are available that I am aware of in this workplace. Such sessions should be considered. However, it is not sufficient to give workers a lesson and then think that it is sufficient ... no ... the employer is still on the hook. If people don't come to lessons, then it is the responsibility of the employer to go to them!

(Ontario Interview \# m3, Summer 2001, emphasis added)

Similarly, the men in the Netherlands, commented that their workstations were not adjusted until after they reported their symptoms to their employers and even then it was not addressed in a timely fashion in some instances:

[My employer] kept promising new office furniture - but it did not materialize - well then my union wrote a few letters. It took five years [before I got it].

(Dutch Interview \# m8, Summer 2000)

\section{Women, RSI and Occupational Health and Safety}

The subjective experience of injury, illness, disease and/or disability is the product of complex processes that involve the interaction between the whole person and 
their particular set of circumstances in terms of their social and cultural environments. Doyal (1995) points out that the bio-medical model reduces the origins of injury, disease and/or disability exclusively to the realm of the material rather than the mental dimensions of the patient. She states that " $[\mathrm{t}]$ his tendency of modern medicine to reduce the complexity of sickness and health to matters of specific biological causation has limited its potential either to understand or to ameliorate the ills of both sexes" (Doyal, 1995: 16). In other words, she argues that the environment plays a significant contributory role in the development of the particular illness and/or disease and by extension injury and/or disability and that without contextualizing the individual's experience(s), the approach of biomedicine to treating the patient is inadequate. This is true for both sexes, but it is particularly important to understand the unique position of women vis-à-vis the cumulative effect of workplace injury and their domestic duties.

As noted earlier, there is a large body of research that shows the association between women's health and their paid employment (Walsh and Egdahl, 1980; Stellman, 1977; Tierny et al., 1990; Hricko and Brunt, 1976; Waldron, 1983; George, 1976, among others). To prevent work related disease or injury it is necessary to investigate to what extent work place conditions could harm a worker. Research in health and safety is then used to set work related safety standards and implement preventative strategies within the workplace. A quick look at rescarch in occupational health and safety shows, however, that historically occupational health and safety researchers have studied male workers only (Skillen, 1995) with the results from such studies then being extrapolated to women (Fausto-Sterling, 1985). Messing $(1991,1994)$ and Walters (1993) regrettably show that this situation is the status quo and that women are frequently excluded as subjects from 
occupational health and safety research. Messing points out that a lack of women in sex specific studies reinforces "the notion that women's concerns about environmental influences are unfounded, hence it is justifiable to exclude women's jobs from prevention efforts" (1994: 11). Indeed, Messing and Grosbois (2001) indicate that this situation is not likely to change because there is a misguided perception among occupational health and safety researchers that women's issues have been included in research that is focused on male workers.

However, simply comparing the working conditions of women and men in different situations is difficult (Vezina and Courville, 1992). Vezina and Courville (1992) have shown that while women and men may hold the same job titles, their work organization, work rhythm, and job classifications in terms of heavy and light workloads are not the same. Indeed, women in certain industries tend to lift a total weight that exceeds that of men labourers. Yet, in terms of Canada, there are no regulatory standards that cover women's jobs, while men's jobs benefit from regulations that specify the maximum force or weight to be lifted in a day, likely based on male specific research. In other words, even though women and men may hold the same job titles, their duties and thus any health problems they may encounter can vary significantly (Messing et al, 1994; Chung et al, 2000).

As for regulatory standards they are highly suspect at the best of times and should be observed with caution (Ziem and Castleman 1989; see also Castleman and Ziem 1988). For example in the case of exposure to chemicals in the workplace, Ziem and Castleman show how threshold limit values (TLVs), which are used to set workplace health and safety regulations, are strongly influenced by industry sponsored research. 
Indeed, Ziem and Castleman (1989) argue that threshold limit values ${ }^{27}$ are not truly reflective of safe levels of exposure to hazardous substances. Their research showed that representatives of interested corporations were instrumental in setting the limits upon which occupational health and safety policies are based. In fact, Ziem and Castleman $(1988,1989)$ contend that the threshold limit values for human exposure to dangerous substances, as worked out by these same interested industry representatives, and upon which occupational health and safety policies are set, are too high and are in reality not safe for human exposure. This is suggestive of the kind of practices that influence regulatory processes. Obviously there is reason to suspect certain occupational standards and the manner in which they are arrived at. This is especially the case given that women are excluded from research studies and thus possible effects of their exposure to many substances are not known.

O'Donnell and Hall (1988) demonstrate that even when we attempt to compare the occupational health problems of women and men, the standards for exposure levels and measures of performance are based on data which is incomplete for race, age, and sex, and that these data are then inappropriately applied to individuals. For example, many work processes were designed for average male populations rather than average worker populations (Messing, 1995). Thus, especially in male-dominated areas, task and workplace design are often hazardous to women and also many men. In view of the ever-

${ }^{27}$ TLVs are intended as unofficial guides of acceptable/permissible exposure levels/limits to chemical and physical agents in the workplace. However, TLVs are widely applied as official limits by many states and countries. These limits or levels refer to maximum allowable concentrations of a substance to which workers may be exposed while at work. In fact TLVs "represent conditions under which it is believed that nearly all workers may be repeatedly exposed, day after day without adverse effect" (Ziem and Castleman, 1988: 11) 
increasing level and range of women's participation in the paid work force, it is thus inappropriate to design tasks specifically in relation to the capacities of either sex or to make the performance of a task dependent on sex-specific characteristics ( ${ }^{\prime}$ 'Donnell and Hall, 1988). This is particularly the case when workers, women and men alike, have to share their workstations as described by the following participant:

At the desk - we would have to adjust it - a table that was going up and down, it became more sophisticated and could bend, the more the ergonomics became sophisticated the worse it became $-I$ had to adjust [the table] several times a day. No [workstation] was specifically assigned to you. When you returned from the washroom someone else would be sitting at your [workstation]. You would find another one that was free. You were constantly readjusting your [workstation]. The adjusting [of the table] you did with the left hand. The knob looked like a daisy, [it was] difficult to handle because if a male had adjusted it before you, you could not undo the knob.

(Ontario interview \# fl, winter 2001)

RSI is a contested condition (Arksey, 1994; 1998; Diwaker and Stothard, 1995; Kome, 1998; van Veldhoven, 1996) that is caused by many consistent repetitive tasks such as keyboarding or the constant clicking of a mouse on a daily and/or regular basis. Not only is there disagreement among members of the medical profession about the existence of the condition itself, but the work-relatedness is also disputed within the medical community - if the condition is recognized at all. That being said, even when RSI is acknowledged as a work-related and compensable condition, women tend to face discrimination from doctors in general and medical experts who are involved in a claim more specifically (cf. Lippel, 2003 and Sanford and Donovan, 1984).

In terms of medical practitioners in general, studies show that physicians tend to discount the views of women. Sanford and Donovan's research (1984) shows that 
physicians tend to diagnose identical conditions in women and men differently. Physicians "were more likely to dismiss the women's symptoms as evidence of hypochondria" (Sanford and Donovan, 1984: 249), or attribute their symptoms to a psychological condition, while men's concerns were taken seriously. Moreover, doctors are taught that medical problems, which women experience "have their roots in mental illness (it's all in your head or it 's all between your ears) or in a pathological inability to adjust to 'the feminine role' [sic]" (Sanford and Donovan, 1984: 248). In other words, traditional stereotypical labels are used to devalue the experiences of women with health related concerns. However, often times when an illness is seen as psychological, the question of personal responsibility also arises (Glenton, 2003).

There is a large body of literature that discusses how the economic interests of capital are not challenged by medicine in terms of legitimating occupational disease (cf. B. Smith, 1987; Hopkins, 1990; Reid et al., 1991; Meekosha and Jakubowicz, 1991 among others). In fact, the economic origins of disease are still redefined by physicians as the individual's fault. Workers, for example, who suffer from RSI are often referred to a psychiatrist by their physicians, with the belief that their 'feelings of pain are in their head' (Reid et al. 1991). In other words, the fault for developing RSI is placed squarely at the feet of the individual. Women who participated on the Dutch RSI forum expressed their frustration about this process of victimization:

I am also familiar with the concerns around psychological stresses that surround RSI and the fact that physicians say that it is a psychological problem. [It is] for them an easy way to get rid of the RSI problem.

(Dutch female forum participant, Fall 2001)

And 
My company doctor as well as my family physician, say that my RSI is a psychological problem. My family physician referred me to a psychiatrist. In the eyes of [my doctor] there are no apparent physical signs that indicate the cause of my RSI.

(Dutch female forum participant, winter 2001)

A reply to this posted message made the following comment:

Yes, I know that that happens and I think that it is awful that it happens. It also happens with other ailments.... Myself - I think that complaints that are not readily objectively identifiable are made to be psychological problems with women much quicker than with men. (Dutch female forum participant, winter 2001)

Furthermore, apart from accusations of malingering, RSI sufferers are told that they are experiencing mass hysteria, normal fatigue or the condition is a psychological problem:

The [experts] think that I am a nut bar ... [they said that they] cannot do anything for [me] ... the lawyer after having called the specialist told me that basically [that] I need psychosocial help. He actually told me that I needed psychiatric help, after he called the specialist! (Ontario Interview \# f11, Fall 2001)

The cause of the injury is thus generally seen in terms of an individual problem rather than having a work-related basis (cf. Reid et al., 1991; Hopkins, 1990; Bammer and Martin, 1992). Indeed, Reid et al. (1991) note that critics of RSI do not acknowledge the phenomenon as an organic reality, nor do they accept that RSI is a work-related injury or disease.

Bammer and Martin (1992: 222) have found that those who do not accept RSI as a work-related organic injury "also criticize recognition of a unified entity called RSI". In other words, critics of RSI are not willing to accept the condition as a legitimate disease arising out of the work activity of labourers and instead tend to focus attention 
upon individuals. Research suggests that women are more likely to suffer from RSI than men, because of the type of work that women do, rather than because they are more prone to developing the condition (Meekosha and Jakubowicz, 1991; Chung et al, 2000). Additionally, Lippel (2003) demonstrates that women do not fare as well as men when they make a workers' compensation claim for RSI related injuries, particularly in Quebec. Thus, men with RSI stand a better chance to gain recognition from the medical profession and by extension the state for their injuries than women with RSI. This was not isolated to the Quebec case, and a pattern of this situation was evident across all workers' compensation jurisdictions in Canada.

Statistics reveal that RSI-related injuries are the leading source of workplace injury (Korrick et al., 1994; Ashbury et al. n.d.) in North American. However, as noted, RSI as a recognized and valid health concern is still under debate within the medical community (cf. Arksey, 1994; 1998; Diwaker and Stothard, 1995; Kome, 1998) one that has not been resolved yet ${ }^{28}$. The scientific knowledge of physicians, which informs their understanding, is not neutral and is itself a social product especially when we consider "the context of policy formation, [where] scientific knowledge of medicine plays a mediating role between the interests of [the market] and the actions of the state" (B. Smith, 1987: 214). As noted, policies are inherently gendered, which then implies that policy outcomes are also gendered and therefore have a differential effect on women and men. This makes it a challenging proposition for those in the Netherlands who suffer from RSI who opt to make a workers' compensation claim while unable to do paid work.

\footnotetext{
${ }^{28}$ Indeed, controversy exists around RSI type injuries. The validity of these injuries is taken into question in terms of their work-relatedness, or whether in fact RSI actually exists for both men and women (Kilbom, 1994; Arksey, 1994, 1998; Kome, 1998).
} 
Obtaining compensation is practically impossible without medical recognition. Place this debate within the context of occupational health and safety legislation in a liberal social policy regime such as Ontario, and we have added another dimension that makes it difficult to get RSI recognized as a work related compensable disease category by workers' compensation boards. Especially since there are those who argue that other disease conditions, which are not work-related, are being forwarded as possible reasons to account for the symptoms experienced by RSI sufferers (cf. Littlejohn, 1989). Lastly, the fact that women with RSI are likely to experience greater difficulties in obtaining medical recognition of their injuries as work-related and not simply a psychological phenomenon, places them in an even more precarious position than men with RSI.

That a link of involvement exists between employers and physicians has been shown by Lippel's (2003) research, which shows how interested third parties have an influence over workers' compensation decisions with regards to claims on the state by RSI sufferers. In fact the role of medicine facilitates distance between economic and political institutions, and "appears to ground policy in the neutral, technical knowledge of a third party" (B. Smith, 1987: 214). Thus, policies and regulations set by the state determine the legitimacy of disease. Such policies can be broad or restrictive. It is demonstrated by B. Smith (1987) that these policies are created at the hands of politicians who have political motivations that do not take the needs of patients into account, but do take the needs of capital into account. In other words, these policies are not based on political considerations - rather they are based on economic considerations. This in turn means that disease can be defined in particular ways, or even defined away (cf. Rosner and Markowitz, 1991). Thus, it can be argued that occupational disease, although a 
reality in and of itself, is a social construct - a definition described to indicate its contextual relation to the workplace. I have argued elsewhere (van Veldhoven, 1996) that the state, the medical profession and workers themselves normalize occupational injuries and disease. By normalizing injuries the mind set of the worker becomes not one of questioning the job relatedness of their injury, but rather one that accepts the jobrelatedness of the injury - if you want to work, expect to become injured (Judkins, 1986: 197-200). This in turn might explain in part why not all women who suffer from RSI opt to make a workers' compensation claim. They have come to accept that the injury becomes part of performing their job.

\section{The Family: Home Life and Where is the Support?}

In both regimes, there are policies in place that allow for support in/for household activities if and when their disability is deemed serious enough by medical gatekeepers (Ministerie van Sociale Zaken en Werkgelegenheid, 2004; Ontario Ministry of Community and Social Services, 2004). In both Ontario and the Netherlands, household support is sponsored by the state, though the administration of the program differs. In Ontario the support for daily living is in the form of income support, allowing a worker with a disability to 'purchase' household care. In the Netherlands, however, the person providing household support is hired by the state, thus the recipient of household support does not have control over who gets to do the job for them. The household support worker, unlike in Ontario, is an employee of the state, within this respect. In both policy regimes these services are severely means tested, using very strict eligibility rules. The result is that in the case of the participants in this study group, the vast majority did not 
qualify, or would not have qualified, for such support, since their disabilities were not considered severe enough within each of the policy regimes ((Ministerie van Sociale Zaken en Werkgelegenheid, 2004; Ontario Ministry of Community and Social Services, 2004).

In terms of experiential accounts and home life, I found a difference between the two study groups. In the case of the Netherlands, the men in this study group appeared to be far more involved with household tasks than the men in Ontario ${ }^{29}$. Indeed the Dutch men were quick to express their concern for their partners when they themselves were unable to perform their household related tasks. None of the Ontario men expressed such a concern and certainly not to the same extent. Indeed some of the Dutch men were quite anxious about the fact that they were not able to contribute to the household in their regular way. Feelings of guilt and concern were expressed:

When your [pregnant] wife with a big tummy is standing there and has difficulty doing the dishes, which does not make you feel very good. I have always tried to do as much as I could. You ask yourself, my heavens, what happened to me? Will I be handicapped for the rest of my life? Or something like that. It is a very frightening prospect.

(Dutch Interview \# ml, Summer 2000)

Another concern that was raised by the Dutch men in this study group was the fact that their injuries limited their ability to participate in parenting affairs such as playing with their children (for instance Dutch Interviews \# m1, \& m9, Summer, 2000). But the one thing that stood out the most, where these Dutch men were concerned, was the fact that

\footnotetext{
${ }^{29}$ Only a few men, however, participated in the research from both jurisdictions. For this reason the findings on this particular issue cannot be conclusive, and are at best indicative. Yet, they are still a valid and interesting observation of this particular study group - one that is worthy of further study.
} 
they felt guilty about their limited ability to help with household chores - a situation not observed in the Ontario study group of men. Indeed, one of the Dutch participants was particularly unhappy about his situation:

.... Yeah - I could not do the cooking any more. I could not clean ... I had lost my independence. My wife was just pregnant - very handy - she had to do all of that work by herself. That has an enormous effect on your daily life. Literally I could only sit with my arms in my lap, because doing anything else was too painful. She [my wife] took over a lot of my - we have always shared household duties 50/50. All tasks varied ... she had to do all of the household chores in the end since I could not do them any longer ... she believed me and gave me $100 \%$ unconditional support. We did not get outside help. We did look into getting someone to help with household chores. [The fact that my wife had to do all of the household chores by herself] I did not like at all. I was simply used to sharing half of the household chores. I was very annoyed [at the situation]. I was used to doing my share of chores around the house - and when you can't do those any longer...I was very upset!

(Dutch Interview \# ml, Summer 2000)

Even though on the whole the men in the study group(s) received support from their partners, not all of the men enjoyed full unconditional support within their homes and from their families. One of the participants remarked that he made a trade off with his wife who, after some time, had become quite impatient with her partner's condition. Their house was in need of significant repair and face-lift. They agreed that she would do all of the remodelling, repairs and repainting of their home, while he would do the household chores (Dutch Interview \#m8, Summer 2000). He noted that his wife made him feel so guilty that he felt compelled to help with everyday household chores, despite the fact that his physician had advised against it (Dutch Interview \# 8, 2000). It isn't just that these men felt bad that they could not pull their weight with household chores, but 
also that there was this implied expectation that their partners expected them to do so.

One of the men ${ }^{30}$, who was ordered to stay at home for a couple of weeks, mentioned that he did do the vacuuming around the house against doctor's orders, simply to keep the peace, despite the fact that he knew that he was not supposed to do so:

... Because when I vacuum - even now [that I am better], when I vacuum just for a quarter of an hour, then I will be sore for days. I should not be doing that at all! But once in a while I do help [my wife] with the vacuuming, however, [when I do] it goes completely wrong with me ... but, it keeps the peace!

(Dutch Interview \# m9, Summer 2000)

None of the Dutch men I interviewed was able to secure state supported household help, though clearly they could have benefited from such support. Instead, those men who were in a relationship had their partners they could depend on, while those who were not in a relationship found alternative ways to looking after the household and other domestic related chores. For instance, one of the men who was not in a relationship counted on his parents for help and support. For this RSI sufferer this was only possible by moving in with his parents, while he was recuperating, and since he was single without dependents he did not need to concern himself with household functions and/or tasks:

Because I could go to my parents - I did not need to worry about the household like cooking and that sort of stuff ... that made a big difference in my recovery. If I did not have [access to] that - ... who knows [what would have happened to me]...!

(Dutch Interview \# m6, Summer 2000)

\footnotetext{
${ }^{30}$ This participant had taken a total of 11 weeks in the Ziektewet. At first his partner, who worked full time outside the home, was very understanding. But after a couple of weeks with this participant staying at home, while she had to go out to her paid work job during the day, she became more insistent that he do some tasks around the home.
} 
Another Dutch male participant who was self employed and whose partner also suffered with RSI, was financially secure enough to hire a housekeeper to do their household chores (Dutch interview \# m4, Summer, 2000).

The men in Ontario, on the other hand, did not indicate at all that they were experiencing feelings of guilt by not doing their part around the house. Indeed, the issue of their suffering with RSI was really a non-issue in terms of doing household chores as far as these men were concerned. At best, concerns were raised about the inability of mowing the lawn:

The injury does not really affect my home/personal life greatly. I might wait with cutting the grass (Ontario Interview \# m8, Summer 2001)

But for the most part it did not seem to be an issue for these Ontario men in this study group and who were in a relationship: household duties were not even on the radar screen. Indeed, it appears that in some instances their injury was not a concern that needed to be considered or addressed. Clearly from the following it appears that it was not even discussed with their spouses:

Tasks at home were restricted, [I] could not work in the garden as often as I would have liked - even when I wanted to make or fix something sometimes. I was not very happy about it. I think that my wife could understand; it was not that I was bedridden, or that I needed to be taken care of. (Ontario Interview \# m3, Summer, 2001, emphasis added)

Or

We don't talk about my injury at home that much - she [my wife] is sympathetic. I have not told her that this could be permanent. You just go through life - you know - take each day as it comes.

(Ontario Interview \# m9, Summer 2001, emphasis added) 
Thus, from the men in the study group(s) I get the sense that in the case of the Netherlands, the men were more involved in doing domestic chores than their Ontario counterparts, and that they felt badly about not being able to always accomplish their tasks. While in Ontario the men gave me the impression that they were less concerned about their inability to carry out their possible domestic responsibilities. Regardless, none of these men in the study group mentioned that they were able to secure state supported household help. For the most part they relied on family members if and when they needed help.

Women in the study group(s) also relied, for the most part, on family members to help have household and/or domestic labour ${ }^{31}$ attended to. In just a few cases, the women were in a position to obtain outside help in the household. However, sometimes such support did not pan out:

For a while I could not do anything that needed my two hands. Nothing - I felt powerless. My children are now grown up, they live in Montreal, [and] they are very busy and cannot help me. I tried to get help - one person came; she saw my house and she wanted to scream. She never came back!

(Ontario Interview \# fl, January, 2001)

The Dutch women who were single without a partner (three out of the eight women), relied for the most part on neighbours and friends:

I live alone ... [I] just wanted to lie down until the pain was gone. I am not married and I do not have any children. I

\footnotetext{
${ }^{31}$ I make a distinction between household labour and domestic labour. Household labour refers to the mundane tasks of keeping the household (vacuuming, doing dishes) in good order, while domestic labour includes household tasks and refers to the responsibility for home, family and household work. However, there may have been instances throughout this dissertation where I inadvertently have used one term for the other.
} 
felt miserable ... I only ate a sandwich with some soup ... heh ... I could not cook. My girlfriend came over to help with household chores - I did not want that ... she has her own family to look after; she is very busy! For years I was able to do my own chores, now I have to ask for help!? I stayed in bed for over a week ... I was so depressed - to lift pots and pans - they are too heavy, [I can't] iron [my clothes] ... very depressing!. My parents live very far away, they have never heard of RSI. They don't understand it at all.

(Dutch Interview \# f13, summer 2000)

One of the single women was able to secure state supported household help, "via the family doctor I was sent to an organization ... [through them] I was able to get someone to help with household chores" (Dutch Interview \# f2, summer 2000). However, she was the only one out of both the men and women in the Dutch study group who was able to secure state supported household help. She did not, though, receive her state funded household support without a struggle and a fight:

First [I had to go] to the Arbo Dienst ... then back to the family physician, then to het GAK. I tell them that I could not even peel a potato or hold a cup of tea ... they said during my physical examination 'yes you can' ..... but I couldn't do it! I said, 'give me a potato, I will show you' ... but of course that was not allowed. ... I told them that I couldn't do a damn thing! I could not even lift a teacup! They finally sent someone ...

(Dutch Interview \# 2, summer 2000)

The remainder of the women in the Netherlands turned to other family members for help with household chores or were in a financial situation where they could afford to get outside help of one sort or another:

My partner is very supportive. At first I did my own household tasks - I worked for four days, hanging out at home doing odd jobs. But to change my life in such a way 
that I need to purchase electronic household gadgets ... a different vacuum cleaner ... or a dishwasher ... to get help with household chores ... Well I am not that bad yet. I rely on my partner to do all the heavy household work - for several months already.

(Dutch Interview \# f10, summer 2000)

Or

At home - absolutely no problem, I received a lot of support ... I simply was not allowed to do any of the household chores any longer. My husband is a sweetheart ... he understood. He also works in an office, so he knows what [RSI] is. [He does everything], hanging the laundry, vacuuming ... everything!

(Dutch Interview \# f11, summer 2000)

And

Now, luckily our [financial] circumstances are such that we can have a lot done for us because we have an awful lot of money ... jah?! I have a housekeeper, I take everything to the drycleaner, I don't do the ironing myself, we simply eat out three times per week and we hardly cook because I can't cut, nor can I peel.

(Dutch Interview \# f5, summer 2000)

In other words, these women, where possible, relied on family members for help with household chores. Those who did not have ready access to family members to help out with household chores either purchased outside help or they relied on friends to come and lend them a hand. To secure state supported household support was very difficult to do, though not impossible since, as noted, one of the single women was able to secure such assistance.

In the case of Ontario the data indicates that the women had similar experiences when it came to doing their household chores. For instance:

The pain was so bad when I came home at night - I could not even turn a jar, I could not lift the plates out of the 
cupboard. I had to have my husband and my kids help me lift the plates. My personal life with the injury changed a lot. I had a lot of support at home. A lot of icepacks ... I felt helpless, I don't like being dependent on anybody ... and no-one else was going to do the garden, even the digging ... Doing laundry was very difficult, I had to get my husband or my sons to carry up the basket from the basement all the way up to the third floor ... I would have had to do that ... that hurt also. My husband he is great he does all the ironing, I am very lucky there. I can't iron, that is hard on the RSI. Vacuuming was a very hard thing ... we have a very light vacuum cleaner, but lifting it up the stairs, I could not do [it].

(Ontario Interview \# f4, summer 2001)

Or

RSI means ... primarily that some things I cannot do anymore ... at home. I cannot open a jar - I am not strong enough ... [my] husband is aware of the condition; he does the laundry and vacuuming. But sometimes I find it very frustrating, like yesterday I could not open two bottles, he notices this, he comes over and just takes the bottle from my hands and opens them. He does not say anything, he just does it - he knows I am frustrated.

(Ontario Interview \# f5, summer 2001)

Some women "did buy some kitchen tools with big handles for an easier grip" (Ontario Interview \# f6, summer 2001). Others secured household help as well as getting family members to help out in addition to purchasing electronic household devices:

I get household support ... someone comes in and cleans ... I had this help before I got injured. Bought kitchen tools such as electric can openers ... changes were made to my life style ... my fridge has not been cleaned for at least 8 months, my husband does the cooking a lot of the time, we have a dishwasher, my son does the laundry, my husband does the ironing. Though I have learned to live with it ... [sometimes] I try to do some ironing, I just take my time ... my neighbours do not understand except for some, my friends and family are very understanding. I let my husband do a lot of the housework. It makes me angry and [it makes me] cry. (Ontario Interview \# f11, summer 2001) 
Unlike most of the Dutch women in the study group, who did not give me the sense that it was frustrating to them when they had to lean on others for household help, all of the Ontario women in the study group expressed their frustration with having to relinquish their control over domestic duties.

The data indicate that the Ontario women in this study group grappled with conflicting feelings, which they felt when it came to performing their household chores. Remarks were made to the effect of "the men do the laundry ... they don't do as good a job as I do, I feel, but they try" (Ontario Interview \# f5, summer 2001). Or some insisted on keeping some household duties within their control such as walking "our dog, he was a lab, he was old but could still really pull” (Ontario Interview \# f4, summer 2001). However, the Dutch women in the study group seemed less concerned about letting their partners take over any of the domestic work. One Dutch woman who was single felt very badly that her friend "came over to help [her] with [her] household chores [because my friend] ha[d] her own family to look after" (Dutch Interview \# f13, summer 2000). Within this context, the Ontario data of this present dissertation research is somewhat consistent with data from a previous research conducted in Southern Ontario (van Veldhoven, 1996). In the previous research project I argued that the conflict experienced by these women with regard to their domestic work points out how ingrained the existing societal ideology is, which assigns domestic labour duties to women (cf. van Veldhoven, 1996). The data for this dissertation points to a similar observation. 


\section{Conclusion}

In this chapter I explored gendered concerns in the debate of paid/unpaid work for RSI sufferers within the parameters of this study group across two different social policy regimes. Women, as discussed, are more likely to develop RSI because of the type of jobs and tasks they perform, and are also more likely to have the added burden of performing household tasks, but without the likelihood of receiving support within this domain. However, the consequences for men who have RSI can be quite severe too, particularly since there is a certain 'macho' ideology among males of denying their injury and pain. In other words, both women and men, who suffer from RSI, have had to grapple with significant lifestyle changes and previous taken-for-granted tasks such as tying shoelaces, washing hair, vacuuming, gardening and/or carrying children became impossible everyday tasks (van Veldhoven, 1996). The injury not only means that paidwork tasks are affected but also that other non-paid work tasks are affected as well, which can no longer be carried out (van Veldhoven, 1996). It does not take much to realize that performing household chores is outside the realm of possibilities for an injured worker who suffers with a chronic condition such as RSI.

Studies show that societal norms and values are such that women are still expected to adopt the responsibilities of the primary caretaker within households (cf. Chandler, 1994; Kiger \& Riley, 1996; Fast \& Frederick, 1998; Sikie-Micanovic, 2001, among others). This then highlights the gendered aspect of this situation, where we have the state possibly recognizing a health and safety concern, in terms of workers' compensation, within the paid or public work sphere. However, while the injury is recognized at the level of paid work the issues of the impact on unpaid and/or domestic 
sphere do not receive much - if any - recognition. In other words, it is possible for workers to get recognition for an injury in the paid workplace, while at the same time not getting recognition for that injury from the same set of ruling relations within the domestic sphere. What little household support and aid there is in either social policy regime is difficult to obtain. This has lead to the almost tragically comical situation that on the one hand you have the state saying: "Yes, you are injured. Here, have some money." While on the other hand the state is saying, "Well no, you are not really that injured! So, no, you cannot get household support for your work at home!"

This then means that even though a worker is injured they will have to continue to perform their domestic tasks, running the risk of further injuring themselves or perhaps developing a permanent disability. Obtaining work-injury coverage for such a situation in the case of Ontario would be difficult since it would not be work-related. Furthermore, any additional injury in either jurisdiction would simply increase and/or shift the costs to both the worker and the state, by having to rely on the respective health care systems on a more frequent and/or permanent basis.

Therefore, for social policy regimes to acknowledge the injury on the one hand in one work domain, but then at the same time refuse to acknowledge that same injury and its consequences in another domain flies in the face of logic - especially because of the cumulative effect household chores have on the RSI type injuries. By not allowing such support, the state is showing its unwillingness to accept/acknowledge, the severity of the injury. Nor is the state recognizing the legitimacy of the domestic or private work sphere, thereby further perpetuating issues of visibility/invisibility of both the injury and the public/private work domain. The gendered aspect of such thinking is particularly evident 
since women are still responsible for the majority of domestic tasks. This is especially important for single mothers who suffer with RSI. The next chapter will consider the medical profession as it relates to the RSI sufferer in the context of compliance and resistance and realizing the sick role. To be considered eligible for workers' compensation, it is essential that the sick role be obtained, for without it, the injured worker is not eligible for worker injury policies. 


\section{Chapter 6 \\ Compliance and Resistance}

\section{Introduction}

How are clinical encounters significant mediating factors in the Repetitive Strain Injury (RSI) experience of the participants? The clinical encounter is the defining moment where RSI sufferers' experiential accounts of their injury nullify the differences of the different social policy regimes' procedures, in terms of dealing with worker injury policies of the different policy regimes. Within this context, injured workers participate in claims-making activities to get their injury validated so that they can get recognition for the sick role. When injured workers visit their health care professionals or medical experts, they participate in a claims-making activity in the hope that they can get access to the sick role, which is a necessary first step but not one that guarantees their entering the workers' compensation process. Indeed, without having obtained the sick role injured workers do not get the chance of accessing the decommodifying aspects of the states' various sources of social provision. This naturally colours the experiences of RSI sufferers who opt to turn to the state for state supported social provision.

Physicians, as members of the ruling relations, participate in perpetuating socially acceptable behaviours. As such, by analyzing claims-making activities we can unpack how the ruling relations organize daily lived experiences - such as allowing an injured worker to obtain the sick role - or not. Moreover, medicine maintains that it has the sole right to define an illness or injury and as such has the privilege of being 'in the know'. In this context, clinical encounters become sites of struggle between the medical expert and the patient or lay person expert over the right to define what ails them. Sites of struggle 
allow for a space where there is room for both compliance and resistance by various actors. I begin my analysis by observing the medical profession and the RSI sufferer, and then proceed to observe the RSI sufferer as they try to get recognition for their condition, their attempt to obtain the sick role. I end the chapter by briefly summarizing the role of trade unions within the broader context of occupational health safety concerns.

\section{The Medical Profession and the RSI Sufferer}

Medicine has become a central and important institution in modern western society. The importance of the institution, some have contended, lies in the ability of physicians to identify and define what will be accepted as a disease or injury (Arksey, 1994; Lupton, 1987; Torrance, 1987). A similar process is observable with a number of other professional organizations, such as lawyers and engineers. These organizations use their control over a certain body of knowledge, accreditation and recognition to set boundaries and exclude or include those who may be viewed as experts (de Swaan, 1990). Such professional organizations participate in what Smith $(1987 ; 1990 ; 1999)$ refers to as 'ruling relations'.

The ability of doctors to define the health and maladies of patients prioritizes the specialized knowledge of the medical institution while subordinating or de-legitimizing the experiential knowledge of the patient or layperson. This is particularly the case for disadvantaged groups, such as women, racial minoroties and lower classes in society (Lupton, 1997). Injured workers who visit a physician enter into relations of ruling. By doing so, their lived experiences are transformed into text and subsequently translated into objectified cases as determined by those who work within existing ruling 
organizational structures, such as medical experts. Patients' or injured workers' lived experiences are then interpreted within the multiple discourses that intersect in the specific institution (Smith, 1987; 1990; 1999). For instance, Smith (1990: 217) uses the example of a welfare caseworker who takes a particular 'stance' toward a welfare client. Other examples include nurses working as nursing case managers who fill out standardized forms that have been created by their employer or organization as part of their duties when visiting patients. As a result patients' lived experiences are transformed into text in an effort to standardize the information compiled by the nursing case manager for their employer. In other words, words on paper or text mediates the nurses' ability to act in the interest of the 'client' and instead of meeting the needs of their patient they in reality work 'in the service of the organization' or their employer (cf. Campbell and Gregor, 2002: 34).

Doctors participate in these relations of ruling in a similar fashion, by taking a 'stance' toward their patient, such as the RSI sufferer, which is informed by intersecting dominant discourses that are relevant to their situation. Waitzkin and Britt (1989a) posit that medical discourse is structured in such a way that it perpetuates a certain ideology and social control. That is, “... doctors transmit certain ideologic [sic] messages that reinforce current social patterns - at work, in the family, and in other areas of life - [by doing so] they help control behaviour in ways that are defined as socially appropriate [for the time]" (Waitzkin and Britt, 1989a: 589). Like the example of nursing case managers, the data gathering techniques of physicians dictate a text mediated work process that constitutes a ruling relation in the interest of a larger structure or organization - the extra local. Clinical encounters can be viewed as micro-political situations where issues of 
ideology and social control may enter into the doctor/patient interaction, frequently without the conscious awareness of all participants (c.f. Waitzkin 1986; Waitzkin and Britt, 1989a; 1989b; Waitzkin et al, 1994). In other words, neither doctors nor patients are consciously aware of the messages of ideology and control that are being conveyed.

Furthermore, as noted elsewhere, physicians who do not run their own independent practices and/or who work in the service of the private sector are not very likely to publicly defend the health interests of workers when the worker and doctor work for the same employer, since such action will bring the doctor into conflict with their employers (Bayer, 1988). And as Walters (1984: 811) so aptly notes doctors, who work for the private sector "... are biased by virtue of the fact that they are employed by companies - 'he who pays the piper calls the tune'". Indeed, company doctors (Walters, 1984) and insurance doctors (Berg et al, 2000) are not held in high regard. Within the medical community, both company doctors and insurance physicians rank low on the status ladder of the medical profession. Neither the company doctor nor the insurance physician have curative tasks and in both cases they perform bureaucratic functions in terms of evaluating disability claims, preventing workplace disabilities and returning injured workers to the workplace (Walters, 1984; Berg et al, 2000). These physicians must follow standardized guidelines, created elsewhere, that help them in their evaluation of a specific problem. Such a "cookbook approach to health care ... hampers the treatment of patients as individuals" (Berg et al, 2000: 766). Yet, these are the very gatekeepers that injured workers must consult when they suffer an injury and when they need to make a compensation claim - either workers' compensation or a private insurance plan. Thus, within the context of injured workers claiming a disability benefit, 
clinical encounters are clearing micro-political situations, though this may understate the true nature of such visits.

To clearly understand the doctor/patient interaction we cannot rely solely on the evidence as provided by the medical 'stance'. Instead we must also include a view from an experiencing-of-life that is not already defined within the ruling. To reveal this relationship, it is necessary to record patients' or injured workers' lay accounts about their lived experiences as they opt to participate in claims-making activities by entering into relations of ruling or the micro politics of medical encounters (Smith, 1987; 1990; 1999; Lupton, 1997; Campbell and Gregor, 2002).

The power to accredit, recognize and organize professions is granted to professional institutions by the state, which is involved in reproducing the dominance of these institutions (Torrance, 1987; de Swaan, 1990; Lupton, 1997, among others). Indeed, medical institutions are powerful social control agencies (Clarke, 1984; Waitzkin and Britt, 1989a; 1989b). Physicians, however, are not simply agents of the state. They perform their duties within the text-mediated constraints of their role, within a larger system of ruling relations. Physicians' place in the system of the power relations in society can be viewed as participating in the reproduction of the existing dominance over subordinated or marginalized groups (Waitzkin and Britt, 1989a; 1989b; de Swaan, 1990; Lupton, 1997). As such, the medical institution is an intricate part of the ruling apparatus, or what Smith (1987) terms the 'extra-local'. Indeed, by encouraging behaviour deemed to be socially appropriate for the time, one can read the 'extra-local' in the 'local'. For instance, a doctor might advise an injured worker to return to work by 
stating that working will be good for their mental health, as happened to one of the forum participants in the Netherlands.

The insurance doctor - he did not understand that I could not study or work with this pain. [He felt that] I had to return quickly to work, that would be good for me, such a young woman. I was speechless ... When I wanted to say something, he [the doctor] said: "Yes, you probably do not agree, but after 30 years of experience, I know what I am talking about, return quickly to work. It [the pain] is simply between your ears". (Dutch Forum participant, November 2001, translated by researcher) $^{32}$

Encouraging the prompt return to work reinforces proper work ethics, and by doing so, the medical profession participates in organizing social behaviour and social control, as suggested by Waitzkin and Britt (1989a, 1989b).

Yet, physicians who act within their various roles and contexts as medical experts are not merely representatives of the ruling apparatus or 'extra-local' agents. They too are ensconced within 'local' relations - their everyday lives are governed and textually coordinated from outside as well. Following Dorothy Smith's line of argument, Campbell and Gregor (2002) note that social organization, in Smith's conceptualization of it, leads from elsewhere into peoples' lives and back out again. Texts and engagement with texts play an important role in, and are part and parcel of, social organization. Texts represent and coordinate the everyday lived actions of people. As such, it constitutes

\footnotetext{
${ }^{32}$ I did not follow and investigate a specific online RSI forum for Ontario since one did not seem to exist. While there is a North American RSI forum, I could not use the data from this online forum since the participants and their information are not restricted to Ontario. Therefore when I refer to "the forum" I am discussing only the Dutch forum. Furthermore, the forum participant in this quotation did not provide any information about her age. It is my sense, however, that she was younger, rather than older. Moreover, the contextual background of the discussion indicated that she is or had been involved in a job retraining project and that she had also collected welfare for a year.
} 
social relations, what Smith refers to as the actual practices and activities through which people's lives are socially organized (Smith, 1987 30). Despite the fact that physicians are textually coordinated, when injured workers go for clinical visits, the power relations are skewed in favour of the physician as gatekeeper. As such, injured workers enter into the relations of ruling with a disadvantage that is predetermined extra-locally and performed locally.

Nevertheless this does not mean that the medical institution cannot and does not come into conflict with the state. We need only witness the numerous occasions when medical bodies and organizations have come into conflict with various governments to understand that these institutions relate in a complex manner. That being said, the relationship between doctors and the state does depend to a large degree on the exact nature of the doctor's function. For example, those practitioners who work within the bureaucracy of the state, such as assessing eligibility for benefits, will have a qualitatively different stance within the intersection of the multiple discourses and opinions than physicians who practice in rural settings. A physician in a rural setting will be relatively unaffected by state discourses in terms of eligibility rules since their doctor/patient encounters are less connected to the benefits system. However, eligibility decisions made by medical practitioners grounded within the state bureaucracy will be influenced by more than the medical discourse but will also be affected by state discourse as well. As such, the perceptions of medical practitioners grounded within the state bureaucracy will be influenced by both the views of the larger medical community toward a specific injury as well as the state discourses around injuries and benefits. Patients who are seeking benefits, therefore, are entering into a relationship with a 
physician who represents the intersection of dominant medical and state discourses.

These discourses will sway the perceptions and views of the physician, and affect the overall relationship.

Thus, in order to understand how a patient confronts the interaction with the benefits system we need to emphasize the lived experience of the patient within that relationship. It is within this regard that Campbell (2000) makes a case for the necessity of uncovering the social organization of actual experiences of actors such as injured workers and their encounters with medical experts, so that the normally invisible extralocal social organization of daily lives can be brought to light. She points out that this is necessary in order to develop truly inclusive policies, such as workers' compensation policies. By the same token, the accounting of our lived experiences from the perspective of the social actor or the local also serves as a reminder of how everyday lived lives are organized within the constraints placed by the extra-local ruling relations. This will influence and have an effect on injured workers and their claims-making activities.

As I noted in the previous chapter, we must keep in mind that RSI is a long-term chronic condition, which can cause adverse social consequences, as demonstrated by one of the forum participants:

It is time to take stock. I have been in pain since March 1997; I have been collecting WAO since June 1998. I started to take medication for the pain in June 1997 and stopped taking it in June 2001. I have taken various therapies without any results. I have been on the RSI tread mill since 1997 and have consulted numerous medical experts. I lost my job in March 2001. I am struggling to keep my family together - you never hear about that [on the forum] - your relationship suffers greatly and is constantly being tested. I thought that I would be able to return to work after a few years - but I realize now that this 
is an illusion and I am ready to accept it. I give up - I surrender.

(Forum member, summer 2001, translated by researcher)

When an injured worker opts to make a claim for compensation they need to have their condition legitimated by a physician. Studying claims-making activities is one way of examining how ruling relations organize the daily-lived experiences of actors. The doctor acts as a gatekeeper to the workers' compensation system. Those who suffer from RSI related symptoms frequently find themselves facing physicians who cannot agree on a diagnosis.

First visit to my doctor ... I was diagnosed with RSI ... second time at the same doctor ... the same condition was given a different diagnosis.

(Ontario interview \# f11, summer 2001; see also van Veldhoven, 1996)

From the experiential data that I have gathered it became clear that there is a disjuncture between a physician's knowledge and what laypersons know about their condition.

I gave up on getting a diagnosis a long time ago. What good does it do, anyway? ... I have been to my family physician, neurologist, orthopaedic surgeon, and physiotherapist; ... where did it get me? ... I have concluded that you are your own expert ... listen to your body.

(Forum member, December 2001)

RSI means pain ... it means pain in my elbow The family doctor did not believe in RSI ... he said ...' if you want to call it RSI - go right ahead'! He was very blunt. He called it "over stressed'; “... take some time ... 6 weeks should do it". After 6 weeks the pain was still there ... nobody would believe me ... I was not taken seriously (Dutch interview \# f2, summer 2000)

I go to the emergency [room]. I have this problem; my thumb feels like it is popping out of my socket. Then the 
doctor comes in.... she still has the door handle in her hand and says what are you doing here. I said, well I have this problem and I started to show her [my thumb]. [The doctor says] well you have no business.... [I say] it feels like it is out of the socket, and she says it is not out of the socket, it takes a lot to take it out of the socket. [The doctor then says] you have to go to a specialist. So I asked did you say that I have tendinitis. She says no, you do not have that, [it] is not a word. She repeated the word that she used, but I did not dare ask her again what it was that I had. She just starts writing. The doctor says that I have no business coming there. She never looked at my thumb. She was not very nice. So I went back to work. But it was very painful. (Ontario interview \# f1, January 2001)

This same participant's problem was subsequently diagnosed by "my regular doctor and he looked at me and said that I strained my thumb" (Ontario interview \# f 1 , January, 2001). When the disjuncture between the layperson's knowledge and what a physician tells them about their condition becomes obvious, sufferers have to rely on their own resources and as such become the "experts ${ }^{33}$ :

... A very good friend of mine who lived in England told me about a book that was out that she knew about. I looked it up on the Internet and [the] union office ordered it for the institution, the staff and I got the book from them and took it home. I started doing my own exercises ... everything that was in this book, is exactly what [symptoms] I had. (Ontario interview \# f4, summer 2001; see also Clarke, 2000:90)

In other words, in most cases the medical expert and layperson do not see eye to eye when it comes to RSI specific knowledge. Recent studies show that the "divisions between lay and professional thinking about disease are now [becoming] blurred and

${ }^{33}$ With 'expert' I am referring to those RSI sufferers who research and investigate the medical literature about their condition and as such develop an expertise about their specific condition. That is, they are not just knowledgeable from the point of view of their experiences, but also from the point of view of the dominant gaze. Within this context, these RSI sufferers are engaged in constructing their own claims and themselves as knowledgeable agents, thus they become the experts (see for instance Whelan, 2000). 
indistinct" (Banks and Prior, 2001). What this demonstrates is that the clinical encounter becomes a site of struggle between the physician and the patient over the right to define the ailment.

Medical experts have been debating the distinction between illness and disease (Asbring and Narvanen, 2003; Glenton, 2003, among others). In our case the juxtaposition is one of nomenclature, whether RSI is a disease or an illness; that is, is RSI recognized and acknowledged as a legitimate claim. In all fairness to the medical profession, RSI is an invisible chronic condition without a specific aetiology or pathology. As such, physicians have great difficulty diagnosing what ails a patient when they are presented with invisible but extreme pain complaints, especially when medical tests do not reveal a physical disorder as is common with soft tissue injuries. In some cases of female patients doctors suggest that the pain is related to hormone fluctuations or that the pain is psychosomatic (Kome, 1998: xiii, among others). For instance:

My company doctor as well as my family physician claim that RSI is a psychological problem.

(Forum member, December 2001, translated by researcher)

... When my family physician cannot find the answer, he will try to toss anything to psychological reasons ... (Forum member, December 2001, translated by researcher)

Some participants from either jurisdiction did not want to consult a family physician at all. It had been their experience that family physicians were not equipped to make a diagnosis These participants perceived the physician's function as being one of gatekeeping the health care system, which involved making referrals to expert or specialized medical knowledge. As noted by some of the participants: 
The family physician is someone who can only determine minor ailments out of a textbook, and to which hospital to send you - if necessary and after that to the specialist. ... That is the impression I have, that is my experience [with family physicians]. When you go to your family doctor and something is not right, than they will refer you [to a specialist], and when you have the flue or you have a soar throat, they will prescribe some medicine (Dutch interview \# m4, Summer, 2000)

Or

[I] Did not go to a doctor [with my injury] because I do not trust the medical profession ... (participant chuckles).

(Ontario interview \# m8, summer 2001)

This suggests a lack of confidence in the medical profession by some of the participants in both the Netherlands and Ontario.

\section{The Sick Role:}

The sick role is a concept that was developed by Parsons (see for instance Glenton, 2003, Nettleton, 1995; Frankel, 1988 and Doyal, 1979 among others). The Parsonian model is based on two basic beliefs and a number of assumptions. The first belief is that being ill is not desirable, and second that the physician is in the more powerful position than the patient. The first assumption, from the perspective of the medical professional, is that physicians are seen as the only technically competent professionals who can assign the sick role to a patient; second, physicians are expected to remain objective and maintain a neutral stance toward any patient, and third, physicians are expected to work for the collective good and not for the individual profit motive. Further assumptions are from the perspective of the patient, first when assigned the sick role, patients are seen as exempted from the usual responsibilities and demands of social 
roles, second, they are not able to 'will' themselves better, third being sick is not a desirable state they want to achieve and finally, patients have an obligation to seek technical competent help. To be assigned the sick role by a physician, a patient must meet all of the assumptions (Frankel, 1988:105-106).

However, Frankel (1988) underscores a number of critiques, pointing out that there exists a wide gap between the theoretical model and reality. For instance the Parsonian model of the sick role is not able to account for preventative health care, thus a patient with lung cancer caused by smoking who is assigned the sick role, should in reality not qualify, given that the smoking caused the condition. This act of smoking nullifies the assumption that being sick is not desirable. Moreover, when patients suffer from chronic conditions, they are faced with the additional hurdle that the 'sick role' concept "is seen as particularly inappropriate for chronic illness" (Glenton, 2003: 2244; Frankel, 1988).

In order to achieve the 'sick role', one's condition must first be validated or legitimized by a member of the medical profession - earlier referred to as the gatekeeping function of medicine. If a physician is unable to establish a diagnosis, the sufferer's condition is not validated, as a consequence their claim to the 'sick role' is denied. That is, they are not given the social license to "be exempt from particular duties for a given period of time" (Glenton, 2003: 2244). Given that chronic conditions have an indefinite life span, and given that the 'sick role' is usually attributed to finite conditions or a timeconstricted sickness, the label does not apply to RSI sufferers. Another concern that RSI sufferers face is when doctors use a psychological or mental basis as an explanation for their condition. By doing so the legitimizing function of the diagnosis - the power to 
define the sufferer as having a physical or non-psychological basis to their illness - is eroded. As well, studies have shown that with the absence of physical evidence of disease health professionals give no weight to patients' self-reported pain. This may be attributed to an "unwillingness among doctors to reveal their uncertainty or limitations" (Glenton, 2003: 2251). However, it may be that physicians are reluctant to assign someone with vague chronic complaints the sick role, as a defence mechanism to limit their clinical encounters with a chronic complainer.

On the other hand, Glenton shows that laypersons may adopt or lay claim to the sick role themselves often through interaction with like sufferers, such as members of the RSI forum. Indeed, accepting the 'sick role', with or without validation by the medical profession, may influence how an injured worker opts to proceed with their claimsmaking activities. As Glenton (2003: 2245) so aptly notes, the social context of the sick role "... reflect[s] the social obligations and expectations that are present in the minds of health professionals, colleagues, family members and sufferers themselves". Cultural expectations placed on the sick person could have a marginalizing effect, which in turn may produce acts of resistance by the chronic sufferer (Ware, 1999). This then influences the claims-making strategies the injured worker opts to follow. Indeed, adopting the sick role without validation by a medical expert is an act of resistance and a claims-making activity.

Claims-making activities as stated earlier, are attempts to transform private troubles into public issues (see Spector and Kitsuse, 1987). According to Spector and Kitsuse (1987), the production of text, such as filling out forms, is a claims-making activity. Within this vein both injured workers and the myriad of medical experts are co- 
participants in claims-making activities or social problems work, since patients who visit their physician are not merely passive participants in the process of the medical encounter. Indeed Whelan (2000) has shown that doctor/patient encounters are participatory processes between the actors. Chronic pain sufferers go to physicians to get a diagnosis (see van Veldhoven, 1996, among others), they want an answer as to why they are in pain. A diagnosis means that their condition is legitimated and their pain is validated. This gives them the opportunity to adopt the sick role. However, by visiting the doctor they engage the clinical gaze and create a paper trail - thus by adopting the sick role they participate in a claims-making activity. This in turn has an influence on how they will proceed from there. Granted, some will neither accept the sick role nor go to a doctor despite the fact that they feel great discomfort. But that too can be construed as a claims-making activity.

\section{RSI, Claims-Making Activities and Adopting the Sick Role}

Claims-making activity, also referred to as social problems work, is a concept borrowed from social constructionism or social problem theorists (Miller and Holstein, 1993). The premise of this approach is to analyse the empirically identifiable acts or steps that a person takes when they make a claim, rather than analysing the condition or the social problem itself. Part of claims-making activities is to focus on the type of claims, or talk, that are being made. However, within this body of literature, it is argued by some (cf. Ibarra and Kitsuse, 1993) that only certain talk qualifies as a claim. These authors make a distinction between talk that is politicized or talk that is making a claim, and talk that is not. In their view, some talk warrants the label 'claim', while other talk 
does not. Thus for Ibarra and Kitsuse (1993) not all talk is seen as social problems work or claims-making activities.

However, Miller (1993) disputes this contention and argues that all talk makes a claim, therefore, all talk is a form of claims-making activity or social problems work. Miller (1993) contends that powerful dominant discourses have the capacity to ward-off challenges and to conceal exclusionary practices performed by ruling relations. It is within this context, that professional discourse marginalizes other ways of knowing. That is, some talk is kept invisible while other talk is not. Similarly, all talk is engaged in a power struggle over meaning; it is within this regard that Miller (1993: 167) conceptualizes a continuum of claims-making activities where at one end you have talk that is readily recognized as legitimate and accepted, while at the other end of the continuum you have marginalized talk that is discarded. Furthermore, all talk is infused with power and power is energized not just in the claims that are being made between claims makers, "but also in sites where these struggles have been silenced". Miller dismisses the notion that there is a clear divide between political and non-political talk. Indeed, all talk is political and Miller argues that the aim should be to make invisible claims visible.

Dorothy Smith (1987), in contrast, uses a method that brings invisible institutional practices to light. She argues that these practices are hidden in text. She posits that we can make these hegemonic discourses visible by studying the everyday practices or interactions of everyday people. A common institutional practice employed by state bureaucracies or medicine is the gathering of personal data through standardized forms. The gathering of the data is through an institutional lens - from the perspective of the 
dominant institutional gaze or the bearer of expert knowledge. Within this regard, institutional practices are actively involved in the creation of text in the form of personal and/or medical records. It is within this context, that we can observe the everyday lived experiences of everyday people (Smith, 1987). Smith refers to this as reading the extralocal (or institutional practices that are reflected in text) in the everyday activities or experiences of everyday people or the local. For example, it does not matter whether a claim is made for workers' compensation benefits, or whether a person is simply consulting a health care professional or medical expert; a written record of the encounter will be archived.

Miller (1993) points out that power resides in all routine encounters between those who wield expert knowledge and those who have experiential or lay knowledge. In the circumstances of RSI sufferers each camp (physicians and those with the RSI condition) promotes their preferred account over meaning, in this case the meaning of RSI. I maintain that all knowledge has authority and as such is expert knowledge. The issue at hand is that not all expert-knowledge is equally valued and meaning becomes a contested terrain, therefore any encounter (and specifically medical encounters that involve gatekeeping functions) becomes a political tug of war over whose knowledge or meaning should reign. Thus, within the context of this dissertation, claims-making activities or social problems talk are disputes (or negotiated processes) over meaning between medical experts or expert knowledge and experiential or lay knowledge. To get acknowledgement or validation by medicine requires entering into such an activity and plays into the hands of the ruling relations. 
Entering into the realm of the ruling relations exposes the lay expert (the injured worker in this case) to the surveillance practices of expert institutional bureaucracies and/or the state. Herein exists a possible tension within the claims-making activities of injured workers or RSI sufferers when they opt to make a workers' compensation claim. That is, when an injured worker makes a claim on the state there is the potential that the claim is made both visible and invisible. By initiating the medical encounter the claim is made visible by the lay expert, but at the same time the medical expert may disregard the claim in which case the claim is not brought forward (a diagnosis is not given) and the lay expert's claim is simply filed away whereby it is made invisible. Doing so marginalizes the claim made by the RSI sufferer however, it does not eliminate the claim, since there will still be a record of the consultation. The recorded encounter is a witness to the claims made by both the lay expert and the medical expert and as such is an indication that claims-making activities that intersect at the site of the medical encounter are visible.

By treating all claims as valid knowledge and thus visible, we also unpack institutional norms. In other words, claims-making activities (or social problems work) are social relations that reveal the extra local practices that extend from elsewhere. That is, the gathering of standardized data, in which both the lay expert and the medical expert take part, originates outside the medical encounter. The standardized text carries the institutional aspect of the relation into the interaction (Campbell and Gregor, 2002: 35). Here divergent strains of interpreting the world merge, as one reveals the hidden claims in text thereby exposing extra local institutional practices, while the other shows that claims are social relations that are textually mediated. Both strains allow for making 
visible the marginalized worlds of the lay expert, albeit from different points of departure. This is important in the context of this dissertation, because, these divergent approaches intersect at the level of the individual and subsequently connects the individual to the broader claims of this dissertation. Indeed, the claims-making activities or social problems work in which individuals take part lay bare the institutional practices of the extra-local.

Liberal social policy regimes tend to have strict eligibility rules and means-tested programs. Workers' compensation policies that use work-related injuries as a test to be eligible for benefits fit within this regime type: the work-relatedness of the injury is the test of eligibility. If an injury (a claim) were not accepted as work-related, the result would be that injured workers whose injuries are not attributed to the workplace would not be eligible to collect workers' compensation benefits - such is the case in Ontario. Even though all of the men who were interviewed in Ontario maintained that their injury was work related, as a result of working with a computer on a regular basis for workrelated purposes, none wanted to make a compensation claim.

Within Medicine RSI is a disease category that is still being socially constructed (see van Veldhoven, 1996; Kome, 1998), the contention being one of nomenclature. As such the medical institution has the advantage of 'being in the know' and is in the position to validate RSI as disease category. However, there is considerable difference of opinion within the medical profession as to whether RSI is legitimate (cf. van Veldhoven, 1996). This opens up a space for medical experts to disqualify or dispute the existence of RSI. It also allows gatekeepers to disregard any claim of RSI. In Ontario RSI, regardless of its construction or nomenclature, is not recognized as a work-related entity. It follows 
then that the Ontario men, who all identified themselves as having RSI, did not think that they would be able to collect workers' compensation for their particular injury and therefore opted not to play a part in the claims-making activities that involved the gatekeeping functions of the state. None felt the need to surrender to the institutional practices of gathering data, which allows for surveillance. Within this context it has to be noted that employers play a large role in the claiming of workers' compensation in Ontario, thus making the prospect of making a successful claim all the more challenging (see Lippel, 2003).

In the Netherlands, which can be viewed as a corporatist or social democratic social policy regime (see O'Connor, 1993; and Esping-Andersen, 1990 among others), the work-relatedness of an injury is not the concern, but rather within this jurisdiction the existence of the injury is at issue. Because there is no necessity to prove workrelatedness the claims-making activities of the injured informant should reflect this regime type and claiming benefits should be less stressful. While this was the case for the men in the Dutch study group, the process was less automatic for some of the Dutch women in the study group who had needed to make a compensation claim. Indeed, some were challenged on their claim to being sick and in fact were denied their sick role by the Dutch insurance doctors - the gatekeepers to the workers' compensation system (Dutch interviews \# 2; \#7, Summer, 2000) ${ }^{34}$. For the Dutch men getting WAO benefits was

${ }^{34}$ In the Netherlands the policies are more conservative than in Ontario in terms of women and mothering responsibilities (see for instance Knijn, 1994; Plantenga, 1996; Kremer, 2001). This could mean that Dutch women are more likely to encounter difficulty with opting to claim benefits when injured than women in Ontario. However, the two Dutch women who faced opposition by WAO officials did not have any mothering duties, since they did not have any children as dependents. Indeed, I would argue that, precisely because their mothering responsibilities are taken more seriously, 
more or less an automatic process. However, the Dutch men did have to submit to a medical gatekeeping test to determine the validity of their claim.

All participants who opted to lay claim on the sick role, in both jurisdictions (Ontario and the Netherlands), experienced a similar institutional practice - the medical exam. Indeed, in both jurisdictions the participants encountered physicians who were not sure how to diagnose their condition:

I went to the hospital - there they said ... yeah ... sir there is nothing wrong with you. [Imagine that], I [was in so much pain] I could only sit around for the entire day, listening to the radio ... I could not walk. ... I could not talk anymore because of the pain ... I could not do anything anymore. At one point I could only lie down all day with my eyes closed. My family physician said ... you know more about RSI than I do ... I will just follow your advice in what you have read.

(Dutch interview \# m6, summer 2000)

No [the doctors did] not really [help with clarifying the condition $], \ldots$ no ... the doctor at the sports clinic could not come up with anything ... they gave me some painkillers sometimes. (Ontario interview \# m3, summer 2001)

Thus when it came to the medical encounter and getting a diagnosis, participants had similar experiences in both policy regimes. That is, RSI sufferers' primary symptoms

women in the Netherlands are more likely to be able to make a WAO claim, simply because it would mean that they could remain at home while convalescing and taking care of dependents at the same time. That, then, could explain why the Dutch state showed reluctance in acknowledging Dutch injured workers' their social citizenship rights within the unpaid work sphere, since the state understands the role of women to be responsible for caring work within the home. However, my interview data did not support this and the one injured worker who was able to secure such support was female. In Ontario the policies are far more restrictive and injured workers in general, who opt to make a workers' compensation claim on the state, face a much more difficult time realizing their social citizenship rights in terms of workers' compensation claims that those in the Netherlands. 
and complaints of severe pain frequently did not get diagnosed and hence did not get a treatment. Indeed, some dismissed out of hand the RSI sufferer's claims to disability:

The doctors did not really believe me. Physicians do not pay a lot of attention to RSI as a diagnosis; they do not take you seriously. The doctor said [to me] ... "just go and do the dishes, then [the disability] will disappear".

(Dutch interview \# m4, summer 2000)

... [T] his doctor said that it was all bullshit ... he said you [are] making it up. [Then] the surgeon says "madam, the little old ladies who knit or garden are always satisfied, the women who work always complain - it has to do with the relationship between you and your employer".

(Ontario interview \# f1, January, 2001)

RSI sufferers face an uncertain future, as with any chronic condition. Many who are afflicted with some form of RSI type injury may take years to recover. Some of the participants in both jurisdictions had been disabled for several years (for instance Ontario interview \# $\mathrm{m} 9$ and \# $\mathrm{f} 13$; Dutch interviews \# $\mathrm{m} 1$ and \# $\mathrm{f}$ ). All have had dealings with either a medical expert such as a physician or specialist (for instance, Dutch interviews \# $\mathrm{m} 1, \# \mathrm{f}, \# \mathrm{f} 7, \# \mathrm{~m} 8$; Ontario interview \# $\mathrm{f} 2, \# \mathrm{~m} 3, \# \mathrm{f} 13$ ) or a health care professional such as physiotherapists or chiropractors (for instance, Ontario Interviews \# m8 and \# $\mathrm{m} 9$; Dutch interview \# $\mathrm{m} 4$ and \# $\mathrm{f7}$ ). By consulting with a healthcare professional or a member of the medical profession, RSI sufferers are making a claim and as such are participating in a claims-making activity, regardless of whether the claims-making activity results in a validation of their condition.

Moreover, a visit to a physician can be seen as attempting to lay claim or gain access to the sick role, which in and of itself is a claims-making activity - this too is a negotiated process. To achieve the sick role means to get public recognition of one's 
pain and suffering. It also gives the sufferer a social license to be exempted from certain responsibilities (such as paid labour) and a social license for the sufferer's need(s) financial or otherwise - to be looked after (such as receiving compensation or insurance benefits) (Nettleton, 1995; Glenton, 2003).

However, Nettleton (1995: 74) points out that accessing the sick role in some cases can take a long time. This is especially the case when certain conditions such as headaches or a stiff neck are normalized or explained away by healthcare professionals and/or members of the medical profession. RSI type complaints typically include headaches, stiff neck or pain in the shoulder area, among other soft tissue complaints. We have already seen that in the case of Ontario these types of symptoms are not necessarily acknowledged as a compensable condition. However, Nettleton is arguing is that such symptoms normally do not get the recognition they deserve in any case, making it more of a challenge to be granted the sick role status. Indeed, Glenton (2003: 2244) actually argues that the sick role, as originally defined, is inappropriate for those suffering a chronic illness.

The concept of the sick role is based on the idea that being sick or ill is a physical verifiable condition (Nettleton 1995; Glenton, 2003, among others). To be granted the sick role necessitates a diagnosis by medical experts. One of the concerns among RSI sufferers is the fact that doctors frequently are unwilling or unable to give a diagnosis because of an absence of physical signs of disease or injury (van Veldhoven, 1996, among others). Indeed, some of the participants in both policy regimes encountered outright disbelief from members of the medical profession. 
Doctors make decisions based on statistical information, not on visits. The doctor would not discuss it with me. He did not listen to me. I could not have these pain symptoms [at my age], I would have to be between 70 or 80 and have arthritis. He was not taking into account any of my symptoms. He was not looking at me personally he was relying on statistics. (Ontario interview \# f13, Fall 2002, emphasis added)

I visited another hospital ... and ... there they did not want to diagnose RSI. There is simply nothing wrong - the tests did show anything. That consultation did not result in anything. The only people who would not believe me were the medical experts. One of those fellows said ... 'yes ... yes it is a psychological problem'. All I heard was - yeah, I don't know-we don't know - we don't know - ... They just did not have an answer for me.

(Dutch interview \# m6)

Dismissing RSI as existing 'between the ears,' or a 'psychological problem' category, undermines or weakens a claim to the sick role since the concept of the sick role is based on symptoms that can be observed physically. Glenton (2003) argues that reclassifying a condition as psychological is medicine's way of delegitimizing a condition for which they cannot find a physical explanation. Moreover, in addition to derailing the claim to the sick role it also places the responsibility of the condition at the feet of the individual that is, a psychological illness is seen as a personal responsibility (Glenton, 2003: 2247). However, despite attempts by medical experts to delegitimize this man's suffering (Dutch interview \# m6), he stood his ground and adopted the sick role regardless of what medicine and physicians had to say.

Frequently the only indication an RSI sufferer had that something was wrong was when they experienced an inability to carry out certain actions without a great deal of pain. 
At work I had typed something then - I could not use my right hand any longer! But the pain stays - I am not improving. The company doctor says ... yeah ... [sigh] ... pain complaints; I can't do anything for you.

(Dutch interview \# m8, Summer 2000)

The pain of the injury may only have manifested itself suddenly, but the consequences it can have are profound, preventing a person from performing common tasks:

There are things I cannot do anymore ... like peeling potatoes. Reading books, doing dishes, the same thing. [I need to] pay attention how I grab something or lift something. I can't play the clarinet any longer [that] really bothers me. Biking is out of the question. I can't hold anything tight. I can't wring clothes.

(Dutch interview \# m8, Summer 2000)

This respondent's description of their experience of pain and incapacity or disability is common and not out of the ordinary for this type of condition (cf. van Veldhoven, 1996). To RSI sufferers it is important to get concrete diagnoses of their condition for a number of reasons, apart from obtaining the recognition of the sick role. These include validation and legitimation of their experience of physical pain, which boosts the sufferers' self esteem and allows them access to treatment. Most importantly, recognition is seen as evidence that 'it' is not all in their head, as is demonstrated by the following participant "I was already happy that I could give it a name" (Dutch interview, \# f11, summer 2000). As well, having a diagnosis allows access to worker disability programs such as long-term disability through their work place, or workers' compensation benefits and perhaps, if necessary, other social support services.

That being said, not all participants, mostly men, in the study group wanted to adopt the label of the sick role, especially in the case of Ontario where the RSI sufferers who participated in the project generally felt that the pain they experienced did not 
warrant a doctor's visit (Ontario interviews, \# f5; \# f7; \# m8; \# m9; \# f12). Indeed, the Dutch participants seemed more readily disposed to accepting the sick role, while the Ontario participants were less likely to do so. All of the participants in the study group were, however, actively participating in claims-making activities. For instance, they all made their private concern public by participating in this very research for this dissertation.

Like Miller (1993) I treat all talk as making a claim; therefore all participants in the study group are taking part in claims-making activities. Moreover, each of these participants by the mere virtue of consenting to doing and participating in an interview are engaged in a social encounter and are making a political claim. Accordingly I recognize myself as an active participant in their claims-making activities. As well, within the context of this dissertation, I understand each interview to communicate valid knowledge; thus all interviews are treated as legitimate and expert ways of knowing. However, some ways of knowing, such as the voice of professional medicine, attempt to discredit other ways of knowing, such as the voice of experience, by trivializing and undermining some people's talk. As a result I view that some talk must be read as a process of marginalization and not as an absence of claims making.

The concept of claims making is a contested process that might ultimately result in the definition of a problem and perhaps a subsequent allocation of resources. In the case of RSI sufferers the claims-making process might result in a diagnosis (definition oi the problem) by a medical expert and perhaps subsequent consent to claim workers' compensation benefits (allocation of resources). However, that is not to say that all claims-making activities by RSI sufferers are aimed at getting workers' compensation 
benefits. It might very well be that RSI sufferers merely want a diagnosis that gives them the recognition of their painful condition so that it can be treated (van Veldhoven, 1996). One of the participants in Ontario had gone to four medical experts to find an answer for his pain. Yet this same individual did not think it necessary to take time off work and make a claim for benefits, he noted that

There was no need to go on WSIB, because there is some disability pension from the employer, but I never had to worry about that.

(Ontario interview \# m3, Summer 2001)

The interesting part about the statement made by this participant is that he never considered WSIB as an option for income maintenance. He did not clarify as to why that would be, other than that he did not think it necessary, since he had access to a disability pension through his employer. This participant was not alone in such an attitude toward state supported income maintenance while injured. Other Ontario respondents, as shown by the following comments, gave similar responses:

I have a long-term disability plan ... I will never need to go on WSIB.

(Ontario interview \# f5, summer, 2001)

...[I] would go on disability through [my] place of work [where I] have a long-term disability [plan].

(Ontario interview \# m9, Summer 2001)

Indeed, this last participant avoided any probing regarding WSIB. He simply did not want to address it. In fact, few of the Ontario participants made any claims on their disability pension or workers' compensation. The sense I got from most of the Ontario participants was that they were uncomfortable with the idea of having to rely on anyone 
else but themselves for income. On the other hand the feeling may have been that their employer would not be supportive and hence an injured worker would dismiss the need for claiming compensation:

[I] would [not] be eligible for any kind of compensation coming out of any organization (WSIB or insurance) 'Cause I don't think that they [the employer, WSIB or insurance agencies] take injuries seriously enough - they would not see that [my particular injury] was workplace related.

(Ontario interview \# m8, summer 2001)

This attitude was not solely evident in the Ontario study group, some of the Dutch participants had a similar stance towards claiming workers' compensation. For instance:

[I have no need for] the WAO. But [I did need] a few weeks in the Ziektewet.

(Dutch interview \# m9, summer 2000)

Though it appeared from the RSI sufferers experiential accounts that the Ontario participants were less likely to make a workers compensation claim, there were also Dutch participants who would rather avoid having to enter into the workers' compensation system, since it was believed that "once in the WAO, one often did not exit the system again" (Dutch interview \# f7, Summer, 2000). The fact that some opted not to make a claim or continue on into the workers' compensation system I did not interpret as participants not taking part in claims-making activities. Instead, I interpreted the act of not exercising their social citizen's right to workers' compensation as engaging in an unusual form of claims-making activities, or a unique way of commenting on the world, what Miller (1993: 169 - 173) has referred to as 'exercising power from the underside'. Though at first glance it may appear that these participants were silenced and 
depoliticised, I took it as a form of resistance. By not claiming workers' compensation, these participants did not need to report to their employer nor submit to a gatekeeping medical exam and thus opted not to submit to the surveillance practices of institutions or ruling relations. This is a form of resistance: a claims-making style that keeps them beyond the medical gaze of the state.

Thus, I understand claims-making activities, referred to previously, to be any strategy employed by actors to draw attention to a situation, including activities intended to be strategies of resistance. For instance an injured worker might draw attention to their condition by initiating a medical encounter and thereby seeking to claim the sick role through official channels, or by claiming the sick role without the validation from experts by refusing to submit to the surveillance practices of the state (an act of resistance). Within this context claims-making activities are understood to be any act that meets this definition. Thus, it is my understanding that claims-making activities are not isolated to just talk, though all talk, as explained by Miller (1993), is involved in a claims-making activity.

Lay knowledge is considered invisible because such knowledge generally does not receive the stamp of approval from 'experts' (see for instance, Arksey, 1994, 1998; Kome, 1998; among others). That is, a patient consulting their physician presents lay knowledge of their condition to the medical expert. However, patients who have initiated the medical encounter are faced with the possibility that their lay knowledge may be discredited or delegitimized by the privileged knowledge of the medical expert. Nevertheless, it is also the case that a record will be created of their visit, which actually makes the claim visible. It is within this context that Miller argues that all knowledge is 
valid knowledge. In fact, Miller draws attention to the point that the purpose of claimsmaking activities is to make invisible claims, such as the lay knowledge of the various issues surrounding RSI, visible. Thus, she argues that we should be treating all claims as valid knowledge thereby making the claim visible.

One of the reasons why injured workers enter into the domain of the medical encounter is to get validation for their condition. If the claim of being injured or ill is validated and a medical expert establishes a diagnosis, the injured worker may then be allowed to adopt the sick role (Glenton, 2003 among others). This in turn implies that the injured worker should take steps to find treatment for their condition. Thus validation by members of the medical profession in part facilitates the process of being granted the sick role, thereby allowing the injured workers leave from their social and other responsibilities in order to have time to convalesce (Nettleton, 1995; Glenton, 2003 among others). However, not all RSI sufferers who had their condition invalidated turned away from adopting the sick role, as mentioned previously. Adopting the sick role can be seen as both an act of resistance and a claims-making activity that can bring attention to the condition. In terms of the women who suffered from RSI, all but one of the women (in Ontario) consulted a physician, thus all but one looked to gaining access to the sick role status. However, in most cases the women did not ask to be relieved from their daily duties, but rather they were looking for answers to what ailed them. They were seeking a diagnosis - indeed in one particular instance the injured woman had never heard of RSI and when she left the doctor's office she felt worried:

The pain was so bad when I came home at night - I could not even turn a jar, I could not lift the plates out of the cupboard. The doctor [in the sports clinic] told me that it 
was repetitive strain injury. [He] did not tell me how I developed it - he just asked me what I do [for a living] ... and as soon as I told him ... what I do [at work] ... that is how [sic] he wrote it down it is RSI. The physiotherapist also said that it was not carpal tunnel, because that [the pain] was not in there, [but] that it was in there (participant points to areas of her arm where it hurts and doesn't hurt). He said also that it was repetitive strain injury. ... I was not familiar with RSI, only with carpal tunnel before I got it. When I left the doctor's office I had no idea what he had been talking about. I was very stressed at that time as well ... but no one explained that the tasks I had been doing [at work] were the cause of my injury.

(Ontario interview \# f4, summer 2001)

In most cases the women's physicians diagnosed their condition to be RSI. For instance physicians diagnosed 13 women out of 18 with RSI (6 Ontario women and 7 Dutch women). Out of the 18 women I interviewed, there was only one woman who did not seek to be granted the sick role by not visiting a physician at any stage (Ontario interview \#12, summer 2001). Instead, she changed her job. The remaining 17 women did visit their physicians and by doing so they were looking to be granted the sick role. As well by seeking the sick role they participate in a claims-making activity. Similarly, most men in the study group visited a physician thereby following the route to claiming the sick role, necessary to obtain validation. All together, there were 8 men who participated in the study group, of these men five (4 in the Netherlands and 1 in Ontario) visited a physician regarding their symptoms.

However, even though physicians were giving these participants a diagnosis, not all were comfortable with placing the cause of the workers' injury solely at the feet of the workers' workplace activities. In both jurisdictions physicians were not willing to accept the work relatedness of the workers' condition - effectively a denial of the worker's assertion. 
[T]he members of the medical profession, never actually came out and said that it was a work related RSI or carpal tunnel. At the time my doctor was not all that keen on filling in the WSIB claim form, although she did fill it in for me. I don't know what her problem was ... but she said that she could not specifically say that it was carpal tunnel or work related. She was reluctant to admit the workrelatedness. Not that she was negative; just that she could not say that it was related to keyboarding. (Ontario interview \# f6, Summer, 2001)

Other physicians were sceptical that the worker's injury was caused at the workplace and thought that it was more likely caused or affected by the worker's activities outside the workplace, again effectively questioning that the injury was solely work-related.

There is a lot of attention placed on RSI [within the workplace]. But if you have RSI yourself ... then people become very sceptical ... for instance when [the company doctor] heard that I was working half days and I was given an assistant he said - perfect, that is good - but what he should have done was send me directly home instead of allowing me to work half days. There is this [implied] assumption that one does a lot of internet work at home well I don't do that at all; I might check my email, or answer a friend's email message. But that happens at most once a week. ... [The company doctor] suggested that I place an egg timer on my desk [at home] - now what kind of remark is that?!

(Dutch interview \# f10, Summer, 2000)

In other words, despite the fact that a diagnosis of RSI allowed these participants access to the sick role, it did not necessarily translate into access to state-supported income maintenance programs, such as worker's compensation. In the case of Ontario, despite the fact that the injured worker (\# f6) is given a diagnosis by her physician thereby allowing her the sick role, the injured worker is kept outside the boundaries of the compensation system or the WSIB, because the physician explicitly denies the work 
relatedness of the condition. In the case of the Netherlands, the participant (\# f10) was diagnosed as having a RSI type injury, but the company doctor implied that the RSI was solely caused by keyboarding or computer mouse use at work. The physician was sceptical of the worker's assertion regarding the injury and thought that the RSI sufferer was also doing a lot of internet work when at home, telling the worker to "place an egg timer" on her desk to measure the time she was spending doing computer and mouse work at home - effectively disbelieving that the worker's condition was solely the result of her paid work. Indeed, the physician kept this RSI sufferer at work instead of allowing her to rest at home, despite the fact that he gave her a diagnosis of RSI and allowed her access to the sick role. The point is that getting a diagnosis and thereby obtaining the sick role is a necessary first step before access to the workers' compensation system is granted. However, it is not a sufficient condition, obtaining the sick role does not actually guarantee access to the compensation system in either policy regime.

\section{A Note on Trade Unions: Are They Facilitating the Process?}

There is a body of literature that looks at the role of trade unions and occupational health and safety policies in the work place (for instance, Robinson, 1988; Cassou and Pissaro, 1988; Sass, 1989; 1996; Macintosh and Gough, 1998; Johansson and Partanen, 2002, O'Neill, no date). Indeed, Robinson (1988) notes that health and safety activities are more obvious in unionized workplaces. Therefore, trade union interest and participation in occupational health and safety issues are paramount for the safety of workers. The question remains whether trade unions facilitate the process of accessing the workers compensations systems. In either policy regime trade unions play an active 
role in the negotiation process of a collective agreement. However, the way labour is organized differs significantly between these regimes.

In the Netherlands, trade unions are organized along sectors, such as for instance the health-care sector or the publishing sector. Moreover, workers are not required to belong to the union when employed within a particular sector. That is, membership in the Netherlands is voluntary, and the worker opts to pay union dues. In Ontario, labour is organized differently. Here trade unions are employer or workplace based. Thus, a collective agreement is negotiated between the particular employer or branch of the employer and a particular trade union local. As well, the employee is required by law to pay union dues referred to as the RAND formula (Krahn and Lowe, 1988), regardless of whether the worker opts to be a member of the union. This formula was applied by Justice Rand to guarantee union security "[o]n the assumption that a union must act on behalf of all employees in a workplace." (Krahn and Lowe, 1988: 214) During my interviews, I did not ask the participants specific questions regarding union involvement or participation in their particular context. However, that being said, during some of the interviews the issue of trade union involvement was raised by some of the participants, (mostly in Ontario). For this reason, it is necessary to briefly address trade union involvement within the context of this dissertation. By no means am I discounting the importance and necessity of collective action. However, given the different approaches to organizing labour in the two policy regimes, I thought it prudent not to place too large a focus on this aspect of the study at this time.

Trade unions have an important role to play in the process of accessing worker injury policies in both policy regimes. However, it is my view that the role trade unions 
have in terms of facilitating the process of accessing workers' compensation in the Netherlands is not similar to that in Ontario. In the Netherlands, the trade union role is observed more at the macro level by negotiating a contract or collective labour agreement (CAO) for all workers in the relevant sector. The union, within this respect is a partner in a tripartite partnership between labour, state and business (Ministerie van Sociale Zaken en Werkgelegenheid, 2004). CAOs are renegotiated once a year or once every two years, depending on the sector. Trade unions negotiate the topping up of salaries while an injured or ill worker is in the Ziektewet, and they negotiate workplace conditions for the entire sector or the level of compensation benefits for injured workers, as described by one of the Dutch participants:

Your salary is continued - that is compulsory in the Netherlands. WAO benefits (participant called this WAO benefits, however, I am pretty sure that he meant Ziektewet benefits) - for the first 6 months the employer tops it up to a $100 \%$. The second half of the year you get $80 \%$ of your last earned wages - this is according to the $\mathrm{CAO}$ (union contract).

(Dutch interview \# m6, Summer 2000)

However, direct involvement by trade unions in facilitating the process at the individual level is limited to giving legal advise or providing a lawyer when taking the WAO to court by appealing a relevant Board's (for instance het GAK or CADANS among others) decision regarding a denial of a compensation claim. The individual can turn to their trade union for help and/or support in the matter. Interestingly, it is not necessary to have been a member of the relevant union first, before developing the injury, to benefit from its services (Dutch Forum Discussion, Fall 2001). Thus, an injured worker who suffers 
from a RSI-type injury can still become a member, however, it takes a year before they can take advantage of the union's services.

Trade unions in Ontario, in contrast, are far more active at the individual level but do not have much sway at the macro level. An injured worker in Ontario who needs help with making a workers' compensation claim can turn to their union local for assistance. In such a situation, union representatives will help or guide an injured worker through the maze that constitutes the pathways or avenues to workers' compensation. Within this respect the union facilitates the process to acquiring or at the very least reporting workrelated injuries to the compensation board (WSIB in the case of Ontario) as demonstrated by the following participant:

[I] started to apply to our short-term disability through our company. One of my union representatives contacted me and convinced me to report it to the WSIB, because it was work related. I submitted my claim to the WSIB [instead]. (Ontario interview \# f2, Summer, 2001)

Or the union might convince an injured worker to appeal a decision by the workers' compensation board (WSIB), as demonstrated by this next participant:

Once I got the results back from my tests I sent in my report to WSIB ... [but] the WSIB refused me, they said well ... that is not a work specific injury. Of course I went to my union, to fight for me. They checked to see if I had another problem - but I don't have any other problems. Hitting the space bar with my thumb is what caused the injury. My doctor said that both my hands were injured by the type of work I do, he did not agree with WSIB for not recognizing the right hand. The union wanted to appeal the decision, [so] I said $O K$ then ... at the moment my claim [that had been denied] is being appealed. (Ontario interview \# fl, January, 2001) 
Though I did not set out specifically to investigate whether trade unions facilitate the process of accessing workers' compensation, there is some evidence from the data I collected to indicate that they do. This would be in keeping with a large body of literature that addresses the role of trade unions and occupational health and safety concerns within the work place (for instance cf. O'Neil, no date; Johansson and Partanen, 2002, among others).

\section{Conclusion}

Unlike in Ontario, injured workers in the Netherlands have the advantage of the Ziektewet or Illness Act, providing a generous recovery period before the workers' compensation system needs to be accessed. Indeed, for the Dutch injured workers to make a claim on the state is practically an automatic process once they have been in the Ziektewet for a period of time, which makes it less of an onerous affair than in Ontario where the injured person has to go through an extensive and time consuming application

process in order to receive compensation. Moreover, there is the perception that claiming workers' compensation comes with a stigma attached, whereas the Ziektewet does not seem to have a stigma attached to it. Though, once faced with opting to enter into the WAO system, Dutch injured workers do seem less comfortable with doing so, but not to the same degree as injured workers in Ontario. Indeed, despite the fact that state supported worker injury policies are in place in both policy regimes, not all injured workers end up accessing or even reporting injuries to workers' compensation systems.

This chapter investigated workers engaging in claims-making activities by seeking to gain recognition for the sick role, which is a necessary first step, before the 
workers compensation system (or any other insurance program) is available to them. This is true for both social policy regimes. However, during clinical encounters, members of the medical profession, who would not always validate the participants' RSI experience, confronted them with resistance in terms of denying them their right to the sick role. This turned out to be a major obstacle for many of the RSI sufferers, who were looking to access their respective compensation (or private insurance) systems because they were too injured to continue with their jobs.

Not all participants, however, were accepting of the decision made by their medical experts. For these participants it meant countering and resisting their physicians' resistance by laying claim to the sick role without the explicit validation from medicine. Other participants suffering with the injury were reluctant to turn to workers compensation systems, since these injured workers had access to alternative sources of income maintenance plans, such as long-term disability. However, in some cases the union intervened and helped the participants in reporting their injuries to the workers' compensation system, and facilitated the process of making workers' compensation claims. This finding is consistent with the literature on the role of unions in occupational health and safety issues. For instance Shannon and Lowe (2002: 468) note "workers who are unionized may feel less vulnerable to reprisals if they submit a claim and they may be provided with information on WC or help in claiming by their union." Indeed, I found this to be true for some of the Ontario participants.

Whether injured workers opt to report their injury to the workers` compensation system, or whether injured workers opt to file a long-term-disability claim through a private insurance provider, they have to get medical validation before they can continue 
with their claims-making activities. The next chapter will discuss alternative income maintenance plans and the manner in which different policy regimes use a combination of the state and market in terms of social provisions. The participants in Ontario indicated that they would be more likely to turn to employer supported private insurance plans, whereas the participants in the Netherlands were less likely to be faced with such an option. Only a select few participants in the Netherlands needed to turn to the market in terms of income maintenance and associated benefits, such as the various therapies that address the possible recovery of the condition. For these people, state sponsored social provision is not available and instead they must purchase their own insurance for such coverage. Yet, in both policy regimes, the clinical encounter is still the key mediating factor in terms of minimizing individuals' experiential differences between the two different jurisdictions. 


\section{Chapter 7 \\ Market-Based Plans}

\section{Introduction}

Not all injuries get reported to workers compensation boards in Ontario.

However, as noted earlier, even when a workplace injury does not lead to time away from work, it should be reported to the workers' compensation board. In the Netherlands, the law (article 9 of the Arbowet) requires that company physicians as of November 1, 1999 report suspected work-related injuries or illnesses to the national centre of occupational related injuries and diseases - het Nederlands Centrum voor Beroepsziekten (Ministerie van Sociale Zaken en Werkgelegenheid, 2004). This is an independent institution at the University of Amsterdam that collects data on occupational health related concerns. There is legislation in place in both policy regimes that requires the reporting of workrelated injuries to a central agency, the workers compensation board (WSIB), in the case of Ontario and het Nederlands Centrum voor Beroepsziekten (NCvB) in the case of the Netherlands.

In the case of Ontario, the reporting of a work-related injury does not necessarily have to translate into making a claim for benefits. Instead, such information may be used for the sole purpose of gathering aggregate data by the state. The gathering of such data allows the state to perform surveillance practices by way of statistical analyses in order to get a sense about certain injury rates or illnesses within a specific sector or industry. This is important, for how else is a policy regime able to assess the seriousness of certain injury rates within specific jurisdictions? As it stands there are no reliable statistics available under the rubric of RSI as a disease category in Ontario, while in the 
Netherlands, such information is gathered by a central agency. Yet, in both policy regimes concerns have been raised about the under reporting of work-related injuries to the relevant and respective agencies or boards (Ministerie van Sociale Zaken en Werkgelegenheid, 2004; Shannon and Lowe, 2002).

Self-employed persons, however, in both social policy regimes fall outside the state provided social provision of workers' compensation systems, and in both jurisdictions they must purchase protection in the event they experience a work interruption attributable to illness or injury (Ministerie van Sociale Zaken en Werkgelegenheid, 2004, Workplace Health and Safety Board, 2005). Thus, the decommodifying aspects of the state are not necessarily equally available to all inhabitants of both jurisdictions in terms of full social citizenship rights, which in this case are self-employed individuals. Furthermore, studies have shown (for instance Shannon and Lowe, 2002) that people who have access to an alternative form of income maintenance plans, such as long-term disability, will not opt to take the workers' compensation route. This then undermines the state's ability to gather aggregate data with regards to injuries, which is necessary information if one of the state's objectives is to eradicate work-related illnesses or injuries, as declared by the WSIB's mission statement previously noted.

This chapter will take a closer look at the issue of individuals opting not to make a workers' compensation claim versus opting to claim long or short-term disability especially, in the case of Ontario. We must keep in mind, however, that not all workers necessarily have additional health insurance coverage beyond the universal provincial health care program in Ontario. That being said, universal health care pays for doctor 
appointments, but not for medications, physical therapies or other treatments. These may be covered for individuals on workers' compensation or with supplementary health plans offered by employers. However, not all health insurance programs cover conventional RSI treatments such as anti-inflammatory drugs, physical therapy or acupuncture (Kuelke, 2003). Moreover, self employed individuals and independent scholars, who do contract work for instance, face similar difficulties. At issue is the fact that some individuals fall outside of the state's social provision boundaries in both policy regimes and they must, therefore, turn to the market to purchase their support, but may not always be in a financial situation to do so.

\section{Employer Provided Support Programs}

When state supported programs such as the Ziektewet or workers' compensation programs are not an option, the injured worker must rely on alternative sources for support (financial or otherwise). In the Netherlands all but three of the participants in the study group relied on state-run programs. These participants in the Dutch study group were not eligible for the state supported programs, since they were self-employed small business owners and had to rely on the market within this regard. One of them remarked that:

When the Arbodienst determines that you as an employer are worker disabled, then nothing happens. In essence there is no support for small employers [when they become ill or disabled]

(Dutch interview \# m4, summer 2000)

While another was more optimistic about her situation: 
As soon as I feel something, I stop [with my work]. I own my own business, therefore I am in a position that I can do that ... I am financially secure; I do not need to worry. RSI has a long incubation period, just like AIDS. I am in a position that I can allow myself to stop working if that should be necessary.

(Dutch interview \# f12, summer 2000)

Workers' compensation programs cover assorted therapies to help workers with a disability on the road to recovery. However, if an injured worker does not qualify for workers' compensation, they must rely on their own resources for such therapies:

I go [for physical therapy] to 'Physical Sense' in Amsterdam, I have to pay that myself; it costs f1.5000. Guilders. My insurance company did not [accept my claim] and did not want to pay for it.

(Dutch interview \# m4, summer 2000)

Or

We are privately insured. What does RSI mean personally?

... At first ... You can't do anything yourself anymore.

Luckily our financial circumstances are such that we can get others to do a lot of things for us because we have an awful lot of money ... you see?!

(Dutch interview \# f5, summer 2000)

These participants did not have a high regard for members of the medical profession and noted that they did not have a good experience with them:

I had visited the doctor, but ... I am not exactly sure that I know ... I did not agree at all with his diagnosis ... I did not trust him.

(Dutch interview \# f5, summer 2000)

And

... The medical world does not know much about RSI, how they should be treating the condition. Yes, I had gone for a consultation with a neurologist ... very unpleasant examination, ... every time they gave me a little shock ... I 
found [the examination] very disturbing ... they could not find anything - nothing at all.

(Dutch interview \# f12, summer 2000)

Thus, in the Netherlands a worker with a disability is generally covered if they become disabled in terms of paid work - as long as they are an employee. However, as is conveyed by these participants, small business owners or self-employed individuals have a different experience than those who are employed. Small business owners must rely more on market-based insurance programs, since state run programs are beyond their reach. The same need to have private insurance is true for self-employed individuals in Ontario, nevertheless, none of the participants in the Ontario study group I interviewed fell into the self-employed category.

In Ontario we find a combination of state-run programs as well as market-based programs for employees. This came to light when some of the participants (Ontario interviews \# $\mathrm{m} 3$, summer, 2001 and \# $\mathrm{m} 9$, summer 2001) noted that they had never considered claiming WSIB since their place of work has long-term disability insurance coverage, typical of larger organizations. This is in keeping with other studies, which have reported that injured workers tend not to file when the injury is not considered serious enough, when they do not want to miss any work, or when they expected to miss work but knew that they could get sick leave or receive short-term disability from their employer, among other reasons (Shannon and Lowe, 2002: 468). In terms of marketbased coverage, most of the Ontario participants ( 9 out of the 13 participants) had access to an additional income maintenance arrangement apart from workers compensation, in the case of a work-related injury. These participants were covered for disability through their employer-administered disability insurance or sick leave plans: 
If I had to take time off, we have a very good sick leave plan here. I have been here 26 years; my sick leave record is very good. My sick leave benefit package is generous enough that we would not have had to suffer financially, had I taken time off work.

(Ontario interview \# f4, summer 2001)

This allowed for the opportunity of not having to rely solely on the WSIB as a possible source of income maintenance or source of additional benefits. However, most of the Ontario participants in this study group understood this option to be replacing WSIB rather than in addition to workers' compensation. Problems can occur, however, when a worker experiences multiple injuries over time. A first injury to one part of the body may be covered by WSIB, but a second subsequent injury (to a different part of the body) may not be covered by WSIB. However, now there is a problem since the second injury will not be covered by an insurance plan, since most insurance plans and/or the WSIB do not allow a worker to collect from both sources simultaneously:

I went back to apply for short-term disability ... I got caught in one of those red tape paper loops. Short term disability acknowledges that workers comp was saying yes we acknowledge the claim for your left arm. I am trying to apply [for insurance benefits] for the other half of my body, which they [WSIB] won't cover ... I just got caught in this round about circle of 'who is going to take me?' You know ... half of my body belongs to one company and the other half belongs to the other side. Neither one of them want any thing to do with the other half ... so ... The insurance through the employer does not pay out while on WSIB, while on WSIB you don't get disability insurance payments. It is one or the other ... and because it was about splitting me down the middle, it got in this fight between them as to who was actually going to pick it up ... and I had been getting all these letters of decline by WSIB ... to be forwarded on to our insurance company ... saying ... yes we have nothing to do with it.

(Ontario interview \# $\mathrm{f}$, summer 2001) 
The point is that having market-based insurance can be beneficial, but not necessarily so. The fact remains though that these Ontario participants had more than WSIB (or EI, and CPP disability for that matter) to choose from, they also had the additional option of a market-based income maintenance scheme in the form of long or short term insurance or sick leave plans. However, in practice this meant that the insurance plans replaced the WSIB or any other state-run option instead of providing additional income support to WSIB income maintenance or benefit possibilities. For instance, one respondent stated that "I have a long term disability plan ... I will never need to go on WSIB" (Ontario interview \# f5, summer, 2001 - emphasis added). Another respondent noted that:

The OHS office did give me a WSIB form to fill out - I did not fill it in. I guess I did not know a lot ... I did not understand it. She [the OHS officer] had just given me this form but did not explain what it was for.

(Ontario interview \# $\mathrm{f} 4$, summer 2001)

The respondents did not view the role of WSIB as providing an additional source of income maintenance or as a source of other associated benefits. Also the respondents in Ontario were not sure exactly what role the WSIB played within the context of keeping track of reported work place injuries, as demonstrated by the following respondent:

Options for income replacement - I have a good health benefits insurance plan at work ... short term is $2 / 3$ of my salary. I am not sure about WSIB - I don't really know ... I have a good insurance plan. I never gave it a thought ... I am not sure what I would do if [I] were too injured [to work]. If I were too injured [to work] I would have to rely [financially] on my teenage son ... boy I would be in trouble! Yep, yep, it would be tough!

(Ontario interview \# f7, summer 2001) 
This lack of understanding of the role of WSIB is an important point to emphasize, since unreported work related injuries should be understood as missed opportunities. Moreover, given that the funding of the system relies on experience rating, in both policy regimes, it is necessary for central agencies to have a good sense of the data on injury rates. Indeed, WSIB reported injuries allow for the gathering of statistical information with regards to the frequency that a certain injury occurs within a given workplace or industry. This is different from the gathering of specific information about an individual for the purpose of allowing a compensation claim to go forward - or not. Whereas the former allows for the aggregate textual information of a specific injury, so that we can perhaps discern a trend, the latter allows for the specific textual information on an individual for the purpose of allowing or denying an application for workers compensation benefits or other forms of income replacement or associated supports. Indeed, one can report a workplace injury to the WSIB without the expectation of claiming benefits, with the aim of simply starting "a paper trail" (Ontario interview \# 7 , summer 2001) of the injury. Thus when the ability to claim insurance benefits is seen as the alternative to WSIB instead of in addition to WSIB, valuable data gets lost. How else can one determine the gravity of a situation in terms of workplace injuries?

However, as is pointed out by Shannon and Lowe (2002: 468), in some cases there is "management pressure to avoid recording injuries," since it may adversely affect employers. This was a concern that was raised earlier by T. Ison (1988) who argued that experience rating would lead to the under reporting of workplace injuries. We should also not forget that not all establishments offer employer supported long or short-term disability programs, nor are all workplaces in Ontario covered by collective agreements. 
For example, one respondent in Ontario (Ontario interview \# f2, summer 2001) had to be convinced by her union representative to pursue a WSIB claim since her injury was work-related, otherwise she would not have pursued it. Thus, at the other end of the spectrum you have the situation where an injured employee would not consider reporting an injury to the WSIB and would keep on working, since they may fear reprisal by the employer if they opted to file for compensation. This then undermines the very notion of the historic compromise (giving up the right to sue the employer in return for a guaranteed income upon a work-related injury) the central tenet of the workers' compensation system in Ontario. Of course by not reporting an injury, as was done by one participant, they risk further injuring themselves (Ontario interview \# m8, summer, 2001). Shannon and Lowe (2002: 468) also mention that injured workers who do not report their injury to workers' compensation boards hold the "belief that pain is a normal consequence of work and ageing". I found this to be true in my previous study (van Veldhoven, 1996) where the data showed that the practice of gathering standardized data normalized the worker's injury and as a consequence the injury came to be understood as 'being part of the job' and hence there was really no reason to report the injury to WSIB.

Based on these interviews I realize that in Ontario there is a mix of policies that incorporate both market and state run worker injury programs for employees, though the state run program remains one that relies on showing the work-relatedness of an injury. Whereas in the Netherlands the disability programs for employees is essentially state supported and still does not rely on showing the work-relatedness of an injury.

However, one unanticipated finding was the fact that in both jurisdictions the employer plays an important and vital role in terms of accessing workers' compensation 
benefits. In Ontario an employer can contest the injury, which as Lippel (2003) has shown, has an impact on whether the claim is denied or accepted by compensation boards ${ }^{35}$. In the Netherlands the injured worker has the advantage that their job is more or less guaranteed for two years, after the reported disability. However, after two years employers are in the position to relieve the individual with a disability or sick individual of their duties. This is of no great comfort to those who are injured and have to rely on their job for future financial security, especially if the worker is nearing retirement age. In this regard, it is more a delaying of the inevitable; a possible job loss, as was expressed by one of the Dutch participants (Dutch interview \# m8, summer 2000) noted earlier. Resistance by the employer in accommodating injured workers within the workplace can be seen as inadvertently contributing to increasing the likelihood of injuring the worker further. This was true for both policy regimes. In the case of the Ontario participants in the study group preferred not to involve the employer regardless of the fact that they had no intention of making a workers' compensation claim. Indeed when workplace adjustments had to be made nothing was done (Ontario interview \# m8, summer 2001) or the workers tended to make such change themselves:

Nobody from the organization came to check my workstation - everything I did, ... I did myself. I was not aware that I could get assistance through the employer. (Ontario interview \# $\mathrm{m} 9$, summer 2001)

While in the Netherlands, this sort of support was usually addressed without question:

... When I first reported my RSI symptoms [to my employer], they gave me more or less carte blanche to adjust everything in my workstation-[I got]- another chair,

\footnotetext{
${ }^{35}$ Insurance companies in Ontario can also contest an injury for which they are providing benefits.
} 
another desk, another mouse and so forth.

(Dutch interview \# m9, summer 2000)

But not necessarily all the time:

[My employer] kept promising me new furniture, $\ldots$ but it was not happening ... then my trade union sent a couple of letters [to my employer]. I had turned to my trade union [for help and] to make sure that I would not get fired ... I wanted to get my original job back.

(Dutch interview \# m8, summer, 2000)

It appears from these interviews that employers in the Netherlands are somewhat more benevolent when we compare the Netherlands with Ontario. However, the experiences of respondents do not differ too significantly in terms of worrying about losing their employment, facing disbelief within the medical community, wanting an answer to their condition or having to deal with uncooperative employers.

In Ontario, which is classified as a liberal social policy regime, it is not too surprising to find a heavier reliance on the private market for social provision in the case of worker-injury. Though a comprehensive state-supported worker injury program is available to workers who get injured, for most of the Ontario participants this was not seen as a viable option. Individuals noted that they would not need to go on WSIB, since their employer offers long-term disability. These workers did not recognize or understand the need for a central data-gathering agency, so the state can monitor overall injury rates within a given industry. By employers offering their employees' alternative options to workers' compensation such as long-term disability insurance benefits, they undermine the state's very ability to assess injury rates within their specific manufacturing sector - a central feature of experience rating, which funds the workers' compensation system in both policy regimes. 


\section{Is It An Issue of Class?}

In the case of the Netherlands, most of the participants in the study group did not have an additional income maintenance option such as private insurance or employer provided insurance plans. Of the three participants who were employers themselves, two were privately covered while the third did not think it necessary to have coverage in the event she could not work any longer, as she explained: "I do not have a special insurance ... I don't need it" (Dutch interview \# f12, summer 2000) - even though the Ziektewet provision or the WAO do not cover employers as noted by Dutch participants (see also Ministerie van Social Zaken en Werkgelegenheid, 2004). However, in Ontario those who are self employed must purchase their own private workers' compensation coverage. Ontario self-employed individuals may do so through the workers' compensation board (WSIB, 2005) or they may turn to privately run insurance companies. Regardless, in both policy regimes self-employed individuals must rely on market forces for worker injury coverage. That being said, none of the Ontario participants in the study group fell into the category of the self-employed. However, several of the Ontario participants in the study group did have access to an alternative form of privately run worker injury protection plans in addition to workers' compensation. Apart from the previously mentioned self-employed injured workers, none of the other Dutch participants had additional insurance coverage and therefore they were solely reliant on state run worker injury policies such as workers' compensation programs. This then raises the question of whether this might be an issue of social class as well as an issue of how these two different policy regimes operate. 
There are a number of ways in which we can conceptualize social class. For instance, possible indicators of social class are one's level of education, level of income and/or occupational status and prestige. A more classic conceptualization is considering an individual's command of capital and/or the labour power of others. In this view, those who are small business owners and thus are self employed either belong to the old middle or to the capitalist executive class (cf. Clement and Miles, 1994:16). Therefore, such persons can be considered to be in a position to purchase their own protection in the form of some kind of insurance in the event they experience a personal work interruption. This issue is relatively uncomplicated in the case of the Netherlands, where the middle and upper classes rely on private health care, while the working class relies on state sponsored programs (cf. van der Velden, 1996). This appeared to be clearly the case in the Dutch study group, where most of the participants, worked for or were employed by someone, and as such did not have the option of additional employer based access to alternative insurance programs or coverage. Their policy regime, in this respect, provides for comprehensive and adequate protection against work interruption in the case of injury or illness. However, the issue of social class, in the case of Ontario is more complicated and nuanced.

As noted, none of the Ontario participants were self employed or small business owners. In other words, all of the Ontario participants were working for or were employed by someone other than herself or himself. That being said, some of the Ontario participants were either members of faculty or were members of staff at an Ontario post secondary institution. Others worked as administrators, clerks, or were service advisors, some were in management positions while others were not. On the whole, most of the 
Ontario participants in the study group had access to an alternative source of income maintenance and associated necessary benefits in addition to being covered by workers' compensation, should they experience a work interruption attributable to injury. Additional insurance is necessary in the case of Ontario since an injury has to be specifically work-related in order to qualify for workers compensation benefits. If an injury occurs outside of work, and thus not work-related, the injured worker can then turn to their market-based insurance plan, which is usually offered through the employer. This scenario is true for the entire Ontario study group.

It is not clear whether the option of long-term disability insurance versus the option of workers' compensation is necessarily an issue of social class in Ontario, unlike in the Netherlands. It is certainly the case that workers who are covered by private longterm disability insurance are likely to be from the middle and upper classes. Yet, it is not necessarily the case that those from the middle and upper classes would avoid using WSIB. This is because not all market based long-term or short-term disability plans offered by and through the employer have extensive coverage for the various often necessary curative therapies for RSI sufferers.

The case of Kuelke (2003), an academic in Southern Ontario is just one such example. In this particular case and by extension that of the other faculty members of the university, the supplementary insurance plan was not adequate to cover the treatment of the RSI condition. Kuelke (2003: 395) notes that "before long, I had a doctor's note in my university personnel files that advised no further keyboarding, and I was on workers' compensation to cover the costs of weekly physical therapy". This to me indicates that despite her privileged position based on her status as an academic and a scholar employed 
by the University, and despite the fact that she also had access to an alternative worker injury plan, Kuelke still found it necessary to report her injuries to the workers' compensation board so as to obtain adequate treatment.

Thus the option of long-term disability versus workers' compensation is not necessarily just about money, other factors play an important role in making this decision. However, it is my sense that generally workers compensation is understood as solely an income replacement venue for workers who have a work-related injury in Ontario. Therefore, making a workers' compensation claim or reporting the injury to WSIB was generally not considered a route the participants in Ontario opted to take, regardless of their class position within society. Thus, for clerks and academic scholars alike the preferred action taken by the Ontario participants was to turn to the 'for profit' market based supplementary long-term disability insurance coverage rather than to turn to the state supported workers' compensation plan.

\section{Conclusion}

Keeping in mind that the respective workers' compensation systems in both policy regimes cover curative therapies and treatments, such as physical or occupational therapy, which are usually necessary treatments in the case of RSI, it is surprising to me that the in most cases the Ontario participants would opt to take the supplementary longterm-disability route. In the Netherlands, like in Ontario, self-employed individuals ${ }^{36}$ are not covered by state sponsored worker-injury policies such as workers' compensation

\footnotetext{
${ }^{36}$ I understand those who own their own business with just a few employees to be selfemployed.
} 
programs. These individuals, as in Ontario, must turn to the market to purchase social provision protection. For self-employed individuals in either policy regime, in the event of injury and illness there are no options available to them. As a result they must purchase their own insurance plans if they want coverage. However, often times, selfemployed individuals do not have the financial resources to purchase such insurance coverage, which places them in a very precarious situation - especially when there are dependents involved. Nevertheless, self-employed individuals are often considered to be in a relatively privileged class position, since - as a self-employed individual - they belong to the old middle class. However, this relative location in society is not doing them any favours, for their relative privileged status cannot supply them with the proper protection in the case of work interruption attributable to illness or injury, such as from RSI.

In the context of this particular research project, in the case of the Dutch participants the class distinction seems more clearly delineated than in the case of the Ontario participants, where it does not seem to matter what the occupational background is in terms of opting to make a workers' compensation claim - or not - by the participants in the study group. Indeed, research performed by Shannon and Lowe (2002: 472) has shown that "occupation and submission of a claim [to workers' compensation] were not significantly associated". In all but a few cases participants expressed their intention that they would never need to turn to workers' compensation since they also had access to long-term disability (for instance Ontario interviews, \# m9, \# f4; \# f5). Moreover, in another case, an Ontario participant had initially wanted to make a claim on her disability plan, but her union representative convinced her to claim workers' 
compensation instead (Ontario interview, \# f2, summer 2001). In other words, by the mere fact that employers offer such supplementary programs to their workers, regardless of occupational status, they undermine the surveillance practices of the state.

Having the option to apply to supplementary insurance programs, participants in Ontario indicated that they would prefer to make a claim on long-term disability and bypass the workers' compensation system. This then leads to the under-reporting of workrelated injuries and illness in general and RSI in particular, thereby making it impossible for the state to accurately monitor such injury/illness rates. This also undermines the funding of the system and shifts the cost of various treatments from employers, where it is supposed to belong, to the universal public health care system, which is funded by taxpayers. 


\section{Chapter 8 \\ Social Policy Regimes and RSI}

\section{Introduction:}

This dissertation research developed out of a number of areas including, my Master of Arts thesis research, a long-standing interest in Occupational Health and Safety issues, and my fascination with the differing social policies that address related and/or similar concerns among nations. I am particularly interested in the de-commodifying aspects of the welfare state, especially in the context of work-injury programs such as workers' compensation systems - which in both jurisdictions examined in this dissertation required labour market attachment to qualify for compensation. An important concept in comparative social policy regime analysis is that of social citizenship and its associated social rights. Assessing the level of de-commodification and whether it is relatively easy to achieve social citizenship rights within welfare states, allows analysts to evaluate the effectiveness of particular social policies and by extension social policy regimes.

Comparative social policy regime theorists, however, tend to study manifest social policy differences at the structural or aggregate level. Such an analysis excludes the experiences of individuals who have the option of engaging in the process of claimsmaking activities or procedural practices when realizing their social citizenship. Thus, analyzing social policies at the structural level cannot capture the full extent to which social citizenship rights are realized at the experiential level. This inadequacy in fully understanding social policy regimes suggests that it is necessary to include experiential accounts of claims-making processes and procedural practices as they relate to the 
specific policies to fully understand when social citizenship rights are being realized - or not.

To capture the complex nature that surrounds potential differences among social policy regimes it is inadequate to rely solely on the concepts of de-commodification and/or familialization. Citizens of Ontario, for example, do not need to be commodified (have labour-market attachments) to get access to the health care system. As well some persons with a disability receive benefits but yet have never been commodified. Decommodification, therefore, is not uncomplicated. In some households we witness persons with a disability looking after family members who themselves have a disability (for instance Ontario interviews \# f1 and \# 2 , Summer 2001). This brings into question the idea of familialization or de-familialization, which refers to the idea of maximizing women's economic independence (Esping-Andersen, 1999: 45). Put another way, the state's ability to rely on 'the family' to look after injured workers, is clearly not always possible (for instance Ontario interview \# f2, Summer 2001). Thus, to better understand social policy regimes, comparative social policy theorists must go beyond the analysis of social policies at the state level, and must also consider the experiences of individuals that are socially located in the processes of claims-making activities within the context of acquiring social provision.

My dissertation uncovered that, despite the manifest differences in terms of injured worker social provision at the policy or structural level, the experiences of workers at the individual level might not be so different. Indeed, even though the two jurisdictions (the Netherlands and Ontario) approach the administration of injured worker programs very differently, my data show that in the case of computer-related repetitive 
strain injuries (RSI) the experiences at the individual level of the process of making a claim are remarkably similar between study participants in the Netherlands and study participants in Ontario - especially when they opt to make a workers' compensation claim and hence need to enter into the site of the ruling relations with members of the medical profession who regulate the plan - the medical gatekeepers. The manner in which medical experts approached their patients did not differ between those who worked for WSIB/WAO or those physicians who worked for private insurance companies (for instance Dutch interview \# m4 or Ontario interview \# f2, Summer 2001).

Early social policy regime analysis overlooked the fact that social policies aimed at decommodifying workers tended to favour male workers over female workers, in that women are more likely to be faced with the additional burden of unpaid caring work, which is far less economically emancipating than paid work (Lewis, 1997). These analyses could not account for the fact that most women in the paid work force also belonged to the unpaid workforce. To address this omission, Esping-Andersen (1999) inserts the family as a crucial player into comparative social policy regime analyses. Social policy regimes can then be understood as clusters of 'welfare production', which consist of a triad relationship between the state, the labour market and the family (1999: 35) rather than clusters of similar social policy approaches to a set of social provisions.

The growing body of literature addressing gender related concerns within the comparative social policy debate (O'Connor, 1998; O’Connor et al., 1999; Lister, 1997; and Lewis, 1992, 1997, among others), underscores the contention that early comparative social policy analysts (for instance Esping-Andersen, 1990; 1999), neglected to analyse how gender relations influence social policies and conversely how these 
policies influence gender relations (O'Connor, 1993; Orloff, 1993, 1996; Mink, 1998; O'Connor et al., 1999). This criticism also encompasses a neglect of the power-relations that women must face and experience within social institutions, which highlights the unequal citizenship rights women experience within welfare state systems. Indeed, all social institutions are sites of gender relations or gender struggles, and as such welfare states are inherently gendered (Porter, 2003).

Feminist writers in addition to pointing out that welfare states are gendered also argue that 'bodies' are gendered. A similar line of argument is observed regarding the issue of disability where there is a growing recognition that the "body is infused with 'able bodied' notions" (Barnes et al, 1999: 65) in such a way that the disabled body is made invisible. Moreover, Oliver (1996) makes the argument that within comparative regime analyses, persons with a disability have no claim to social citizenship rights on account of impairment. However, unlike gender related issues, disability concerns are largely overlooked within comparative social policy regime research. This dissertation to some extent addresses this void.

Barnes et al (1999: 54-55) note that there is an increasing overlap between chronic illness and impairment. That is, in the latter part of the twentieth century, the majority of reported cases of impairment or disability are linked to chronic pain. It is at this point that I make the connection between RSI and disability. As was evident from the data in terms of this study group and other studies, RSI is both a chronic condition and extremely painful for many of its sufferers. Indeed, depending on the level of advancement of their condition, RSI sufferers may experience an inability to maintain labour market ties (van Veldhoven, 1996; Kome, 1998; among others), as was witnessed 
for both Dutch and Ontario participants(for instance Dutch interviews \# f2 and \# f7; Ontario interviews \# $\mathrm{f} 2$ and \# f13). Since the participants in this dissertation were at various stages of their impairment, they also had varying disabilities.

Like many other communities, the disability community is not homogeneous and is composed of many different individuals with various levels of disability as well as a variety of disabilities (for instance, Oliver, 1996; Fawcett, 1996). Nonetheless, RSI sufferers fall well within the domain of the disability community. It is safe to say that a worker with a disability/injury within a set of social relations, either the household or the workplace, faces a number of challenges over and above those of persons who do not have injuries that are disabling (Oliver, 1996, among others). If that person is female in addition to having a disability/injury, she faces additional disadvantages (cf. Doe and Kimpson, 1999). Moreover there are economic consequences to such circumstances. A number of studies show a connection between ill health and/or impairment and industrial diseases and/or injuries with a disproportionate number of impaired persons or persons with a disability falling below national poverty lines (Barnes et al, 1999; Doe and Kimpson, 1999; Fawcett, 1996; 2000; Messing, 1991; 1994; 1995; Doyal, 1979 among others). As with many persons with a disability, RSI sufferers too face the prospect of living in poverty in addition to a host of many other challenges that they must address from day to day.

When people become injured or disabled they often can no longer do their work; in fact, many injured people live alone (For instance Dutch interviews \# f2, and \# f13, among others). Unlike gender relations, however, disability relations are not being considered in the literature and hence persons with a disability remain invisible from 
welfare state analysis. Persons with a disability for the most part, receive benefits through or from the state in some form or another (Fawcett, 1996; Oliver, 1996; Morris, 1996). It is for exactly this reason that persons with a disability should be incorporated in welfare state policy analysis. They too are members of society and how they experience the triad relationship between the state, the labour market and the family, which is the 'welfare production' (Esping-Andersen, 1999), needs to be made visible. Just as women are consumers and producers of the welfare state (e.g. Mink, 1998), so too are persons with a disability (Fawcett, 1996; Morris, 1996, Oliver, 1996).

Some social policy theorists have contended that an analysis based on decommodification and social citizenship rights, is uni-dimensional and somewhat problematic. It only accords paid work any valuation, while unpaid work is not given any role or recognition within the formation of policy regimes. Solely focusing on these concepts at the structural level downplays the very complex nature of any one welfare state and overlooks the many dimensions that play a role within policy formations. For instance, Siaroff (1994) identifies four alternative regime clusters based on female work desirability, the religious orientation of a society and family welfare orientation. Janoski (1998: 6) argues that we need to go beyond the use of the working classes battle with capitalism as the motive force of explaining citizenship rights, since it cannot effectively account for gender, race and ethnicity issues. Indeed Janoski (1998: 217 - 224) posits a regime type based on four citizenship rights (legal, political, social and participation rights) as opposed to just one (social rights). These rights are instituted against an equilibrium of rights and obligations both at the micro and macro levels of society. Olsen (1998) suggests that there is a definite need for a more inclusive analysis in comparative 
welfare state research. Arts and Gelissen (2001) contend that we also need to insert the notion of 'solidarity' into the debate to get a better understanding of how the different social policy regimes cluster around the administration of social citizenship rights. Such changes would certainly lead to a need to examine disability issues in comparative social policy regimes. RSI sufferers, as disabled persons, are affected by the triad intersection of the state, market and family in terms of welfare production. This dissertation adds to the debate by inserting the experiential accounts of individuals who live through the procedural practices of realizing social citizenship rights within the context of worker injury policies and RSI, and within their respective social policy regimes.

\section{Laying Claim on The Sick Role and Domestic Chores: Where Is The State In All of This?}

The previous chapters compared the two jurisdictions studied in this dissertation in terms of specific issues separately. Here I draw the data together and consider both men and women while placing the conclusions within the broader domain of the social policy regime debate and the context of the triad intersection of state, market and family as well as the claims-making activities of the different players. Race and gender issues notwithstanding, my dissertation incorporates disability relations within the social policy regime debate from the individual's perspective. In other words, this dissertation aims to reflect the experiences of these injured and/or disabled workers who tell their own story. It examines how the participants in this dissertation suffering from a computer related RSI come to understand their particular policy regime in terms of their attempt to get their condition legitimated. This process is important to those who suffer an injury, 
especially when their injury is invisible such as with RSI. Invisible injuries are often questioned and hence their legitimacy is cast in doubt. When others stigmatize an illness as questionable, the injured worker's access to the sickrole could be treated as illegitimate, and as a consequence the rights and privileges they might find in the sickrole could be undermined and/or not granted (Nettleton 1995).

Injuries caused by consistent repetitive motion fall under the rubric of Repetitive Strain Injury (RSI). Because of its debilitating properties and its workplace connection, RSI is classified as an occupational health and safety issue (see van Veldhoven, 1996) as well as a disability issue. Within the context of the previous section on regime analysis, the Netherlands and Ontario represent two different social policy clusters (cf. EspingAndersen, 1990; 1999). In either jurisdiction the recognition of a workplace injury as legitimate and thus visible, is necessary and crucial in terms of entitlement to compensation. To qualify for workers' compensation in Ontario the 'cause' of the injury is relevant. In this jurisdiction a disability needs to be specifically workplace related before the injured/disabled worker is entitled to benefits (Piva, 1975; Elgie, 1989). In the Netherlands the 'consequence' of the injury is what matters and the injury does not have to be work-related in order to qualify for compensation (cf. Cox, 1993; Aarts et al., 1996). What is important in the Netherlands is that the injured person is employed at the time of injury. Thus, the Netherlands has adopted a broader view of entitlement based on the principle of 'social risk' rather than 'occupational risk', while Ontario based its compensation entitlements on the principle of 'occupational risk', more commonly found in workers' compensation insurance programs in Western industrialized jurisdictions (Cox, 1993). Yet, in each jurisdiction, medical experts are responsible for determining 
levels of disability and subsequent eligibility to benefits (cf. Cox, 1993; Schrijvers, 1991; van Veldhoven, 1996; Doe and Kimpson, 1999).

In the case of Ontario, 'medical gatekeepers' are used primarily to determine whether the injury is work-related, not to deny whether the injury actually exists. The injured workers are initially screened by the family physician and the actual gatekeeping function is performed by the regulatory physicians who are employed by the workers' safety and insurance board (WSIB). In the Netherlands, the 'gatekeepers' are either occupational health and safety physicians employed by the state (the Arbo Dienst) or insurance doctors employed by het GAK or CADANS, which are the Ontario WSIB equivalents. These physicians determine whether the injury actually exists and whether the claim to having an injury is compelling, but the cause of the injury is not in question. Here the physicians play an active role in the regulatory process in that they need to objectify and categorize the disability within the definitional boundaries that reflect the institutional concerns, which have been determined by the extra-local or policy makers. Company physicians, though not the final arbiters regarding workers' compensation claims, also play a role within this regard. This 'gate-keeping' function allows for either a speedy or a delayed entry into the respective workers' compensation systems - if an entry is allowed at all. Within this context, family physicians, in either jurisdiction, do not play any role in determining eligibility for benefits.

The ability of doctors to define the health and illness of patients prioritizes the specialized knowledge of the medical institution while subordinating the knowledge and lived experience of the patient or lay knowledge (for instance, Nettleton, 1995). When injured people enter into relations of ruling, their experiences are translated into 
objectified cases as determined by those who work within the existing ruling organizational structures, and are interpreted within the multiple discourses that intersect in the specific institution. The experiences of RSI sufferers, however, do not originate only out of their clinical encounters with their respective medical experts, but also out of the way in which the ruling relations organize the every day lived worlds of the relevant actors (such as, the various medical experts, the compensation bureaucrats, the employers, family members, insurance adjudicators as well as the injured workers among many others).

At issue are the constructed realities of privileged experts vis-à-vis the lived realities of (injured) individuals. That is, how 'claims-making activities' by members of the medical profession as agents for the state or the 'extra local,' construct the realities of the 'local' or RSI sufferers in this case. The gathering of the data by the different medical experts serves to create standardized knowledge. This standardized and normalized form of organization of social relations is mediated through text (cf. D. Smith, 1987; 1990; 1999). As such, I understand social policy to be the mediator of social relations between the local (RSI sufferers) and extra-local (policy makers).

The intent of policy is reflected in the extra-local institutional categorizations, which are composed by ruling relations and is revealed in the text of the policy (Campbell and Gregor, 2002). My dissertation analysis encompasses both the Ontario (WSIB) and the Dutch workers' compensation benefits systems (WAO). However, in the case of the Netherlands, the notion of 'disability from an occupational risk' has been expanded to the 'notion of disability as a social risk'. That is, the injured worker should still be able to maintain their economic independence while they have a disability. This 
objective of the Dutch policy is reflected in the ability of injured workers to access the Ziektewet provision with minimal medical or institutional gaze, for up to one year, without fear of losing their means of income and wages (for instance Dutch interviews, \# $\mathrm{ml}$; \# $\mathrm{m6}$; \# f7, among others). Within this context I consider the Netherlands to be relatively social democratic in its organization of injured workers' social provision, in that it allows full de-commodification for a limited time period for those who have had labour market attachments.

This experience is in stark contrast to the experiences of the Ontario dissertation group who were more likely to turn to market-based private insurance plans rather than the option of making a claim on the state (for instance Ontario interviews \# $\mathrm{f} 4$; \# $\mathrm{m} 9$; \# f11, Summer 2001; among others). Yet I maintain that differences at the policy level in terms of the two different policy regimes disappeared at the individual level. Indeed, once the Dutch injured workers were faced with having to continue their convalescence after their Ziektewet provision had expired, which is often the case in chronic conditions, they needed to turn to workers' compensation benefits. It is at this point that the differences between the two divergent jurisdictions tend to fall away, when considering the experiential accounts of the injured workers in the two study groups.

At this intersection injured workers engage in claims-making activities. They need medical validation before they are able to take the next step into the claims-making journey for income maintenance, while unable to participate in paid work. The simple fact that they feel it necessary to enter into a medical encounter is a claims-making activity in and of itself, since this claims-making activity seeks recognition of the sickrole. If injured workers are accorded the sickrole, - that is they receive validation of 
their claim - they are then excused from particular social duties (Glenton, 2003; Barnes et al, 1999) such as being excused from labour market participation and are given permission to convalesce.

This can be troublesome from a gendered perspective, given that women are likely to continue their unpaid labour duties within their homes, despite their injuries (cf. Gannagé, 1989; Tierny et al, 1990). Help from friends and family members notwithstanding, for these women attaining the sick role may excuse them from participation in paid labour, however, not necessarily from domestic labour. Indeed, the many domestic chores that needed doing within the home frequently remained tasks, which the female respondents of both study groups continued to need to perform. Any of the household chores too painful for them to do and therefore completed by partners and/or other family members were seen in terms of "I had my husband and my kids help me [out]" (Ontario interview \# 4, Summer 2001). Such actions are viewed as "helping out' with household routines rather than an expected everyday accepted shared responsibility. As well, any household chores performed by partners were seen as a 'temporary' solution rather than the 'status quo':

... my partner is very supportive. At first I did all of my own household duties. Now my partner does all of the heavy household chores - for the time being ... I do not accept that this is a permanent situation.

(Dutch interview \# f10)

These findings are in keeping with the findings of previous research for my MA thesis in Southern Ontario (van Veldhoven, 1996).

However, in terms of the male respondents who participated in this study, there was a notable difference in terms of their attitude towards doing household chores. The 
Ontario men felt less compelled to participate in household chores and did not verbalize any feelings of guilt when it was too painful for them; it simply was not an issue. This is not the case in the Netherlands. One Dutch male respondent was rather despondent when he was unable to contribute to household chores, his wife was pregnant at the time and he felt very ashamed when he had to rely on his friends for help with arranging their furniture after a move (Dutch interview \# $\mathrm{ml}$ ). Some of the Dutch men actually lamented the fact that they were not accorded the sympathy they were looking for from their spouses. In fact, the Dutch injured male partners were for the most part still expected to keep up with their agreed upon domestic responsibilities:

At first things went very well at home. [My partner] would be very sympathetic. She would say 'well if you have pain take it easy for a while'. But at a certain moment, after a couple of weeks, my partner ended up doing all of the household chores by her self ... of course - and she was fed up - she began by saying once in a while - hey you do something! [She felt that], I should be better by now... Yes it is difficult to understand what [RSI] actually is and I could not explain it to her.

(Dutch interview \# m9)

Another Dutch male respondent, who was at home under the Ziektewet provision, was expected to accept all the responsibility for the domestic chores while his wife continued with the house renovations (Dutch interview \# m8). In contrast, the Ontario men tended to express their concern in terms of their inability to cut the grass or participate in a sport when asked how the injury affected their home life:

The injury does not really affect my home/personal life greatly. I might wait with cutting the grass ... There are some limits that I do - I might not play baseball ... It bothers me in that I wish I could do something ... but I can't only because I don't want to further injure myself ... 
it bothers me a little. Sometimes the pain keeps me awake at night! My wife encourages me to go to the massage therapist - we do not discuss it too much.

(Ontario interview \# m8, Summer 2001)

In other words, my data indicated that for those suffering from this particular and invisible workplace injury, there are differences between the genders and also within genders regarding perceived gender roles when it comes to participating in domestic chores across the jurisdictions. Moreover, in both of these jurisdictions the injured workers in this study had very limited access to state funded household support. Only one person in both study groups was able to obtain state supported household help. This was in the Netherlands and the participating person had to fight for it (Dutch interview \# f2). That is, in terms of these experiential accounts, the state played a very limited role when it came to providing much needed household support for injured workers in either social policy regime - despite the differences at the policy level. Indeed, in both jurisdictions, these injured workers had to rely on family members, friends or neighbours to help them out with the various domestic duties and or chores. However in terms of relying on family and friends for economic support, this did not seem to be the case.

The next section considers the 'claims' and 'counter claims' made by the various players such as injured workers, the state, members of the medical profession, or the bureaucrats of the workers' compensation systems from the perspective of the individual. That is, the injured workers experiences of the various claims and counter claims made by members of the medical profession when they opted to report their injury to the various workers' compensation systems either to pursue a workers' compensation claim or simply to report their injury as a workplace health and safety concern in either jurisdiction. 


\section{Resistance and Compliance - Striving for The Sick Role and The State}

Medical gatekeepers screen injured workers who turn to the state for economic and social provision such as workers' compensation. Indeed, injured workers need validation from members of the medical profession who tend to represent the perspective of the ruling relations (cf. D. Smith 1987, 1990, 1999; Campbell and Gregor, 2002), before they are allowed entry into the system. As such, medicine is understood as a significant part of the ruling apparatus. Unfortunately, as Nettleton (1995) points out, the ruling apparatus is not without prejudice since medical knowledge is mediated by the social and political circumstances of the time in which physicians practice. Moreover, this places physicians in a very powerful position. They are able to legitimate what counts as disease, illness and/or injury, as well as create the very possibility of them while marginalizing or silencing the claims making activities of injured individuals (Nettleton: 18-19). This in turn serves to maintain established social orders (see for example: Waitzkin and Britt, 1989).

However, my research for this dissertation shows that not all individuals are easily marginalized or depoliticised by the claims-making activities of the elite, that is, from the perspective of the dominant discourses. In other words, these individuals are not easily silenced by the gate-keeping functions of the 'experts' steeped in the dominant discourses of health and medicine - or the 'extra local' (cf. Smith, 1999). Rather, some participants in this dissertation research became the authors of their own claims-making activities from a depoliticised position; they took part in making counter claims from the margins (cf. L. Miller, 1993). Indeed, these injured individuals found ways to make their 
concerns heard and hence make their concerns visible through finding alternate routes or outside sources where they could participate in 'claims-making activities' of their own.

I refer to issues of resistance as 'lived experiences' by injured workers who do not get validation from experts (particularly those in gate-keeping functions). By this I mean the lived experiences of some of the members of each dissertation study group in both jurisdictions. All of the individuals in this dissertation suffer from RSI related problems (and have self-identified themselves as such) and all had been diagnosed with some form of RSI or RSI related 'medical problem' by a member of the medical elite at some point outside of their interaction with representatives of the respective workers' compensation systems. When some of these individuals entered into the relations of ruling in terms of gatekeeping encounters, they experienced varying views and ideas from different doctors, but with the same end result - a denial of benefits - which these individuals then resisted in some form or another.

Though a large body of literature exists within political economy regarding issues of power relations and resistance, it tends to explain it from the perspective of oppression by dominant groups. To my knowledge little has been written about the 'lived' experiences of the marginalized actors who resist the claims made by the 'extra-local' or ruling relations from the perspective of the depoliticised actor. For example, a political economic perspective does not satisfactorily explain why in some instances physicians accept the claims of their patients' lived experience(s), that is, of pain and disability, while in other cases, members of the medical profession dismiss such claims out of hand. Clearly, in either case, the physician is a member of the medical elite who is informed by the many intersecting discourses that inform their medical gaze. Yet, why is it that one 
medical practitioner follows an orthodox branch of exercising medicine, while another chooses to follow a more holistic form of practising medicine by giving their patients voice and validation?

Best (2001: 9) points out that any claim being made about a condition is essentially an argument which contains four elements: 1) that it exists; 2) it is problematic; 3) it holds particular characteristics, and; 4) that some sort of action should be taken to deal with it. Indeed, Best (2001) observes that claims making activities necessitate actors to make claims about certain characteristics that they perceive are present in a problem - which refers to point number three. He also notes that such a problem "... may attract diverse claims-makers who, while generally allied about the concerns about the problem, disagree about the details of these characteristics" (2001: 9). Indeed, claims can point to multiple characteristics, which are sometimes contradictory. However, it must be accepted that a condition exists and that the condition is essentially problematic. As long as that is agreed upon, it is possible that actors can "pick and choose among the available characteristics presented in various claims, adopting some and ignoring others" (Best, 2001: 8-9).

It is entirely possible, for instance, that in some cases physicians may agree that a medical condition such as RSI exists, but not agree on some of the characteristics of the condition. By the same token, they may choose to adopt the claims being made by injured workers about their experiences with RSI. While other doctors may dismiss out of hand the fact that injured workers are knowers of their lived experiences and thus ignore their claims about 'pain', 'numbness', 'inability to raise hands above shoulders' and the like. It must be disheartening from the perspective of an injured worker, when 
they run into such inconsistencies during clinical encounters. On the one hand, an injured worker may experience opposition from medical professionals during clinical visits, while on the other hand there may be no such resistance from medical experts regarding their claims. Regardless, we are still dealing with power differentials. The injured worker is not the one who gets to validate their own condition and is often marginalized or depoliticised and in a less advantaged power situation.

It is my sense then that we need to address the multiplicity of power relations that transpire at the micro sites during clinical encounters. In order to attempt to make sense of this, I am borrowing some ideas put forth from a Social Constructionist Approach. Specifically, I wish to integrate 'claims-making activities' by marginalized groups, which L. Miller (1993: 155) refers to as "claims-making from the underside", into a broader political economic perspective. My aim is to analyze the power relations between the 'knowing' experts of RSI - the medical specialists and the experiential accounts of the RSI sufferers - as negotiated by the injured workers or the local. Within this context, clinical encounters are understood as sites of intersecting discourses where power relations are negotiated that are 'lived' realities as negotiated in text or talk (cf. Smith, 1987; 1999; L. Miller, 1993). The implication of this is that "different communities of speakers will have different ways of making claims, and some of these ways will be less visible than others" (Miller, 1993: 154). Within this regard we are looking at physician/patient relationships, where differing views regarding a person's condition (healthy or not healthy/injured or not injured) are negotiated processes between two or more 'knowing' experts, such as the physician and the patient or injured worker. The worker attempts to obtain validation for their condition and thereby achieve the rights and 
privileges of the sick role and as such make their claims visible.

These relationships and/or negotiations are constrained and/or determined by the dominant ideologies of capitalism. As well, as noted earlier, the state employs 'gatekeepers' who participate in claims making activities to discredit (i.e. make invisible) the claims made by marginalized groups (in this case, the injured workers, or RSI sufferers) in order to limit the number of compensation benefits to be paid out (Dutch interviews \# $\mathrm{f}$; \# f7; and \# $\mathrm{m} 8$; Ontario interview \# f13). Indeed, the president of the RSI association in the Netherlands notes that health and safety insurance doctors were "... ordered by the state to allow as few [injured workers] as possible into the WAO" (Dutch interview \# f7). This participant, recounting a recent news story, claimed that the Dutch state used the media to make claims of their own to support their contentious position, by releasing stories about how the "WAO numbers are rising...again" (Dutch interview \# $\mathrm{f} 7$ emphasis added by participant). Such tactics can be viewed as laying the foundation for restructuring debates on policy matters that will allow gatekeepers to keep a larger number of injured workers out of the WAO system.

Gatekeepers' functions fulfill different roles in the claims making activities surrounding RSI. But in essence, the State is regulating the body-social through these gate-keeping tasks, which are performed by medical doctors. Yet, injured workers, who are marginalized by the medical experts' constructed realities of them, make counter claims to have their concerns made visible or heard and to counter their marginalization or depoliticization (Dutch interview \# $\mathrm{f} 2$ and \# 7 ; Ontario interview \# 2 , \# f11 and \# f13; Miller, 1993). In other words, these workers resist the state's attempt - the extra local - to regulate them outside of their social safety net by not accepting the verdicts of 
physicians (that is, agents for the extra local) about their condition. In this case, it is the injured worker who chooses to accept or discard certain characteristics of a problem, which is understood as their attempt to reclaim power over their condition/situation. Within this context, their 'claims making activities' may involve the help of outsiders to directly confront the ruling relations when they fear that their claim for the sickrole will not be granted and hence they will not be given access to the safety net, which is constructed through a set of policies constituting a segment of a social policy regime.

\section{Making a Claim on The State: Experiential Accounts of RSI Sufferers in Two Jurisdictions}

As mentioned, in order to be deemed eligible for benefits from workers' compensation in the Netherlands - like in Ontario - it is necessary to undergo a medical exam conducted by a state employed occupational health insurance physician. This was true for both state sponsored support programs, such as workers' compensation as well as market based private insurance. However, such encounters are not always without resistance by the state. For example, in the early 1990's one of the participants ran into strong opposition from the Dutch equivalent of the workers' compensation board (het GAK which acts as an independent agent for the WAO) regarding the validation of her condition and hence her compensation benefits:

I was fighting with the whole of 'het GAK' ... about ... do I have a [medical] condition ... or don't I have a [medical] condition.

(Dutch interview \# f2)

When this participant initially ran into resistance from the attending occupational health 
and safety insurance physician, she used an educational tool - a videotape about RSI - to teach or persuade her designated regulating agent for the state or 'gatekeeper' about the injury:

... Then finally I got a doctor... [who was willing to listen] ... I showed a video [about RSI] ... there were other people there ... They wanted to [learn about] RSI ... I finally had someone ... damn it ... who believed in me. That story got into the newspapers; that het GAK was willing to recognize RSI.

(Dutch interview \# f2)

For this respondent, it at first seemed that 'het GAK', upon the recommendation of the gatekeeper physician, would validate RSI and that she would get the recognition of her medical condition she was looking for. However, the validation did not last long. The Dutch equivalent of the WSIB - het GAK - overturned the physician's conclusion and recommendation for benefits. The board (het GAK), concerned with keeping claims made on the state to a minimum (Dutch interview \# 7 , Summer 2001) removed this physician from the case:

The story got in the newspaper that 'het GAK' recognized RSI. [After that] I did not have contact with her any more ... When I wanted to phone her [I was told that] she was not in. I found out that they moved her to another office. That scared me ... they did not want to recognize RSI ... not [by] het GAK as an organization. (Dutch interview \# f2)

Her concern was that the medical gatekeepers of the WAO, as agents for the state, refused to accept that her claims of RSI as an injury were legitimate. In other words, the WAO would not accept her 'lived reality' of her condition - there was no RSI. This was quite obvious once another physician was assigned to her case: 
That [first doctor] wanted to believe me ... I [was] so happy with that lady ... finally someone who wanted to believe in me. Then I got this gentleman ... he said ... NO

... if that lady told you RSI ... [there] must have been a mistake ... I don't believe in it.

(Dutch interview \# f2)

The replacement physician dismissed out of hand the predecessor's diagnosis, subsequently delegitimized her RSI claims and felt that the participant was capable of doing work. In other words, this participant was denied any claims for workers' compensation benefits. The second physician overturned any decisions made by the previous occupational health and safety insurance physician regarding the participant's injury and her approved workers' compensation benefits:

First I was assigned an occupational health and safety physician who believed in me and after that I got one who did not believe in me ... it totally depends on who you get...

(Dutch interview \# f2)

Her concern that the WAO would not accept her claims of RSI as legitimate were being realized and the 'lived reality' of her condition was invalidated or made invisible. Subsequently, the participant decided to seek help from a third 'independent' party in an attempt to secure her right to these benefits. To retain her compensation payments, the participant made her 'lived experience' visible by making counter claims in the public media, thereby directly challenging the 'claims making activities' by the agent of the extra-local, the occupational health insurance physician.

Though the Dutch workers compensation board initially discontinued her benefits this participant did eventually succeed in having her compensation payments reinstated by invoking the help of the media who printed her story in local and national newspapers 
(Dutch interview \#2, summer, 2000). Apparently the Dutch equivalent of the workers' compensation board is concerned about public relations. Unfortunately, her experience of injury and benefit denial and the reluctance of state employed occupational health insurance physicians to accept RSI, as a legitimate injury was not an isolated incident. Another illustration of resistance by the WAO to accept RSI as legitimate demonstrates how another Dutch participant used the judicial system in order to make her 'claimsmaking activities' visible. This worker took the Dutch workers' compensation board to court when they denied her RSI injuries as a valid claim on the state for benefits:

Het GAK would not even accept the letter and diagnosis of doctor van Eijsden (well known independent Dutch RSI specialist in the Netherlands and Europe). They declared that I could ... do 40 hours of administrative work. I took them to court over this. I collected welfare until the judge made his ruling - that took one and half years. I won the court case in the end. (Dutch interview \# f7)

This participant also defied the claims made by the WAO 'gatekeeper'. However, she turned to the court system, rather than to the media, to have the decision made by the compensation board reconsidered. This was a very unusual course of events for the Netherlands where turning to the legal system is thought of as a very extreme activity and such lawsuits are not commonplace. As in the previous Dutch case, the occupational health insurance physician employed by the state dismissed the claims of RSI out of hand, despite the fact that a leading European medical specialist in the field had diagnosed the participant with this debilitating injury. The board deemed her disability to be 14 per cent - based on the claims made by the state employed occupational health physician who contested the claims made by the independent RSI expert - in essence this 
assumed that she was considered to be 86 per cent without a disability.

Such gathering of and subsequent compartmentalizing of knowledge is referred to by D. Smith (1987: 216-217) as restructuring 'every day lived experience' into hierarchical strata, a bureaucratic tactic in which the relations of ruling fragment knowledge to subvert class opposition. The workers' compensation board would not consider the claims made by a well-known independent medical expert as valid. This meant that in the eyes of the WAO the respondent was considered healthy and/or fit enough to do her job and thus did not qualify for workers' compensation benefits. Consequently she was forced to go on welfare while her case was before the courts since she could not work. Indeed, the independent expert diagnosed her condition to be considered 100 per cent instead of 14 per cent disabled. It did not end there for this participant. Indeed, when the courts finally overturned the decision by het GAK, the Dutch equivalent of the workers' compensation board insisted that she report for an evaluation every subsequent year ${ }^{37}$ :

Every year again it was a big fight with het GAK to get my injury recognized. A fight for which you have no energy ... because every day you do your best to get better ... because you wan to work, dance and play sports like everyone else; at the same time you try to accept that you have a disability. (Dutch interview \# f7)

These 'lived experiences' of RSI sufferers enduring resistance by the state, which do not allow them into the social safety net, are not isolated to just the Dutch situation.

\footnotetext{
${ }^{37}$ The relevant policy suggests that injured workers, whose injuries are validated and are approved to enter into the Dutch workers' compensation system, resubmit to a clinical gatekeeping function after five years. Thus generally benefits are granted in five-year blocks.
} 
An Ontario participant, who worked as an online reservations sales agent, invoked the help of her trade union and her family physician to counter the claims made by WSIB gatekeepers - the Ontario workers' compensation board. She had an initially successful claim for compensation, when she developed RSI like symptoms that applied to her left side of the body. But when she developed these symptoms on her right side as well, WSIB experts denied any work relatedness and cancelled her benefits all together. She notes that:

[T] hey would still acknowledge that my left arm was work related - they had no problem with that. But they would not acknowledge in any way shape or form a problem with my right arm. Not just that it was not work-related, but because they would not acknowledge that it was work related. They said that I could go back to work and work with one arm. Well whether it was work related or not, there was an injury that was preventing me from doing my job. But they did not acknowledge the work relatedness; they cut my claims off all together... period ... because in their eyes I should be able to work one handed. So, they cut me in middle and said that yes you have a problem with your left hand, but we want nothing to do with the right side of your body.

(Ontario interview \# f2, Summer 2001)

She turned to her union official, her physiotherapist and her family doctor for help. But despite the fact that:

... all my doctors ... [said that] ... I had a work related injury, ... [the] WSIB would have no part of it .... It is very discouraging ... from an employee point of view ... it makes you not want to make a [WSIB] claim and just go with your own insurance instead. The WSIB ... the smallest thing, they either jump on you or they cut you off. They don't listen.

(Ontario interview \# f2, Summer 2001)

The claims made by the state representatives were not revoked. Even though " $[\mathrm{m}] \mathrm{y}$ 
union did as much as they could ... to appeal it ... and ... [m]y doctor called their doctor, and all I know is that my doctor lost his temper because of that". Indeed, this participant had never been physically examined by any of the WSIB medical experts and her physician:

... felt that their doctor (WSIB physician) was a quack, quote unquote, because he could not figure how you can deem anything from a piece of paper without ... never even see[ing] [me].

(Ontario interview \# f2, Summer 2001)

This last remark was made with respect to the fact that, the WSIB gatekeepers in this instance relied solely on paper work that had been provided by the various actors involved in the case.

This idea of recognizing one side of the body and not the other was not unusual among members of the Ontario study group. Another participant ran into a similar problem when she turned to the WSIB for economic support (Ontario interview \# fl). However, she also encountered resistance from the WSIB to having her injury recognized. Though the board was willing to acknowledge that there was a work-related injury on one side of the body they were not willing to acknowledge that the injury on the other side was work-related. Hence, in the view of the Board she was still able to maintain her paid duties and thus she could not be granted the sickrole and subsequent benefits. This respondent also turned to her union representative to help her fight the decision of the WSIB; she too was faced with having to turn to other means of economic and social support.

The experiential accounts of these respondents are very similar, despite the fact that they originate in two very different jurisdictions in terms of regime policies. In each 
of these accounts the respondents note their anxiety regarding the denial of their claims for benefits while they are unable to participate in paid work. Moreover, faced with this concern they all turn to a third party to help them get the decision by the respective workers' compensation systems overturned. The difference between the two though is that in the case of the Netherlands the two participants were able to secure their benefits, while in the case of the Ontario participants, at the time of the interview their appeals were still under consideration. However that does not take away from the fact that the experiences of both the Dutch and Ontario respondents were similar in terms of having to fight for their right to economic and social security while they were unable to work due to their injury. Their experiential accounts reflected all of the concomitant feelings of fear, despair, anxiety, pain and insecurity that one experiences when faced with a chronic debilitating condition and an uncertain (economic) future. In other words, despite the differing approaches to workers' compensation at the policy level these participants did not live those differences at the experiential level.

Another similarity experienced by participants of this study group was the fact that their claims were adjudicated without the insurance and/or compensation physicians seeing them (the injured worker) in person. Indeed, this practise was witnessed in both jurisdictions and respondents in either jurisdiction expressed their feelings of surprise, frustration and discomfort in this regard (Ontario interviews \# f2; \# f6; Dutch interview \# $\mathrm{ml}$ ). Though the outcome of the different adjudications may vary between cases, decisions made by the respective workers' compensation boards affect the economic stability and future of these workers with a disability, and are based on knowledge that is mediated through text rather than on knowledge that is based on individual physical 
examinations by the respective medical gatekeepers. This text-mediated knowledge reflects the institutional interests of the extra local, and is gathered in a standardized and organized fashion. Indeed, in the case of these respondents, gatekeepers tended to rely on third party textual based information to guide them in their decision with regards to awarding a claim rather than their own medical gaze of the body:

But I was declared 100 per cent disabled without the fact that any [doctor] had seen me or had spoken with me.

Another medical expert of the CADANS ${ }^{38}$ simply made a decision based [on the text written] on paper. [This person] never saw me.

(Dutch interview \# ml)

While in this instance the outcome was in favour of the respondent in terms of receiving benefits, he was nevertheless not happy with this course of events and noted that "[I] never saw anyone again ... [I] found that a very bizarre situation" (Dutch interview \# $\mathrm{ml}$ ). Indeed, at that time he had hoped that he would be given a clean bill of health and resume with his paid work duties. His displeasure with this result notwithstanding, he opted not to make a counter claim and appeal the decision. The point being that in both jurisdictions medical experts representing the relations of ruling make decisions solely based on text. In other words, the experiences of these RSI sufferers tended to be textually mediated.

Such a practise points to the restructuring and fragmentation of knowledge as experienced and understood by injured workers. Within this context, Smith (1987: 217) argues that strategies of collecting fragmented data as text are used to ensure that personal troubles "... do not become the bases of political organization uncontrolled by

\footnotetext{
${ }^{38}$ Het CADANS performs a similar function as het GAK. The workers' compensation board that the injured person deals with depends on the sector she or he works in.
} 
the institutional structure of state and relations of ruling." Furthermore, in both jurisdictions respondents explained that they were aware of their respective workers' compensation systems. However, they were not entirely sure how the system worked and admitted that they did not understand it, as described by the following respondents "the system is not very transparent - I don't understand a thing of it" (Dutch interview \# m6), or:

The OHS office did give me a WSIB form to fill out - I did not fill it in. I guess I did not know a lot ... I did not understand it. She [OHS officer] had just given me this form but did not explain what it was for (Ontario interview \# f4, Summer 2001)

The experiential accounts of these injured workers show that some tended to engage in counter claims of resistance when they felt threatened and were facing marginalization by the state. Marginalization in this case, would mean that the concerns and everyday lived experiences of these workers would be made invisible and their claims disallowed. To ensure that they are not depoliticised and/or marginalized these workers participated in claims making activities to counter any claims made by the ruling relations. However, since their claims were not being acknowledged on their own, they utilized third parties by having them help make the claims of pain and insecurity by these RSI sufferers made visible. In other words, these injured workers resisted the actions of the state to delegitimize their injury. Instead they persisted in their quest for validation of their condition and the granting of the sick role, with all of its associated rights, regardless of the counter claims made by state representatives in the form of medical gatekeepers.

As well, these examples show that there is a disjuncture between the extra local 
(policy-makers) and the local (RSI sufferers). Indeed, it demonstrates that the intent of policy, to guarantee social and financial protection in terms of the day-to-day work and domestic routines, upon injury (Piva, 1975; Elgie, 1989; Cox, 1993; Aarts et al., 1996) may not follow through at the level of the individual. Furthermore, it also points to the fact that this break between the experiences of RSI sufferers and the intent of policy is evident in both jurisdictions. In either policy regime there are examples of injured workers who have to fight for their right to claim entitlement for compensation While it is important to reveal the disjuncture between the everyday lived experiences of the RSI sufferers and the intent of policy, it is also necessary to point out that 'claims making activities' play an important role in making visible the break between the local (the knowers of lived experience) and the extra local (the policy makers). Within this context, 'gatekeepers' who act as agents for the extra local allow the validation of the injury to go forward, or they contest the health knowledge of the local's everyday lived experience with RSI.

However, as demonstrated, these 'claims making activities' are not just made by members of the 'gate-keeping' community - the medical professionals. The marginalized themselves (the injured workers) actively participate in these activities, albeit from a marginalized position. Both the agents of the extra local (the policy makers) and the local (knowers of RSI) negotiate truths about the injured worker's condition, which are constructed through the 'claims-making activities' by them. These contested health knowledges are mediated through intersecting medical discourses or texts when the injured workers enter ruling relations during clinical encounters. However, to validate their own experiences, their lived experience as knowers of RSI, they need to keep their 
claims-making activities from becoming invisible. Injured workers, whose health knowledges are not initially validated, can create a visible space for their "claims-making activities' by invoking help from other forms of dominant ideologies or taking individual action, which can lead to the legitimation of their health knowledge.

\section{Why Bother: RSI Sufferers and Market-Based Income Maintenance Programs}

Not all who suffered with a RSI type condition in this study group were in a position that they could rely on the state for income maintenance or did not feel that turning to the state was an option they would follow. This was especially the case in Ontario, where some participants had access to employer supplied disability insurance and/or sick leave provision ${ }^{39}$, while others could rely on coverage through their partner's insurance. The case for one respondent, who had made a claim to the WSIB, serves as an example:

The physician sent the forms to WSIB ... next thing I get was this ... 'your claim has been denied' ... despite the fact that my doctor felt that it was work related. They said that I could appeal it, but I never saw any of their doctors. They never asked to see me. I went to their [physiotherapy] clinic, but I had to pay it myself, because [WSIB] disallowed the claim. I claimed it on our health insurance [and] I got 50 per cent back. My doctor sent me to the physiotherapist ... at first, the physiotherapist acted as if it would be an allowable claim so they did not charge me anything. Until I had gone three or four times, [then] OHIP presented me with a bill ... they [had] said that they would pay the claim, I paid it and then I submitted it to my insurance. I used my sick leave to take time off work. (Ontario interview \# f6, Summer 2001)

\footnotetext{
${ }^{39}$ These provisions were the result of negotiations in terms of collective agreements with trade unions or professional associations.
} 
Unlike some of the other participants (for instance Ontario interview \# f2, Summer 2001), who felt compelled to fight the decision made by WSIB when her claim was denied, this participant did not engage the WSIB with making any counter claims. Instead, she noted that she was lucky because she could rely on her husband financially and his insurance covered her therapy if her condition should worsen (Ontario interview \# 6, Summer 2001).

This is not to say that the situation is less challenging if the choice is made to turn to the market and make an insurance claim rather than the state. As one of the respondents experienced when she was caught in a quagmire between the claims making activities of the state and those of the employer supported insurance company through which she was covered. In her situation, the gatekeepers at WSIB wanted to admit to the work-relatedness of her condition on one side of her body, but not the other. The participant turned to her insurance company in the hope that she could get full coverage through them.

The insurance through the employer does not pay out while on WSIB. While on WSIB you don't get disability insurance payments. It is one or the other ... and because it was about splitting me down the middle, it got in this fight between them as to who was actually going to pick it up ... and I had been getting all these letters of decline by WSIB ... to be forwarded to them on to our insurance co ... saying ... yes we have nothing to do with it. I had to go through the process of getting more medical information. (Ontario interview \# f2, Summer 2001)

In addition to the host of clinical encounters and the medical tests that she needed to submit to for the WSIB, she ended up with having to agree to engage in even more medical tests to comply with the regulatory gaze of the market: 
I had to go through the process of getting more medical information. ... [I]n total I saw: my family doctor, a hand specialist, two orthopaedic surgeons - possibly three, a neurologist, in there I had nerve conduction tests, bone scans, MRIs on both my arms. It took 6 months to get approved for benefits ... [the insurance company] asked for a lot, my Dr would send in forms, and ... [to the] credit [of] my Dr. ... I think that he saw more paper work than any person I have ever met. Uhmm continually he kept going ... he would send in forms, [the insurance company] would say, not enough we want more.

(Ontario interview \# f2, emphasis added).

In a desperate need for money so that the rent could be paid and food could be purchased she began to use her personal credit for income maintenance:

It took 6 months without any income. I lived off my credit card for that period of time. Literally, that is all I had, there was nothing ... We used to be on welfare ... having had previous experience with the system ... I was putting that off for as long as possible ... I went to the head of the insurance dept and said ... look I am giving you everything I possibly can, can't you resolve this?

(Ontario interview \# f2, summer 2001)

In other words, the ruling relations in the form of medical experts tend to play a pivotal role in determining access to income maintenance for those who are injured. Indeed, both the state (WSIB) and market (private insurance) based programs utilize medical gatekeepers to screen claimants. It is within this regard that medicine holds significant power over the lives of injured workers. Moreover, as noted, in the case of the Ontario workers' compensation system, the injury needs to be work related, however in the case of market based disability insurance the injury does not need to be work related. Rather, the injured worker simply needs to be employed at the time of injury, which is similar to the Dutch state run program. However, unlike the Dutch state run compensation 
program, private insurance tends to provide income maintenance for a limited period of time:

To claim insurance the injury does not need to be a work related injury, unlike WSIB. To be able to collect insurance benefits, I had to prove that I could not do any gainful employment. Currently (mid May '01) I still have tendinitis in my left wrist and I have problems with my right shoulder. I have been back at work since the summer of 2000, because my short-term disability of 6 months and my long-term disability of one year have run out. They were not extended ... under disability insurance guidelines, the first 18 months is deemed ... I am unable to perform the jobs I was hired for ... that was not a problem ... I obviously was not going to work on any computer of any form, after that it is the inability to do any job that is gainful employment ... [However], I got a letter [from my the insurance company] saying that I could proof read. ... [M]y first thought was, if you can find me a job that will pay me as much as I am making now doing proofreading ... I'll take it thank you very much. But in this day and age there is not a lot you can do that does not involve computer work in great amounts, of some form or description. Sooo back to work I went contrary to my Doctor, who did not want me to go back [yet].

(Ontario interview \# f2, summer 2001)

Others within the Ontario study group for this dissertation simply preferred not to turn to a state run program because they felt that their access to a market based disability plan was sufficient as explained by this Ontario participant:

I have a good health benefits insurance plan at work ... short term is $2 / 3$ of my salary. I am not sure about [making a claim to] WSIB - I don't really know ... I have a good insurance plan.

(Ontario interview, \# 17, Summer 2001)

While another participant felt similarly and noted that he "would go on disability through [his] place of work - [there is] ... long term disability" (Ontario interview, \# m9). 
In the case of the Netherlands, this situation is somewhat different in that, the Ziektewet provision notwithstanding, all Dutch employees are covered by the state through the WAO. However, in the Dutch case those who own a small business or who are self-employed tend to fall through the cracks, since they should provide for their own income maintenance plans when they are unable to attend to their business. That is, the self-employed do not qualify for the Ziektewet provision, yet they are not always in a financial position where they can withstand a long-term disability. Some participants in the Dutch dissertation study group fell into this category. For these participants it was not an issue of opting for a state supported program or a market based program. Employees all have access to the benefits of the Ziektewet provision and after that the security of the WAO. However, self-employed individuals fall outside the parameters of state supported income maintenance provisions. For these workers it is not possible to access the state supported workers' compensation programs as explained by the following respondent:

When you are declared worker disabled by the Arbodienst, nothing really happens when you are self-employed. In essence, nothing much exists in terms of income maintenance when you are an owner.

(Dutch interview \# $\mathrm{m} 4$, summer 2000)

This can be problematic for the small self-employed business owner who may not have a large enough operating capital to withstand large bouts of disability related work interruptions. Such individuals may have to turn to welfare programs. There were three self employed RSI sufferers in the Netherlands who participated in this project. Two of them, who were partners, did have their own private disability insurance but they ran into resistance with medical gatekeepers nonetheless: 
I did not have a good experience with the medical experts. The doctors did not believe me and would not give me a referral for physiotherapy. I researched the possibilities myself ... the physicians would not send me. This meant that I had to pay for it [physiotherapy]. The insurance won't pay for it, because the doctors would not give a diagnosis and referral.

(Dutch interview \# m4, summer 2000)

The third RSI sufferer who was self employed but did not have her own insurance. She felt that she did not need such coverage (Dutch interview \# f12). The experiential accounts of the remainder of the Dutch respondents did not make any reference to market-based income maintenance provisions such as employer supported insurance programs.

\section{Concluding Remarks: The Devil is in the Details}

In this dissertation I have attempted to account for the perceptions and feelings of disabled workers who suffer from a Repetitive Strain Injury. My dissertation considers the experiential accounts of these RSI sufferers in two distinctly different social policy regimes. One jurisdiction represented a liberal social policy regime (Ontario), while the other jurisdiction represented a corporatist/social democratic regime (the Netherlands). The need to be aware of the experiential lived accounts of workers with a disability, as they are facing the inability to continue their paid work duties, within the social policy regime debate served as the rationale for the research.

Given the growing literature on Repetitive Strain Injuries as an occupational health and safety concern, the growing number of workers affected by the condition and the fact that welfare states tend to increasingly support the adoption of neo-liberal 
policies, which aim to reduce the cost of social safety nets, it is important to study the effects of such policies on the injured workforce and their future. My discussion takes place within the context of a comparative social policy regime debate. For the methodological analysis I relied on concepts borrowed from D Smith (1987), though this was not an institutional ethnographic project. Her thoughts on the ruling relations and reading the 'extra-local' in the 'local' formed the basis of the analysis. The idea of claims-making activities, borrowed from social constructionists, provided further explanation and analysis of the context of injured workers striving to attain the sick role which is understood to be a claims-making activity. As a result of the qualitative nature of this dissertation and the relatively small size of the study group, the conclusions drawn are not necessarily representative of the population. Nevertheless the conclusions and observations are very suggestive and reveal real differences and similarities between the jurisdictions. In order to confirm these findings a research design with a larger number of participants is required. Nevertheless, these conclusions are very informative and compelling and as such provide a basis for further research.

By letting injured workers speak about their experiences with the workers' compensation process in the two jurisdictions when faced with making a claim (or not), and the problems they encountered (or not), I address directly a major problem with the present literature on comparative social policy regime-analysis - namely a shortage of research that integrates the subject's views into the comparative policy regime debate. Therefore an aim of this dissertation was to give voice to those who experience these processes, the injured workers themselves. A common theme found in the interview data collected from the RSI sufferers in both the Netherlands and Ontario demonstrated that 
the injured workers in both jurisdictions were generally aware of their respective workers' compensation programs. However, there was a general lack of understanding regarding the mechanics behind the policy - how these programs actually worked and how they were practiced. Such evidence is suggestive of a lack of educational and informative programs for workers in general and injured workers in particular, with regard to workers' compensation programs in both jurisdictions.

Despite this seeming common experience of lack of knowledge/understanding, there were differences between the two jurisdictions on this theme. In the case of the Netherlands, injured workers have access to the Ziektewet provision, after which - if still needed - they move onto the WAO. This process is practically automatic in that the Dutch injured worker who is in the Ziektewet, does not need to make a separate application for workers' compensation. In the case of Ontario, however, normally the responsibility lies with the injured worker to make the application for workers' compensation. The problem of course is when injured workers are not aware of the process regarding when and how or what qualifies in terms of making a workers' compensation claim, it is possible that they will not go ahead and make a claim especially if the injury is not perceived to be work-related. For the Dutch injured worker this is not such a pressing concern, relative to the Ontario injured worker, given that they do not need to have a work related injury to qualify for workers' compensation. Despite this, the lack of understanding by Dutch RSI sufferers regarding the workers' compensation system was still a source of stress for them.

Another common experience that the interview data uncovered, between the two jurisdictions, was the concern from these injured workers with respect to the 'faceless' 
adjudications that determine their qualification for compensation for their disability. It was frequently the case that such decisions respecting their possible benefits, were made by medical gatekeepers without a physical consultation - that is without seeing the injured worker in person. In other words, decisions were made about an injured worker's ability to maintain an income without medical experts performing a physical exam.

This common experience was another source of stress for injured workers in both social policy regimes. The RSI sufferers in the study group critiqued the way in which their medical and personal information was gathered - on paper - and then used to make a decision regarding their economic future, without giving them the opportunity to explain and voice their concerns of pain and disability or demonstrate their physical limitations in person. Indeed, those who did get to see a member of the medical profession who performed the screening functions for the workers' compensation systems also expressed these same concerns. Often times the questions that were asked of them did not necessarily apply to their specific case.

In particular, the RSI sufferers in this study group were very critical of the fact that the testing of physical motor skills, which were not necessarily performed during clinical encounters, reflected predetermined questions from elsewhere. Their contention being that these tests did not test their true disability, but rather tested whether a compensation claim should fall within the institutional/medical parameters as established by the institution. In other words, this gathering of systematic knowledge turned the RSI sufferers and workers with a disability from subjects into objects and reduced their lived experiences to textually based abstractions. It allowed the medical gatekeepers to gaze at their disability from the standpoint of the relations of ruling and not from the standpoint 
of their lived actuality - as an actual subject. Indeed, such organization of expert knowledge strongly suggests a process of expanding control of the ruling relations and serves to undermine any possible concerns and/or problems that might arise out of people's lived experiences (cf. Smith 1987).

As noted earlier, clinical encounters and the managing of injuries through workers' compensation systems serve to normalize injured workers' experiences (van Veldhoven, 1996). The normalization process (Foucault, 1979) is achieved by the gathering of such systematic text mediated knowledge referred to earlier. I argued that the normalization process served to weaken possible resistance and opposition by injured workers. Somewhat similarly, my research findings for this dissertation show that the activities of the workplace, which tend to cause the disabling injuries in the first place, are seldom challenged. In fact, the majority of the injured workers interviewed for this dissertation in both jurisdictions, felt that the state had a role to play in regulating the workplace in terms of protecting them from disability and harm. The data show the important role that employers play within both the workers' compensation systems. Without an employer's cooperation injured workers in both jurisdictions are faced with yet an additional challenge of getting their experiences counted as legitimate and valid. It is very possible that without the cooperation of the employer, the injured worker may have their claim for compensation denied.

Yet, what is interesting is that any normalization process does not wholly eradicate the resistance of injured workers. Some RSI sufferers, in both jurisdictions, actively refused to accept counter claims by medical experts who attempted to delegitimize their experiential accounts of RSI when they were seeking to collect workers 
compensation benefits. Indeed several of the RSI sufferers turned to third parties for help, such as the media, the legal system or union representatives, to have their concerns heard and hence made visible, particularly when medical gatekeepers attempted to invalidate their experiential knowledge and therefore attempted to make their already invisible injury disappear. Thus, in both jurisdictions RSI sufferers recounted their experiences of resisting the efforts of medical practitioners who tried to invalidate their experiences with the injury.

The next common thread that ran through the experiential accounts of the participants in both jurisdictions is that of medical resistance. Many of the participants, despite the manifest differences at the structural level in the two jurisdictions, encountered resistance from medical gatekeepers when they were at the point of entering into the respective workers' compensation systems. This resistance was in terms of getting their condition recognized by the medical community as either work-related or as a valid physical disability. These RSI sufferers experienced a great deal of anguish. They expressed their concerns in terms of 'being frightened', 'economic uncertainty', 'loss of hope', 'no faith in the system', 'lack of future', 'unable to accept their disability' and in some cases they experienced 'mild' to 'deep depression'.

These experiential accounts of the respondents in both jurisdictions are telling. A social policy regime that looks after its subjects with compassion and understanding would not have its injured workers providing accounts of despair, as witnessed here. In other words, despite the very different approaches to offering income maintenance possibilities for injured workers in two very different policy regimes, the injured workers' experiential accounts of the process of making a claim were remarkably similar. 
Such evidence is strongly suggestive of the fact that an analysis of social policy regimes solely based on manifest policy differences at the structural level alone is inadequate and that such an analysis should take procedural practices such as claims-making activities of actors into account in order to get a better understanding of how the differing policies play out at the experiential level of the policy process. Within this regard this dissertation has contributed to comparative social policy regime analysis, by including the experiential accounts of injured workers involved in the process of making a claim on the state.

The interview data suggests that employers in both jurisdictions play a significant role with regard to the injured workers' ability to gain access to workers' compensation benefits and the subsequent ability to convalesce without further injury. A possible reason why we witness these injured workers' experiences of resistance by medical experts, acting as screening agents for state supported workers' compensation programs in both jurisdictions, might be because both policies rely on the method of experience rating to finance their compensation programs. The practice of experience rating to fund workers' compensation programs can lead to employers placing undue pressure on the state or for that matter medicine (cf. Lippel, 2003). This in turn undermines the integrity, the true nature and intent of workers' compensation policies and restricts the policy's ability to address workplace hazards and income maintenance for those who get injured. Indeed experience rating encourages employers to minimize the serious nature of possible disabling situations within the workplace and tends to lead to the under-reporting of injuries (cf. Ison, 1988; 1994). Perhaps the manner in which these programs are financed is one possible area for further investigation and improvement, so that injured 
workers do not run into undue complications and hardship when they are faced with having to opt for workers' compensation.

Within this regard, trade unions could play a more significant role, especially when it comes to educating the workforce about the dangers of the workplace - given that neither state nor employer seem to be accepting of this responsibility. An issue that needs to be clarified with labour is the role that workers' compensation programs fulfill. It serves as a centralized agency that can keep a protective eye for workers on industry in terms of work place injuries. When such injuries are not reported, the process is undermined. Moreover, though market based programs have their place in the triad relation of social provision, their income maintenance programs, in the form of disability insurance, are often times too short in duration. Use of these programs, however, can affect a worker since by the end of the short period of coverage the injured worker is too late to report a work related injury to the state for workers' compensation, and thus is left without financial support during a possibly crucial period of her/his life.

In both jurisdictions, power relations are such that organizations that represent labour are at a disadvantage. Within this context, state regulations may alleviate such imbalances of power. Therefore, it is prudent for the state to take more of an independent approach to regulating the workplace, for the sake of those who participate in funding the public sphere: the workers. Furthermore, the role that doctors play in terms of their gatekeeping functions, though important, should perhaps be redesigned in such a way to allow patients/injured workers a more collaborative clinical encounter given that their lives are shaped by the outcomes of such encounters. It is therefore necessary to recast 
the role of the ruling relations within this regard to allow the local a more decisive say in extra local relations. 


\section{Appendix 1 \\ Ethical Considerations}

My dissertation aims to learn more about the effectiveness of workers' compensation policies from a lay perspective through documenting the experiences of RSI sufferers with claims-making processes in terms of the procedural practices of the policy and comparing their experiences with the intended purpose of the workers' compensation policies. The research in this dissertation is designed to give voice to those who have such an injury. As well I am to develop an understanding of how, why and if RSI has evolved as a legitimate compensable disease in two different jurisdictions as perceived by the injured workers and their experiences with the policy processes in the jurisdictions.

Experiential data was gathered mainly through face-to-face, in depth, semistructured interviews. Participation was entirely voluntary. There were no preset time constraints to an interview, however on average the interviews lasted approximately 30 to 60 minutes. Follow-up interviews were not necessary, though the participants had consented to do a follow up interview had it been necessary. Participants were informed that they did not need to answer questions they were not comfortable with and that they could end the interview at any time.

Research for my dissertation involves people who have been diagnosed with RSI and are citizens of either Ontario or the Netherlands. The relationship between participants and the researcher is one of respect. Open, two-way communication was encouraged. There were no inducements offered to participants in this dissertation. Participants were informed of the purpose of this research as well as the procedures of the interviews. They were told that participation was voluntary and that they could withdraw 
at any point during the research and writing of this dissertation. They were assured that if they withdrew from the research for this dissertation, any notes or tapes of their interview would be destroyed. I explained the means for ensuring confidentiality when asked to do so.

All aspects of this dissertation were made clear. The participants were asked to sign a letter of consent before the interviews commenced. All transcribed materials contain pseudonyms. All identifying information regarding participants was removed from the interview material. This material is available to the researcher and the faculty supervisor only and is used for research purposes only. General patterns will be presented in the research report, with no individuals identifiable. These materials, including tapes, transcriptions and computer disks, are stored in a locked filing cabinet in the locked office of the researcher.

Participants were debriefed throughout the research process. The justification for potentially difficult questions was discussed prior to their being asked. Participants were encouraged to ask questions, make suggestions and otherwise influence the research process. They were given the opportunity at the end of each session, to go over the material covered in the interview and seek clarification of the process from the researcher. I made every effort for all participants to be informed regarding the progress of my research this dissertation before leaving the session. 


\section{Appendix 2 \\ Consent Agreement}

\section{Consent Agreement}

I agree to participate in a study that investigates how people experience RSI.

This research is being done by Friskjen (Pum) van Veldhoven for completion of her Ph.D. dissertation in Sociology at Carleton University. She will answer any questions I have concerning this study. I understand that she can be contacted at (613) 761-9357, by e-mailfvveldho@ccs.carleton.ca or by message at the Department of Sociology and Anthropology, Carleton University (613) 520-2600, ext. 2582. As well, she can be contacted at (613) 236-5868 ext. 242. The faculty supervisor for this study is Professor Wallace Clement who may be contacted at the Institute of Political Economy, Carleton University (613) 520-2600, ext. 8858, or by e-mail wallace_clement@carleton.ca.

The purpose of this study is to learn if the experiences of people who experience RSI differ between Ontario and the Netherlands. The research is designed to develop an understanding of how RSI sufferers cope with their condition.

I have been assured that all information that I provide will be treated with the utmost confidentiality. I understand that all identifying information will be removed from the interview material and that this information will be used for research purposes only. No individual will be identified in any way in the research report.

I understand that I may refrain from answering any questions asked in the interview and that I may withdraw from the study at any time. I understand that any notes or tapes pertaining to my interview will be destroyed once they are no longer useful for research purposes.

\section{HAVE READ THE CONSENT AGREEMENT AND AGREE TO PARTICIPATE IN THIS RESEARCH.}

Name:

Signature:

Date: 


\section{Appendix 3 \\ Interview Schedule}

Interview Schedule

Socio-economic:

Employed/how long/full or part time?

Occupation; type of work/job?

Level of education/training?

Describe a typical day at work

Self employed.... How long?

How long have you suffered from RSI?
Demographic:

Where do you live?

Living arrangement?

Gender/ Age?

Dependants?

Income bracket more than or less

than $\$ 30.000$ ?

\section{$\underline{\text { Medical Sociology }}$}

Participant's or self perception/evaluation of RSI

1) Do you experience any discomfort when performing tasks;

2) When did you first begin to feel this discomfort?.... where;

3) Did the discomfort turn into pain ..... explain;

4) Can you describe the pain;

5) What did you think caused your pain ..... explain;

6) Did the pain go away at anytime, or did the pain just get worse - explain;

7) What did you blame the pain upon .... explain

8) What do you believe your pain is caused by?

9) When you first became aware of the pain, did it worry you;

10 a) Do you believe that your pain is caused by your job? If not why?

$10 \mathrm{~b}$ ) If yes, what is it about your work that is the cause of your pain?

11) Were you suspecting that you were suffering from RSI - why?

12) How did you find out that you had RSI (diagnosed by a doctor or self-diagnosis);

13) What is RSI - how do you see/undersland/define RSI;

Actions taken by participant to address the medical problem

1) What steps did you take when you realized that you had RSI;

2) What happened next;

3) Did you report the injury - to whom - explain;

4) Were you away from work with this problem? If yes, how long?

5) Have you returned to work, if so were changes made to your job or workplace/station?

\section{Clinical Encounters}

1) Your experience when you first went to your doctor(s)/were you believed/familiar with RSI?

2) Other medical professionals

3) Overall impression of how your injury was perceived and received by medical professionals? 


\section{Identity Conflict - Gender Issues}

What impact did your injury (RSI) have on your life / what does 'having RSI' mean to you

1) At home - explain;/at work - explain;/ were you believed

2) Able to fully perform any duties at home/work - how does that make you feel explain;

3) Does your work at home affect your injury?

4) Does your injury affect your life at work? ...explain ...

5) How do you perceive/see yourself now that you have this injury?

6) How are you - and other members of the household - coping with the injury?

\section{Welfare Regime Analysis}

What kinds of policies (social security) are in place - general awareness of participant

1) Income maintenance (disability/ workers compensation/general welfare)

2) Social support (to avoid depression/ health care) -access social support, other than financial;

3) Household support - are services/programs available that allow someone to come to the house and help you with everyday chores/care (cooking/cleaning/feeding/ laundry); Provided by the government, the community or private? Who pays? (state/public insurance; private insurance; private/public mix; no insurance/out of pocket).

\section{Availability of programs (private/public) - participant's experience with RSI and} the state

1) Do you have access to (any) income maintenance or financial support while unable to work;

2) Did you apply for income maintenance benefits - why or why not and what kind (state/private);

3) Are you actually receiving financial support or benefits - type and how much (\% of salary);

Forms of support - other than financial

1) Do you rely on outside help with household tasks - if so who (family, friends, state) explain;

2) In the event of state supported help or care - what steps were needed to secure such services;

3) Did you receive such support/care in a timely fashion?

4) How helpful/understanding/supportive have state officials or civil servants been? 


\section{Experience with state officials}

1) What happened when you applied for income maintenance benefits - explain;

2) How many steps did you need to take before you were able to secure benefits explain;

3) Did you have any difficulty collecting/ did you have to wait long - explain;

4) What steps were/are needed to stay on benefits - what is involved;

\section{$\underline{\text { Miscellaneous }}$}

Is there anything I'm overlooking that should be included?

Do you know anyone else with your injury that/who would be willing to talk to me? 


\section{Bibliography}

Aarts, L., R., Burkhauser \& P. De Jong (eds.), Curing the Dutch Disease: An International Perspective on Disability Policy Reform, Aldershot: Avebury, 1996

Amenta, E., C. Bonastia \& N. Caren, "US Policy in Comparative and Historical Perspective: Concepts, Images, Arguments, and Research Strategies", Annual Sociological Review, 27, 2001: 213-234

Arksey, H., "Expert and lay participation in the construction of medical knowledge", Sociology of Health and Illness, 16(4), 1994: 448-468

Arksey, H., RSI and the Experts: The Construction of Medical Knowledge, London: UCL Press, 1998

Arts, W., and J. Gelissen, "Welfare States, Solidarity and Justice Principles: Does the Type Really Matter?", Acta Sociologica, 44, 2001: 283 - 299

Asbring, P., and A. Narvanen, "Ideal versus reality: physicians perspectives on patients with chronic fatigue syndrome (CFS) and fibromyalgia", Social Science and Medicine, 57, 2003: $711-720$

Ashbury, F., B. Kralj, R. Allingham, W. Chan, "Soft-Tissue Occupational Injuries, Age and gender: An Analysis of Workplace Health in Ontario", a report to the Ontario Workers' Compensation Board, no date

Babbie, E., The Practice of Social Research: seventh edition, Toronto: Wadsworth Publishing, 1995

Bammer, G., and B. Martin, "Repetition Strain Injury in Australia: Medical Knowledge, Social Movement, and De Facto Partisanship", Social Problems, 39(3), 1992: 219-237

Barnes C., G. Mercer, T. Shakespeare, Exploring Disability: A Sociological Introduction, Cambridge: Polity Press, 1999

Banks J., and L. Prior, "Doing things with Illness: The micro politics of the CFS clinic", Social Science and Medicine, 52, 2001: 11-23

Bates, M., Biocultural Dimensions of Chronic Pain: Implications for Treatment of MultiEthnic Populations, Albany: State University of New York Press, 1996

Bayer, R., (ed.), The Health and Safety of Workers: Case Studies in the Politics of Professional Responsibility, New York: Oxford University Press, 1988

Berg, B., Qualitative Research Methods for the Social Sciences, Toronto: Allyn and Bacon, 1995 
Berg, M., K. Horstman, S. Plass \& M. v. Heusden, "Guidelines, professionals and the production of objectivity: standardisation and the professionalism of insurance medicine", Sociology of Health \& Illness, 22(6), 2000:765-791

Best, J., "The Diffusion of Social Problems", in J. Best (ed.), How Claims Spread: CrossNational Diffusion of Social Problems, New York: Aldine De Gruyter, 2001

Borchorst, J., "Welfare State Regimes, Women's Interests and the EC", in D. Sainsbury (ed.), Gendering Welfare States, London, U.K.: Sage Publications, 1994

Bryman, A., Social Research Methods, New York: Oxford University Press, 2004

Bussemaker, J., \& K. van Kersbergen, "Gender and Welfare States: Theoretical Reflections", in D. Sainsbury (ed.), Gendering Welfare States, London, U.K.: Sage Publications, 1994

Cameron, M., "Women and the 'Uneven' Development of Workers' Compensation Law", Australian and New Zealand Journal of Sociology, 30(I), 1994:36-46

Campbell, M., "Canadian nurses' professionalism: A labor process analysis", International Journal of Health Services, 22, 1992: 751-765

Campbell, M., "Institutional Ethnography and Experiences as Data", Qualitative Sociology, 21(1), 1998: 55-73

Campbell, M., "Research on Health Care Experiences of People with Disabilities: Exploring the Social Organization of Service Delivery", in B. Altman and S. Barnartt (eds.), Expanding the Scope of Social Science research on Disability, Stamford, CT: Jai, 2000

Campbell, M., and N. Jackson, "Learning to nurse: Text, accounts and action", Qualitative Health Research, 2(4), 1992:475-496

Campbell, M. \& F. Gregor, Mapping Social Relations: A Primer in Institutional Ethnography, Toronto: Garamond Press, 2002

Capen, K., "The courts, expert witnesses and fibromyalgia", Canadian Medical Association Journal, July; 153(2), 1995: 206-208

Cassou, B., \& B. Pissaro, "Workers' Participation and Occupational Health: The French Experience", International Journal of Health Services, 18(1), 1988: 139 - 152

Castleman, B. \& G. Ziem, "Corporate Influence On Threshold Limit Values", American Journal of Industrial Medicine, 13, 1988: 531 - 559 
Chandler, B., "The value of Household Work", Research Paper, Income and Expenditure Accounts, Statistics Canada, 1994

Clarke, J., "The Search for Legitimacy and the 'Expertization' of the Lay Person: The Case of Chronic Fatigue Syndrome", Social Work in Health Care, 30(3), 2000: 73-93

Clement, W. \& J. Myles, Relations of Ruling: Class and Gender in Postindustrial Societies, Montreal \& Kingston: Mc Gill-Queen's University Press, 1994

Cohen, M., and J. Quintner, "Fibromyalgia syndrome, a problem of tautology", Lancet, October; 342 (8876), 1993: 906-909

Courtenay, W., "Constructions of Masculinity and their influence on men's well-being: a theory of gender and health", Social Science and Medicine, 50, 2000: 1385 - 1401

Cox, R., The Development of the Dutch Welfare State: From Workers' Insurance to Universal Entitlement, Pittsburgh: University of Pittsburgh Press, 1993

Diwaker, H., and J. Stothard, "What do doctors mean by tenosynovitis and repetitive strain injury?", Occupational Medicine, April; 45(2), 1995: 97-104

Doe, T. and S. Kimpson, Enabling Income: CPP Disability Benefits and Women with Disabilities, Ottawa: Policy Research, Status of Women Canada, 1999

Doyal, L., The Political Economy of Health, London: Pluto Press, 1979

Doyal, L., What Makes Women Sick: Gender and the Political Economy of Health, London: Macmillan Press LTD, 1995.

Elgie, R., "History of Legislative reform of workers' compensation in Ontario", Rapport, II(12), 1989:5-6

Esping-Andersen, G., Social Foundations of Postindustrial Economies, Oxford: Oxford University Press, 1999

Esping-Andersen, G., The Three Worlds of Welfare Capitalism, Princeton: Princeton University Press, 1990

Evans, P. \& G. Wekerle (eds.), Women and the Canadian Welfare State, Toronto: Toronto University Press, 1997

Fast, J. and J. Frederick, "The Time of Our Lives: Juggling Work and Leisure Over the Life Cycle", Statistics Canada, 1998 
Fausto-Sterling, A., Myths of Gender, New York: Basic Books, 1985

Fawcett, G., Living with Disability in Canada: An Economic Portrait, Ottawa: Human Resources Development Canada, 1996

Fawcett, G., Bringing down the Barriers: The Labour Market and Women with Disabilities in Ontario, Ottawa: Canadian Council on Social Development, 2000

Foster M., and C. Tilse, "Referral to rehabilitation following traumatic brain injury: a model for understanding inequities in access", Social Science and Medicine, 56, 2003: $2201-2210$

Foucault, M., Discipline and Punish: The Birth of the Prison, Alan Sheridan, trans., 1977, New York: Random House, 1979

Frankel, G., "Patient-Physician Relationships: Changing Modes of Interaction", in S. Bolaria and H. Dickinson (eds.) Sociology of Health Care in Canada, Toronto: Harcourt Brace Jovanovich, 1988

Gal, J., "Decommodification and beyond: a comparative analysis of work-injury programmes", Journal of Eurupean Social Policy, 14(1), 2004: 55 - 69

Gannagé, C. Double Day, Double Bind: Women Garment Workers, Toronto: The Women's Press, 1989

George, A., Occupational Health Hazards to Women, Ottawa Advisory Council on the Status of Women, October 1976

Goldenberg, D., \& J. Waddell, “Occupational Stress and Coping Strategies among Female Baccalaureate Nursing Faculty", Journal of Advanced Nursing, 15, 1990:531-543

Glenton, C., "Chronic back pain sufferers - striving for the sick role", Social Science and Medicine, 57, 2003: 2243-2252

Grahame, P. "Ethnography, Institutions, and the Problematic of the Everyday World", Human Studies, 21 (4), Oct., 1998: 347-360

Gran, B., "A Second Opinion: Rethinking the Public-Private Dichotomy for Health Insurance", International Journal of Health Services, 33(2), 2003: 283-313

Guelke, J., "Road-kill on the information highway: repetitive strain injury in the academy", The Canadian Geographer, 47(4), 2003: 386-399

Gustafsson, S., "Childcare and Types of Welfare States", in D. Sainsbury (ed.), Gendering Welfare States, London, U.K.: Sage Publications, 1994 
Hansen, N., 'Passing' Through Other Peoples' Spaces: Disabled Women Geography, and Work, Unpublished PhD. Thesis, Glasgow, Scotland: University of Glasgow, 2002.

Harrison, S. and G. Dowswell, "Autonomy and Bureaucratic Accountability in Primary Care: What English General Practitioners Say", Sociology of Health and Illness, 24(2), March, 2002:208-226

Haynes, S, A. LaCroix, T. Lippin, "The Effects of High Job Demands and Low Control on the Health of Employed Women", in J. Quick (ed.), Work Stress: Healthcare Systems in the Workplace, New York: Praeger, 1987

Hobson, B., "Solo Mothers, Social Policy Regimes, and the Logics of Gender", in D. Sainsbury (ed.), Gendering Welfare States, London, U.K.: Sage Publications, 1994

Hopkins, A., "The Social Construction of Repetition Strain Injury", Australia and New Zealand Journal of Sociology, 25(2), 1989: 239-259

Hopkins, A., "The Social Recognition of Repetition Strain Injuries: An Australian/American Comparison", Journal of Social Sciences and Medicine, 30(3), 1990: 365-372

Hricko, A. and M. Brunt, Working for your Life: A Woman's Guide to Job Health Hazards, Berkeley: Labor Occupational Health Program, 1976

Ison, T., Compensation Systems For Injury and Disease: The Policy Choices, Toronto: Butterworths, 1994

Ison, T., "The Significance of Experience Rating", Osgoode Hall Law Journal, 24(4), 1988:723-742

Janoski, T., Citizenship and Civil Society: A Framework of Rights \& Obligations in Liberal, Traditional, and Social Democratic Regimes, Cambridge: Cambridge University Press, 1998

Jensen, R., B. Klein, L. Sanderson, "Motion-related wrist disorders traced to industries, occupational groups", Monthly Labor Review, 106(9), 1983: 13-16

Jenson, J., "Redesigning the 'Welfare Mix' for Families: Policy Challenges" a discussion paper F/30, Canadian Policy Research Networks, February 2003

Johansson, M. and T. Partanen, "Role of Trade Unions in Workplace Health Promotion", International Journal of Health Services, 32(1), 2002: 179 - 193

Judkins, B., We offer Ourselves as Evidence: Toward Workers' Control of Occupational Health, New York: Greenwood Press, 1986 
Kiger, G \& P. Riley, "Gender Differences in Perceptions of Household Labor", The Journal of Psychology, 130(4), July, 1996: 357-370

Kilborn, A., "Assessment of Physical Exposure in Relation to Work-Related Musculoskeletal Disorders: What Information Can Be Obtained from Systematic Observations", Scandinavian Journal of Work, Environment and Health, 20(special issue), 1994: $30-45$

Kirby, S., K. McKenna, Experience, Research, Social Change: Methods from the Margins, Toronto: Garamond Press, 1989

Knijn, T., "Fish without Bikes: Revision of the Dutch Welfare State and Its Consequences for the (In)dependence of Single Mothers", Social Politics, 1(1), 1994:83105

Kome, P., Wounded Workers: The Politics of Musculoskeletal Injuries, Toronto: Toronto University Press, 1998

Korrick S., K. Rest, L. Davis, D. Christiani, "Use of State Workers' Compensation Data for Occupational Carpal Tunnel Syndrome Surveillance: A feasibility Dissertation in Massachusetts”, American Journal of Occupational Medicine, 25, 1994: 837 - 850

Krahn, H., \& G. Lowe, Work, Industry, and Canadian Society, Toronto: Nelson, Canada, 1988

Krahn, H., \& G. Lowe, Work, Industry \& Canadian Society ( $4^{\text {th }}$ edition), Toronto: Thomson Nelson, Canada, 2002

Kremer, M., “A Dutch Miracle for Women?”, Social Politics, 8(2), 2001:182-185

Krute, A., \& M.E. Burdette, "1972 Survey of Disabled and Non-disabled Adults: Chronic Disease Injury and Work Disability", Social Science Bulletin, April, 1978:3-16

Leira, A., "The 'Woman-Friendly' Welfare State?: The case of Norway and Sweden", in J. Lewis (ed.), Women and Social Policies in Europe: Work, Family and the State, Aldershot: Edward Elgar Publishing Ltd., 1993

Lewis, J., "Gender and the Development of Welfare Regimes", Journal of European Social Policy, 2(3), 1992:159-173

Lewis, J. "Gender and Welfare States: Some Further Thoughts", Social Politics, 4(2), 1997: 160-177

Lewis, J. \& I. Ostner, "Gender and the Development of welfare regimes", Journal of European Social Policy, 2(3), 1992:159-173 
Lippel, K., "watching the Watchers: How Expert Witnesses and decision-makers Perceive Men's and Women's Workplace Stressors" in Messing et al. (Eds.), Invisible: Issues in Women's Occupational Health, Charlotte Town: gynergy books, 1995

Lippel, K., "Compensation for Musculoskeletal Disorders in Quebec: Systemic Discrimination against Women Workers", International Journal of Health Services, 33(2), 2003: $253-281$

Lister, R., Citizenship: Feminist Perspectives, New York: New York University Press, 1997

Littlejohn, G., "Fibrositis/Fibromyalgia Syndrome in the workplace", Rheumatic Disease Clinics of North America, February, 15(1), 1989:45-60

Lupton, D., "Foucault and the Medicalisation Critique", in A. Petersen and R. Bunton (eds.), Foucault: Health and Medicine, London: Routledge, 1997

Lupton, D., Medicine as Culture: Illness, Disease and the Body in Western Societies, London: Sage Publications, 2003

Luxton, M.., "Two Hands for the Clock: Changing Patterns in the Gendered Division of Labour in the Home", in M. Luxton and H. Rosenberg, Through the Kitchen Window: The Politics of Home and Family, Toronto: Garamond Press, 1986

Luxton M., E. Reiter, “Double, Double, Toil and Trouble ... Women's Experience of Work and Family in Canada 1980-1995", in P. Evans, G. Wekerle (eds.), Women and the Canadian Welfare State, Toronto: University of Toronto Press, 1997

Luxton M. and H. Rosenberg, Through the Kitchen Window: The Politics of Home and Family, Toronto: Garamond Press, 1986

Macintosh, M., and R. Gough, "The Impact of Workplace Change on Occupational Health and Safety: A Study of four Manufacturing Plants, Human factors and ergonomics in manufacturing, 8(2), 1998:155 - 175

Marshall, T.H., Class Citizenship and Social Development, Westport, Connecticut: Greenwood Publishers, 1973

McKeen, W., "The Shaping of Political Agency: Feminism and the National Social Policy Debate, the 1970s and Early 1980s", Studies in Political Economy, autumn, 66, $2001: 37-58$

Meekosha, H., and A. Jacubowicz, "Repetition strain injury: The rise and fall of an 'Australian' disease", Critical Social Policy, 11, 1(31), 1991:18-37 
Messing, K., "Putting Our Heads Together: Academic and Feminist Approaches to Studying the Health of Workers", NSWA Journal, 3(3), 1991: 355 - 366

Messing, K., "Women's Occupational Health and Androcentric Science", Canadian Women Studies, 14(3), 1994: 11 - 16

Messing, K., "Chicken or Egg: Biological Differences and the Sexual Division of Labour", in K. Messing, B. Neis and L. Dumais (eds.), Invisible: Issues in Women's Occupational Health, Charlotte Town: gynergy books, 1995

Messing, K., B. Neis and L. Dumais (eds.), Invisible: Issues in Women's Occupational Health, Charlotte Town: gynergy books, 1995

Messing, K. and S. de Grosbois, "Women Workers Confront One Eyed Science: Building Alliances to Improve Women's Occupational Health", Women and Health, 33(1-2), 2001: $125-141$

Miller, L., "Claims-Making from the Underside: Marginalization and Social Problems Analysis", in G. Miller and J. Holstein (eds.), Constructionist Controversies: Issues in Social Problems Theory, New York: Aldine De Gruyter, 1993

Miller, G. \& J. Holstein (eds.), Constructionist Controversies: Issues in Social Problems Theory, New York: Aldine De Gruyter, 1993

Ministerie van Sociale Zaken en Werkgelegenheid, 1999

Ministerie van Sociale Zaken en Werkgelegenheid, 2004, http://home.szw.nl

Ministry of Community and Social Services, 2003

Ministry of Human Resources and Development, (HRDC), 1994

Mink, G., Welfare's End, Ithaca: Cornell University Press, 1998

Morris, J., (ed.), Encounters with Strangers. Feminism and Disability, London: Women's Press, 1996

Nettleton, S., The Sociology of Health \& Illness, Cambridge: Polity Press, 1995

Neuman, L., Social Research Methods: Qualitative and Quantitative Approaches, Toronto: Allyn and Bacon, 1994

Newman, S., R. Fitzpatrick, T. Revenson, S. Skevington, G. Williams, Understanding Rheumatoid Arthritis, London: Routledge, 1996 
O'Connor, J.S., "Class, Gender and Citizenship, in the comparative analysis of Welfare State Regimes: Theoretical and Methodological issues", British Journal of Sociology, 44(3), 1993:501-518

O'Connor, J.S., "Social Justice, Social Citizenship, and the Welfare State, 1965-1995: Canada in Comparative Context", in R. Helmes-Hayes and J. Curtis (eds.), The Vertical Mosaic Revisited, Toronto: Toronto University Press, 1998

O'Connor, J.S., A.S. Orloff, S. Shaver, States, Markets, Families: Gender, Liberalism and Social Policy in Australia, Canada, Great Britain and the United States, Cambridge: Cambridge University Press, 1999

O'Donnell, C. and P. Hall, Getting Equal: Labour Market Regulation and Women's Work, Boston: Allen \& Unwin, 1988

O'Neil, R., "When it comes to Health and Safety, your life should be in union hands", editorial in Hazards Magazine, no date

Oliver, M., Understanding Disability: from Theory to Practice, New York: St. Martin's Press, 1996

Olsen, G., "Locating the Canadian Welfare State: Family Policy and Health Care in Canada, Sweden, and the United states", in J. O'Connor and G. Olsen (eds.), Power Resources Theory and the Welfare State, Toronto: University of Toronto Press, 1998

Oorschot, W. and K. Boos, "Disability policies in Europe: The Netherlands", Tilburg Institute fro Social Security Research, November 1999.

Orloff, A.S., "Gender and the Social Rights of Citizenship: the comparative analysis of gender relations and welfare states", American Sociological Review, 58(June), 1993:303328

Orloff, A.S., "Gender in the Welfare State", Annual Review of Sociology, 22, 1996:5178

Piva, M., "The Workmen's Compensation Movement in Ontario", Ontario Historical Society, 1975:39-56

Plantenga, J., "For Women Only? The Rise of Part-time Work in the Netherlands", Social Politics, 3(1), 1996:57-71

Pulkingham, "Gender and U.I. Reform", Studies in Political Economy, 56(Summer), 1998: $7-48$ 
Reid, J., C. Ewan, E. Lowy, "Pilgrimage of Pain: The Illness Experiences of Women with Repetition Strain Injury and the Search for Credibility", Journal of Social Science and Medicine, 32(5), 1991:601-612

Robinson, J., "Labor Union Involvement in Occupational Safety and Health, 1957 1987", Journal of Health Politics, Policy and Law, 13(3), 1988: 453 - 468

Robinson, S., "Reducing Repetitive Motion Injuries with Preventive Ergonomic Strategies", Public Health Reports, 109(2), 1994:182-183

Rosenberg, H., "The Home is the Workplace: Hazards Stress and Pollutants in the Household", in M. Luxton and H. Rosenberg, Through the Kitchen Window: The Politics of Home and Family, Toronto: Garamond Press, 1986

Rosner, D., and G. Markowitz, Deadly Dust: Silicosis and the Politics of Occupational Disease in Twentieth-Century America, Princeton: Princeton University press, 1991

RSI-forum, message posted by participant, summer 1999

Sainsbury, D. (ed.), Gendering welfare States, London, U.K.: Sage Publications, 1994

Sainsbury, D., "Dual welfare and Sex segregation of Access to Social benefits: Income Maintenance Policies in the U.K., the U.S., the Netherlands and Sweden, Journal of Social Policy, 22(1), 1993:69-98

Sanford, L., \& M. Donovan, Women and Self-esteem, Garden City: Anchor Publications/Double Day, 1984

Sass, R., "The Implications of Work Organization for Occupational Health Policy: The Case of Canada", International Journal of Health Services, 19(1), 1989: 157 - 173

Sass, R., "A message to the Labour Movement: Stop and Think!", International Journal of Health Services, 26(4), 1996:595 - 609

Schrijvers, A., "The Netherlands Introduces Some Competition Into the Health Services", JAMA, 266(16), 1991:2215-2217

Seltzer, C., "Moral Dimensions of Occupational Health: The Case of the 1969 Coal Mine Health and Safety Act", in R. Bayer (ed.), The Health and Safety of Workers: Case Studies in the Politics of Professional Responsibility, New York: Oxford University Press, 1988

Shannon, H., and G. Lowe, "How Many Injured Workers Do Not File Claims for Workers' Compensation Benefits?", American Journal of Industrial Medicine, 42, 2002 : $467-473$ 
Siaroff, A., "Work, Welfare and Gender Equality: a new Typology", in D. Sainsbury (ed.), Gendering welfare States, London, U.K.: Sage Publications, 1994

Sikie-Micanovic, L., "Some Conceptualizations and Meanings of Domestic Labor", Drustvena Istrazivanja, 10, 45(54-55), July-October, 2001: 731-766

Skillen, L., "Nurses' Work Hazards in Public Health Units", in K. Messing, B. Neis and L. Dumais (eds.), Invisible: Issues in Women's Occupational Health, Charlotte Town: gynergy books, 1995

Smith, B., Digging Our Own Graves: Coal Miners and the Struggle over Black Lung Disease, Philadelphia: Temple University Press, 1987

Smith, D., The Everyday World As Problematic: A Feminist Sociology, Toronto: University of Toronto Press, 1987

Smith, D., Texts, Facts, and Femininity: Exploring the Relations of Ruling, London: Routledge, 1990

Smith, D., "The Ruling Relations" in D. Smith, Writing the Social: Critique, Theory and Investigations, Toronto: University of Toronto Press, 1999

Stellman, J., Women's Work, Women's Health: myths and realities, New York: Pantheon, 1977

de Swaan, A., The Management of Normality: Critical Essays in Health and Welfare, London: Routledge, 1990

Tierny, D., P. Romito, K. Messing, "She Ate Not the Bread of Idleness: Exhaustion is Related to Domestic and Salaried Working Conditions Among 539 Quebec Hospital Workers", Women and Health, 16(1), 1990:21-42

Torrance, G., "Socio-Historical Overview: The Development of The Canadian Health System" in D. Coburn, C. D'Arcy, G. Torrance, P. New (eds.), Health and Canadian Society: Sociological Perspectives, Toronto: Fitzhenry \& Whiteside, 1987

van Veldhoven, F., White Pain, Blue Experience: The Normalization of Women's Repetitive Strain Injury, MA Dissertation, Hamilton: McMaster University, 1996

Vezina, N., and J. Courville, "Integration of Women into Traditionally Masculine Jobs", Women and Health, 18(3), 1992: $97-118$

Voiss, D., “Occupational Injury: Fact, Fantasy, or Fraud?”, Neurological Clinics, May, 113(2), 1995:431-446 
Waitzkin, H., "Micropolitics of Medicine: Theoretical Issues", Medical Anthropology Quarterly, 17(5), 1986: 134-136

Waitzkin, H., and T. Britt, "A Critical Theory of Medical Discourse: How Patients and Health Professionals Deal with Social Problems", International Journal of Health Services, 19(4), 1989a: 577-597

Waitzkin, H., and T. Britt, "Changing the Structure of Medical Discourse: Implications of Cross-National Comparison", Journal of Health and Social Behavior, vol. 30 (Dec), 1989b: 436-449

Waitzkin, H., T. Britt and C. Williams, "Narratives of Aging and Social Problems in Medical Encounters with Older Persons", Journal of Health and Social Behavior, 35(4), 1994: 322-348

Waldron, I., "Employment and Women's Health: An Analysis of Causal Relationships", in E. Fee (ed.), Women, and Health: The Politics of Sex in Medicine, Farmingdale, N.Y.: Baywood Publishing Co., 1983

Walker, H., L. Rogers, and M. Zelditch, "Acts, Persons, Positions, and Institutions: Legitimating Multiple Objects and Compliance with Authority", in S. Chew \& D Knottnerus (eds.), Structure, Culture, and History: Recent Issues in Social Theory, New York: Rowman \& Littlefield Publishers, Inc., 2002

Walsh, D., and R. Egdahl (eds.), Women, work and Health: Challenges to Corporate Policy, New York: Springer-Varley, 1980

Walters, V., "Company Doctors: Standards of Care and Legitimacy: A Case Dissertation From Canada", Social Science and Medicine, 19(8), 1984:811-821

Walters, V., "Beyond Medical and Academic Agendas: Lay Perspectives and Priorities", Atlantis, 17(1), 1993: 28 - 35

Ware, N., "Toward a Model of Social Course in Chronic Illness: The Example of Chronic Fatigue Syndrome", Culture, Medicine and Psychiatry, 23, 1999: 303-331

Waylonis, G.W. and R.H. Perkins, "Post-traumatic fibromyalgia: a long-term follow-up", American Journal of Physical Medicine and Rehabilitation, 73(6), 1994:403-412

Whelan, E., "Well now, who's the doctor here?" Boundary-work and Transgression in Patient and Expert Knowledges of Endometriosis", PhD Dissertation, Ottawa: Carleton University, 2000

Workers' Compensation Board of Ontario, "Allowed Lost Time Claims by Gender for Accidents Occurring in 1990-1994", March, 1995 
Workplace safety \& Insurance Board of Ontario, summer 1999, personal communication Workplace Safety \& Insurance Board of Ontario, Operational Policy Manual, October 2004, http://www.wsib.on.ca/wsib/wopm.nsf/home/opmhome

Ziem G., and B. Castleman, "Threshold Limit Values: Historical Perspectives and Current Practice", Journal of Occupational Medicine, 30(11), 1989: 910 - 918 